Faculty of Medicine University of Szeged

Theoretical Medicine Doctoral School

\title{
Abeta(1-42) enhances neuronal excitability and disrupts synaptic plasticity by altering glutamate recycling
}

Ph.D. Thesis

\section{Edina Varga}

Department of Medical Chemistry

University of Szeged, Szeged

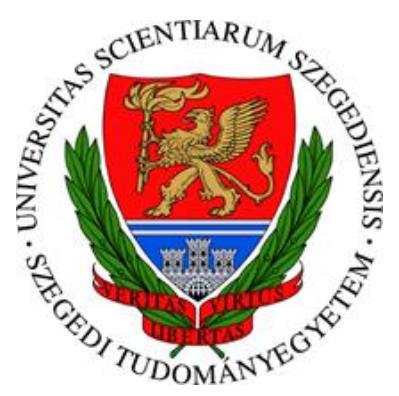

\section{Supervisor: Viktor Szegedi Ph.D.}

Institute of Biochemistry, Biological Research Center

Hungarian Academy of Sciences, Szeged

\section{Consultant: Lívia Fülöp Ph.D.}

Department of Medical Chemistry

University of Szeged

\section{Szeged}

2015 
"Life is not easy for any of us. But what of that? We must have perseverance and above all confidence in ourselves. We must believe that we are gifted for something, and that this thing, at whatever cost, must be attained." 


\section{LIST OF PUBLICATIONS}

\section{RELEVANT PUBLICATIONS}

I. Edina Varga, Gábor Juhász, Zsolt Bozsó, Botond Penke, Lívia Fülöp, Viktor Szegedi: Amyloid-\$1-42 disrupts synaptic plasticity by altering glutamate recycling at the synapse.

JOURNAL OF ALZHEIMER'S DISEASE. 2015 Jan; 45(2):449-56.

$\mathrm{IF}_{2013}=3.612$

II. Edina Varga, Gábor Juhász, Zsolt Bozsó, Botond Penke, Lívia Fülöp, Viktor Szegedi: Abeta(1-42) enhances neuronal excitability in the CA1 via NR2B subunitcontaining NMDA receptors.

NEURAL PLASTICITY. 2014:584314.

$\mathrm{IF}_{2013}=3.608$

\section{OTHER PUBLICATION}

III. Melinda E. Tóth, Viktor Szegedi, Edina Varga, Gábor Juhász, János Horváth, Emőke Borbély, Balázs Csibrány, Róbert Alföldi, Nikolett Lénárt, Botond Penke, Miklós Sántha: Overexpression of Hsp27 ameliorates symptoms of Alzheimer's Disease in APP/PS1 mice.

CELL STRESS AND CHAPERONES. 2013 Nov; 18(6):759-71.

$\mathrm{IF}_{2012}=3.017$ 


\section{TABLE OF CONTENTS}

LIST OF PUBLICATIONS

I. TABLE OF CONTENTS

3

II. ABBREVIATIONS 5

III. INTRODUCTION 7

3.1. GENERAL DESCRIPTION OF ALZHEIMER'S DISEASE …………......................................

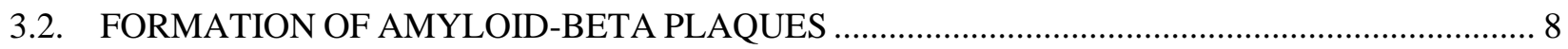

3.2.1. THE AMYLOID CASCADE HYPOTHESIS ……………................................................... 8

3.2.2. DIFFERENT AGGREGATION FORMS OF AMYLOID-BETA ………………...................... 10

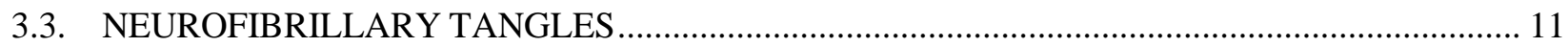

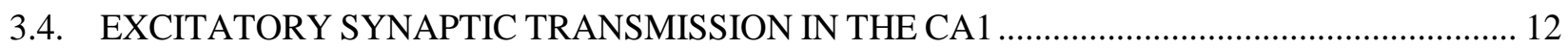

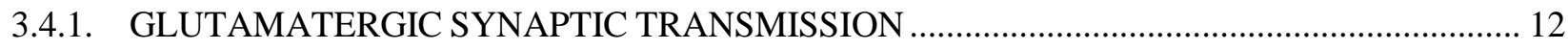

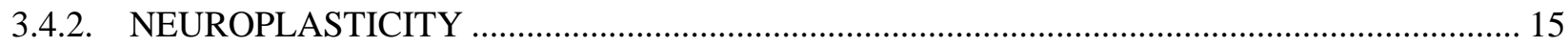

3.5. INVESTIGATION OF EXCITATORY EXTRACELLULARLY EVENTS IN THE CA1 .............. 18

3.6. AMYLOID-BETA INDUCES NEURONAL HYPEREXCITABILITY ………………................... 19

3.7. THERAPEUTIC APPROACHES IN ALZHEIMER'S DISEASE:

FOCUSING ON GLUTAMATE TOXICITY AND THE SCAVENGER SYSTEM .......................... 21

IV. AIMS

24

V. MATERIALS AND METHODS 25

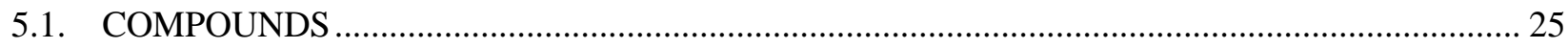

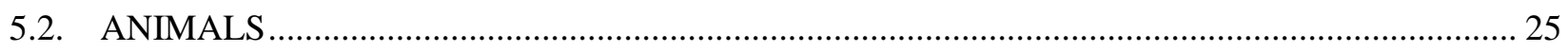

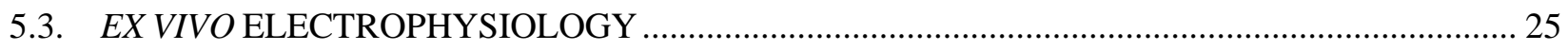

5.3.1. EXTRACELLULAR RECORDING USING MULTI-ELECTRODE ARRAY ……………….... 25

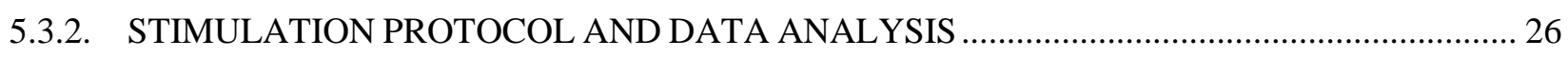

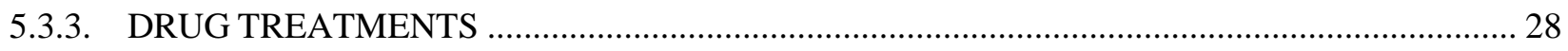

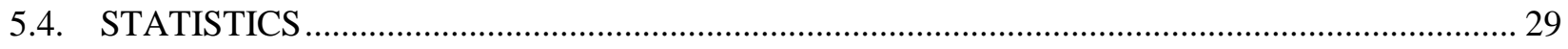

5.5. SYNTHESIS AND CHARACTERIZATION OF AMYLOID-BETA.............................................. 30

VI. RESULTS 31

6.1. EVOKED FIELD POTENTIALS, BUT NOT SPONTANEOUS SPIKES ARE MEDIATED BY AMPA RECEPTORS...

6.2. SPONTANEOUS FIRING, BUT NOT FIELD POTENTIAL IS GOVERNED BY NMDA RECEPTOR FUNCTION 33 
6.3. AMYLOID-BETA(1-42) INDUCES HYPEREXCITATION VIA NR2B

6.4. AMYLOID-BETA(1-42) INDUCED IMPAIRMENT OF LTP REQUIRES NR2B ACTIVATION 40

6.5. GLUTAMATE SCAVENGER RESCUES AMYLOID-BETA(1-42)-IMPAIRED LTP

6.6. THE EFFECT OF AMYLOID-BETA(1-42) IS MIMICKED BY TBOA, A GLUTAMATE REUPTAKE INHIBITOR...

6.7. CHARACTERIZATION OF AMYLOID-BETA

7.1. THE UNDERLYING MECHANISM OF EVOKED FIELD POTENTIAL AND SPONTANEOUS SPIKING GENERATION ARE NOT CORRELATED.

7.2. POSSIBLE INVOLVEMENT OF THE CA1 LOCAL MICROCIRCUITRY IN THE REGULATION OF SPONTANEOUS SPIKING

7.3. AMYLOID-BETA(1-42)-INDUCED HYPEREXCITATION AND LTP IMPAIRMENT REQUIRES NR2B ACTIVATION.

7.4. GLUTAMATE SCAVENGER AS A NOVEL THERAPEUTIC OPPORTUNITY AGAINST ALZHEIMER'S DISEASE

VIII. SUMMARY 54

IX. CONCLUSION 55

X. ACKNOWLEDGEMENT 56

XI. REFERENCES 57

XII. SUPPLEMENTARY MATERIAL 68

XIII. APPENDIX 71 


\section{ABBREVIATIONS}

\begin{tabular}{|c|c|}
\hline $\operatorname{Abeta}(1-42)$ & amyloid-beta(1-42) \\
\hline $\mathrm{ACh}$ & acetylcholine \\
\hline ACSF & artificial cerebrospinal fluid \\
\hline AD & Alzheimer's disease \\
\hline AICD & amyloid precursor protein intracellular domain \\
\hline AMPA & $\alpha$-Amino-3-hydroxy-5-methyl-4-isoxazolepropionic acid \\
\hline AMPAR & $\alpha$-Amino-3-hydroxy-5-methyl-4-isoxazolepropionic acid receptor \\
\hline ANOVA & analysis of variance \\
\hline APP & amyloid precursor protein \\
\hline Apo & apolipoprotein \\
\hline BDNF & activity-dependent brain derived neurotrophic factor \\
\hline CaMKII & calcium/calmodulin-dependent protein kinase II \\
\hline cAMP & cyclic adenosine monophosphate \\
\hline CNQX & 6-cyano-7-nitroquinoxaline-2,3-dione \\
\hline CREB & cyclic adenosine monophosphate response element binding protein \\
\hline CTF & C-terminal fragment \\
\hline EAATs & excitatory amino-acid transporters \\
\hline E-LTP & early phase of long-term potentiation \\
\hline EPSC & excitatory postsynaptic current \\
\hline ERK & extracellular signal-regulated kinase \\
\hline esyn & extrasynaptic \\
\hline FAD & familiar Alzheimer's disease \\
\hline fEPSP & field excitatory postsynaptic potential \\
\hline GABA & gamma-aminobutyric acid \\
\hline Glu & glutamate \\
\hline GluR & glutamate receptor \\
\hline GOT & glutamic-oxaloacetate transminase \\
\hline GPT & glutamic-pyruvic transaminase \\
\hline GSK3 $\beta$ & glycogen synthase kinase $3 \beta$ \\
\hline ifenprodil & $\alpha$-(4-Hydroxyphenyl)- $\beta$-methyl-4-benzyl-1-piperidine-ethanol-(+)-tartrate \\
\hline iGluR & ionotropic glutamate receptor \\
\hline iNOS & nitric-oxide synthase \\
\hline IP3 & inositol triphosphate \\
\hline Low $\mathrm{Mg}^{2+} \mathrm{ACSF}$ & low magnesium concentration-containing artificial cerebrospinal fluid \\
\hline LTD & long-term depression \\
\hline L-LTP & late phase of long-term potentiation \\
\hline LTP & long-term potentiation \\
\hline МАРК & mitogen-activated protein kinase \\
\hline MEA & multi-electrode array \\
\hline
\end{tabular}




$\begin{array}{ll}\text { mGluR } & \text { metabolic glutamate receptor } \\ \text { MK801 } & (+) \text {-MK801 hydrogen maleate } \\ \text { NFT } & \text { neurofibrillary tangles } \\ \text { NMDA } & \text { N-methyl-D-aspartate } \\ \text { NMDAR } & \text { N-methyl-D-aspartate receptor } \\ \text { Oxa } & \text { oxaloacetate } \\ \text { PKA } & \text { protein kinase A } \\ \text { PKC } & \text { protein kinase C } \\ \text { PSEN } & \text { presenilin } \\ \text { PPF } & \text { paired-pulse ratio } \\ \text { Pyr } & \text { sodium pyruvate } \\ \text { SAD } & \text { sporadic Alzheimer's disease } \\ \text { SRE } & \text { serum response element } \\ \text { Syn } & \text { synaptic } \\ \text { TBOA } & \text { DL-threo- } \beta \text {-benzyloxyaspartate } \\ \text { VGlut } & \text { vesicular glutamate transporter } \\ \text { WB } & \text { Western Blot }\end{array}$




\section{INTRODUCTION}

\subsection{GENERAL DESCRIPTION OF ALZHEIMER'S DISEASE}

Alzheimer's disease (AD) is the most prevalent form of dementia affecting mainly the elderly population. Estimates suggest that 36 million people were diagnosed with AD worldwide, and this number will double every 20 years (Lundkvist, Halldin et al. 2014). Not just the patients themselves, but their families and the society are also affected. The total costs of dementia were estimated to be $\$ 600$ billion worldwide (Menting and Claassen 2014).

$\mathrm{AD}$ was first described in a female patient by a German psychiatrist and neuropathologist, Alois Alzheimer in 1907 and the disease was named after him (Alzheimer, Stelzmann et al. 1995). The main hallmarks of $\mathrm{AD}$ are the progressive cognitive impairment, behavioral changes and permanent loss of memory (De-Paula, Radanovic et al. 2012). Although AD is in the focus of intense research, no effective treatment is currently available.

The disease is associated with early onset and progressive impairment in several brain areas having critical role in episodic memory, language and behavior (Weiner, Neubecker et al. 2008). It is estimated that the pathological process in AD brain begins at least 10-15 years before the first cognitive symptoms appear (Perrin, Fagan et al. 2009), including short-term memory loss and logopedic progressive aphasia (Magnin, Sylvestre et al. 2013). As the disease progresses, more severe memory loss and behavioral disturbances leading to confusion and lack of orientation occur (Mintzer, Mirski D et al., 2000). Two forms of AD can be distinguished, sporadic (SAD) and familiar (FAD), however they share common histological and clinical symptoms (Sassi, Guerreiro et al. 2014), and presumably common pathomechanisms. Two main neuropathological brain lesions are described in the brain tissues of AD patients: the extracellular accumulation of amyloid-beta (Abeta) and the intraneural neurofibrillary tangles (NFT) formed by hyperphosphorylated tau protein (Grundke-Iqbal, Iqbal et al. 1986).

The heterogeneity of AD is evident in their clinical, anatomical and biological characteristics. Fisher and coworkers demonstrated neuropsychologically defined AD subtypes using CERAD for their work (Consortium to Establish a Registry for Alzheimer's Disease) along with PET studies and classified the disease into five neuropsychological AD syndromes: typical $\mathrm{AD}$, temporal (pure amnestic) variant $\mathrm{AD}$, left (language) variant $\mathrm{AD}$, right (visuoperceptive) $\mathrm{AD}$ and frontal (executive) variant AD (Fisher, Rourke et al. 1996, Fisher, Rourke et al. 1997, Lam, Masellis et al. 2013). 


\subsection{FORMATION OF AMYLOID-BETA PLAQUES}

\subsubsection{THE AMYLOID CASCADE HYPOTHESIS}

Several factors can contribute to the pathogenesis of $\mathrm{AD}$, however the exact mechanism is unknown. Soon after the discovery of AD-associated mutations in the amyloid precursor protein (APP) gene, the Abeta cascade hypothesis was postulated by John Hardy in 1992 that became the dominating hypothesis in the field (Hardy and Higgins 1992). The Abeta cascade hypothesis proposes that the deposition of Abeta in the brain is a crucial step in the development of AD. The hypothesis links histopathological and genetic properties that lead to development of Abeta depositions and $\mathrm{AD}$ dementia.

Amyloid depositions are formed by Abeta peptides that derive from the much larger APP. APP is a widely expressed transmembrane glycoprotein and its gene is located on human chromosome 21 and expressed in several tissues (Lemmin, Dimitrov et al. 2014). It exists at least in ten isoforms, which are generated by differential splicing of exons 7 and 8, mainly $\mathrm{APP}_{695}$, $\mathrm{APP}_{751}$ and $\mathrm{APP}_{770}$ in the brain. In human cortex, the ratio of different APP isoforms is approximately $\mathrm{APP}_{695} / \mathrm{APP}_{751} / \mathrm{APP}_{770}=20: 10: 1$, however this ratio could change in different regions (Nalivaeva and Turner 2013). APP $_{695}$ is the exon 7-skipped isoforms, and is most abundant in the neurons (LeBlanc, Chen et al. 1991), while $\mathrm{APP}_{751}$ and $\mathrm{APP}_{770}$ are expressed in glial cells (Kitazume, Yoshihisa et al. 2012). It was shown that Abeta was produced from $\mathrm{APP}_{695}$ isoform via the cleavage of the APP intracellular domain by the action of $\beta$-secretase (Belyaev, Kellett et al. 2010), while another group suggests that Abeta could be released from APP 770 by the actions of both $\alpha$ - and $\beta$-secretases in the endothelial cells of the brain (Kitazume, Tachida et al. 2010). APP plays a major role in the regulation of several important signaling pathways especially in the nervous system, such as synaptogenesis (Wang, Yang et al. 2005), axon elongation (Chasseigneaux, Dinc et al. 2011) or iron export (Duce, Tsatsanis et al. 2010), however its basic physiological function is not fully clear.

APP can be processed by secretases in two main pathways depending on the secretase that actually cleave it (reviewed by Vingtdeux, Sergeant et al. 2012). In the non-amyloidogenic pathway (Figure 1, left), $\alpha$-secretase cuts APP within the Abeta sequence, releasing soluble secreted form of APP ( $\mathrm{APP} \alpha)$ and the membrane-associated C-terminal fragment (CTF $\alpha)$, which in turn is further processed by $\gamma$-secretase resulting in the release of the P3 peptide and amyloid precursor protein intracellular domain (AICD). 
In the amyloidogenic pathway (Figure 1, right), APP is initially cleaved by $\beta$-secretase to generate a large soluble secreted form of APP (sAPP $\beta$ ) and leaving the membrane-anchored Cterminal fragment comprised of 99 amino-acid (CTF $\beta$ or C99). The intracellular sorting of $\beta$ secretase is a critical step in APP processing (Chia, Toh et al. 2013). The subsequent action of CTF $\beta$ by $\gamma$-secretase releases Abeta peptide on the extracellular side, which produces Abeta species of 39-43 amino acids and the APP intracellular domain (AICD or C51) in the cytoplasm. It is noteworthy that AICD may have a potential gene expression regulatory function (Mattson 2003). Furthermore, lysosomal processing of APP is a likely site of Abeta production (Tam, Seah et al. 2014). The $\gamma$-secretase complex is composed of presenilin (PSEN), nicastrin (NCT), $\gamma$ secretase activating protein (GSAP), Pen-2 and Aph-1 proteins.

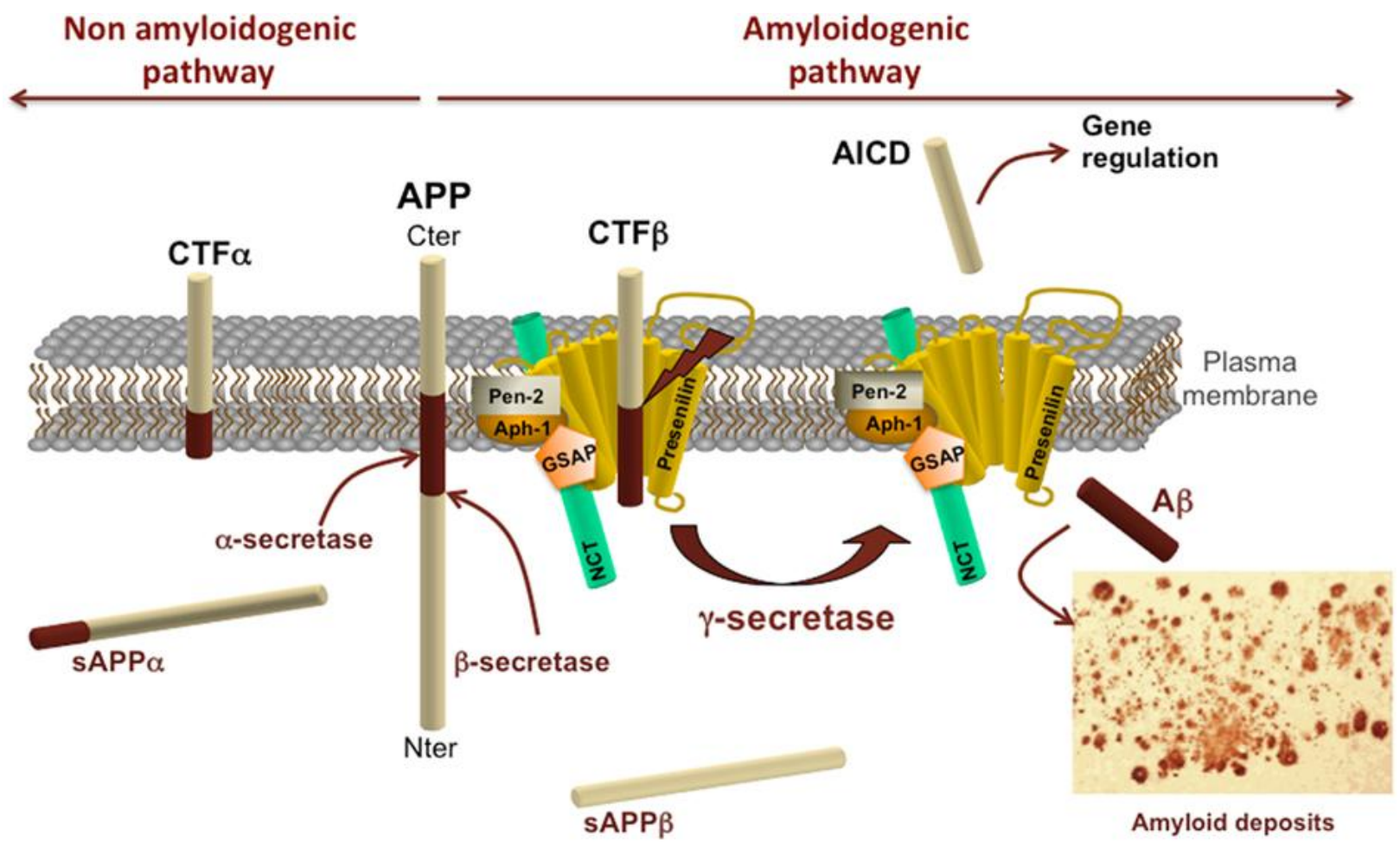

Figure 1. Schematic representation of the two APP proteolytic pathways. APP may be cleaved in two distinct processes: non-amyloidogenic (left) and amyloidogenic (right). Alternative cleavage of APP by the $\alpha$-secretase enzyme produces soluble, non-toxic compounds such as membrane-associated CTF $\alpha$ and sAPP $\alpha$. In the amyloidogenic pathway, Abeta is released from the APP through the action of the $\beta$ - and $\gamma$ secretases. Abeta and AICD are produced by the $\gamma$-secretase cleavage of the CTF $\beta$, which is then retained in the cytoplasmic membrane. Abbreviations: APP (amyloid precursor protein), CTF (C-terminal fragment), sAPP (soluble secreted form of amyloid precursor protein), Abeta (amyloid-beta) and AICD (amyloid precursor protein intracellular domain). Figure from Vingtdeux, Sergeant et al. 2012. 
The hypothesis, that $\mathrm{AD}$ could be inherited in an autosomal dominant manner is further supported by research data. The disease-associated mutation that was first described is in the gene coding APP. More AD-associated mutations have been identified, such as the autosomal dominant mutations in presenilin 1 (PSEN1) and presenilin 2 (PSEN2), which induce increased activity of $\gamma$-secretase, causing a shifted balance towards amyloidogenic Abeta(1-42) versus shorter Abeta(1-40) or Abeta(1-38) species (Wanngren, Lara et al. 2014), and also disrupt the endoplasmic reticulum $\mathrm{Ca}^{2+}$ homeostasis (Schneider, Reverse et al. 2001). PSEN1 mutation is found in approximately $80 \%$ of cases of FAD (Sepulveda-Falla, Barrera-Ocampo et al. 2014).

The apolipoprotein E (apoE) gene, which plays a role in the clearance of Abeta from the brain, was also shown as the major genetic risk factor for familial and sporadic AD. Three common apoE alleles have been described: apoE2, apoE3 and apoE4. The apoE4 allel has been consistently associated with $\mathrm{AD}$, and this allel causes dysfunction of the lipid transport system and lipid homeostasis in the brain of AD patient (Guerreiro, Gustafson et al. 2012).

\subsubsection{DIFFERENT AGGREGATION FORMS OF AMYLOID-BETA}

Abeta, a misfolded protein, is widely regarded as a central player in the in the pathogenesis of AD. The accumulation of soluble Abeta(1-42) in the brain of patients and animal models of AD is associated with impairments of cognition and memory (Walsh, Klyubin et al. 2002). Progressive neuronal degeneration was also aggravated by membrane-associated oxidative stress induced by aggregation of Abeta (Mattson 2003).

Abeta aggregation is a complex process, involving the misfolding of Abeta into soluble and insoluble forms. Monomeric Abeta is mainly composed of $\alpha$-helical conformation, whereas the misfolded polymers are rich in $\beta$-sheet structures (Zhao, Chiu et al. 2012). It was shown that the soluble pool of Abeta may exist both at the extracellular and at the intracellular space (LaFerla, Green et al. 2007). Several studies have shown that misfolding of monomeric Abeta leads to the formation of oligomers, which then rapidly grow to larger polymers or fibrils (Ni, Shi et al. 2011, Zhao, Chiu et al. 2012).

Two forms of amyloid plaques are distinguished in the AD brain: diffuse and senile, or neuritic plaques, which were originally described by Alois Alzheimer. Diffuse plaques are amorphous in their shape and are not surrounded by dying or damaged neurons (Joachim, Mori et al. 1989), however these deposits may be the precursors of fibrillogenesis (Pappolla, Omar et al. 1992). Neuritic plaques have a diameter of around 50-200 $\mu \mathrm{m}$; they contain a central core riched 
in Abeta. It is often associated with axonal and dendritic injury and surrounding reactive astrocytes (McGeer, Itagaki et al. 1987). The major components of amyloid deposits are the 3943 amino acid-containing residues of Abeta peptide, which derive from the sequential cleavages of its precursor protein.

The aggregation and deposition of Abeta in the brain is believed to be the link to the neuronal cell death and loss of cognitive function seen in AD. Although the fibrillated form of Abeta containing plaques is large, insoluble and more compact than the oligomers, the most toxic forms of Abeta are generally believed to be the soluble oligomers. The size of oligomer populations ranges from 8-22 KDa (low molecular weight) to 123-908 KDa (high molecular weight) (Fulop, Mandity et al. 2012). Evidence has been reported that both synthetic and brainderived human oligomer Abeta(1-42) are synaptotoxic, playing an essential pathogenic role in decreased spine density, damage certain forms of synaptic plasticity (Shankar, Bloodgood et al. 2007, Selkoe 2008, Li, Hong et al. 2009, Fulop, Mandity et al. 2012). The oligomer Abetainduced long-term potentiation (LTP) inhibition can be rescued by the application of anti-Abeta antibodies in vivo (Walsh, Klyubin et al. 2002), suggesting that indeed Abeta is the primal synaptotoxic agent. The number of plaques does not correlate well with the severity of dementia (reviewed by Shankar and Walsh 2009), which suggest that the highly aggregated form of the peptide is nontoxic. On the other hand, the aggregated insoluble forms of Abeta may lead to lateronset and more severe memory loss, associated with inflammatory reactions induced by fibrillar Abeta (Bamberger, Harris et al. 2003). Moreover, so-called "reverse oligomers" may dissociate from the plaques forming a halo of highly toxic Abeta forms around the plaque-core (Martins, Kuperstein et al. 2008, Koffie, Meyer-Luehmann et al. 2009).

\subsection{NEUROFIBRILLARY TANGLES}

Although the amyloid cascade hypothesis is the most widely accepted hypothesis that explains the development of $\mathrm{AD}$, it does not consider the interaction of Abeta peptide with tau. Tau plays an essential role in regulating microtubule dynamics, axonal transport and neurite outgrowth (Biernat and Mandelkow 1999). These functions are modulated by site-specific phosphorylation of the tau protein (Hamdane, Sambo et al. 2003).

It was reported that physiological assembly of the microtubule system in AD brain is disturbed by abnormally hyperphosphorylated forms of microtubule-associated tau protein forming intracellular NFTs. NFTs are formed by paired, helical $\sim 10 \mathrm{~nm}$ filaments especially in 
the hippocampal formation, amygdala, cortical and subcortical areas (reviewed by Selkoe 2011). The phosphorylated tau proteins are no longer able to stabilize the microtubules, which leads to disruption of neuronal transport and cause cell death (Baumann, Mandelkow et al. 1993).

\subsection{EXCITATORY SYNAPTIC TRANSMISSION IN THE CA1}

\subsubsection{GLUTAMATERGIC SYNAPTIC TRANSMISSION}

The non-essential amino-acid, L-glutamate (Glu) is the major excitatory neurotransmitter in the mammalian central nervous system, and plays principal role in neural activation, especially in the cortical and hippocampal regions, which are associated with learning and memory (Dale and Kandel 1993, Staubli, Rogers et al. 1994). There are two large families of glutamate receptors (GluRs) located on the membrane of the neurons: ionotropic GluRs (iGluRs) and metabotropic GluRs (mGluRs), respectively. All of these receptors are comprised of 4 subunits forming a tetrameric structure (Willard and Koochekpour 2013).

$\alpha$-Amino-3-hydroxy-5-methyl-4-isoxazolepropionic acid receptor (AMPAR) is an ionotropic transmembrane receptor, which has a lower affinity for Glu than the N-methyl-D-aspartate receptor (NMDARs) (Patneau and Mayer 1990). AMPARs are the major mediators of Glumediated fast excitatory synaptic transmission, are critical for the mediation of field potentials often used as an experimental readout for neuronal excitability (Bashir, Alford et al. 1991). The functional properties of the AMPARs are highly dependent on its subunit combinations. AMPARs lacking GluR2 subunit are permeable to $\mathrm{Ca}^{2+}$ (Wright and Vissel 2012).

NMDARs are both ligand-gated and voltage-dependent, and their activation requires the simultaneous binding of Glu and either D-serine or glycine (Kleckner and Dingledine 1988). NMDAR activation also requires membrane depolarization, because either $\mathrm{Mg}^{2+}$ or $\mathrm{Zn}^{2+}$ ion blocks the pore of the channel under basal circumstances, and this blockade is voltage-sensitive (Low, Zheng et al. 2000). This type of receptor is a multimeric assembly of glycine- or D-serine binding NR1 and NR3A-B, as well as Glu-binding NR2A-D subunits and is predominantly permeable to $\mathrm{Ca}^{2+}$, in addition to $\mathrm{Na}^{+}$and $\mathrm{K}^{+}$(Laube, Kuhse et al. 1998, Awobuluyi, Yang et al. 2007). $\mathrm{Ca}^{2+}$ influx via NMDARs triggers several cascade pathways that may alter synaptic efficacy and neuronal morphology. Of particular interest here, NR2A subunit-containing NMDARs localized mainly at the synaptic domain are antiapoptotic and participate in the induction of LTP in the CA1. In contrast, extrasynaptic NMDARs (esyn NMDARs) containing 
mainly NR2B subunit (on pyramidal cells) were shown to activate apoptotic pathways and to promote synaptic depression (Hardingham, Fukunaga et al. 2002).

Following presynaptic depolarization, vesicles may release their contents of Glu into the synaptic cleft by a highly $\mathrm{Ca}^{2+}$-dependent mechanisms. Glu can bind to GluRs of the postsynaptic cell, initiating cation-flow, which depolarizes the post-synaptic neuron (Llinas, Steinberg et al. 1981). After Glu is released into the synaptic cleft, the unwanted Glu is cleared off by the Glu transporter systems. The released Glu requires extremely large number of Glu transporters. There are two Glu transporter systems in the brain: the vesicular Glu transporters (VGLUT) and the excitatory amino-acid Glu transporters (EAATs), both are abundantly expressed both in neuronal and glial cells in many regions of brain (Bar-Peled, Ben-Hur et al. 1997).

To prevent over-stimulation, EAATs bind Glu from the extracellular space and then undergo a conformational change which allows transportation of the Glu through the plasma membrane (Focke, Wang et al. 2013). The EAAT subtypes are expressed in different regions of the brain. EAAT1 and the most abundant transporter EAAT2 are expressed on glial cells of the hippocampus and cerebral cortex and responsible for $80-90 \%$ of all Glu transport (Rothstein, Dykes-Hoberg et al. 1996). Recent data also shows that the Glu uptake capacity of astrocytes is much higher than that of neurons (Proper, Hoogland et al. 2002). Furthermore, EAAT2 is also present on presynaptic side of the neuron (Yang, Gozen et al. 2009). EAAT3 is also highly expressed in these regions, most probably on post-synaptic side in neuronal cells (Popoli, Yan et al. 2012). EAATs-mediated Glu transport is $\mathrm{Na}^{+}$-dependent and is highly efficient even against a 1000-fold concentration gradient (Attwell and Mobbs 1994). One Glu molecule is transported together with two or three $\mathrm{Na}^{+}$ions and one $\mathrm{H}^{+}$exchanges for one $\mathrm{K}^{+}$ion. These transporters are regulated by protein kinases, growth factors and second messengers (Focke, Wang et al. 2013). 


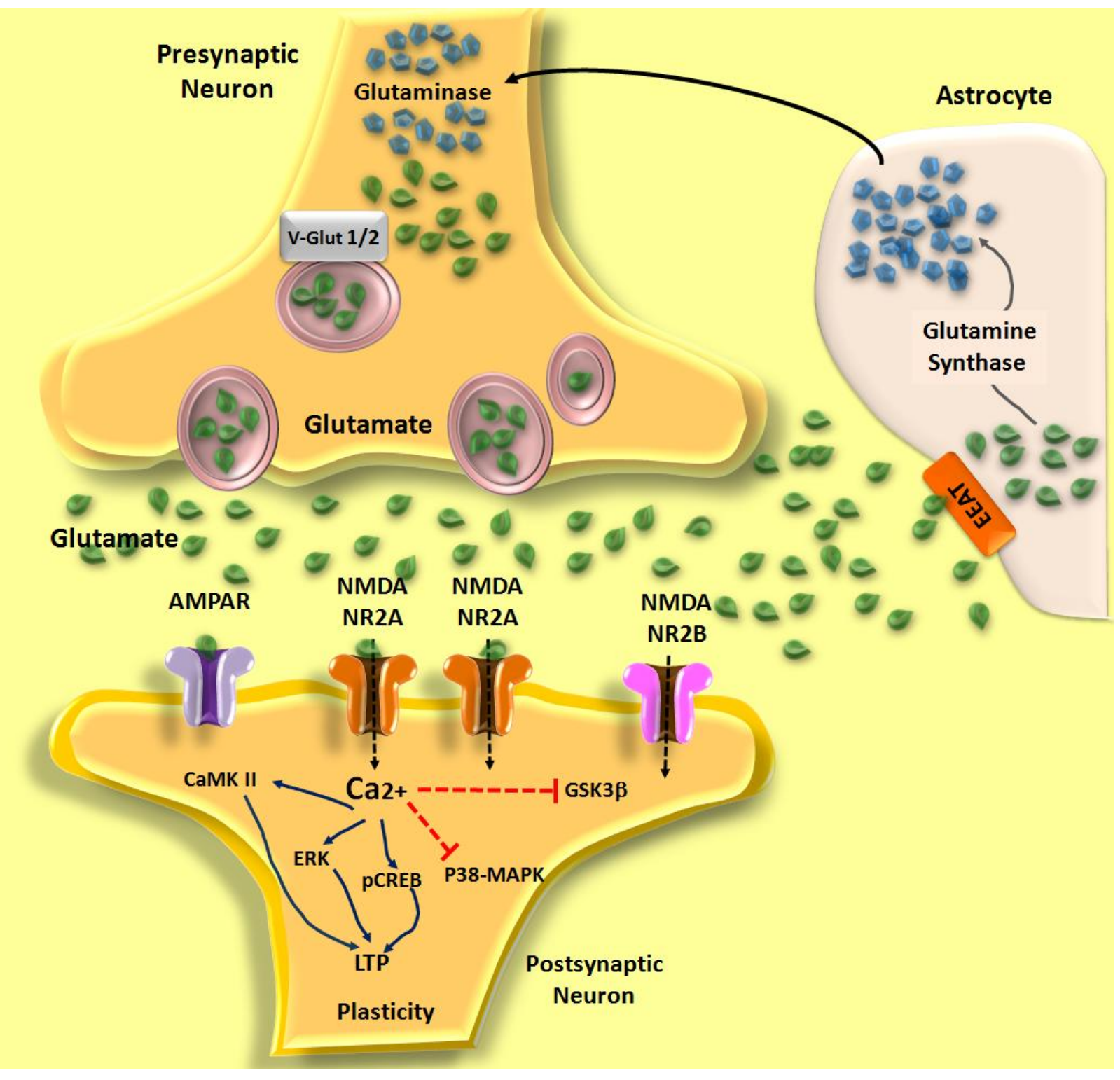

Figure 2. Glutamatergic synaptic transmission. During excitatory synaptic transmission, Glu is briefly released into the synaptic cleft, and then it binds to GluRs present mainly on the postsynaptic cell. The $\mathrm{Ca}^{2+}$ influx through NMDARs or AMPARs lacking GluR2, leads to activation of several molecular pathways such as CaMKII and ERK-MAPK stream which are critical to CREB phosphorylation and induction of LTP. However, other intracellular signaling can also be activated, which may lead to tau hyperphosporylation (GSK3 $\beta$ ) and LTD (p38-MAPK). The normal physiological level of Glu is mediated by both neuronal and glial EAATs. Glu is transported via EAATs and transformed to glutamine by the glutamine synthase, then released into the extracellular space. The glutamine is taken into the presynaptic terminals and is converted into Glu by glutaminase. The produced Glu is packaged into vesicles via VGLUT. Abbreviations: Glu (glutamate), GluRs (glutamate receptors), NMDARs (N-methyl-D-aspartate receptors), AMPARs ( $\alpha$-Amino-3-hydroxy-5-methyl-4-isoxazolepropionic receptors), CaMKII $\left(\mathrm{Ca}^{2+} /\right.$ calmodulin-dependent protein kinase II), ERK (extracellular signal-regulated kinase), p38-MAPK (p38-mitogen-activated protein kinase), CREB (cAMP response element binding protein), LTP (long-term potentiation), GSK3 $\beta$ (glycogen synthase kinase $3 \beta$ ), LTD (long-term depression), EAATs (excitatory amino-acid glutamate transporters) and VGLUT (vesicular glutamate transporters). Figure from CamposPena V and Meraz-Rios MA, Neurochemistry, 2014. 
Without glial cells' contribution, normal synaptic function of glutamatergic neurons is not possible involving development of learning and memory (Hertz and Zielke 2004). Recent data shows that the Glu uptake capacity of astrocytes is much higher than that of neurons (Proper, Hoogland et al. 2002). In addition, glial EAATs have high diffusion rate in the membrane: unbound transporters further away from the synapse can replace Glu-bounded closer to the synapse (Edwards 2015). Glial cells take up Glu through highly efficient EAATs and convert it to glutamine via the glutamine synthase pathway, then release glutamine into the extracellular space (see above, Figure 2).

This mechanism is an essential contributor to normal Glu release from the neuron (Rothstein and Tabakoff 1984). The glutamine is taken up into the presynaptic terminals and metabolized into Glu by the mitochondrial phosphate-activated glutaminase enzyme. The produced Glu is packaged into synaptic vesicles by VGLUT. This process is highly dependent on the tight cooperation of synaptic terminals and glial cells (Campos-Pena and Meraz-Rios 2014).

\subsubsection{NEUROPLASTICITY}

The ability of synapses to change their efficiency is also known as synaptic plasticity. This mechanism is dependent on the pattern by which synapses are stimulated and by several neurotropic factors and modulators. LTP is the most studied form of long-term synaptic plasticity, which widely regarded as one of the major mechanism that might be the cellular basis of learning and memory (Teyler and Discenna 1984). LTP was first described in the rabbit dentate gyrus of the hippocampus by Terje Lømo and Timothy Bliss in 1973 (Teyler and Discenna 1984). Since its original observation, it has been also described in other brain structures, such as cerebral cortex, cerebellum and amygdala (Kimura, Nishigori et al. 1989, Clugnet and LeDoux 1990, Crepel and Jaillard 1991). In particular, NMDAR-dependent LTP in the CA1 is the most widely studied type of LTP, and there is evidence showing that this form of neuroplasticity is impaired in AD (reviewed by Selkoe 2008). In my thesis, I am focusing on the NMDAR-dependent LTP at the Schaffer-collateral pathway in the CA1.

Two forms of LTP can be distinguished: early-phase of LTP (E-LTP) and late-phase of LTP (L-LTP). A weak, high frequency stimulation (single train of 100 pulses at $100 \mathrm{~Hz}$ ) can trigger an increase in synaptic efficacy that lasts for about 1-2 hours, while triggering the L-LTP requires repeated, strong high frequency stimulation (multiple trains of 100 pulses at $100 \mathrm{~Hz}$ ) that lasts for over 3 hours or even days (Figure 3, reviewed by Lu, Christian et al. 2008). However, Villers A 
and her coworkers found that a single train of high frequency stimulation $(100 \mathrm{~Hz}, 1 \mathrm{sec})$ also induces L-LTP (8 h) in mice hippocampal slices (Villers, Godaux et al. 2012). It is generally evidenced that the induction of E-LTP and L-LTP is very different, thus their biochemical pathways can lead to distinct changes in the synapses. E-LTP requires modification of various proteins and their trafficking at synapses, but is independent from gene transcription and protein synthesis, while L-LTP requires changes in gene expression and protein synthesis ( $\mathrm{Lu}$, Christian et al. 2008). However, it is also shown that L-LTP induced by a single train is independent from protein synthesis (Villers, Godaux et al. 2012).

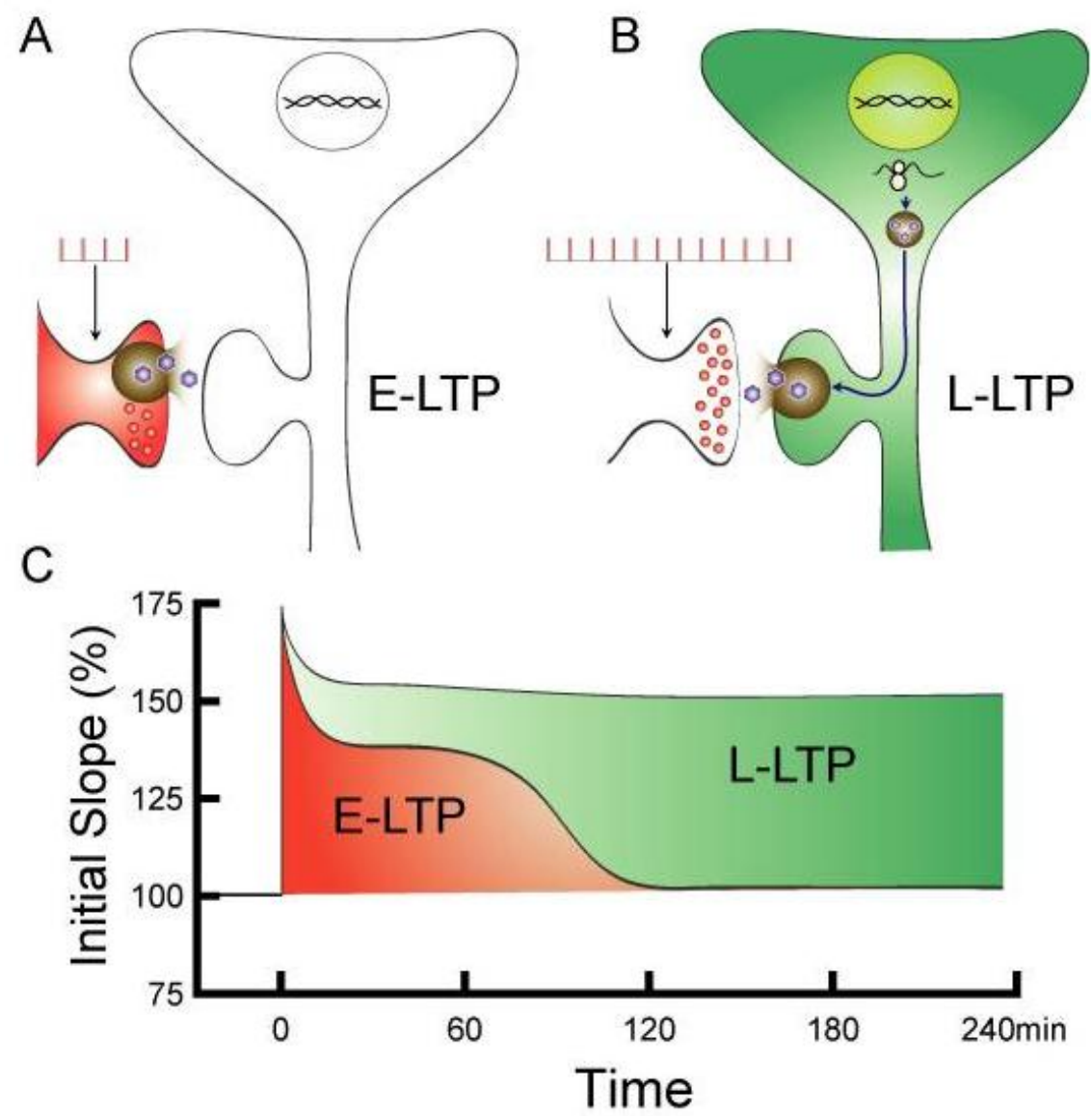

Figure 3. The timeline of the LTP phases. Panel A shows that a weak, high frequency stimulation can evoke an increase in synaptic efficacy (E-LTP), while triggering the L-LTP requires repeated, strong high frequency stimulation and dependent on gene transcription (B). The morphological changes in spines reduced over a long time $(\mathrm{C})$. This figure also shows the activity-dependent secretion of BDNF at the presynaptic side (red in A and C) may require development of E-LTP and L-LTP (green in B and C). Abbreviations: LTP (long-term potentiation), E-LTP (early-phase of long-term potentiation), L-LTP (latephase of long-term potentiation) and BDNF (brain derived neurotrophic factor). Figure from Lu, Christian et al. 2008. 
E-LTP involves Glu transmission and several postsynaptic processes that lead to enhanced Glu release from the presynapse and increased sensitivity to Glu on the postsynaptic side. When Glu is released from the presynaptic side onto the dendritic spine of the postsynaptic neuron, it can bind GluRs localised to the postsynaptic density (PSD) (reviewed by Byth 2014). The PSD involves iGluRs and several signaling proteins, and is linked to the actin filaments that support the structural framework of the spine. PSD contains NMDARs, which can enable $\mathrm{Ca}^{2+}$ ion influx to the spine, and they require for a binding Glu and its coagonist. These coagonists, namely glycine or D-serine can bind to the NMDARs gating its activity, moreover they may play a role in astroglial regulation of neural plasticity (Fossat, Turpin et al. 2012). The activation of NMDARs requires $\mathrm{Mg}^{2+}$ ion removal from the channel. This occurs when there is a strong activation of nearby AMPARs, which can mediate rapid synaptic transmission. Moreover, Glu has to bind to NMDARs in the presence of depolarized postsynaptic membrane in order to activate the receptor (Bliss and Collingridge 1993). During LTP induction, nonsynaptic AMPARs are rapidly trafficked into the postsynaptic membrane, which is mediated by the activation of various protein kinases. Activated CaMKII phosphorylates the GluR1-containing AMPARs, increasing their sensitivity to Glu and increasing the synaptic expression of AMPAR (Lisman, Yasuda et al. 2012). CaMKII activation also induces remodeling of the cytoskeleton and functions as retrograde signal generator along with protein kinase $\mathrm{C}(\mathrm{PKC})$ : a second messenger, namely nitrogen-oxide (NO) is released to the presynaptic terminal to increase the probability of neurotransmitter vesicle release (Johnstone and Raymond 2011). The activity-dependent brain derived neurotrophic factor (BDNF) released from presynaptic sites may also be necessary for ELTP and have a crucial role for L-LTP induction (see above, Figure 3).

Elevated intracellular $\mathrm{Ca}^{2+}$ triggers CaMKII, which in turn activates adenylyl-cyclase and cAMP kinase, required for L-LTP. The increased $\mathrm{Ca}^{2+}$ influx via L-type voltage-dependent $\mathrm{Ca}^{2+}$ channels (VDCC) is also critical for translation and for the activation of cAMP-mediated transcription (Morgan and Teyler 1999), while mitogen-activated protein kinase (MAPK) cascade can mediate cAMP response element binding protein (CREB) phosphorylation (Kanterewicz, Urban et al. 2000). The regulation of CREB has been shown to play a role in several protein kinases' activation including protein kinase A (PKA), which may contribute to transcription via serum response element (SRE) by activating the ERK-MAPK stream (Adams, Anderson et al. 2000, Davis, Vanhoutte et al. 2000). Protein synthesis occurs in dendrites too, and this type of local translation is necessary for L-LTP induction (Huang and Kandel 2005). 
In summary, L-LTP differs from E-LTP in its requirement for gene transcription and in its association with structural and morphological changes at synapses. Induction of LTP results the functional and morphological development of synapses: the pre- and postsynaptic structures such as dendritic spines and axonal buttons are stabilized, the postsynaptic density via postsynaptic scaffolding proteins (PSD-95) are increased and also results enhanced postsynaptic sensitivity to Glu (Ehrlich, Klein et al. 2007). However, during induction and during E-LTP, the morphological changes of spine dynamics reduced progressively, and they are less stable over longer time (Yuste and Bonhoeffer 2001). The latter phase of LTP is associated with postranslational modifications that increase the excitatory postsynaptic current (EPSC). Moreover, presynaptic synthesis of synaptotagmin-1 and increased synaptic vesicle numbers suggest that protein synthesis is not restricted to the postsynaptic side (Ahmad, Polepalli et al. 2012). LTP induction also results in the growth of new spines, increased an dendritic spine number and formation of new synapses on the CA1 pyramidal cells.

\subsection{INVESTIGATION OF EXCITATORY EXTRACELLULARLY EVENTS IN THE CA1}

In my thesis I used multi-electrode electrophysiological recordings from hippocampal slices for investigating cellular events. Extracellular recording from hippocampal slices has long been a method of choice for determining the changes in excitability and synaptic plasticity of the CA1 microcircuitry (Dingledine, Dodd et al. 1980).

Spontaneous spikes and far more often, field excitatory postsynaptic potentials (fEPSPs) are recorded extracellularly from a local network of neurons, however, the relationship between these two phenomena is not fully clear. Intuitively, both electrophysiological events correlate with the excitability of the network under investigation, but these events are generated by different mechanisms. Evoked fEPSPs are mainly composed of subthreshold events from a population of neurons, like dendritic depolarizations (Tominaga, Tominaga et al. 2002) and glial contributions to the net extracellular charge-flow arising mainly from the function of transporters (Diamond, Bergles et al. 1998, Luscher, Malenka et al. 1998). In contrast, spontaneous firing represents only neuronal suprathreshold events (Brock, Coombs et al. 1952). Another difference is that a fEPSP is evoked by a stimulus, and therefore it is the result of a coordinated and synchronized electrical activity of a cell population mediated by synaptic connections. Spontaneous spikes, in contrast, 
are not evoked by an external stimulus, and they are more likely to be dependent on intrinsic network connections and properties (Cohen and Miles 2000).

Several protocols have been introduced to evoke LTP since its original description. By definition, NMDA-dependent LTP is a process of Hebbian synaptic plasticity, where input specificity, associativity, cooperativity, and persistence are the governing rules.

\subsection{AMYLOID-BETA INDUCES NEURONAL HYPEREXCITABILITY}

Seizures in patients with $\mathrm{AD}$ have been investigated by many researchers over the last decades. It was shown that AD patients can exhibit more than one spontaneous seizures, but the relationship of epilepsy and with AD pathophysiology has remained unknown (Rao, Dove et al. 2009). Recent studies show that the occurrence of unprovoked seizures is 5-10-fold greater in $\mathrm{SAD}$, and 87-fold greater in the less elderly cohort of patients (50-59 years old) than in the reference population (Amatniek, Hauser et al. 2006). Minkeviciene et al. have also demonstrated that Abeta-induced neuronal hyperexcitability culminates in epileptiform activity (Minkeviciene, Rheims et al. 2009). This fact shows that the brain network shifts towards hyperexcitability in $\mathrm{AD}$, leading to several effects: neuronal dysfunction, cell death and cognitive decline. Importantly, this process enhances the production of Abeta, because Abeta release is dependent on the network activity (Cirrito, Kang et al. 2008, Kang, Lim et al. 2009).

Several animal models were used to elucidate the relationship between AD and epilepsy. Numerous findings confirmed that excitotoxic effects of Glu contribute to progressive neuronal loss in AD (Koh, Yang et al. 1990, Pomara, Singh et al. 1992, Harkany, Abraham et al. 2000, Amatniek, Hauser et al. 2006). Alternations in Glu uptake regulatory system can lead to increased Glu level and subsequent increase in the excitability of the network. EAATs may be central players in this mechanism, and indeed, recent findings suggest that Abeta oligomers inhibit normal Glu recycling at the synapse (Awobuluyi, Yang et al. 2007, Li, Hong et al. 2009, Chen, Reese et al. 2011), resulting in elevated ambient extracellular Glu level in the brain (Matos, Augusto et al. 2008, Mura, Zappettini et al. 2012), which might be responsible for the overexcitation seen in AD. Abeta blocks Glu reuptake by inhibiting both neuronal and glial EAATs (Li, Hong et al. 2009, Matos, Augusto et al. 2012), which might lead to esyn NMDAR activation. The activation of esyn NMDARs impairs LTP (Li, Jin et al. 2011), enhances LTD (Liu, Yang et al. 2013) and promotes apoptosis (Hardingham, Fukunaga et al. 2002). Recent findings suggest that Abeta binds to prion protein, mGluR5 and integrin receptors, and this 
complex initiates a molecular cascade mediated by Fyn kinase (Larson, Sherman et al. 2012, Um, Nygaard et al. 2012, Um, Kaufman et al. 2013), which subsequently phosphorylates NMDARs. Increased phosphorylation of NMDARs enhances their sensitivity to Glu and modifies their opening kinetics.

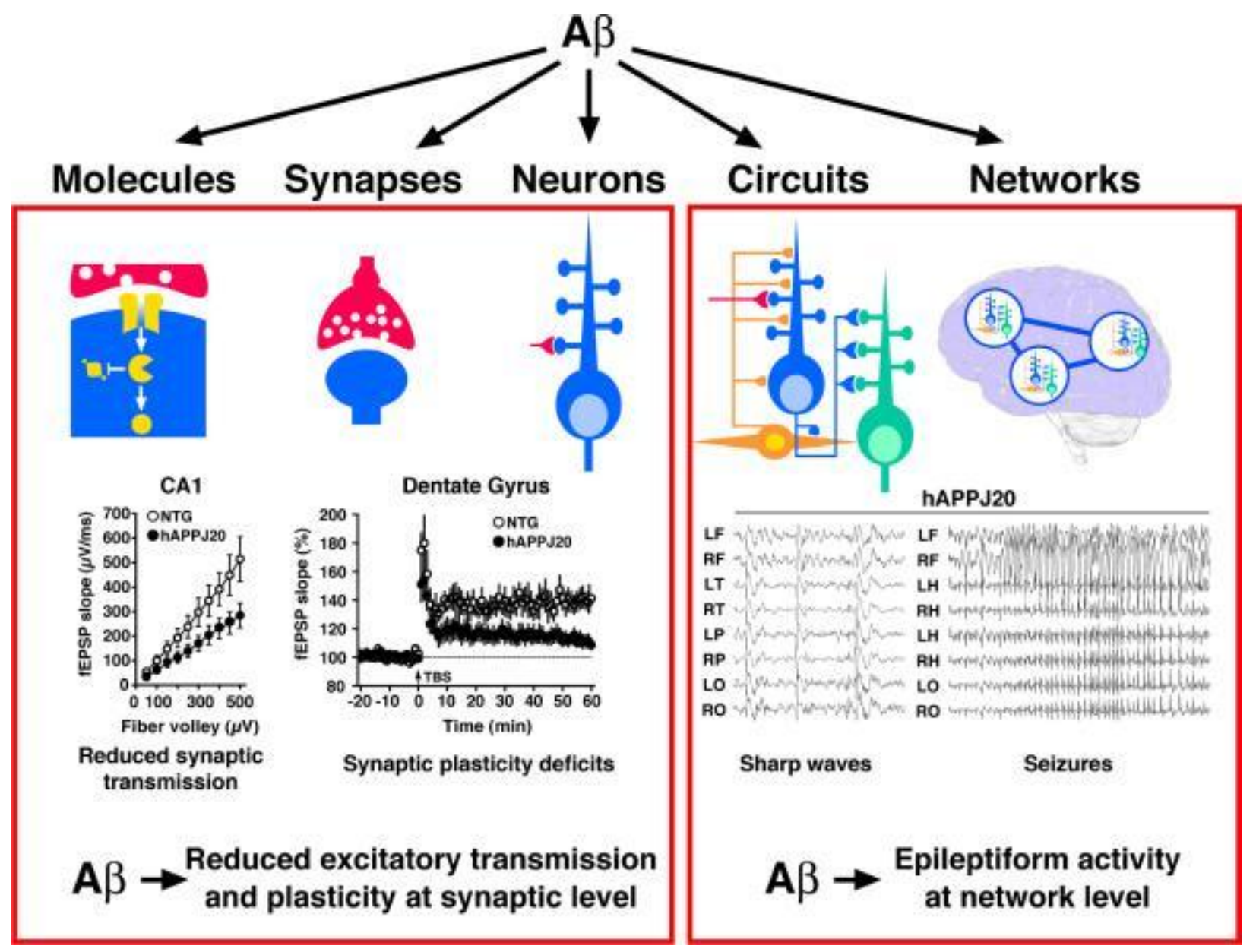

Figure 4. Effect of Abeta at multiple levels of complexity. Abeta causes failure of excitatory neurotransmission and impairs synaptic plasticity at the level of specific synapses (left). The hAPP-J20 transgenic mice also show epileptiform activity and seizures at the network level (right). These results suggest that aberrant network synchronization is a primary effect of high Abeta level. Abbreviations: Abeta (amyloid-beta), hAPP-J20 (human amyloid precursor protein transgenic mice), F (frontal), fEPSPs (field excitatory postsynaptic potentials), H (hippocampal), L (left), NTG (nontransgenic mice), O (posterior-parietal), P (parietal), R (right), T (temporal), TBS (theta-burst stimulus). Figure from Palop and Mucke 2009.

The brain can be described as a complex system of networks and is classified by multiple levels of complexity. Molecular and synaptic alternations can influence the network function in higher levels manifesting in rhythmic neural activity. It is well characterized that Abeta interferes with excitatory neurotransmission at synaptic level, however its effect on the network is still 
undetermined. Figure 4. is a good summary of the effect of Abeta on synaptic transmission and on the network (see above, Figure 4) (reviewed by Palop and Mucke 2009). The authors have shown that paired-pulse ratio (PPF) and LTP was depressed in human APP (hAPP) expressing transgenic mice, as well as these mice also exhibited frequent generalized cortical epileptiform spike discharges that may lead to cognitive deficit (Palop, Chin et al. 2007). Although, their experimental data also show that the excitatory transmission was reduced in the hippocampus of transgenic mice, epileptiform activity was recorded from both hippocampal and cortical regions of the same mouse strain.

\subsection{THERAPEUTIC APPROACHES IN ALZHEIMER'S DISEASE: FOCUSING ON GLUTAMATE TOXICITY AND THE SCAVENGER SYSTEM}

Several studies have clearly indicated that Abeta toxicity is mediated by Glu excitotoxicity, involving Glu spillover and esyn NMDARs activation, excessive $\mathrm{Ca}^{2+}$ influx and consequent activation of cascade pathways resulting in cell death. Thus, Glu plays a critical role in Abeta pathology, therefore GluR antagonists could be promising therapeutic targets against AD.

Currently, the only drug that targets the Glu system and is used for treating AD in the clinic is memantine, a non-competitive NMDAR antagonist. This compound exhibits higher affinity to NMDARs than the endogenous NMDAR antagonist, $\mathrm{Mg}^{2+}$ ion (Chen, Pellegrini et al. 1992). Memantine can attenuate the excessive $\mathrm{Ca}^{2+}$ flow into the cell without interfering with normal physiological processes. It was also shown that memantine favorably binds to and blocks NMDARs during its prolonged activation, however this process takes place during a few milliseconds, thus memantine is not able to act or accumulate in the channel under normal synaptic activity (reviewed by Revett, Baker et al. 2013). Furthermore, it was also shown that memantine is able to reverse Abeta-induced LTP damage (Klyubin, Wang et al. 2011), reduces Abeta plaque number and increases synaptic density in a mouse model of AD (Dong, Yuede et al. 2008). Despite these findings, the clinical efficiency of the drug is still debated (Schneider, Dagerman et al. 2011).

Increased extracellular Glu level may activate esyn NMDARs leading to neuronal overactivation and cell death. More recently, Abeta-induced neuronal hyperexcitability via esyn NMDARs has been suggested to play a critical role in hyperexcitation (Costa, Lacor et al. 2012, Koeglsperger, Li et al. 2013). Indeed, p38-MAPK pathway is altered by Abeta resulting in LTD facilitation via both esyn NMDARs and mGluRs (Chen, Lin et al. 2013). Moreover, blocking 
NR2B subunits by ifenprodil or Ro-6981 rescued Abeta-induced LTP disruption (Li, Jin et al. 2011, Zhang, Wang et al. 2013), suggesting that it might be a potential therapeutic target against AD. Indeed, recent papers have suggested that memantine itself has greater affinity for esyn NMDARs that to synaptic NMDARs (Xia, Chen et al. 2010).

It is also likely that Abeta increases extracellular Glu levels by damaging the function of Glu transporters. Jacob et al. have found that gene expression and protein levels of EAATs are altered in AD brains, especially in the hippocampus and frontal cortex (Jacob, Koutsilieri et al. 2007). This suggests that by restoring the normal level of EAAT in the brain, a possible protection can be reached. Interestingly, ceftriaxone, a $\beta$-lactam antibiotic was shown to have a side effect that increases the expression of EAATs in the brain (Rothstein, Patel et al. 2005), and this might be exploited as a treatment against AD.

Another approach might be to reduce brain Glu level through the BBB. The blood Glu level is regulated by two Glu transaminases, glutamic-pyruvic transaminase (GPT) and glutamicoxaloacetate transaminase (GOT). These enzymes play a critical role in reducing Glu levels in the blood by converting Glu into other molecules along with their substrates, pyruvate (Pyr) and oxaloacetate (Oxa) (Figure 5) (Palmada and Centelles 1998). If the blood Glu level is decreasing, the EAATs localized on the brain capillaries can pump out the excess Glu from the CNS with higher efficiency.

$$
\begin{aligned}
& \text { glutamate }+ \text { pyruvate } \stackrel{\text { GPT }}{\longleftrightarrow} \text { alanine }+\alpha \text {-ketoglutarate } \\
& \text { glutamate }+ \text { oxaloacetate } \stackrel{\text { GOT }}{\longleftrightarrow} \text { aspartate }+\alpha \text {-ketoglutarate }
\end{aligned}
$$

Figure 5. Glu metabolism. Glu can be converted to alanine and $\alpha$-ketoglutarate (by GPT) or aspartate and $\alpha$-ketoglutarate (by GOT) by reversible mechanism in the brain. These processes require the substrates of the enzymes. Abbreviations: Glu (glutamate), glutamic-pyruvic transminase (GPT) and glutamicoxaloacetate transminase (GOT).

It was shown that the intravenous administration of either Pyr or Oxa decreases blood Glu level and subsequently reduces brain Glu concentration (Teichberg, Cohen-Kashi-Malina et al. 2009, Boyko, Stepensky et al. 2012). Based on this fact, blood Glu scavenger system was proposed by Vivian Teichberg as a new approach for the treatment of neurological conditions associated with excitotoxicity (Zlotnik, Gurevich et al. 2007). Indeed, these Glu scavengers have protective effect in several disorders, such as traumatic brain injury (Zlotnik, Gurevich et al. 
2007), stroke (Castellanos, Sobrino et al. 2008), ischemia (Marosi, Fuzik et al. 2009) and neuropathy (Nie and Weng 2010). We suggest that this method may be a promising treatment against AD. Indeed, GPT could prevent Abeta-induced LTD enhancement in a slice experiment without affecting baseline synaptic activity (Li, Hong et al. 2009). Moreover, application of a Glu uptake inhibitor mimicked the action of Abeta on LTD enhancement, indicating that Abeta oligomers perturb synaptic plasticity by altering Glu recycling (Li, Hong et al. 2009).

Based on these findings, we aimed to investigate further the connection between Glu homeostasis and Abeta-induced synaptic plasticity impairment. 


\section{AIMS}

There is growing evidence that Abeta oligomers mediate synaptic impairment in AD, however the exact mechanism of synaptic depression is still unknown.

My Ph.D. work aims to identify a possible pathway of increased neuronal excitability and impaired synaptic plasticity caused by Abeta(1-42) using electrophysiological recordings by a multi-electrode array setup.

We aimed to clarify the following points:

1) Is there a difference between the mechanism of evoked and spontaneous neuronal events?

2) Which receptors are involved in the generation of fEPSP and spontaneous spiking activity?

3) How does Abeta influence evoked and spontaneous neuronal activity?

4) Can we mimick the effect of Abeta by blocking Glu reuptake?

5) Can we prevent the effect of Abeta by reducing the extracellular Glu level in the brain? 


\section{MATERIALS AND METHODS}

\subsection{COMPOUNDS}

For the preparation of artificial cerebrospinal fluid (ACSF), all salts, glucose, 6-cyano-7nitroquinoxaline-2,3-dione (CNQX), (+)-MK801 hydrogen maleate (MK801), $\alpha-(4-$ hydroxyphenyl)- $\beta$-methyl-4-benzyl-1-piperidineethanol (+)-tartrate (ifenprodil), sodium pyruvate (Pyr), GPT and DL-threo- $\beta$-benzyloxyaspartate (TBOA) were purchased from Sigma-Aldrich (St Louis, MO).

\subsection{ANIMALS}

The study conformed to EU Directive 2010/63/EU and was approved by the regional Station for Animal Health and Food Control under Project License XVI/8/2013. BALB/c mice were housed in groups of $2-3$ under standard conditions $\left(24^{\circ} \mathrm{C}, 12 \mathrm{~h}\right.$ light-dark cycle) with food and water available ad libitum.

\subsection{EX VIVO ELECTROPHYSIOLOGY}

\subsubsection{EXTRACELLULAR RECORDING USING MULTI-ELECTRODE ARRAY}

Transverse acute hippocampal slices of $400 \mu \mathrm{m}$ in thickness were prepared from the brains of 3 month old mice using a McIlwain tissue chopper (Campden Instrument, Loughborough, UK). Slices were incubated in ACSF gassed with $95 \% \mathrm{O}_{2}, 5 \% \mathrm{CO}_{2}$ at $35^{\circ} \mathrm{C}$ for $60 \mathrm{~min}$. ACSF was composed of (in mM): $130 \mathrm{NaCl}, 3.5 \mathrm{KCl}, 3 \mathrm{CaCl}_{2}, 1.5 \mathrm{MgSO}_{4}, 0.96 \mathrm{NaH}_{2} \mathrm{PO}_{4}$, $24 \mathrm{NaHCO}_{3}$ and $10 \mathrm{D}$-glucose, $\mathrm{pH}$ 7.4. Individual slices were transferred to a 3D multi-electrode array (MEA) chip with 60 tip-shaped and $60 \mu \mathrm{m}$ high electrodes spaced by $200 \mu \mathrm{m}$ (Qwane Biosciences, Lausanne, Switzerland, Figure 6). The surrounding solution was removed quickly, and the slice was immobilized by placing a grid onto it. The slices were continuously perfused with oxygenated $\operatorname{ACSF}\left(3 \mathrm{ml} / \mathrm{min}\right.$ at $\left.36^{\circ} \mathrm{C}\right)$ throughout the entire recording session. Data were recorded using a standard, commercially available MEA 60 setup (Multi Channel Systems MCS GmbH, Reutlingen, Germany). 

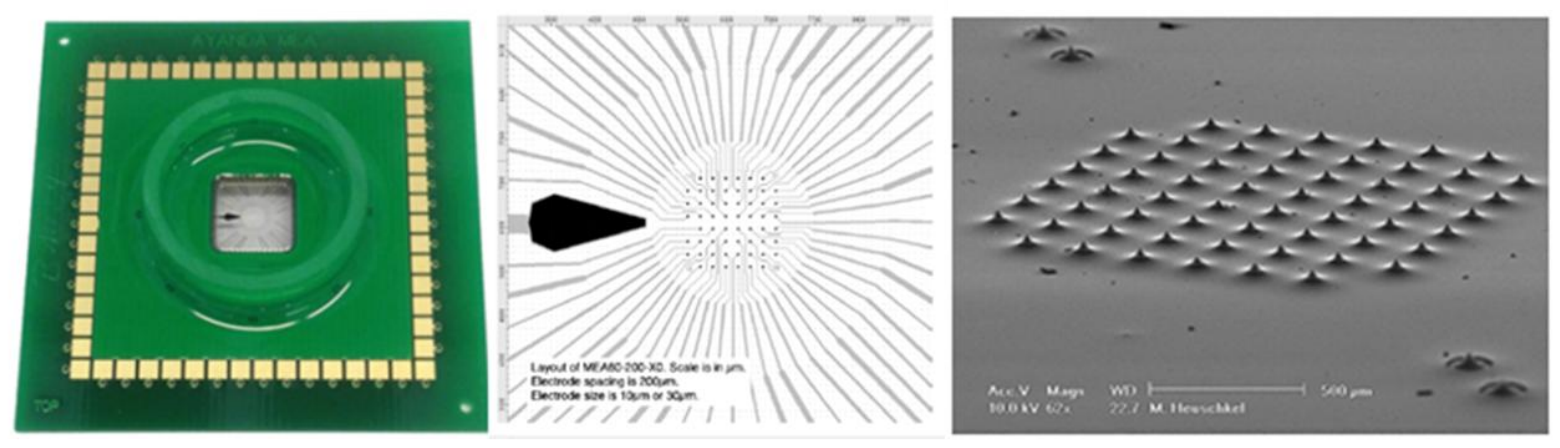

Figure 6. 3D tip-shaped MEA60 biochip. MEA biochips are realised on small glass substrate that consist of micro-fabricated platinum electrodes that are used to measure electrical activity from hippocampal slices (left). Middle figure shows the schematic array of the chip. The tip-shape electrodes penetrate through the upper outer dead cell layer of the slice thereby enabling to record signals that come from healthy neurons in the deeper layer of the slice (right) (Qwane Biosciences, Lausanne, Switzerland). Abbreviation: MEA (multi-electrode array).

\subsubsection{STIMULATION PROTOCOL AND DATA ANALYSIS}

Care was taken to place the stimulating electrode in the same region at every slice. The Schaffer-collateral was stimulated by injecting a biphasic voltage waveform $(-100 /+100-\mu \mathrm{s})$ through one selected electrode at $0.033 \mathrm{~Hz}$. Evoked fEPSPs were recorded from the proximal stratum radiatum at $10 \mathrm{kHz}$ (Figure $\mathbf{7 A}$ ), while spontaneous spiking activity from the stratum pyramidale in the $\mathrm{CA} 1$ at a frequency of $25 \mathrm{kHz}$ for $5 \mathrm{~min}$ epochs (Figure 7B). After a $30 \mathrm{~min}$ incubation period, the threshold and maximum stimulation intensities for evoked responses were determined. To evoke responses, $30 \%$ of the maximal stimulation intensity was used. For analyzing the peak-to-peak amplitudes of fEPSPs MC_Rack program, while for sorting and analyzing the spiking activity, Spike2 software package (Cambridge Electronic Design, Cambridge, UK) was used. Evoked fEPSPs recordings were filtered above $10 \mathrm{~Hz}$, while spontaneous activity was filtered between $300-3000 \mathrm{~Hz}$ offline.

Before any treatment, fEPSPs were recorded for 1 hour followed by a 5 min spike recording $(0$ h). Electric stimulation was ceased during spontaneous activity recordings. After 30 min treatment, spiking activity was also recorded, and the number of spikes after treatment $(1.5 \mathrm{~h})$ was normalized to the initial firing activity $(0 \mathrm{~h})$. On the other hand, the level of evoked fEPSPs (the last 10 peak-to-peak amplitudes) was compared to the average of the 20 peak-topeak amplitudes of the control level in all cases (Figure 8A). 


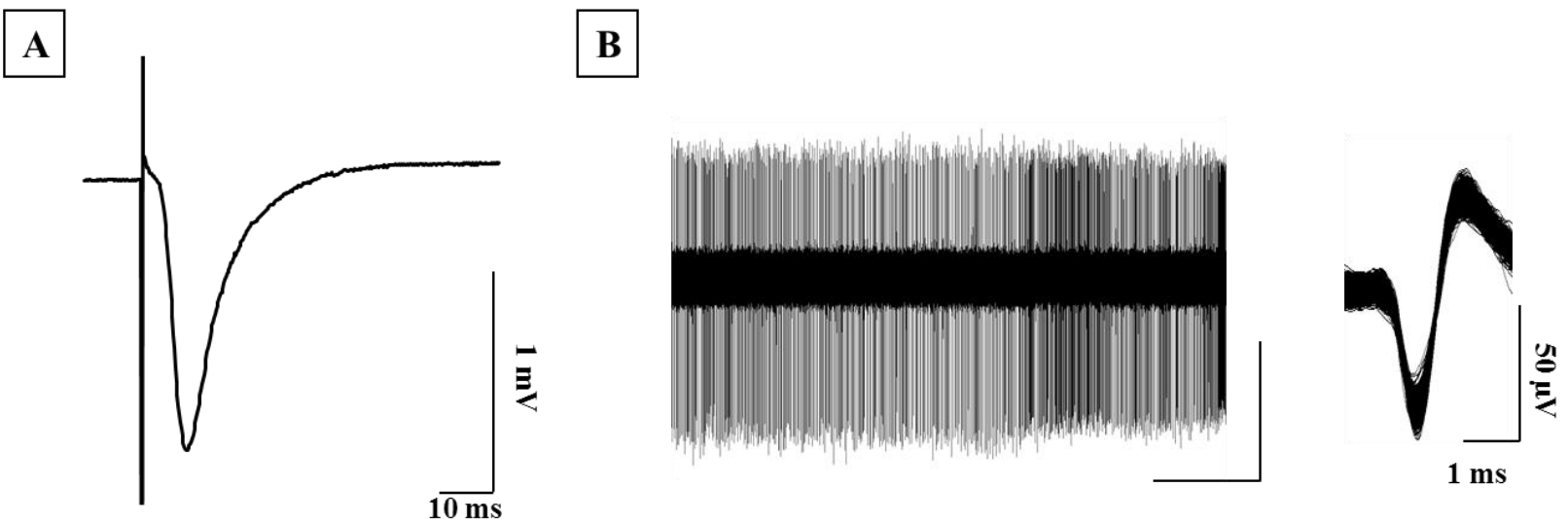

Figure 7. Exemplar recordings in the CA1. Both evoked fEPSPs and spiking activity recording electrodes were located in the CA1 region of a mouse hippocampal slice. The fEPSPs were recorded from the proximal stratum radiatum (A) and the spontaneous spiking was recorded from the stratum pyramidale (B). Both fEPSPs and spiking activity were recorded from the same slice. Data were considered as multi-unit activity. Abbreviation: fEPSPs (field excitatory postsynaptic potentials).

In the other groups, which were treated with Abeta, spontaneous activity was recorded before treatment $(0 \mathrm{~h})$ followed by $25 \mathrm{~min}$ fEPSPs recording, than spiking activity was also recorded for 5 min $(0.5 \mathrm{~h})$. Number of spikes was normalized to the initial firing activity $(0 \mathrm{~h})$, which was taken as $100 \%$ in all channels. The threshold for spike detection was set to 2.5 -fold of noise level. The data of those electrodes were included in the analysis where the initial spiking activity was above $0.5 \mathrm{~Hz}$. Firing activity ranged from 150 to 1000 spikes $/ 5 \mathrm{~min}$. Data were considered as multi-unit activity. Field EPSPs were recorded for $25 \mathrm{~min}$, followed by a 5 min spiking recording, then again fEPSPs were recorded. The level of evoked fEPSPs (the last 10 peak-topeak amplitudes) was compared to the control level in all cases (Figure 8B).

In a second set of experiments, where we focused on LTP, slices were treated for $1 \mathrm{~h}$ before inducing LTP. The level of LTP (the last 10 peak-to-peak amplitudes) was compared to the average of the last 20 peak-to-peak amplitudes of evoked fEPSPs before applying theta-burst stimulation (TBS). TBS comprised of 15 trains administered at $5 \mathrm{~Hz}$, the individual trains contained 4 pulses separated by 10-ms (Figure 9). 


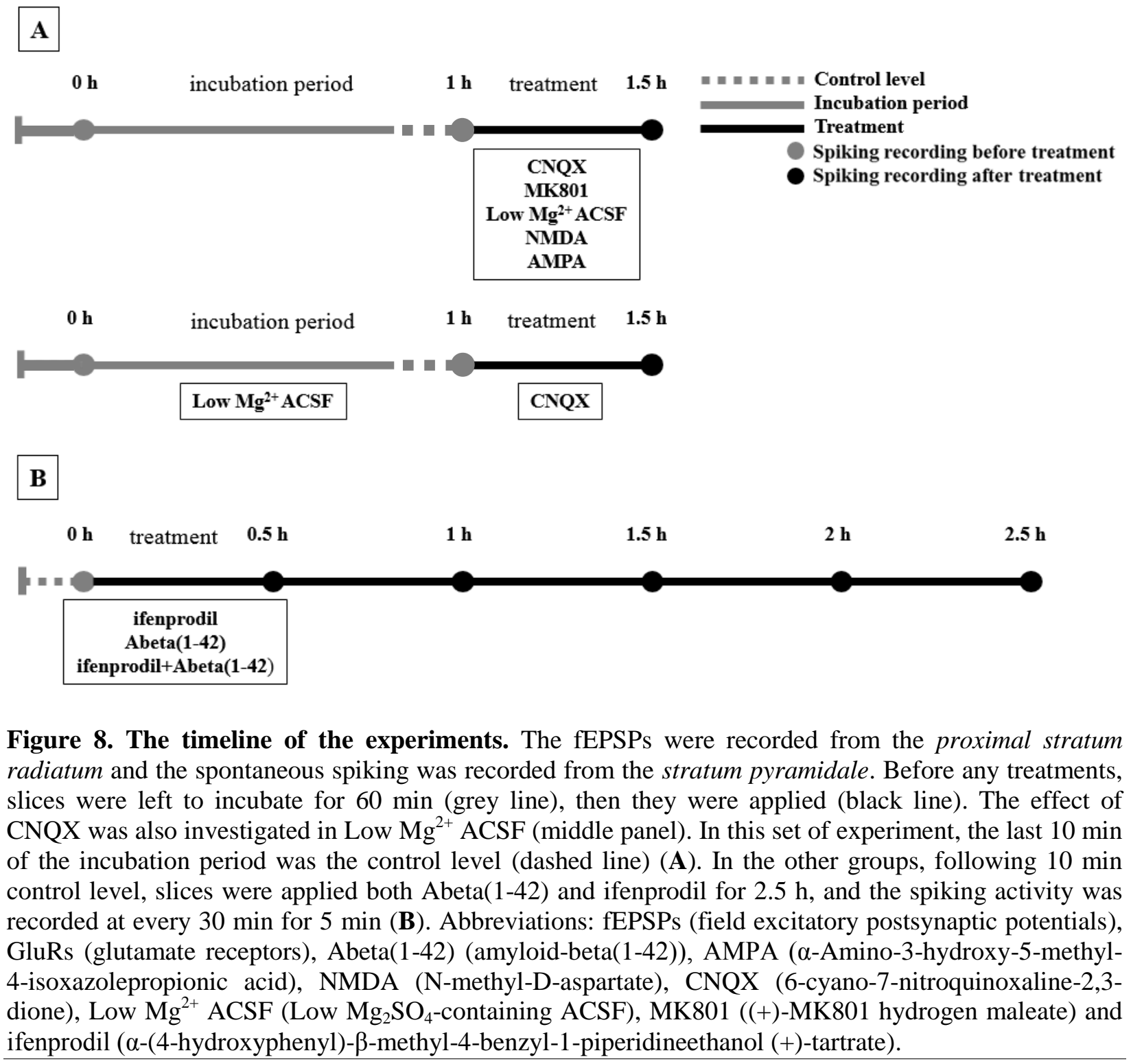

\subsubsection{DRUG TREATMENTS}

All slices were incubated for 30 min without stimulation in the recording chamber before any recording was done. Following the first spike-recording $(0 \mathrm{~h})$, slices were left to incubate a further 60 min with continuous electric stimulation, then slices were applied with $10 \mu \mathrm{M}$ CNQX or $10 \mu \mathrm{M}$ MK801 or $25 \mu \mathrm{M}$ MK801 or ACSF containing low concentration of $\mathrm{Mg}_{2} \mathrm{SO}_{4}$ (Low $\mathrm{Mg}^{2+}$ ACSF; $0.25 \mathrm{mM}$ ) or $0.5 \mu \mathrm{M}$ NMDA or $0.05 \mu \mathrm{M}$ AMPA for 30 min (Figure 8A). Spontaneous spiking was recorded before and $30 \mathrm{~min}$ after the $5 \mathrm{~min}$ treatment epochs. The effect of CNQX was also tested in Low $\mathrm{Mg}_{2} \mathrm{SO}_{4}$-containing ACSF $(0.25 \mathrm{mM})$, where modified ACSF was perfused to the slices from the beginning of the experiment. 
Other cohorts of slices were treated with $1 \mu \mathrm{M}$ oligomer Abeta(1-42), ifenprodil $(3 \mu \mathrm{M})$ and ifenprodil+Abeta(1-42) for $2.5 \mathrm{~h}$. The spiking activity was also recorded at every $30 \mathrm{~min}$ for 5 min (Figure 8B).

Next, slices were treated with $1 \mu \mathrm{M}$ oligomer $\operatorname{Abeta}(1-42)$ for $60 \mathrm{~min}$, then LTP was induced by the TBS protocol. LTP was followed for 1.5 hour after TBS. During treatment, evoked fEPSPs were recorded. In the other hand, after $10 \mathrm{~min}$ control level, slices were treated with 1 $\mu \mathrm{M}$ Abeta(1-42) or $5 \mu \mathrm{M}$ TBOA for 60 min before LTP was induced (Figure 9). Another cohort of slices was treated with $3 \mu \mathrm{M}$ ifenprodil or $0.82 \mathrm{mM}$ Pyr for $10 \mathrm{~min}$ then $2.06 \mathrm{U} / \mathrm{ml}$ GPT for 60 min before LTP induction. Separate groups of slices were treated with these compounds together with $\mathrm{Abeta}(1-42)$ or TBOA.

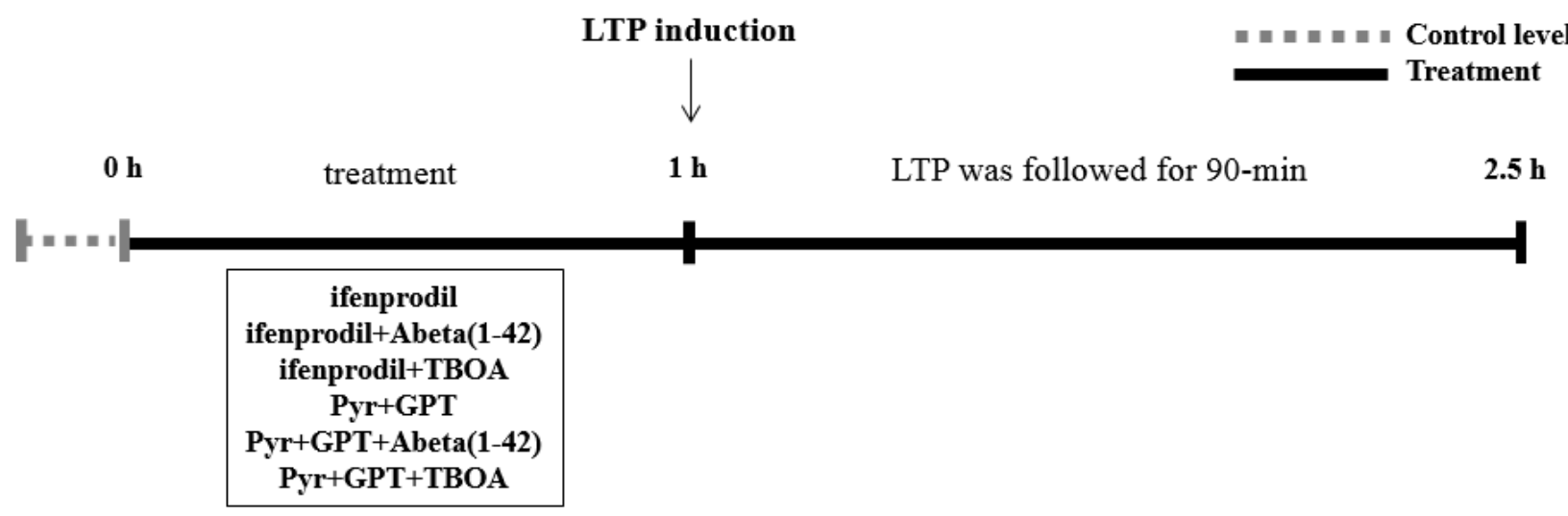

Figure 9. The timeline of the LTP experiments. Evoked fEPSPs were recorded from the proximal stratum radiatum. After $10 \mathrm{~min}$ control level (grey line), slices were applied different treatments for 60 min (black line), then LTP was evoked by TBS and was followed for $90 \mathrm{~min}$. Abbreviations: LTP (longterm potentiation), fEPSPs (field excitatory postsynaptic potentials), TBS (theta burst stimulus), ifenprodil $\quad(\alpha-(4-h y d r o x y p h e n y l)-\beta$-methyl-4-benzyl-1-piperidineethanol-(+)-tartrate), $\quad$ Abeta(1-42 (amyloid-beta(1-42)), TBOA (DL-threo- $\beta$-benzyloxyaspartate), Pyr (sodium pyruvate) and GPT (glutamic-pyruvic transaminase).

\subsection{STATISTICS}

Testing for normality was done with the Kolmogorov-Smirnov normality test. Our fEPSPs data have shown normal distribution, hence independent samples t-test and one-way repeated measures analysis of variance (ANOVA) was used with the Bonferroni test for post-hoc analysis.

Despite of this, spiking data have shown nonparametric distribution, thus we used nonparametric tests (Kruskal-Wallis test was followed by Mann-Whitney U-test) for determining differences between two and several groups.

The $p$ value $\leq 0.05$ was considered significant in all cases. Data were analyzed using SPSS statistical software. 


\subsection{SYNTHESIS AND CHARACTERIZATION OF AMYLOID-BETA}

Detailed description of the synthesis and characterization of Abeta(1-42) is reported in Bozso and his coworkers and in Fulop and her coworkers (Bozso, Penke et al. 2010, Fulop, Mandity et al. 2012). To summarize shortly, a depsipeptide derivative of Abeta(1-42) was synthesized and after purification, it was used in lyophilized form. A $200 \mu \mathrm{M}$ stock solution of the peptide was prepared in $0.1 \mathrm{mM} \mathrm{NaOH}$, and the $\mathrm{pH}$ was set to 11.0. After incubation for 2 hour at ambient temperature, the stock solution was diluted into ACSF to a concentration of $50 \mu \mathrm{M}$ and the $\mathrm{pH}$ was set to 7.3. The peptide solution was incubated for 12 hour at $37^{\circ} \mathrm{C}$ and prior to use, it was diluted with ACSF to a final concentration of $1 \mu \mathrm{M}$.

Aggregation grade and the size distribution of the oligomers were checked by Western Blots (WB) by following the methods described in Fulop, Mandity et al. 2012. Oligomers were detected either with sequence-specific BAM10 antibodies (Sigma-Aldrich), or with conformation specific OC antibodies (Millipore), which detects the oligomers of fibrillar nature, i.e. of betasheet structure. 


\section{RESULTS}

\subsection{EVOKED FIELD POTENTIALS, BUT NOT SPONTANEOUS SPIKES ARE MEDIATED BY AMPA RECEPTORS}

Evoked fEPSP are regarded as the input, while spiking rate as the output of the neuronal network; however, the relationship between these two phenomena is not fully clear. We recorded fEPSPs from the proximal stratum radiatum (see above, Figure 7A) and in parallel spontaneous spikes from the stratum pyramidale (see above, Figure 7B) of the CA1 using MEA electrodes. Both fEPSPs and spontaneous activity could be abolished by application of $1 \mu \mathrm{M}$ tetrodotoxin (data not shown).

First, we investigated the contribution of AMPARs to evoked fEPSPs and spontaneous activity using CNQX $(10 \mu \mathrm{M})$, an AMPAR inhibitor. Blocking AMPARs resulted in a complete reduction of evoked fEPSPs (untreated: $\mathrm{n}=5 ; 98.84 \pm 2.41 \%$ vs. CNQX: $\mathrm{n}=5 ; 4.62 \pm 0.45 \%$, $p<0.001$, independent samples t-test; Figure 10A,B). Conversely, spontaneous activity remained unaffected (untreated: $\mathrm{n}=5 ; 139.55 \pm 44.95 \%$ vs. CNQX: $\mathrm{n}=5 ; 182.18 \pm 56.76 \%$, Mann-Whitney Utest; Figure 10C), suggesting that AMPARs have a key role in generating fEPSPs, but not spiking activity.

Under physiological conditions, NMDARs activation is dependent on depolarization, e.g. on previous AMPARs activation (Bliss and Collingridge 1993). Thus we changed to Low $\mathrm{Mg}^{2+}$ ACSF $(0.25 \mathrm{mM})$ to remove the depolarization-dependent $\mathrm{Mg}^{2+}$ plug from the NMDARs (Derchansky, Shahar et al. 2004). Consistent with our previous findings, applying CNQX in Low $\mathrm{Mg}^{2+}$ ACSF for 30 min, fEPSPs were completely abolished (untreated: $\mathrm{n}=7 ; 101.54 \pm 1.69 \%$ vs. CNQX in Low $\mathrm{Mg}^{2+}$ ACSF: $\mathrm{n}=6 ; 6.44 \pm 0.36 \%, p<0.001$, independent samples $\mathrm{t}$-test; Supplementary Figure 1), suggesting that CNQX-inhibited fEPSPs are independent from NMDARs activation.

We have also tried to activate AMPARs by applying a low concentration of AMPA (0.05 $\mu \mathrm{M})$, but we observed epileptiform field responses and a huge elevation of basal activity which hindered the unambiguous detection of action potentials (Supplementary Figure 2).

These findings suggest that evoked fEPSPs, but not spontaneous spikes require AMPARs activity. 

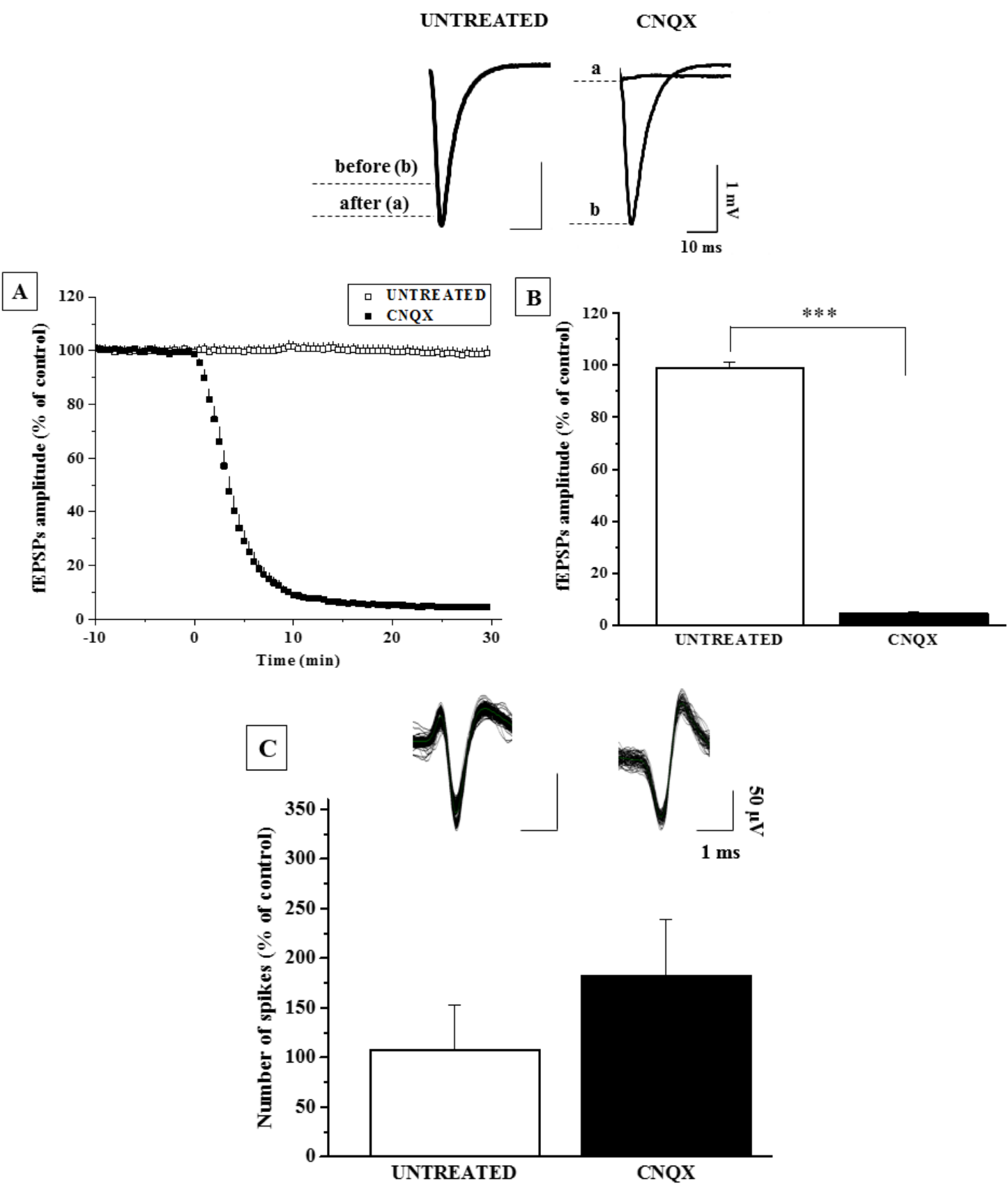

Figure 10. AMPARs regulate mainly fEPSPs but not spontaneous spikes. Panel A shows the changes of fEPSPs amplitudes over time: blocking AMPARs completely inhibited fEPSPs compare to untreated slices. The upper panel shows representative fEPSPs before (b) and after (a) treatment. Bar graphs represent the average of the fEPSPs amplitudes of the 25-30 min period after treatment $(\mathbf{B})$. CNQX induced a complete reduction of evoked fEPSPs $(\mathrm{n}=5, p<0.001)$, however the spontaneous activity was not affected $(\mathbf{C})$. Above panel $\mathrm{C}$, superimposed representative spontaneous activities. Error bars represent SEM; $* * * p \leq 0.001$. Abbreviations: fEPSP (field excitatory postsynaptic potential), AMPARs ( $\alpha$-Amino-3hydroxy-5-methyl-4-isoxazolepropionic acid receptors) and CNQX (6-cyano-7-nitroquinoxaline-2,3dione). 


\subsection{SPONTANEOUS FIRING, BUT NOT FIELD POTENTIAL IS GOVERNED BY NMDA RECEPTOR FUNCTION}

Next, we focused on NMDARs to test how the modulation of these receptors affect both evoked fEPSPs and spiking activity. Applying an NMDAR antagonist, MK801 did change evoked fEPSP amplitudes in neither $10 \mu \mathrm{M}$ nor in $25 \mu \mathrm{M}$ (untreated: $\mathrm{n}=5$; $98.8 \pm 2.4 \%$ vs. MK801 in $10 \mu \mathrm{M}: \mathrm{n}=5 ; 101.23 \pm 1.17 \%$ vs. MK801 in $25 \mu \mathrm{M}: \mathrm{n}=5 ; 104.49 \pm 1.72$, one-way ANOVA, Bonferroni post-hoc test; Figure 11A,B). In contrast, MK801 caused a dose-dependent inhibition of spiking rate (untreated: $n=5 ; 139.55 \pm 44.95 \%$ vs. MK801 in $10 \mu M: n=5 ; 96.73 \% \pm 32.22$, $p=0.48$ vs. MK801 in $25 \mu \mathrm{M}: \mathrm{n}=5 ; 29.23 \pm 22.93, p=0.035$, Mann-Whitney U-test; Figure 11C).

\section{UNTREATED $\quad$ MK801 $(10 \mu \mathrm{M}) \quad$ MK801 $(25 \mu \mathrm{M}) \quad(0.25 \mathrm{mM})$}

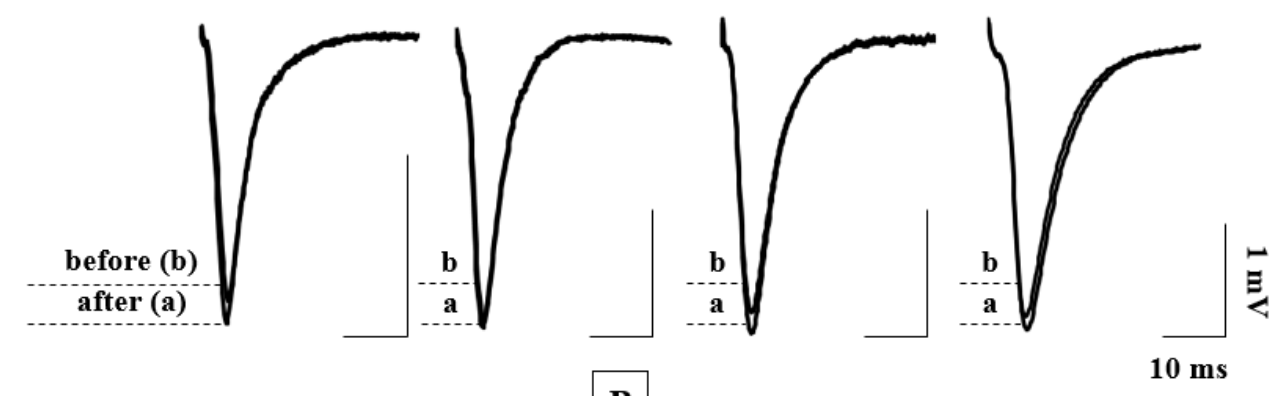

A

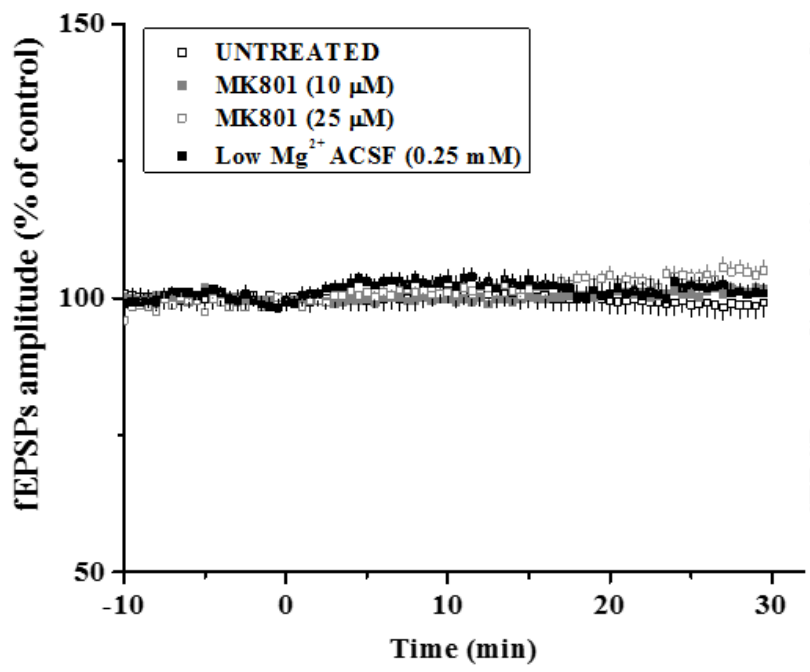

$\mathbf{B}$

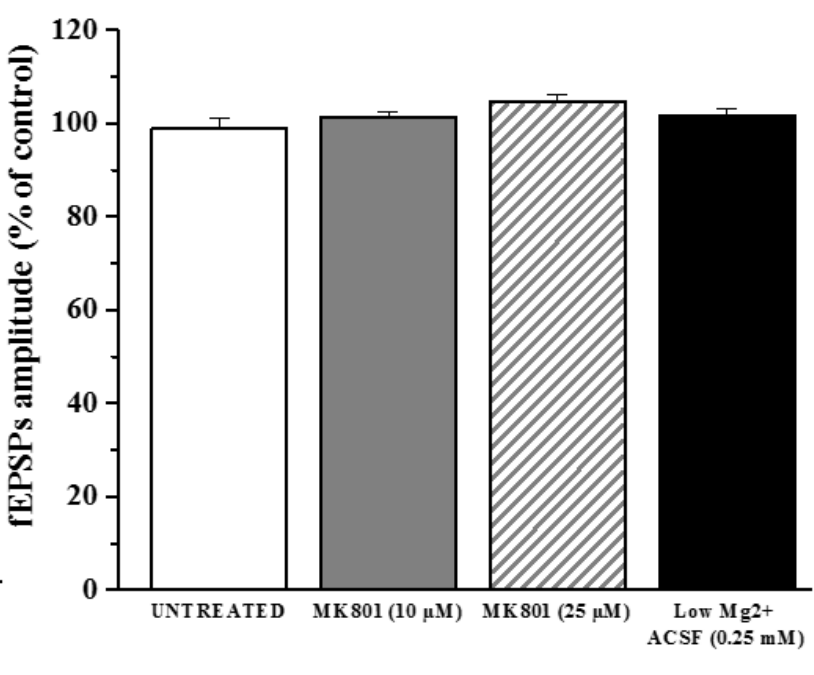




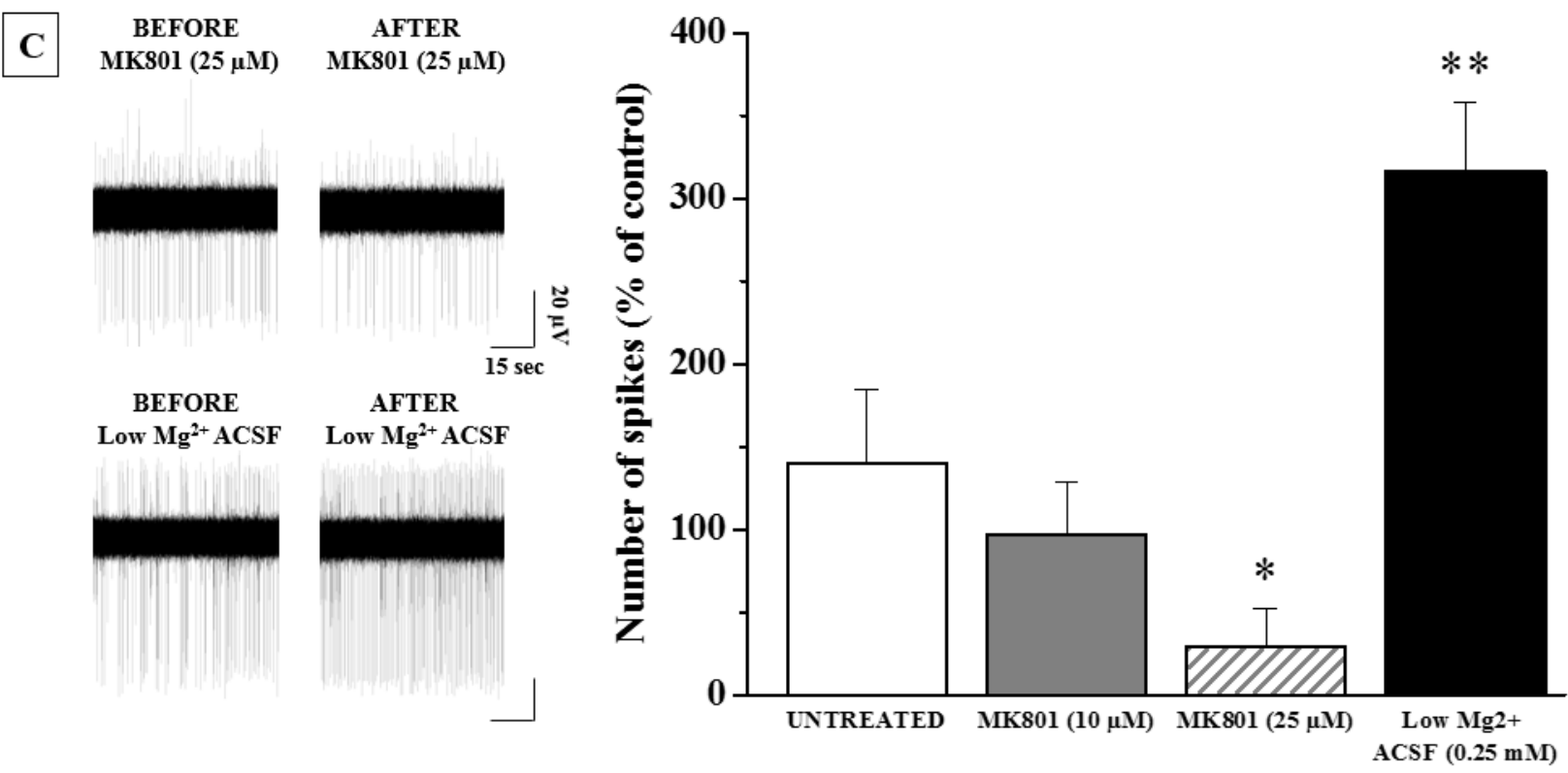

Figure 11. NMDARs influence spontaneous spiking but not fEPSPs. Panel A shows the changes of fEPSPs amplitudes over time and the upper panel depicts representative fEPSPs before (b) and after (a) treatments. Blocking (MK801) or enhancing (Low $\mathrm{Mg}^{2+}$ ACSF) NMDAR function did not change the fEPSPs amplitudes. Bar graphs represent the average of the fEPSPs amplitudes of the 25-30 min period after treatments (B). MK801 dose-dependently reduced spiking frequency, while Low $\mathrm{Mg}^{2+} \mathrm{ACSF}$ increased firing rate (untreated vs. MK801 in $25 \mu \mathrm{M}: p=0.035$ and untreated vs. Low $\mathrm{Mg}^{2+} \mathrm{ACSF}^{2}$ $p=0.004)(\mathbf{C})$. Representative spikes are shown at the left from the respective groups. Error bars represent SEM; ${ }^{*} p \leq 0.05$ and $* * p \leq 0.01$. Abbreviations: NMDAR (N-methyl-D-aspartate receptor), fEPSPs (field excitatory postsynaptic potentials), MK801 (+)-MK801 hydrogen maleate) and Low $\mathrm{Mg}_{2} \mathrm{SO}_{4} \mathrm{ACSF}$ (low $\mathrm{Mg}_{2} \mathrm{SO}_{4}$-containing artificial cerebrospinal fluid).

Next, we tried to enhance NMDAR function. We have supposed that removal the depolarization-dependent $\mathrm{Mg}^{2+}$ plug from the NMDARs may induce elevated spiking activity without any effect on evoked fEPSPs. Indeed, Low $\mathrm{Mg}^{2+}$ ACSF induced a massively elevated frequency of the spontaneous activity compared to the untreated slices $(n=7,316.34 \pm 41.89 \%$, $p=0.004$, Mann-Whitney U-test; Figure 11C), but evoked fEPSP responses remained unchanged ( $\mathrm{n}=7,101.54 \pm 1.69 \%$, one-way ANOVA, Bonferroni post-hoc test).

Based on these results we hypothesized that spontaneous firing is mediated by the ambient Glu concentration acting on the esyn NMDARs. 

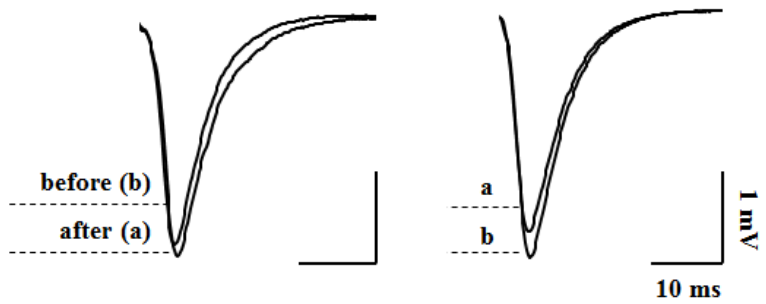
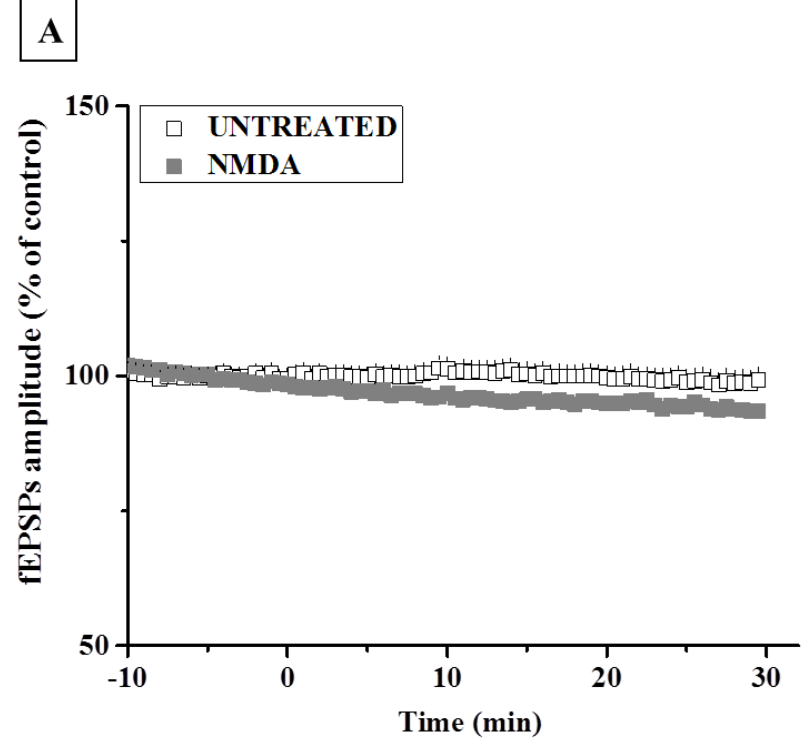

C

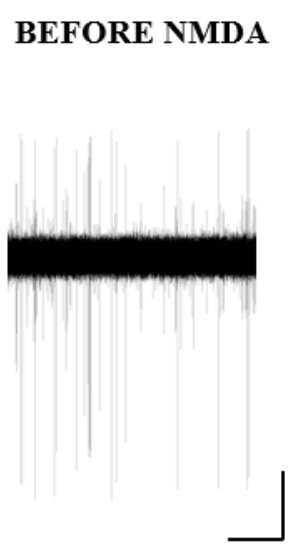

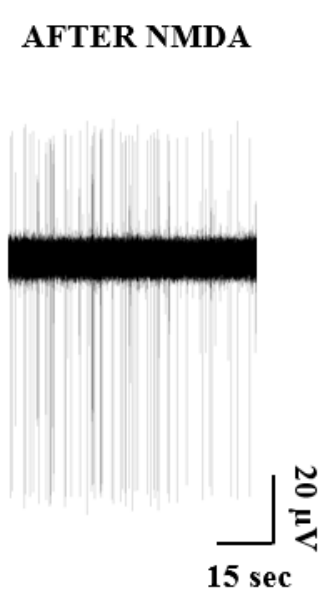

B
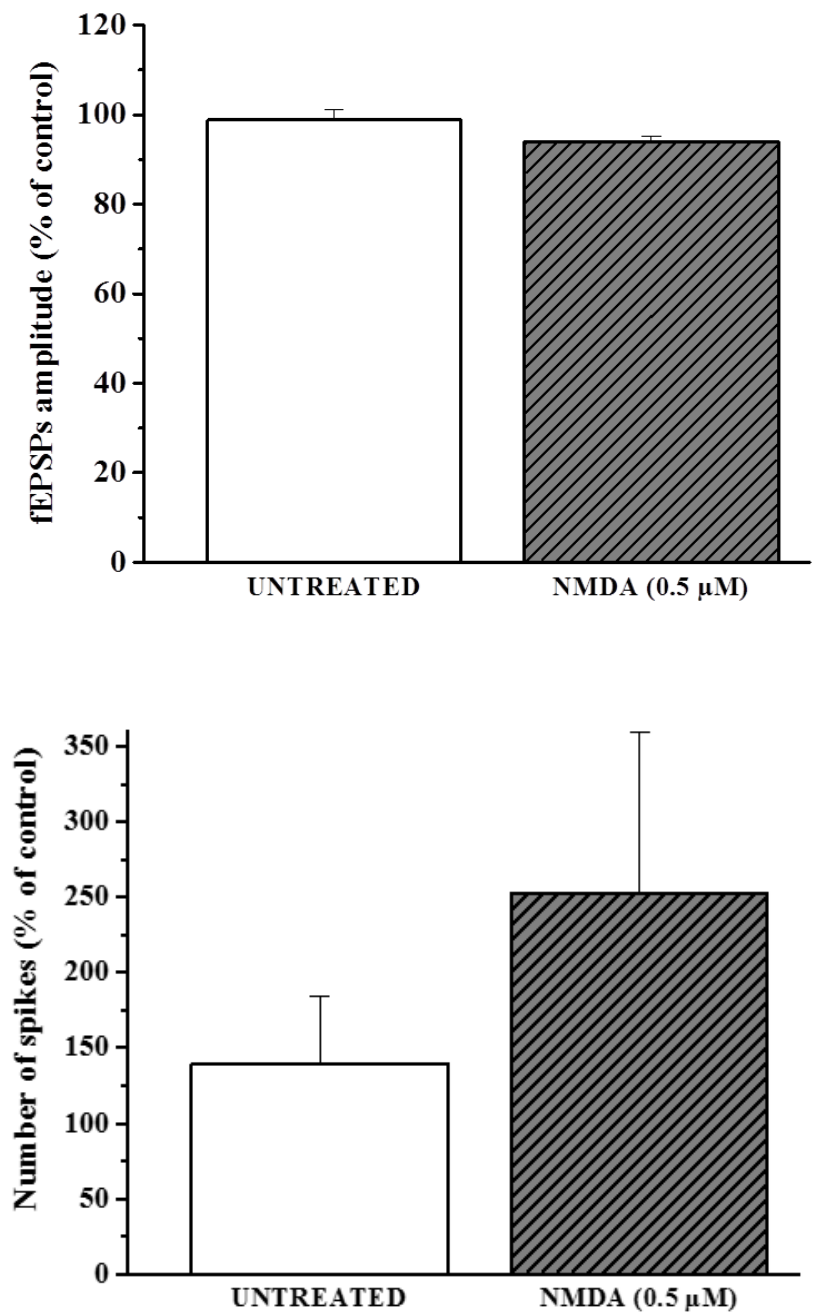

Figure 12. NMDA induces a trend of elevated firing rate without affecting fEPSPs. Figure A represents the change of fEPSP amplitudes and the upper panel shows raw fEPSPs before (b) and after (a) treatment. Small concentration of NMDA $(0.5 \mu \mathrm{M})$, which was reported to activate esyn NMDARs, did not affect fEPSPs. Bar graphs show the average of the fEPSPs amplitudes of the 25-30 min period after treatment (B). Low concentration of NMDA elevated spiking frequency, although not significantly (C). Left panel shows exemplar spikes from the respective group. Error bars represent SEM. Abbreviations: esyn NMDAR (extrasynaptic N-methyl-D-aspartate receptor) and fEPSPs (field excitatory postsynaptic potential). 
Therefore, we tried to activate selectively this set of receptors by applying low concentration of NMDA $(0.5 \mu \mathrm{M})$ in normal ACSF (Harney, Jane et al. 2008). This treatment resulted in unaltered fEPSPs (untreated: $n=5 ; 98.8 \pm 2.40 \%$ vs. NMDA: $n=9 ; 94.03 \pm 1.04 \%$; independent samples t-test; see above, Figure 12A,B), but influenced spiking activity (untreated: $n=5$; $139.55 \pm 44.95 \%$ vs. NMDA: $\mathrm{n}=9 ; 253.02 \pm 105.9 \%, p=0.51$, Mann-Whitney U-test; Figure 12C). This change is almost significant, thus low concentration of NMDA induced a trend of elevated firing rate.

These various findings suggest that evoked fEPSPs are mediated by AMPARs, but spontaneous spiking mainly requires esyn NMDARs activity.

\subsection{AMYLOID-BETA(1-42) INDUCES HYPEREXCITATION VIA NR2B}

Excessive neuronal activity is a phenomenon associated with early AD, however underlying mechanisms are not well understood. After establishing that fEPSPs and spontaneous firing are mediated by distinct set of receptors, we tried to investigate the effect of Abeta(1-42) on evoked fEPSPs and spontaneous activity. Spiking rate was determined every $30 \mathrm{~min}$ in 5 min epochs within the time frame of the recordings.

In the untreated slices the amplitude of fEPSPs increased slightly until $1.5 \mathrm{~h}$ reaching $103.36 \pm 2.67 \%$ of the initial amplitude, then decreased to initial value $(\mathrm{n}=5 ; 0.5 \mathrm{~h}: 100.8 \pm 1.65 \%$; $1 \mathrm{~h}: 102.9 \pm 1.84 \% ; 2 \mathrm{~h}: 100.86 \pm 3.38 \%$ and $2.5 \mathrm{~h}: 98.18 \pm 4.04 \%$, one-way repeated measures ANOVA, Bonferroni post-hoc test; Figure 13). Similarly, spiking frequency did not change over time $(\mathrm{n}=5 ; 0.5$ h: $124.34 \pm 29.72 \% ; 1$ h: $129.57 \pm 53.28 \% ; 1.5$ h: $139.55 \pm 44.95 \% ; 2$ h: 102.48 \pm 28.42 and 2.5 h: 76.16 $\pm 28.08 \%$, Mann-Whitney U-test; Figure 14).

Abeta(1-42) applied in $1 \mu \mathrm{M}$ did not change fEPSPs amplitudes (Abeta(1-42): $\mathrm{n}=7 ; 0.5 \mathrm{~h}$ : $107.08 \pm 2.43 \%$; 1 h: $106.41 \pm 2.93 \% ; 1.5$ h: $103.54 \pm 3.07 \% ; 2$ h: $100.92 \pm 3.06 \%$ and 2.5 h: $97.1 \pm 2.97 \%$, one-way repeated measures ANOVA, Bonferroni post-hoc test), compared to untreated slices (see above; Figure 13), suggesting that Abeta(1-42) did not affect the AMPARmediated synaptic transmission. On the other hand, Abeta(1-42) induced a massively elevated firing ( $\mathrm{n}=7$; 0.5 h: $182.6 \pm 30.91 \%$; 1 h: $242.29 \pm 83.31 \%, p=0.043 ; 1.5$ h: $233.29 \pm 83.31 \% ; 2$ h: $240.32 \pm 85.0 \%, p=0.036$ and 2.5 h: $244.72 \pm 64.21 \%, p=0.001$, Mann-Whitney U-test; Figure 14) compared to untreated slices, suggesting that NMDARs are involved in the effect of Abeta(1-42). 

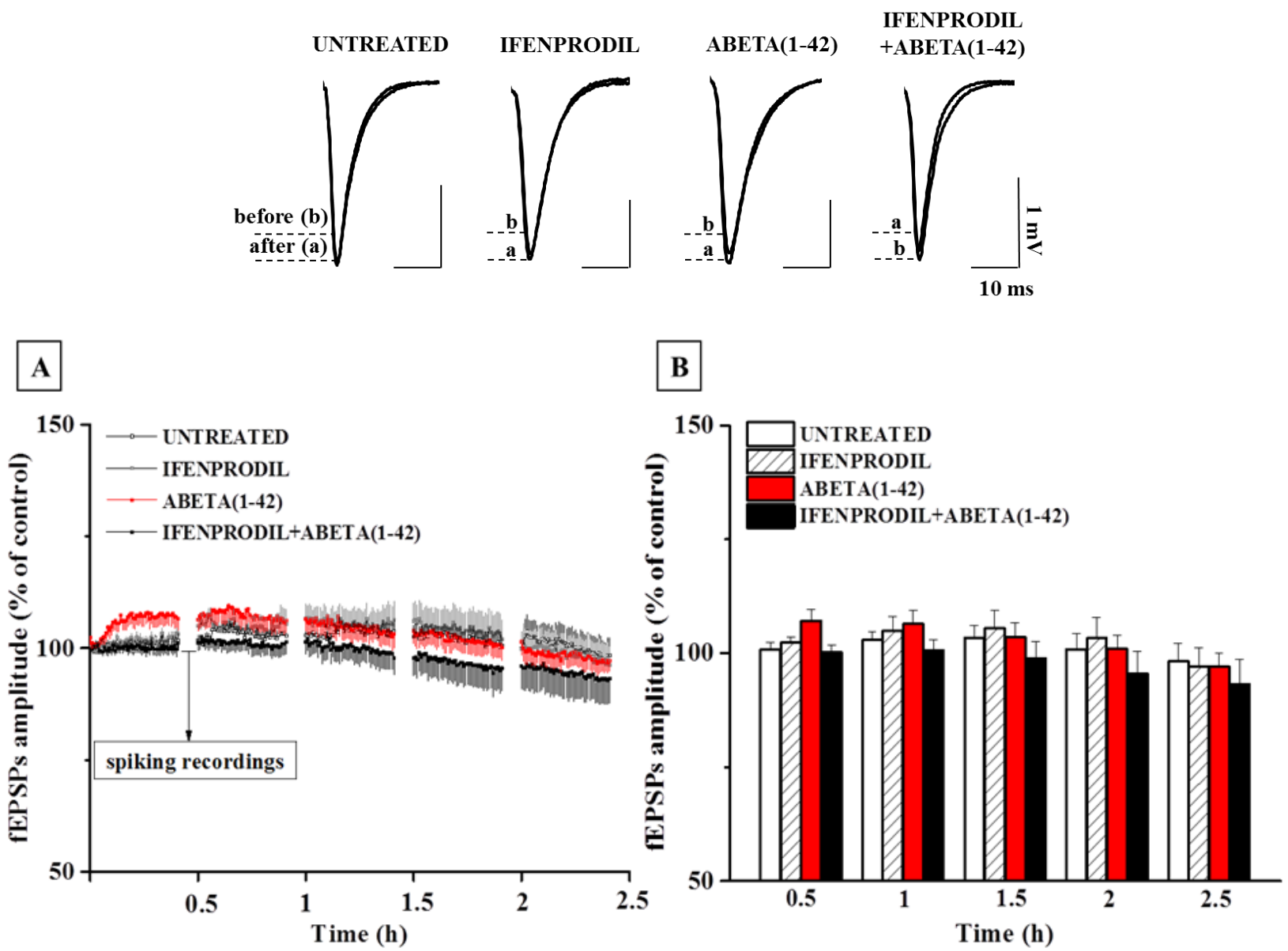

Figure 13. Neither Abeta(1-42) nor ifenprodil changed fEPSPs amplitudes. Representative fEPSPs are shown before (b) and after (a) treatment in the upper panel, and panel A shows the changes of fEPSPs amplitudes over time. Neither Abeta(1-42) nor ifenprodil affected fEPSPs amplitudes (one-way repeated measures ANOVA with Bonferroni correction) (A). Bar graphs depict the mean of the last 5 min of every recording epoch. The level of fEPSPs amplitudes (the last 10 peak-to-peak amplitudes) were compared to the average 20 peak-to-peak amplitudes of the control level $(0 \mathrm{~h})$ in all cases. Error bars represent SEM. Abbreviations: Abeta(1-42) (amyloid-beta(1-42)), ifenprodil ( $\alpha$-(4-Hydroxyphenyl)- $\beta$-methyl-4-benzyl-1piperidineethanol (+)-tartrate) and fEPSPs (field excitatory postsynaptic potential).

Several recent findings suggest that the deleterious effect of Abeta is mediated via the NR2B subunit-containing NMDARs (Tackenberg, Grinschgl et al. 2013, Zhang, Wang et al. 2013). To test whether the observed hyperexcitation in our experimental setup is sensitive to NR2B antagonism, we have applied ifenprodil, an antagonist of the NR2B. Ifenprodil did not change either fEPSPs (ifenprodil: $\mathrm{n}=5$; 0.5 h: $102.26 \pm 1.35 \%$; 1 h: $104.95 \pm 3.00 \%$; 1.5 h: $105.45 \pm 3.91 \%$; 2 h: $103.28 \pm 4.53 \%$ and 2.5 h: $96.99 \pm 4.15 \%$, one-way repeated measures ANOVA, Bonferroni post-hoc test; Figure 13) compared to the untreated slices, or spiking activity (ifenprodil: $\mathrm{n}=5$; 0.5 h: $127.11 \pm 53.62 \%, 1$ h: $163.58 \pm 101.77 \%$; 1.5 h: $81.37 \pm 37.37 \%, 2$ h: $110.35 \pm 65.81 \%$ and 2.5 h: $120.26 \pm 64.58 \%$, Mann-Whitney U-test; Figure 14), suggesting that NR2B-activation is not 
required for basic synaptic transmission in the CA1. However, Abeta(1-42) induced elevated spiking activity was prevented by ifenprodil (ifenprodil+Abeta(1-42): $\mathrm{n}=5 ; 0.5 \mathrm{~h}$ : 157.44 $\pm 84.19 \%$; $1 \mathrm{~h}: 196.87 \pm 79.61 \% ; 1.5 \mathrm{~h}: 116.36 \pm 61.71 \% ; 2 \mathrm{~h}: 101.72 \pm 76.26 \%$ and $2.5 \mathrm{~h}:$ $88.88 \pm 59.67 \%, p=0.038$, Mann-Whitney U-test; Figure 14) without changing of fEPSPs amplitudes (ifenprodil+Abeta(1-42): $\mathrm{n}=5 ; 0.5$ h: $100.17 \pm 1.53 \% ; 1 \mathrm{~h}: 100.57 \pm 2.38 \%$; $1.5 \mathrm{~h}$ : 98.85 $\pm 3.66 \% ; 2$ h: $95.45 \pm 4.97 \%$ and 2.5 h: $93.15 \pm 5.47 \%$, one-way repeated measures ANOVA, Bonferroni post-hoc test; Figure 13).

These results suggest that the hyperexcitability caused by Abeta(1-42) requires the activation of NR2B-subunit containing NMDARs, but not AMPARs. 

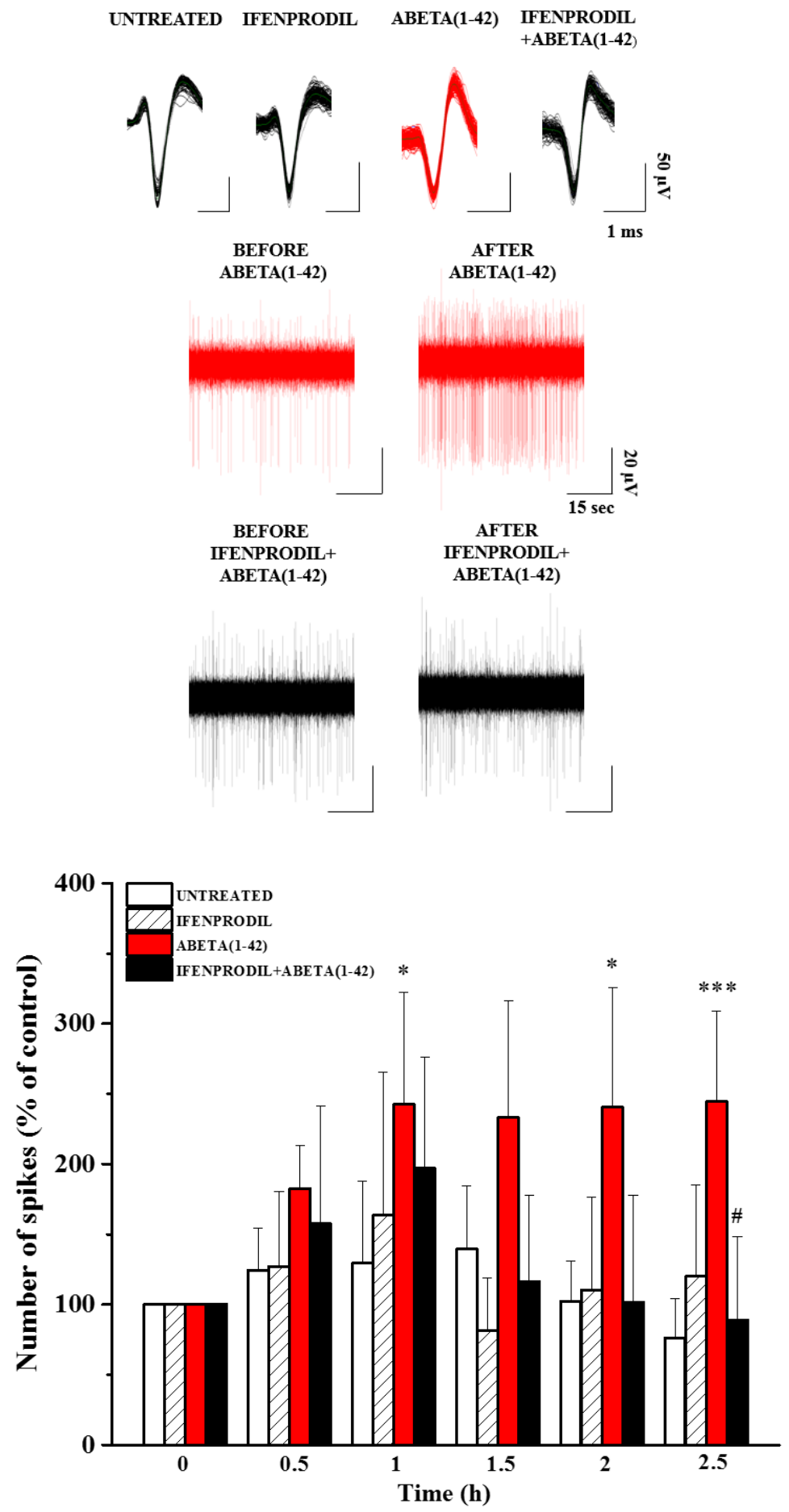

Figure 14. Abeta(1-42) causes hyperexcitation via NR2B. Upper panel shows exemplar units from the respective recordings. Abeta(1-42) induced elevated spiking activity (untreated vs. Abeta(1-42): $1 \mathrm{~h}$ : ${ }^{*} p=0.043 ; 2 \mathrm{~h}:{ }^{*} p=0.036$ and $2.5 \mathrm{~h}:{ }^{* * *} p=0.001$; Mann-Whitney U-test). Ifenprodil did not affect spontaneous activity, but prevented the increased spiking rate caused by Abeta(1-42) (Abeta(1-42) vs. ifenprodil+Abeta(1-42) $2.5 \mathrm{~h}{ }^{*} p=0.038$; Mann-Whitney U-test). Error bars represent SEM; * $p \leq 0.05$; $* * * p \leq 0.001$ and ${ }^{*} p \leq 0.05$. Abbreviations: Abeta(1-42) (amyloid-beta(1-42)) and ifenprodil ( $\alpha$-(4Hydroxyphenyl)- $\beta$-methyl-4-benzyl-1-piperidineethanol (+)-tartrate). 


\subsection{AMYLOID-BETA(1-42) INDUCED IMPAIRMENT OF LTP REQUIRES NR2B ACTIVATION}

There is growing evidence that oligomer Abeta impairs synaptic plasticity in AD. Despite intense research, the exact mechanisms involved in Abeta-mediated synaptic dysfunction are not fully clear, thus we investigated the effect of $\operatorname{Abeta(1-42)~preparation~on~LTP~in~the~hippocampal~}$ slices.

Untreated slices showed a persistent elevated level of fEPSPs after LTP induction (168.33 $\pm 5.58 \%, \mathrm{n}=12)$, while Abeta(1-42) reduced the magnitude of LTP $(124.35 \pm 4.88 \%, \mathrm{n}=9$; $p<0.001$, one-way ANOVA, Bonferroni post-hoc test; Figure 15).

Several studies suggest that different NR2 subunits of NMDARs may have divergent roles in NMDAR-dependent LTP activation and Abeta pathology (reviewed by Koffie, Hyman et al. 2011). To test whether LTP activation requires NR2B-containing NMDARs function, slices were treated with an NR2B antagonist, ifenprodil. We have observed that ifenprodil did not alter the level of LTP compared to untreated slices $(176.81 \pm 4.93 \%, n=5$; one-way ANOVA, Bonferroni post-hoc test), suggesting that NR2B-activation is not required for LTP in the CA1. Furthermore, ifenprodil prevents the Abeta(1-42) induced reduction of LTP magnitude $(166.03 \pm 12.38 \%, \mathrm{n}=5$; $p=0.003$, one-way ANOVA, Bonferroni post-hoc test; Figure 15), suggesting that Abeta(1-42) induces LTP damage via NR2B-containing NMDARs.

Based on these findings, we propose that NR2B-containing NMDARs activity is not required for LTP, but is essential for the effect of Abeta(1-42). 

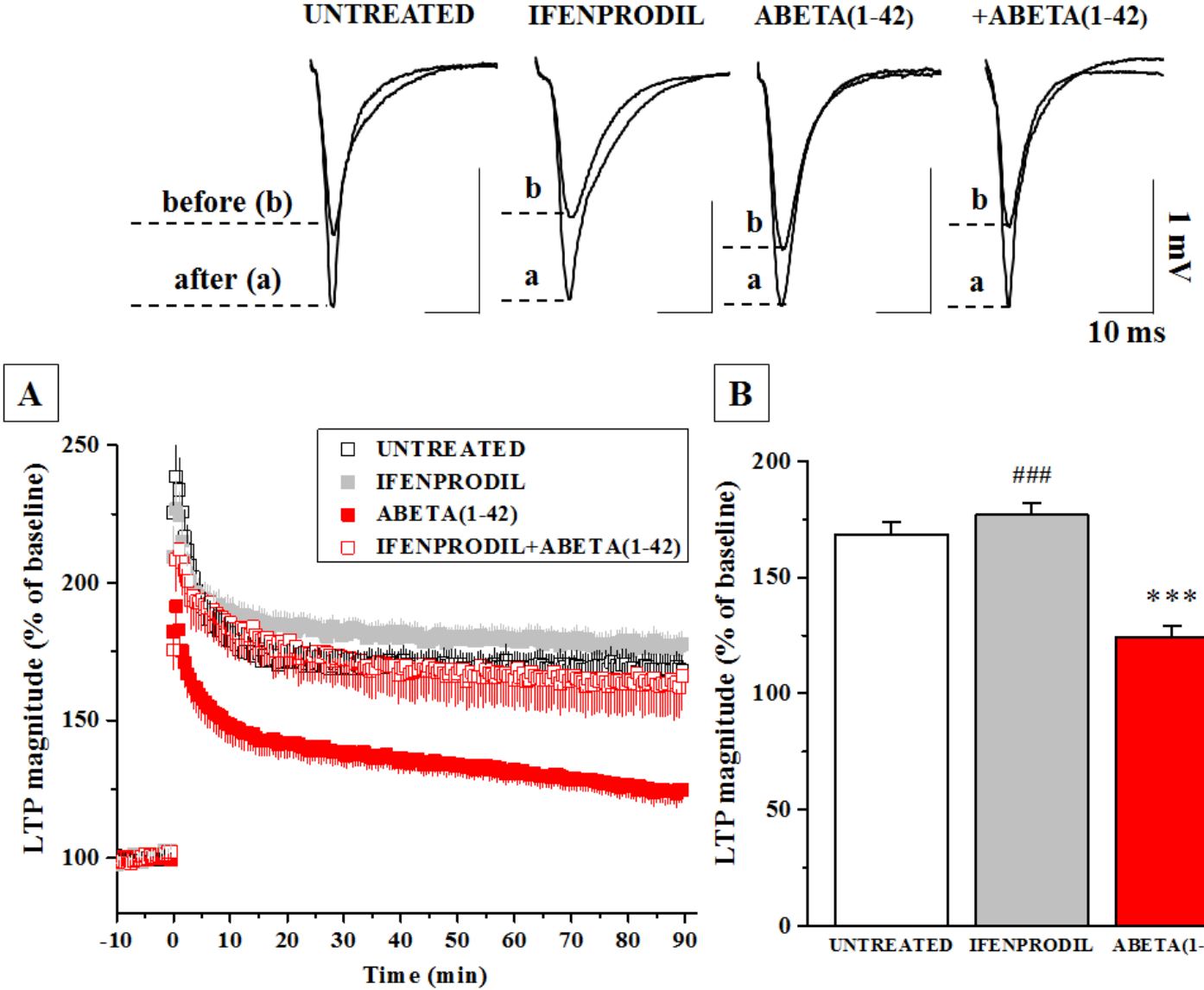

\section{B}

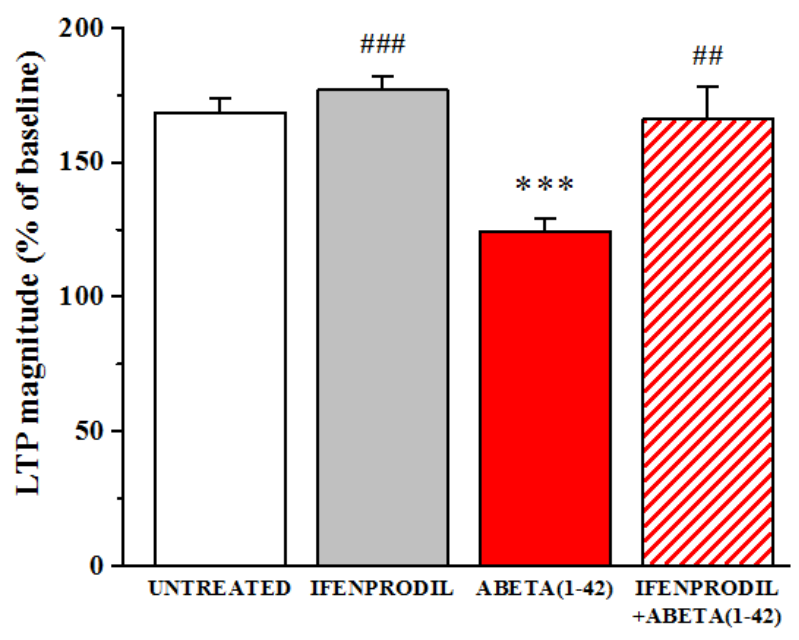

Figure 15. Ifenprodil prevents Abeta(1-42)-induced LTP impairment. Upper panel shows representative fEPSPs before (b) and after (a) treatment. Panel A shows the changes of fEPSPs amplitudes over time. LTP was altered in Abeta(1-42) treated slices compared to untreated group (untreated vs. Abeta(1-42): ***p<0.001; one-way ANOVA, Bonferroni post-hoc test) (B). Ifenprodil did not affect the level of LTP, however it prevented Abeta(1-42)-impaired LTP (Abeta(1-42) vs.

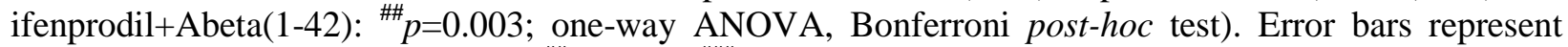
SEM; $* * * p \leq 0.001$ vs. untreated; ${ }^{\# \# \leq 0.01 ; ~}{ }^{\# \#} p \leq 0.001$ vs. Abeta(1-42). Abbreviations: Abeta(1-42) (amyloid-beta(1-42)), LTP (long-term potentiation), fEPSPs (field excitatory postsynaptic potential) and ifenprodil ( $\alpha$-(4-Hydroxyphenyl)- $\beta$-methyl-4-benzyl-1-piperidineethanol (+)-tartrate).

\subsection{GLUTAMATE SCAVENGER RESCUES AMYLOID-BETA(1-42)-IMPAIRED LTP}

Li S et al., suggest a novel mechanism by which Abeta(1-42) oligomers induce synaptic impairment. The authors have shown that the peptide blocks the Glu uptake regulatory system which can lead to synapse depression (Li, Hong et al. 2009). To investigate this possibility, slices were treated with GPT and its substrate, Pyr for 10 min followed by Abeta(1-42) for $60 \mathrm{~min}$, then LTP was induced. 
We have found that Pyr+GPT treatment did not change the magnitude of LTP compared to untreated slices (Pyr+GPT: 157.32 $\pm 6.68 \%, \mathrm{n}=5$; one-way ANOVA, Bonferroni post-hoc test, Figure 16). However, Abeta(1-42)-induced LTP damage was prevented by Glu scavenger (Abeta(1-42) vs. Pyr+GPT+Abeta(1-42): 159.66 $\pm 6.37 \%, \mathrm{n}=5 ; p=0.006 ;$ one-way ANOVA, Bonferroni post-hoc test; Figure 16).

Our data suggest that applying Glu scavenger restores the Abeta(1-42)-induced reduction of LTP.

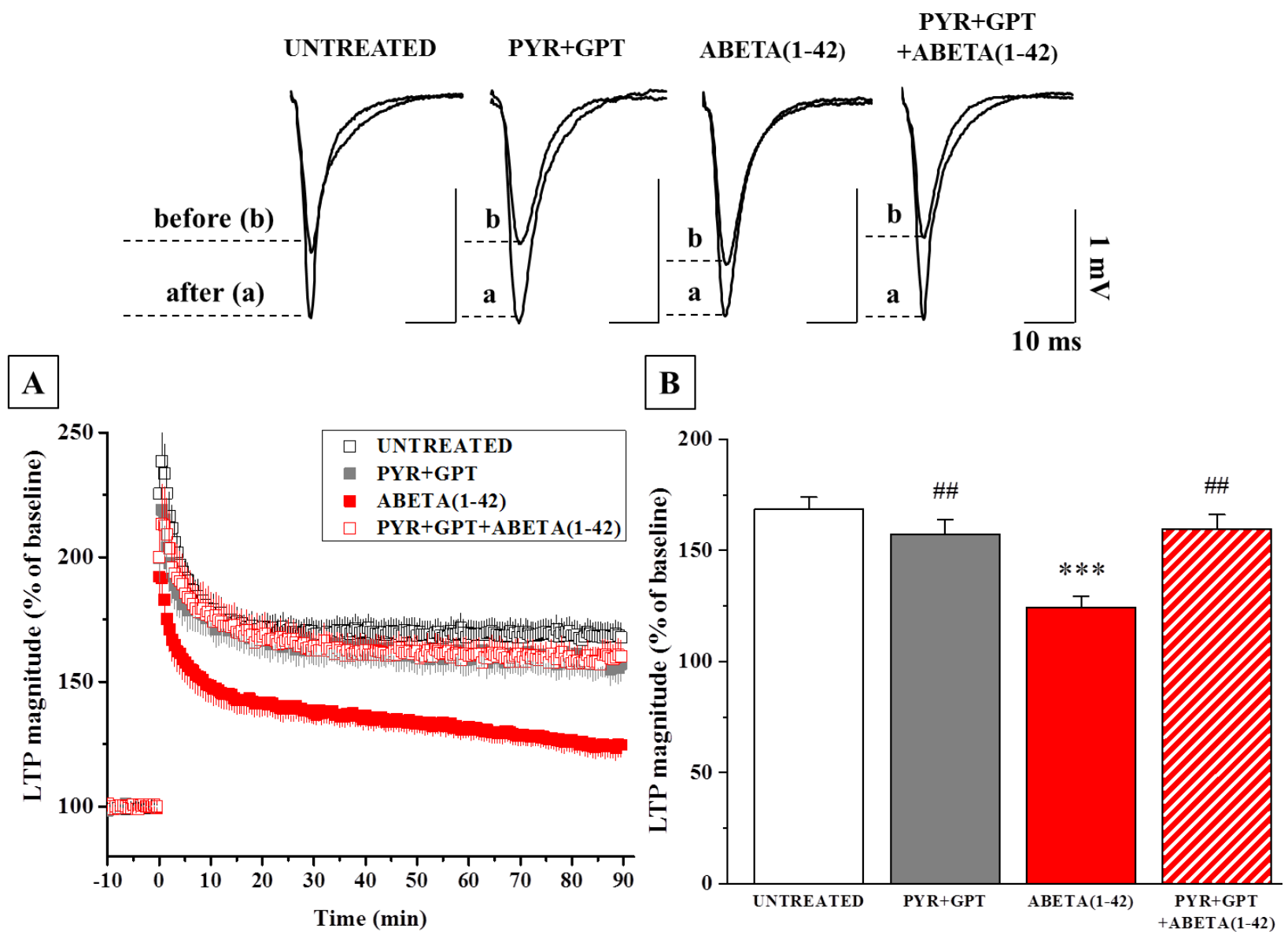

Figure 16. Glu scavenger rescues Abeta(1-42)-impaired LTP. Insets show representative fEPSPs before (b) and after (a) treatment. Panel A represents the changes of fEPSPs amplitudes over time. Pyr+GPT treatment did not change the LTP level compared to untreated slices, however Abeta(1-42)induced LTP damage was prevented by Glu scavenger (Abeta(1-42) vs. Pyr+GPT+Abeta(1-42): $\# p=0.006$; one-way ANOVA, Bonferroni post-hoc test) (B). Error bars represent SEM; $* * * p \leq 0.001$ vs. untreated; ${ }^{\# \#} \leq 0.01$ vs. Abeta(1-42). Abbreviations: Abeta(1-42) (amyloid-beta(1-42)), LTP (long-term potentiation), fEPSPs (field excitatory postsynaptic potential), Pyr (sodium pyruvate) and GPT (glutamicpyruvic transaminase). 


\subsection{THE EFFECT OF AMYLOID-BETA(1-42) IS MIMICKED BY TBOA, A GLUTAMATE REUPTAKE INHIBITOR}

Based on previous findings, we supposed that Abeta may interrupt Glu uptake. In order to address, whether a Glu reuptake inhibitor, TBOA can mimick the effect of Abeta(1-42), we applied the slices with TBOA for 60 min before LTP induction. Indeed, LTP was impaired by TBOA compared to untreated slice $(123.22 \pm 3.48 \%, \mathrm{n}=6 ; p<0.001 ;$ one-way ANOVA, Bonferroni post-hoc test, Figure 17).

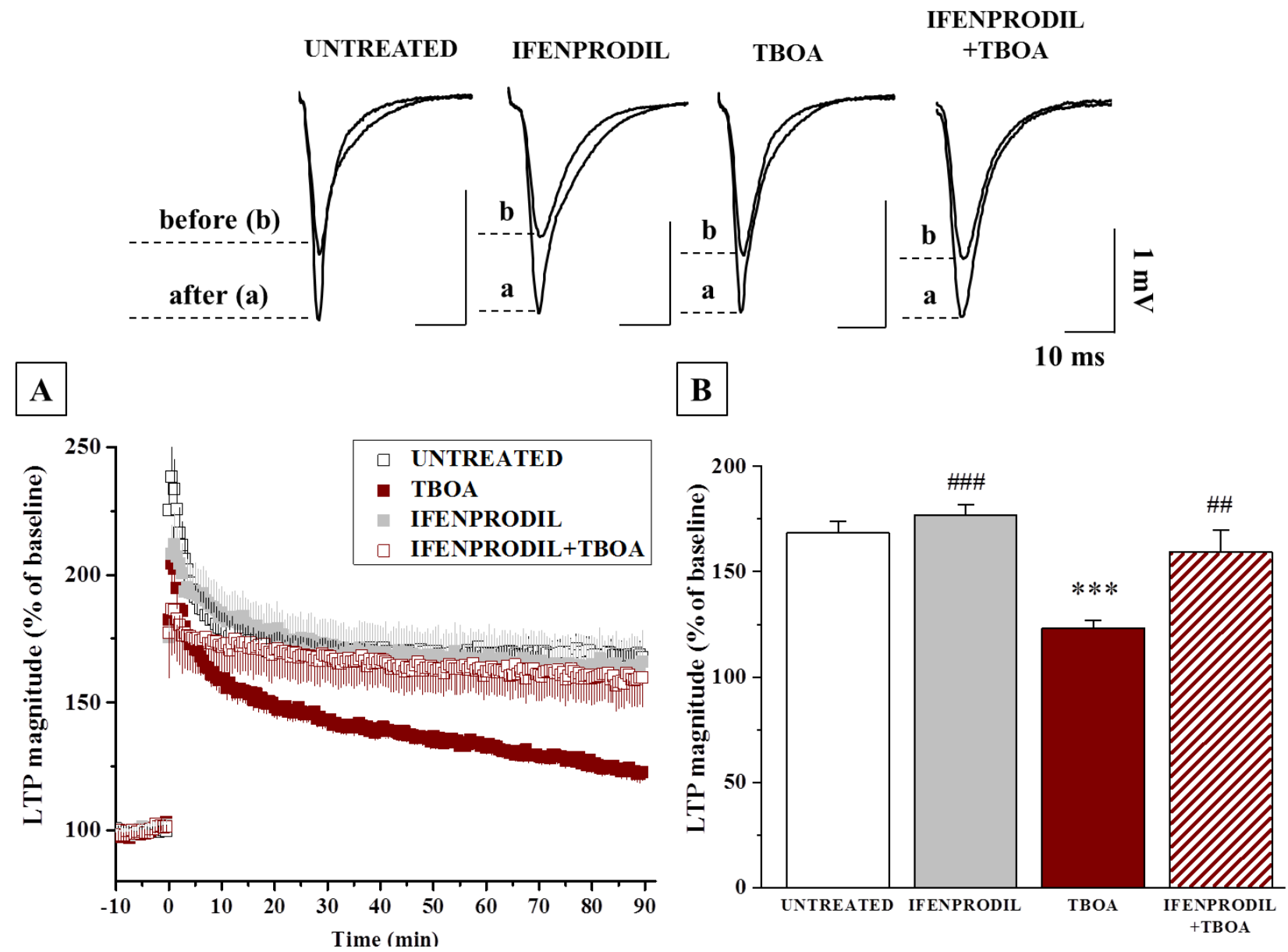

Figure 17. Blocking NR2B restores TBOA-induced LTP impairment. Upper panel shows exemplar fEPSPs before (b) and after (a) treatment. Panel A represents the changes of fEPSPs amplitudes over time. LTP was impaired by TBOA compared to untreated group (untreated vs. TBOA: *** $p<0.001$; oneway ANOVA, Bonferroni post-hoc test), which was prevented by ifenprodil (TBOA vs. ifenprodil+TBOA: ${ }^{\#} p=0.013$; one-way ANOVA, Bonferroni post-hoc test) (B). Error bars show SEM; $* * * p \leq 0.001$ vs. untreated; ${ }^{\# \#} p \leq 0.01$ and ${ }^{\# \# \#} p \leq 0.001$ vs. TBOA. Abbreviations: ifenprodil ( $\alpha$-(4-Hydroxyphenyl)- $\beta$-methyl-4-benzyl-1-piperidineethanol(+)-tartrate), $\quad$ TBOA $\quad$ (DL-threo- $\beta$ benzyloxyaspartate), LTP (long-term potentiation) and fEPSPs (field excitatory postsynaptic potential). 
Next, we tested whether NR2B subunit activation is required for the effect of TBOA. We have found that ifenprodil prevents TBOA-induced LTP damage, which suggests that NR2B subunit activation is essential for the effect of TBOA on LTP (TBOA vs. ifenprodil+TBOA: 159.29 $\pm 10.67 \%, \mathrm{n}=4 ; p=0.013$; one-way ANOVA, Bonferroni post-hoc test, see above, Figure 17).

We proceeded to apply Glu scavenger to test whether the inhibitory effect of TBOA was due to the elevated extracellular Glu level. To investigate this possibility, slices were treated with GPT and its substrate, Pyr for $10 \mathrm{~min}$ followed by TBOA for $60 \mathrm{~min}$, then LTP was induced. We have found that TBOA failed to impair LTP after Glu scavenger treatment (TBOA vs. Pyr+GPT+TBOA: $169.28 \pm 8.18, \mathrm{n}=5 ; p=0.001$; one-way ANOVA, Bonferroni post-hoc test, Figure 18).

Collectively these results suggest that TBOA and Abeta(1-42) share common pathway in synaptotoxicity. The effect of Abeta(1-42) is mimicked by Glu reuptake inhibition, however both could be prevented by a Glu scavenger and NR2B inhibition, suggesting that Abeta(1-42) disrupts synaptic plasticity by altering Glu recycling at the synapse in the CA1. 


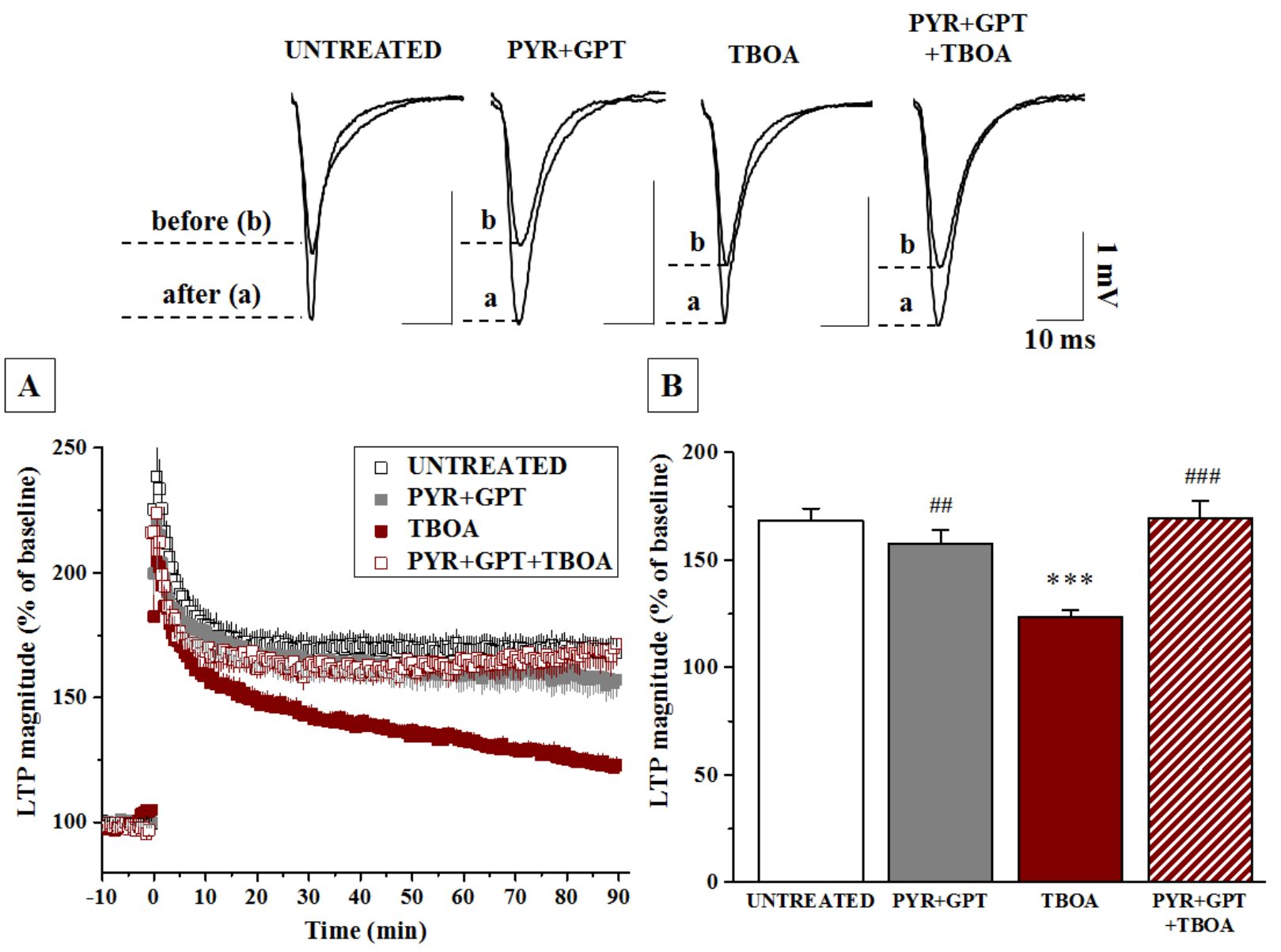

Figure 18. Glu scavenger restores the effect of TBOA. Insets show representative fEPSPs before (b) and after (a) treatment. Panel A represents the changes of fEPSPs amplitudes over time. TBOA impaired LTP, which was rescued by Glu scavenger (TBOA vs. Pyr+GPT+TBOA: ${ }^{\# \#} p=0.001$; Bonferroni post$h o c$ test). Error bars represent SEM; $* * * p \leq 0.001$ vs. untreated; ${ }^{\# \#} p \leq 0.01$ and ${ }^{\# \# \#} p \leq 0.001$ vs. TBOA. Abbreviations: TBOA (DL-threo- $\beta$-benzyloxyaspartate), LTP (long-term potentiation), fEPSPs (field excitatory postsynaptic potential), Pyr (sodium pyruvate) and GPT (glutamic-pyruvic transaminase).

\subsection{CHARACTERIZATION OF AMYLOID-BETA}

The size distribution of Abeta(1-42) oligomers formed in $50 \mu \mathrm{M}$ after incubation at $37^{\circ} \mathrm{C}$ was studied on WB by using two different antibodies: the monoclonal BAM10 antibody is sequence specific and binds to the N-terminal end of the peptide, while OC stains the oligomers of fibrillar nature (protofibrils, oligomers with beta-sheet structure (Glabe 2008).

Supplementary Fig. 3 shows the results of the WB experiments (Supplementary Figure 3). BAM10 staining reveals the presence of both low- and high- molecular weight oligomers in the sample, while their positive staining with the OC antibody indicates that they have protofibrillar characteristics. The presence of SDS stable dimers and trimers in the sample closely resembles to Abeta(1-42) derived from biological sources, namely from transfected 7PA2 cells (Davis, 
Marsden et al. 2011) and from human brain (Shankar, Bloodgood et al. 2007, Klyubin, Betts et al. 2008). These species were shown to have strong synaptotoxic properties (Townsend, Shankar et al. 2006). On the other hand, protofibrillar species, which are also abundant in our sample, were also reported to be synaptotoxic (Minkeviciene, Rheims et al. 2009). 


\section{DISCUSSION}

Neuronal hyperexcitability in early $\mathrm{AD}$ and in $\mathrm{AD}$ modeling mice is an emerging finding that points to a network dysfunction as a critical component of the pathomechanism. Soluble Abeta species have been increasingly implicated as the key pathologic components of the disease, thus elucidating the mechanisms by which these species alter neuronal function is important. There is growing evidence that soluble Abeta oligomers mediate synaptic impairment in $\mathrm{AD}$, but the exact mechanism of synaptotoxicity remains to be determined.

In my thesis work, we examined a possible pathway of neuronal excitability and impaired synaptic plasticity caused by Abeta. First, we identified two possible mechanisms that regulate extracellular excitatory events in the CA1, and then we examined how Abeta affects these events. Second, we investigated the receptors and receptor subunits that are required for Abetainduced excitotoxicity and LTP impairment. Third, we tested whether interfering with the pathway we identified previously can prevent the effect of Abeta peptide.

\subsection{THE UNDERLYING MECHANISM OF EVOKED FIELD POTENTIAL AND SPONTANEOUS SPIKING GENERATION ARE NOT CORRELATED}

Extracellular recordings of fEPSP is one of the most common ways for determining the excitation and synaptic plasticity in hippocampal slices. Evoked fEPSPs are commonly evoked by electric stimulation at Schaffer-collaterals and are recorded from the proximal apical dendrites of the CA1 stratum radiatum. Monitoring the changes in the peak-to-peak amplitudes of fEPSPs is widely used as a readout for investigation of synaptic plasticity. The changes of spontaneous spiking activity under conditions that modify network excitability are, however, less well studied in acute slices. In these sets of experiments we have studied the involvement of AMPARs and NMDARs in fEPSPs evoked by Schaffer-stimulation and in spontaneous firing in the CA1.

We shown that these two electrophysiological markers previously thought to underlie measures of excitation, are not correlated. Under our conditions, inhibiting AMPAR with CNQX

blocked fEPSPs, however, the spiking rate remained unaffected. In contrast, modulating NMDAR function influenced spontaneous activity without any change in evoked fEPSPs. Blocking NMDARs ablated, while enhancing NMDAR function increased spontaneous activity.

Importantly, the spontaneous spikes we recorded here were almost exclusively localized to the stratum pyramidale layer of CA1; hence they were presumably generated by principal cells. 
Multi-unit activity recordings do not allow to separate the firing from individual neurons and may include bursts of spikes fired by the same neuron. Thus in our study, spiking represents the global amount of activity within this network, and most probably the activity of principal cells. The firing rates observed in this study were comparable to previously reported values in slices of CA1 of the guinea pig (0.22 and 1.8 spikes/sec) (Cohen and Miles 2000).

\subsection{POSSIBLE INVOLVEMENT OF THE CA1 LOCAL MICROCIRCUITRY IN THE REGULATION OF SPONTANEOUS SPIKING}

The activity of CA1 pyramidal cells is regulated by the excitation arriving from CA3 through the Schaffer-collateral, and by the inhibition of the local interneuron microcircuitry. Although the activity of CA1 inhibitory cells has been reported to be scarce compared to CA3 in acute slices, powerful pyramidal somatic inhibition could be detected upon minimal electric stimulation (Beyeler, Retailleau et al. 2013), showing that the inhibition is very effective.

What is the driving force of the interneuronal activity? One possible explanation is that the spontaneous activity of the incoming axons of the CA3 principal cells recruits a CA1 inhibitory microcircuitry via the Schaffer-collateral. This is unlikely, because there is no correlation between CA3 multi-unit activity and the extracellularly recorded inhibitory post-synaptic potential in the CA1 (Beyeler, Retailleau et al. 2013). Another possibility is that the spontaneous discharge of CA1 interneurons, although scarce, is keeping a strong blockade of the principal cells. Favoring this hypothesis, the resting membrane potential is more hyperpolarized in CA1 compared to CA3 pyramidal neurons (Fricker, Verheugen et al. 1999, Tyzio, Ivanov et al. 2003). These spontaneous discharges might be regulated by the ambient Glu concentration via NMDARs. Indeed, tonic activation of NMDARs by ambient Glu has been described in virtually all pyramidal cells of the CA1 of the hippocampus in slice models (Sah, Hestrin et al. 1989, Dalby and Mody 2003, Angulo, Kozlov et al. 2004, Cavelier, Hamann et al. 2005). Importantly, as Le Meur et al. has shown (Le Meur, Galante et al. 2007), neither AMPA/kainate receptors nor mGluRs contributes to this tonic excitation of pyramidal neurons. This tonic current is not

dependent on vesicular release of transmitters from neurons, but is affected by inhibition of the enzyme converting Glu in glutamine in glial cells, indicating that ambient Glu is mainly of glial origin. Consistent with these findings, we have also shown that spontaneous spiking is driven by NMDAR activity, but not by AMPARs, indicating that the tonic activation could reach the threshold of spike generation. 
The question arises that why do not AMPARs mediate spontaneous activity? NMDARs have a much higher affinity for Glu than do AMPARs; in steady-state conditions, the EC50 for Glu at NMDARs is over two orders of magnitude lower than at AMPARs (Patneau and Mayer 1990). Esyn NMDARs containing the NR2B subunit have even higher affinity than synaptic NR2Acontaining receptors (Priestley, Laughton et al. 1995). It should be noted, that evoked firing, which is usually detected in the form of population spikes (pop-spikes for short) in CA1 extracellular recordings, is mediated by AMPAR signaling (Wood and Tattersall 2001). Under our conditions, action potentials were not inhibited by AMPAR blockade (CNQX). The reason behind this discrepancy might be that evoked pop-spikes require a synchronous discharge of a population of cells. This coordinated function might be based on the fast AMPAR function.

\subsection{AMYLOID-BETA(1-42)-INDUCED HYPEREXCITATION AND LTP IMPAIRMENT REQUIRES NR2B ACTIVATION}

Numerous studies have reported that Abeta can affect the function of NMDARs (Shankar, Bloodgood et al. 2007, Juhasz, Marki et al. 2009, Dinamarca, Rios et al. 2012, Tackenberg, Grinschgl et al. 2013, Xu, Cao et al. 2014), which may lead to excitotoxicity and neuronal hyperactivation seen in the early stage of AD. Abeta can bind to integrin receptors and this complex initiates a molecular cascade mediated by Fyn kinase, which subsequently phosphorylates NMDARs (Larson, Sherman et al. 2012). Furthermore, there is evidence that Abeta affects esyn NMDAR function. Memantine, a clinically effective drug in the treatment of $\mathrm{AD}$, was shown to block preferentially esyn NMDARs, further arguing for the Abeta and esyn NMDARs connection (Szegedi, Juhasz et al. 2010, Xia, Chen et al. 2010).

Next, we investigated the effect of $\operatorname{Abeta}(1-42)$ on spontaneous firing, and found that the peptide increased the rate of spontaneous discharges, but did not alter evoked fEPSPs. These results suggest that NMDARs are involved in the hyperexcitability induced by Abeta(1-42). Similar results have been recently reported by Varghese et al. using cultured embryonic rat hippocampal cells. Abeta increased spontaneous firing activity dose-dependently, reaching the maximum after 1 hour of treatment, which was followed by a complete cessation of spikes following a few hours (Varghese, Molnar et al. 2010). The discrepancy between this and our result may be due to the fact that the authors have used a cell culture largely devoid of glial elements, while we have used a complex microcircuitry built up from all of the neuronal cell types (including glia) forming elaborate connections. 
Abeta induced enhancement of spontaneous spiking activity could be prevented by blocking the NR2B subunits, suggesting that Abeta activates esyn NMDARs. The role of esyn or perisynaptic NMDARs in Abeta(1-42)-induced changes in functional synaptic plasticity and subsequent cell death has been received much attention recently (Palop and Mucke 2009, Li, Jin et al. 2011, Talantova, Sanz-Blasco et al. 2013). Esyn NMDARs contain predominantly NR2B subunits, which in contrast to NR2A-containing synaptic NMDARs trigger apoptotic signaling cascade (Hardingham, Fukunaga et al. 2002). Recently, it was shown using organotypic hippocampal cell cultures, that Abeta induces neuronal death and subsequent tau hyperphosporylation via esyn NR2B subunit (Tackenberg, Grinschgl et al. 2013).

Blocking NR2B subunits does not only prevent hyperexcitation caused by Abeta, but also rescues Abeta induced LTP impairment, suggesting that blocking NR2B subunits might be a promising target in $\mathrm{AD}$. Tackenberg et al. also suggest that esyn NR2B-enriched NMDARs activation is essential for tau-dependent neurodegeneration (Tackenberg, Grinschgl et al. 2013). It was also shown that the opposite form of synaptic plasticity, LTD requires both syn and esyn receptor activation (Liu, Yang et al. 2013), while LTP is not mediated by esyn NMDARs (Hu, Klyubin et al. 2009, Zhang, Wang et al. 2013). It should be noted, however, that contradictory data is available on the role of NR2B-subunit containing NMDARs on LTP: esyn NDMARs are also recruited to the synapse during LTP (Harney, Jane et al. 2008) and may play an essential role in LTP maintenance (Foster, McLaughlin et al. 2010, Hasegawa, Mukai et al. 2014). However, others have reported that Abeta oligomers directly activate NMDARs especially via NR2A subunit (Domingues, Almeida et al. 2007, Texido, Martin-Satue et al. 2011). In our hands, ifenprodil is not required the LTP magnitude suggesting that NR2B activation do not require for LTP.

\subsection{GLUTAMATE SCAVENGER AS A NOVEL THERAPEUTIC OPPORTUNITY AGAINST ALZHEIMER'S DISEASE}

Since the late 1980's, disturbances in the Glu uptake system has been suggested as a cause for $\mathrm{AD}$ which leads to excitatoxicity in the hippocampal and the cortical regions (Hardy, Cowburn et al. 1987, Perry, Perry et al. 1987). The spillover of Glu from the synapse contributes to normal physiological processes in the hippocampus (Asztely, Erdemli et al. 1997, Min, Rusakov et al. 1998, Scimemi, Fine et al. 2004). However, under certain pathological conditions, 
increased spillover results in excessive esyn receptor activation, which enhances network excitability and promotes pro-apoptotic pathways.

Abeta has been shown to elevate extracellular Glu concentration in the brain without altering gamma-aminobutyric acid (GABA) level (Mura, Zappettini et al. 2012). The mechanism behind this is probably the inhibition of the transporters mediating Glu clearance (Figure 19A). The level of brain extracellular Glu is regulated by EAATs expressed mainly on the astrocytes, which efficiently remove the excess of this neurotransmitter from the synaptic cleft (reviewed by (Anderson and Swanson 2000), thus Glu transporters play a critical role in limiting esyn diffusion of Glu and provide normal function of glutamatergic neurons (Hertz and Zielke 2004). Indeed, Abeta was shown to inhibit both glial and neuronal EAATs (Bashir, Alford et al. 1991, Masliah, Alford et al. 2000, Li, Hong et al. 2009, Marosi, Fuzik et al. 2009). Rossi and coworkers have reported that under certain pathological conditions, for example during epileptic activity, ischaemia or AD, EAAT may reverse its function leading to Glu release into the extracellular side (Rossi, Oshima et al. 2000). Furthermore, down-regulation or abnormal expression and protein levels of EAAT1 and EAAT2 are altered in the hippocampus and frontal cortex of AD patients (Scott, Pow et al. 2002, Jacob, Koutsilieri et al. 2007) and in APP transgenic mice (Masliah, Alford et al. 2000), further supporting that Glu level regulation fails during AD pathomechanism. These effects may lead to Glu spillover from the synapses and subsequent activation of esyn receptors, however the exact mechanism by which Abeta impairs EAATs remains unknown. Some available data suggest an indirect mechanism, namely Abeta interaction with the cell membrane or after being endocytosed, the peptide can trigger intracellular signaling pathways in astrocytes (Wyss-Coray, Loike et al. 2003), which may modulate Glu transporters levels/activity by alternating the phosphorylation states of EAATs (Daniels and Vickroy 1999, Gosselin, Meylan et al. 2013). Moreover, Abeta induced hyperexcitability appears to involve tau, because deletion of tau reduces seizures in some of the transgenic mouse models of AD (Roberson, Scearce-Levie et al. 2007). Li S et al. suggest that Abeta depresses peak NMDAR currents as a result of desensitization of the receptor (Li, Shankar et al. 2010). Interesting result is that several Glu uptake inhibitors are able to reduce NMDAR desensitization (Arnth-Jensen, Jabaudon et al. 2002). 


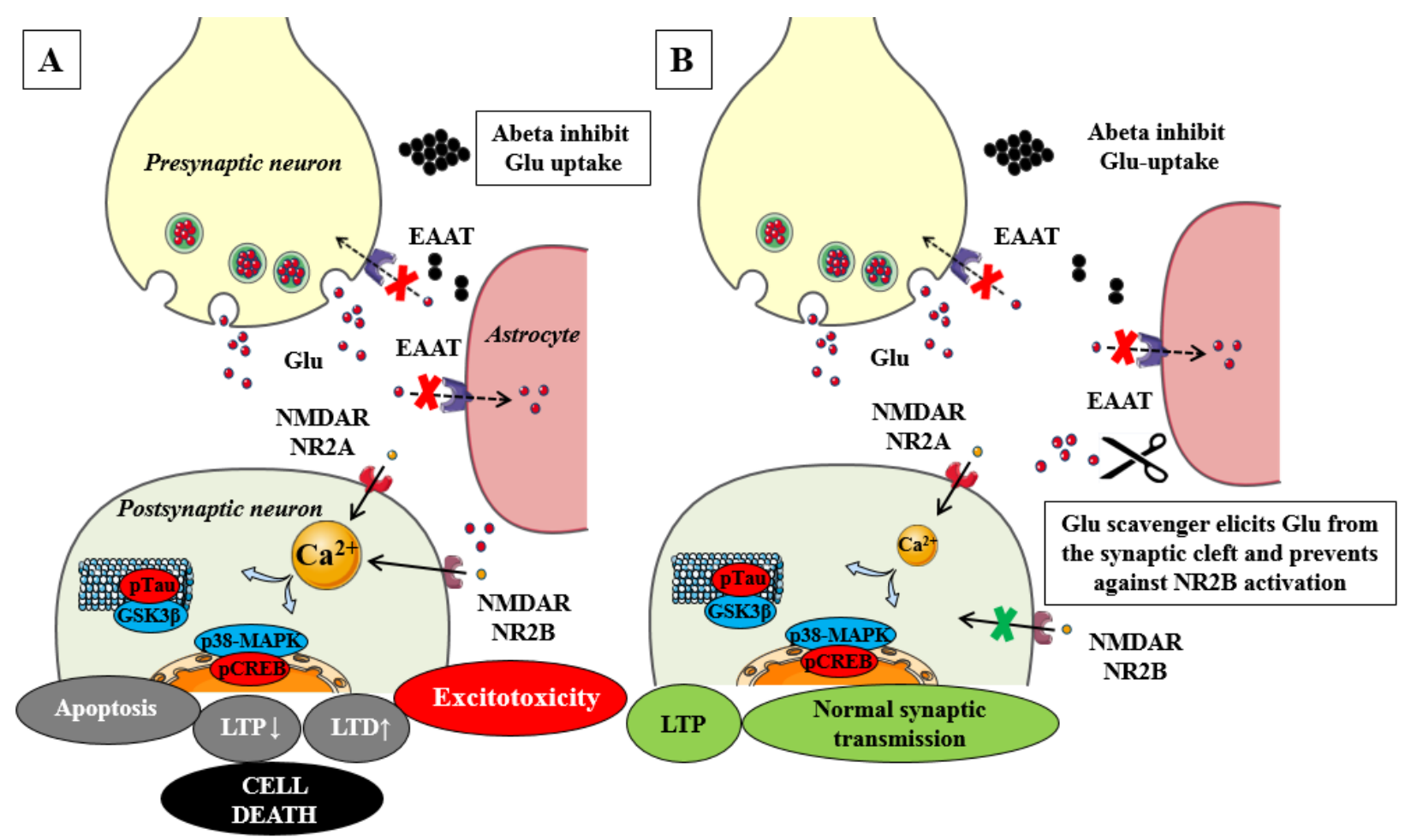

Figure 19. Abeta(1-42) perturbs Glu recycling at synapses. Abeta enhances the ambient Glu level by the blockade of Glu transporters (EAATs). Elevated ambient Glu level would be a spillover and subsequent esyn NR2B-enriched esyn NMDAR activation. Excessive activation of NMDARs increases the influx of $\mathrm{Ca}^{2+}$ and activates signaling pathways responsible for tau hyperphosphorylation (GSK3 $\beta$ ), inhibited LTP (p38-MAPK), enhanced LTD, apoptosis and finally cell death (A). Decreasing extracellular Glu level using Glu scavenger may be able to prevent the synaptic plasticity impairment caused by Abeta (B). Abbreviations: Abeta(1-42) (amyloid-beta(1-42)), Glu (glutamate), EAATs (excitatory amino-acid glutamate transporters), esyn (extrasynaptic), NMDAR (N-methyl-D-aspartate receptor), GSK3 $\beta$ (glycogen synthase kinase 3 $\beta$ ), LTP (long-term potentiation), LTD (long-term depression), pTau (hyperphosporylated tau protein), pCREB (phosporylated cyclic adenosine monophosphate response element binding protein) and p38-MAPK (p38-mitogen-activated protein kinase).

Our results extend this line of research by showing that reducing Glu that has been spilledover from the synapse, with a Glu scavenger enzyme also prevents Abeta-induced LTP impairment (Figure 19B). We have also shown that the effect of Abeta(1-42) is mimicked by TBOA, a Glu reuptake inhibitor. Blocking NR2B-subunit or using a Glu scavenger restores impaired LTP caused by either of the compounds. These results agree with Li and his coworkers' findings: reducing ambient Glu in the brain is protective against Abeta induced synaptic depression (LTD) (Li, Hong et al. 2009). A recent paper by Chen and Herrup makes the suggestion that although the level of glutamine synthase is elevated in AD brains, its activity is severely compromised by oxidative damage, leading to impaired Glu metabolism (Chen and Herrup 2012). It is also reported that the interaction between Abeta and glutamine synthase can 
induce the inactivation of the enzyme leading to excessive depolarization of the neurons via mGluRs and NMDARs (Blanchard, Stockwell et al. 2002, Blanchard, Thomas et al. 2002).

Neuronal hyperactivity and the appearance of seizures could further aggravate memory loss through a synergic mechanism. The secretion of Abeta is governed by neuronal activity (Kamenetz, Tomita et al. 2003, Cirrito, Kang et al. 2008) during pathological events, such as epileptiform activity induced by electrical stimulation, as well as during normal physiological processes, such as the sleep-wake cycle (Kang, Lim et al. 2009). Increased excitability induced by Abeta may result in a "vicious cycle" leading to massive neuronal loss and the formation of Abeta deposits. Excessive Glu release activates NMDARs which in turn stimulate a shift from $\alpha$ to $\beta$-secretase cleavage of the APP facilitating further Abeta(1-42) production (Lesne, Ali et al. 2005). 


\section{SUMMARY}

Taken together, we have shown that two electrophysiological events recorded from hippocampal slices, evoked fEPSPs and spontaneous spikes are not generated by the same mechanisms (Varga, Juhasz et al. 2014). Evoked fEPSPs, but not firing activity was mainly regulated by AMPARs. In contrast, spontaneous spikes are mediated by NMDAR function. Bath application of synaptotoxic Abeta(1-42)-enhanced firing activity in an NR2B-dependent manner without altering evoked fEPSPs. These effects may contribute to synaptic dysfunctions seen in early AD.

Our results also provide evidence that Abeta(1-42) impairs Glu recycling at the synapse, which leads to Glu spillover and NR2B-subunit containing NMDAR activation (Varga, Juhasz et al. 2014). Excessive activation of NMDARs increases $\mathrm{Ca}^{2+}$ influx and activates signaling pathway responsible for synaptic loss, apoptosis and neuronal death. Blocking NR2B or decreasing extracellular Glu level offers protection against the synaptic plasticity impairment caused by Abeta.

Based on our results, we suggest a possible therapeutic targets against Abeta. Glu scavengers may be a novel therapeutic opportunities for AD, because reducing ambient Glu in the brain may be protective against Abeta-induced synaptic dysfunction. Abeta and Glu toxicity mediated dysfunction have been closely associated, however decreasing the extracellular Glu level can be also protective in other conditions such as brain ischemia (Marosi, Fuzik et al. 2009), stroke (Campos, Rodriguez-Yanez et al. 2011), traumatic brain injury (Boyko, Stepensky et al. 2012) or certain psychiatric disorders (Mitani, Shirayama et al. 2006, Shinohe, Hashimoto et al. 2006). 


\section{CONCLUSION}

The main conclusions of my thesis are:

1) Evoked fEPSPs, but not spontaneous firing is mainly regulated by AMPARs. In contrast, spontaneous spikes are mediated by NMDAR function.

2) Abeta(1-42)-induced hyperexcitation and LTP impairment requires NR2B-subunit containing NMDARs activation.

3) Abeta(1-42) perturbs Glu recycling that is prevented by a Glu scavenger.

4) Blocking Glu reuptake mimics the effects of Abeta.

5) Glu scavenger may be novel therapeutic opportunity for AD. 


\section{ACKNOWLEDGEMENT}

First and foremost, I would like to express my special thank to Dr. Viktor Szegedi for his professional mentorship and for initiating my scientific career under his valuable scientific guidance. I am especially grateful to Dr. Gábor Juhász for his professional help in the use of multi-electrode array setup.

I am grateful to Prof. Botond Penke for supporting me during all these years and for the opportunity to work at the Department of Medical Chemistry. I am also grateful to Dr. Lívia Fülöp and Dr. Zsolt Bozsó for support and providing me with amyloid-beta preparations.

I specially wish to thank for my colleagues, Dr. Balázs Barkóczi and Róbert Averkin for their professional help and expert support on my work.

I am grateful to Emőke Borbély for her essential help in the statistical analysis.

I would like to give special thanks to my friends, Györgyi Utassy and Judit Márton for their professional help in data analysis and outstanding help in correcting my dissertation.

Special thanks to all the members of the laboratory especially to János Horváth and Ágnes Szántai for their kind help during the experiments and for a nice working atmosphere.

Last but not least, I would like to express a huge thanks to my family and friends for the love and support, especially to my love, Gergely Borbély, who always encouraged me in the recent period of my life.

The financial support of Gedeon Ricther Centenarium Foundation and the Campus Hungary program are gratefully acknowledged.

This study was supported by the following Grants: OTKA PD 83581 from the Hungarian

National Scientific Fund, TÁMOP-4.2.2.A-11/1/KONV-2012-0052 from the National Development Agency (NFÜ), and FP7-PEOPLE-2012-IAPP “STEMMAD.” Viktor Szegedi is a Bolyai fellow. 


\section{REFERENCES}

1. Adams, J. P., A. E. Anderson, A. W. Varga, K. T. Dineley, R. G. Cook, P. J. Pfaffinger and J. D. Sweatt (2000). "The A-type potassium channel Kv4.2 is a substrate for the mitogen-activated protein kinase ERK." J Neurochem 75(6): 2277-2287.

2. Ahmad, M., J. S. Polepalli, D. Goswami, X. Yang, Y. J. Kaeser-Woo, T. C. Sudhof and R. C. Malenka (2012). "Postsynaptic complexin controls AMPA receptor exocytosis during LTP." Neuron 73(2): 260-267.

3. Alzheimer, A., R. A. Stelzmann, H. N. Schnitzlein and F. R. Murtagh (1995). "An English translation of Alzheimer's 1907 paper, "Uber eine eigenartige Erkankung der Hirnrinde"." Anat 8(6): 429-431.

4. Amatniek, J. C., W. A. Hauser, C. DelCastillo-Castaneda, D. M. Jacobs, K. Marder, K. Bell, M. Albert, J. Brandt and Y. Stern (2006). "Incidence and predictors of seizures in patients with Alzheimer's disease." Epilepsia 47(5): 867-872.

5. Anderson, C. M. and R. A. Swanson (2000). "Astrocyte glutamate transport: review of properties, regulation, and physiological functions." Glia 32(1): 1-14.

6. Angulo, M. C., A. S. Kozlov, S. Charpak and E. Audinat (2004). "Glutamate released from glial cells synchronizes neuronal activity in the hippocampus." J Neurosci 24(31): 6920-6927.

7. Arnth-Jensen, N., D. Jabaudon and M. Scanziani (2002). "Cooperation between independent hippocampal synapses is controlled by glutamate uptake." Nat Neurosci 5(4): 325-331.

8. Asztely, F., G. Erdemli and D. M. Kullmann (1997). "Extrasynaptic glutamate spillover in the hippocampus: dependence on temperature and the role of active glutamate uptake." Neuron 18(2): 281-293.

9. Attwell, D. and P. Mobbs (1994). "Neurotransmitter transporters." Curr Opin Neurobiol 4(3): 353-359.

10. Awobuluyi, M., J. Yang, Y. Ye, J. E. Chatterton, A. Godzik, S. A. Lipton and D. Zhang (2007). "Subunit-specific roles of glycine-binding domains in activation of NR1/NR3 N-methyl-Daspartate receptors." Mol Pharmacol 71(1): 112-122.

11. Bamberger, M. E., M. E. Harris, D. R. McDonald, J. Husemann and G. E. Landreth (2003). "A cell surface receptor complex for fibrillar beta-amyloid mediates microglial activation." $\mathbf{J}$ Neurosci 23(7): 2665-2674.

12. Bar-Peled, O., H. Ben-Hur, A. Biegon, Y. Groner, S. Dewhurst, A. Furuta and J. D. Rothstein (1997). "Distribution of glutamate transporter subtypes during human brain development." $\underline{\mathbf{J}}$ Neurochem 69(6): 2571-2580.

13. Bashir, Z. I., S. Alford, S. N. Davies, A. D. Randall and G. L. Collingridge (1991). "Long-term potentiation of NMDA receptor-mediated synaptic transmission in the hippocampus." Nature 349(6305): 156-158.

14. Baumann, K., E. M. Mandelkow, J. Biernat, H. Piwnica-Worms and E. Mandelkow (1993). "Abnormal Alzheimer-like phosphorylation of tau-protein by cyclin-dependent kinases cdk2 and cdk5." FEBS Lett 336(3): 417-424.

15. Belyaev, N. D., K. A. Kellett, C. Beckett, N. Z. Makova, T. J. Revett, N. N. Nalivaeva, N. M. Hooper and A. J. Turner (2010). "The transcriptionally active amyloid precursor protein (APP) intracellular domain is preferentially produced from the 695 isoform of APP in a beta\}secretase-dependent pathway." J Biol Chem 285(53): 41443-41454.

16. Beyeler, A., A. Retailleau, C. Molter, A. Mehidi, J. Szabadics and X. Leinekugel (2013). "Recruitment of Perisomatic Inhibition during Spontaneous Hippocampal Activity." PLoS One 8(6): e66509.

17. Biernat, J. and E. M. Mandelkow (1999). "The development of cell processes induced by tau protein requires phosphorylation of serine 262 and 356 in the repeat domain and is inhibited by phosphorylation in the proline-rich domains." Mol Biol Cell 10(3): 727-740. 
18. Blanchard, B. J., B. R. Stockwell and V. M. Ingram (2002). "Eliminating membrane depolarization caused by the Alzheimer peptide Abeta(1-42, aggr.)." Biochem Biophys Res Commun 293(4): 1204-1208.

19. Blanchard, B. J., V. L. Thomas and V. M. Ingram (2002). "Mechanism of membrane depolarization caused by the Alzheimer Abeta1-42 peptide." Biochem Biophys Res Commun 293(4): 1197-1203.

20. Bliss, T. V. and G. L. Collingridge (1993). "A synaptic model of memory: long-term potentiation in the hippocampus." Nature 361(6407): 31-39.

21. Boyko, M., D. Stepensky, B. F. Gruenbaum, S. E. Gruenbaum, I. Melamed, S. Ohayon, M. Glazer, Y. Shapira and A. Zlotnik (2012). "Pharmacokinetics of glutamate-oxaloacetate transaminase and glutamate-pyruvate transaminase and their blood glutamate-lowering activity in naive rats." Neurochem Res 37(10): 2198-2205.

22. Bozso, Z., B. Penke, D. Simon, I. Laczko, G. Juhasz, V. Szegedi, A. Kasza, K. Soos, A. Hetenyi, E. Weber, H. Tohati, M. Csete, M. Zarandi and L. Fulop (2010). "Controlled in situ preparation of A beta(1-42) oligomers from the isopeptide "iso-A beta(1-42)", physicochemical and biological characterization." Peptides 31(2): 248-256.

23. Brock, L. G., J. S. Coombs and J. C. Eccles (1952). "Synaptic excitation and inhibition." J Physiol 117(2): 8p.

24. Byth, L. A. (2014). "Ca(2+)- and CaMKII-mediated processes in early LTP." Ann Neurosci 21(4): 151-153.

25. Campos, F., M. Rodriguez-Yanez, M. Castellanos, S. Arias, M. Perez-Mato, T. Sobrino, M. Blanco, J. Serena and J. Castillo (2011). "Blood levels of glutamate oxaloacetate transaminase are more strongly associated with good outcome in acute ischaemic stroke than glutamate pyruvate transaminase levels." Clin Sci (Lond) 121(1): 11-17.

26. Campos-Pena, V. and M. A. Meraz-Rios (2014). "Alzheimer Disease: The role of A $\beta$ in the glutamatergic system." Neurochem

27. Castellanos, M., T. Sobrino, S. Pedraza, O. Moldes, J. M. Pumar, Y. Silva, J. Serena, M. GarciaGil, J. Castillo and A. Davalos (2008). "High plasma glutamate concentrations are associated with infarct growth in acute ischemic stroke." Neurology 71(23): 1862-1868.

28. Cavelier, P., M. Hamann, D. Rossi, P. Mobbs and D. Attwell (2005). "Tonic excitation and inhibition of neurons: ambient transmitter sources and computational consequences." Prog Biophys Mol Biol 87(1): 3-16.

29. Chasseigneaux, S., L. Dinc, C. Rose, C. Chabret, F. Coulpier, P. Topilko, G. Mauger and B. Allinquant (2011). "Secreted amyloid precursor protein beta and secreted amyloid precursor protein alpha induce axon outgrowth in vitro through Egr1 signaling pathway." PLoS One 6(1): e16301.

30. Chen, H. S., J. W. Pellegrini, S. K. Aggarwal, S. Z. Lei, S. Warach, F. E. Jensen and S. A. Lipton (1992). "Open-channel block of N-methyl-D-aspartate (NMDA) responses by memantine: therapeutic advantage against NMDA receptor-mediated neurotoxicity." J Neurosci 12(11): 44274436.

31. Chen, J. and K. Herrup (2012). "Glutamine acts as a neuroprotectant against DNA damage, betaamyloid and H2O2-induced stress." PLoS One 7(3): e33177.

32. Chen, K. H., E. A. Reese, H. W. Kim, S. I. Rapoport and J. S. Rao (2011). "Disturbed neurotransmitter transporter expression in Alzheimer's disease brain." J Alzheimers Dis 26(4): 755-766.

33. Chen, X., R. Lin, L. Chang, S. Xu, X. Wei, J. Zhang, C. Wang, R. Anwyl and Q. Wang (2013). "Enhancement of long-term depression by soluble amyloid beta protein in rat hippocampus is mediated by metabotropic glutamate receptor and involves activation of p38MAPK, STEP and caspase-3." Neuroscience 253: 435-443. 
34. Chia, P. Z., W. H. Toh, R. Sharples, I. Gasnereau, A. F. Hill and P. A. Gleeson (2013). "Intracellular itinerary of internalised beta-secretase, BACE1, and its potential impact on betaamyloid peptide biogenesis." Traffic 14(9): 997-1013.

35. Cirrito, J. R., J. E. Kang, J. Lee, F. R. Stewart, D. K. Verges, L. M. Silverio, G. Bu, S. Mennerick and D. M. Holtzman (2008). "Endocytosis is required for synaptic activity-dependent release of amyloid-beta in vivo." Neuron 58(1): 42-51.

36. Clugnet, M. C. and J. E. LeDoux (1990). "Synaptic plasticity in fear conditioning circuits: induction of LTP in the lateral nucleus of the amygdala by stimulation of the medial geniculate body." J Neurosci 10(8): 2818-2824.

37. Cohen, I. and R. Miles (2000). "Contributions of intrinsic and synaptic activities to the generation of neuronal discharges in in vitro hippocampus." J Physiol 524 Pt 2: 485-502.

38. Costa, R. O., P. N. Lacor, I. L. Ferreira, R. Resende, Y. P. Auberson, W. L. Klein, C. R. Oliveira, A. C. Rego and C. M. Pereira (2012). "Endoplasmic reticulum stress occurs downstream of GluN2B subunit of N-methyl-d-aspartate receptor in mature hippocampal cultures treated with amyloid-beta oligomers." Aging Cell 11(5): 823-833.

39. Crepel, F. and D. Jaillard (1991). "Pairing of pre- and postsynaptic activities in cerebellar Purkinje cells induces long-term changes in synaptic efficacy in vitro." J Physiol 432: 123-141.

40. Dalby, N. O. and I. Mody (2003). "Activation of NMDA receptors in rat dentate gyrus granule cells by spontaneous and evoked transmitter release." J Neurophysiol 90(2): 786-797.

41. Dale, N. and E. R. Kandel (1993). "L-glutamate may be the fast excitatory transmitter of Aplysia sensory neurons." Proc Natl Acad Sci U S A 90(15): 7163-7167.

42. Daniels, K. K. and T. W. Vickroy (1999). "Reversible activation of glutamate transport in rat brain glia by protein kinase $\mathrm{C}$ and an okadaic acid-sensitive phosphoprotein phosphatase." Neurochem Res 24(8): 1017-1025.

43. Davis, R. C., I. T. Marsden, M. T. Maloney, L. S. Minamide, M. Podlisny, D. J. Selkoe and J. R. Bamburg (2011). "Amyloid beta dimers/trimers potently induce cofilin-actin rods that are inhibited by maintaining cofilin-phosphorylation." Mol Neurodegener 6: 10.

44. Davis, S., P. Vanhoutte, C. Pages, J. Caboche and S. Laroche (2000). "The MAPK/ERK cascade targets both Elk-1 and cAMP response element-binding protein to control long-term potentiationdependent gene expression in the dentate gyrus in vivo." J Neurosci 20(12): 4563-4572.

45. De-Paula, V. J., M. Radanovic, B. S. Diniz and O. V. Forlenza (2012). "Alzheimer's disease." Subcell Biochem 65:329-52.(doi): 10.1007/1978-1094-1007-5416-1004_1014.

46. Derchansky, M., E. Shahar, R. A. Wennberg, M. Samoilova, S. S. Jahromi, P. A. Abdelmalik, L. Zhang and P. L. Carlen (2004). "Model of frequent, recurrent, and spontaneous seizures in the intact mouse hippocampus." Hippocampus 14(8): 935-947.

47. Diamond, J. S., D. E. Bergles and C. E. Jahr (1998). "Glutamate release monitored with astrocyte transporter currents during LTP." Neuron 21(2): 425-433.

48. Dinamarca, M. C., J. A. Rios and N. C. Inestrosa (2012). "Postsynaptic Receptors for Amyloidbeta Oligomers as Mediators of Neuronal Damage in Alzheimer's Disease." Front Physiol 3: 464.

49. Dingledine, R., J. Dodd and J. S. Kelly (1980). "The in vitro brain slice as a useful neurophysiological preparation for intracellular recording." J Neurosci Methods 2(4): 323-362.

50. Domingues, A., S. Almeida, E. F. da Cruz e Silva, C. R. Oliveira and A. C. Rego (2007). "Toxicity of beta-amyloid in HEK293 cells expressing NR1/NR2A or NR1/NR2B N-methyl-Daspartate receptor subunits." Neurochem Int 50(6): 872-880.

51. Dong, H., C. M. Yuede, C. Coughlan, B. Lewis and J. G. Csernansky (2008). "Effects of memantine on neuronal structure and conditioned fear in the Tg2576 mouse model of Alzheimer's disease." Neuropsychopharmacology 33(13): 3226-3236.

52. Duce, J. A., A. Tsatsanis, M. A. Cater, S. A. James, E. Robb, K. Wikhe, S. L. Leong, K. Perez, T. Johanssen, M. A. Greenough, H. H. Cho, D. Galatis, R. D. Moir, C. L. Masters, C. McLean, R. E. Tanzi, R. Cappai, K. J. Barnham, G. D. Ciccotosto, J. T. Rogers and A. I. Bush (2010). "Ironexport ferroxidase activity of beta-amyloid precursor protein is inhibited by zinc in Alzheimer's disease." Cell 142(6): 857-867. 
53. Edwards, R. H. (2015). "Mobile binding sites regulate glutamate clearance." Nat Neurosci 18(2): 166-168.

54. Ehrlich, I., M. Klein, S. Rumpel and R. Malinow (2007). "PSD-95 is required for activity-driven synapse stabilization." Proc Natl Acad Sci U S A 104(10): 4176-4181.

55. Fisher, N. J., B. P. Rourke, L. Bieliauskas, B. Giordani, S. Berent and N. L. Foster (1996). "Neuropsychological subgroups of patients with Alzheimer's disease." J Clin Exp Neuropsychol 18(3): 349-370.

56. Fisher, N. J., B. P. Rourke, L. A. Bieliauskas, B. Giordani, S. Berent and N. L. Foster (1997). "Unmasking the heterogeneity of Alzheimer's disease: case studies of individuals from distinct neuropsychological subgroups." J Clin Exp Neuropsychol 19(5): 713-754.

57. Focke, P. J., X. Wang and H. P. Larsson (2013). "Neurotransmitter transporters: structure meets function." Structure 21(5): 694-705.

58. Fossat, P., F. R. Turpin, S. Sacchi, J. Dulong, T. Shi, J. M. Rivet, J. V. Sweedler, L. Pollegioni, M. J. Millan, S. H. Oliet and J. P. Mothet (2012). "Glial D-serine gates NMDA receptors at excitatory synapses in prefrontal cortex." Cereb Cortex 22(3): 595-606.

59. Foster, K. A., N. McLaughlin, D. Edbauer, M. Phillips, A. Bolton, M. Constantine-Paton and M. Sheng (2010). "Distinct roles of NR2A and NR2B cytoplasmic tails in long-term potentiation." J Neurosci 30(7): 2676-2685.

60. Fricker, D., J. A. Verheugen and R. Miles (1999). "Cell-attached measurements of the firing threshold of rat hippocampal neurones." J Physiol 517 ( Pt 3): 791-804.

61. Fulop, L., I. M. Mandity, G. Juhasz, V. Szegedi, A. Hetenyi, E. Weber, Z. Bozso, D. Simon, M. Benko, Z. Kiraly and T. A. Martinek (2012). "A foldamer-dendrimer conjugate neutralizes synaptotoxic beta-amyloid oligomers." PLoS One 7(7): e39485.

62. Glabe, C. G. (2008). "Structural classification of toxic amyloid oligomers." J Biol Chem 283(44): 29639-29643.

63. Gosselin, R. D., P. Meylan and I. Decosterd (2013). "Extracellular microvesicles from astrocytes contain functional glutamate transporters: regulation by protein kinase $\mathrm{C}$ and cell activation." Front Cell Neurosci 7: 251.

64. Grundke-Iqbal, I., K. Iqbal, Y. C. Tung, M. Quinlan, H. M. Wisniewski and L. I. Binder (1986). "Abnormal phosphorylation of the microtubule-associated protein tau (tau) in Alzheimer cytoskeletal pathology." Proc Natl Acad Sci U S A 83(13): 4913-4917.

65. Guerreiro, R. J., D. R. Gustafson and J. Hardy (2012). "The genetic architecture of Alzheimer's disease: beyond APP, PSENs and APOE." Neurobiol Aging 33(3): 437-456.

66. Hamdane, M., A. V. Sambo, P. Delobel, S. Begard, A. Violleau, A. Delacourte, P. Bertrand, J. Benavides and L. Buee (2003). "Mitotic-like tau phosphorylation by p25-Cdk5 kinase complex." J Biol Chem 278(36): 34026-34034.

67. Hardingham, G. E., Y. Fukunaga and H. Bading (2002). "Extrasynaptic NMDARs oppose synaptic NMDARs by triggering CREB shut-off and cell death pathways." Nat Neurosci 5(5): 405-414.

68. Hardy, J., R. Cowburn, A. Barton, G. Reynolds, E. Lofdahl, A. M. O'Carroll, P. Wester and B. Winblad (1987). "Region-specific loss of glutamate innervation in Alzheimer's disease." Neurosci Lett 73(1): 77-80.

69. Hardy, J. A. and G. A. Higgins (1992). "Alzheimer's disease: the amyloid cascade hypothesis." Science 256(5054): 184-185.

70. Harkany, T., I. Abraham, W. Timmerman, G. Laskay, B. Toth, M. Sasvari, C. Konya, J. B. Sebens, J. Korf, C. Nyakas, M. Zarandi, K. Soos, B. Penke and P. G. Luiten (2000). "betaamyloid neurotoxicity is mediated by a glutamate-triggered excitotoxic cascade in rat nucleus basalis." Eur J Neurosci 12(8): 2735-2745.

71. Harney, S. C., D. E. Jane and R. Anwyl (2008). "Extrasynaptic NR2D-containing NMDARs are recruited to the synapse during LTP of NMDAR-EPSCs." J Neurosci 28(45): 11685-11694. 
72. Hasegawa, Y., H. Mukai, M. Asashima, Y. Hojo, M. Ikeda, Y. Komatsuzaki, Y. Ooishi and S. Kawato (2014). "Acute modulation of synaptic plasticity of pyramidal neurons by activin in adult hippocampus." Front Neural Circuits 8: 56.

73. Hertz, L. and H. R. Zielke (2004). "Astrocytic control of glutamatergic activity: astrocytes as stars of the show." Trends Neurosci 27(12): 735-743.

74. Hu, N. W., I. Klyubin, R. Anwyl and M. J. Rowan (2009). "GluN2B subunit-containing NMDA receptor antagonists prevent Abeta-mediated synaptic plasticity disruption in vivo." Proc Natl Acad Sci U S A 106(48): 20504-20509.

75. Huang, Y. Y. and E. R. Kandel (2005). "Theta frequency stimulation induces a local form of late phase LTP in the CA1 region of the hippocampus." Learn Mem 12(6): 587-593.

76. Jacob, C. P., E. Koutsilieri, J. Bartl, E. Neuen-Jacob, T. Arzberger, N. Zander, R. Ravid, W. Roggendorf, P. Riederer and E. Grunblatt (2007). "Alterations in expression of glutamatergic transporters and receptors in sporadic Alzheimer's disease." J Alzheimers Dis 11(1): 97-116.

77. Joachim, C. L., H. Mori and D. J. Selkoe (1989). "Amyloid beta-protein deposition in tissues other than brain in Alzheimer's disease." Nature 341(6239): 226-230.

78. Johnstone, V. P. and C. R. Raymond (2011). "A protein synthesis and nitric oxide-dependent presynaptic enhancement in persistent forms of long-term potentiation." Learn Mem 18(10): 625633.

79. Juhasz, G., A. Marki, G. Vass, L. Fulop, D. Budai, B. Penke, G. Falkay and V. Szegedi (2009). "An intraperitoneally administered pentapeptide protects against Abeta (1-42) induced neuronal excitation in vivo." J Alzheimers Dis 16(1): 189-196.

80. Kamenetz, F., T. Tomita, H. Hsieh, G. Seabrook, D. Borchelt, T. Iwatsubo, S. Sisodia and R. Malinow (2003). "APP processing and synaptic function." Neuron 37(6): 925-937.

81. Kang, J. E., M. M. Lim, R. J. Bateman, J. J. Lee, L. P. Smyth, J. R. Cirrito, N. Fujiki, S. Nishino and D. M. Holtzman (2009). "Amyloid-beta dynamics are regulated by orexin and the sleep-wake cycle." Science 326(5955): 1005-1007.

82. Kanterewicz, B. I., N. N. Urban, D. B. McMahon, E. D. Norman, L. J. Giffen, M. F. Favata, P. A. Scherle, J. M. Trzskos, G. Barrionuevo and E. Klann (2000). "The extracellular signal-regulated kinase cascade is required for NMDA receptor-independent LTP in area CA1 but not area CA3 of the hippocampus." J Neurosci 20(9): 3057-3066.

83. Kimura, F., A. Nishigori, T. Shirokawa and T. Tsumoto (1989). "Long-term potentiation and Nmethyl-D-aspartate receptors in the visual cortex of young rats." J Physiol 414: 125-144.

84. Kitazume, S., Y. Tachida, M. Kato, Y. Yamaguchi, T. Honda, Y. Hashimoto, Y. Wada, T. Saito, N. Iwata, T. Saido and N. Taniguchi (2010). "Brain endothelial cells produce amyloid \{beta from amyloid precursor protein 770 and preferentially secrete the O-glycosylated form." $\mathrm{J}$ Biol Chem 285(51): 40097-40103.

85. Kitazume, S., A. Yoshihisa, T. Yamaki, M. Oikawa, Y. Tachida, K. Ogawa, R. Imamaki, Y. Hagiwara, N. Kinoshita, Y. Takeishi, K. Furukawa, N. Tomita, H. Arai, N. Iwata, T. Saido, N. Yamamoto and N. Taniguchi (2012). "Soluble amyloid precursor protein 770 is released from inflamed endothelial cells and activated platelets: a novel biomarker for acute coronary syndrome." J Biol Chem 287(48): 40817-40825.

86. Kleckner, N. W. and R. Dingledine (1988). "Requirement for glycine in activation of NMDAreceptors expressed in Xenopus oocytes." Science 241(4867): 835-837.

87. Klyubin, I., V. Betts, A. T. Welzel, K. Blennow, H. Zetterberg, A. Wallin, C. A. Lemere, W. K. Cullen, Y. Peng, T. Wisniewski, D. J. Selkoe, R. Anwyl, D. M. Walsh and M. J. Rowan (2008). "Amyloid beta protein dimer-containing human CSF disrupts synaptic plasticity: prevention by systemic passive immunization." J Neurosci 28(16): 4231-4237.

88. Klyubin, I., Q. Wang, M. N. Reed, E. A. Irving, N. Upton, J. Hofmeister, J. P. Cleary, R. Anwyl and M. J. Rowan (2011). "Protection against Abeta-mediated rapid disruption of synaptic plasticity and memory by memantine." Neurobiol Aging 32(4): 614-623. 
89. Koeglsperger, T., S. Li, C. Brenneis, J. L. Saulnier, L. Mayo, Y. Carrier, D. J. Selkoe and H. L. Weiner (2013). "Impaired glutamate recycling and GluN2B-mediated neuronal calcium overload in mice lacking TGF-beta1 in the CNS." Glia 61(6): 985-1002.

90. Koffie, R. M., B. T. Hyman and T. L. Spires-Jones (2011). "Alzheimer's disease: synapses gone cold." Mol Neurodegener 6(1): 63.

91. Koffie, R. M., M. Meyer-Luehmann, T. Hashimoto, K. W. Adams, M. L. Mielke, M. GarciaAlloza, K. D. Micheva, S. J. Smith, M. L. Kim, V. M. Lee, B. T. Hyman and T. L. Spires-Jones (2009). "Oligomeric amyloid beta associates with postsynaptic densities and correlates with excitatory synapse loss near senile plaques." Proc Natl Acad Sci U S A 106(10): 4012-4017.

92. Koh, J. Y., L. L. Yang and C. W. Cotman (1990). "Beta-amyloid protein increases the vulnerability of cultured cortical neurons to excitotoxic damage." Brain Res 533(2): 315-320.

93. LaFerla, F. M., K. N. Green and S. Oddo (2007). "Intracellular amyloid-beta in Alzheimer's disease." Nat Rev Neurosci 8(7): 499-509.

94. Lam, B., M. Masellis, M. Freedman, D. T. Stuss and S. E. Black (2013). "Clinical, imaging, and pathological heterogeneity of the Alzheimer's disease syndrome." Alzheimers Res Ther 5(1): 1.

95. Larson, M., M. A. Sherman, F. Amar, M. Nuvolone, J. A. Schneider, D. A. Bennett, A. Aguzzi and S. E. Lesne (2012). "The complex PrP(c)-Fyn couples human oligomeric Abeta with pathological tau changes in Alzheimer's disease." J Neurosci 32(47): 16857-16871a.

96. Laube, B., J. Kuhse and H. Betz (1998). "Evidence for a tetrameric structure of recombinant NMDA receptors." J Neurosci 18(8): 2954-2961.

97. Le Meur, K., M. Galante, M. C. Angulo and E. Audinat (2007). "Tonic activation of NMDA receptors by ambient glutamate of non-synaptic origin in the rat hippocampus." J Physiol 580(Pt. 2): 373-383.

98. LeBlanc, A. C., H. Y. Chen, L. Autilio-Gambetti and P. Gambetti (1991). "Differential APP gene expression in rat cerebral cortex, meninges, and primary astroglial, microglial and neuronal cultures." FEBS Lett 292(1-2): 171-178.

99. Lemmin, T., M. Dimitrov, P. C. Fraering and M. Dal Peraro (2014). "Perturbations of the straight transmembrane alpha-helical structure of the amyloid precursor protein affect its processing by gamma-secretase." J Biol Chem 289(10): 6763-6774.

100. Lesne, S., C. Ali, C. Gabriel, N. Croci, E. T. MacKenzie, C. G. Glabe, M. Plotkine, C. MarchandVerrecchia, D. Vivien and A. Buisson (2005). "NMDA receptor activation inhibits alphasecretase and promotes neuronal amyloid-beta production." J Neurosci 25(41): 9367-9377.

101. Li, S., S. Hong, N. E. Shepardson, D. M. Walsh, G. M. Shankar and D. Selkoe (2009). "Soluble oligomers of amyloid Beta protein facilitate hippocampal long-term depression by disrupting neuronal glutamate uptake." Neuron 62(6): 788-801.

102. Li, S., M. Jin, T. Koeglsperger, N. E. Shepardson, G. M. Shankar and D. J. Selkoe (2011). "Soluble Abeta oligomers inhibit long-term potentiation through a mechanism involving excessive activation of extrasynaptic NR2B-containing NMDA receptors." J Neurosci 31(18): 6627-6638.

103. Li, S., G. M. Shankar and D. J. Selkoe (2010). "How do Soluble Oligomers of Amyloid betaprotein Impair Hippocampal Synaptic Plasticity?" Front Cell Neurosci 4: 5.

104. Lisman, J., R. Yasuda and S. Raghavachari (2012). "Mechanisms of CaMKII action in long-term potentiation." Nat Rev Neurosci 13(3): 169-182.

105. Liu, D. D., Q. Yang and S. T. Li (2013). "Activation of extrasynaptic NMDA receptors induces LTD in rat hippocampal CA1 neurons." Brain Res Bull 93: 10-16.

106. Llinas, R., I. Z. Steinberg and K. Walton (1981). "Relationship between presynaptic calcium current and postsynaptic potential in squid giant synapse." Biophys J 33(3): 323-351.

107. Low, C. M., F. Zheng, P. Lyuboslavsky and S. F. Traynelis (2000). "Molecular determinants of coordinated proton and zinc inhibition of N-methyl-D-aspartate NR1/NR2A receptors." Proc Natl Acad Sci U S A 97(20): 11062-11067.

108. Lu, Y., K. Christian and B. Lu (2008). "BDNF: a key regulator for protein synthesis-dependent LTP and long-term memory?" Neurobiol Learn Mem 89(3): 312-323. 
109. Lundkvist, J., M. M. Halldin, J. Sandin, G. Nordvall, P. Forsell, S. Svensson, L. Jansson, G. Johansson, B. Winblad and J. Ekstrand (2014). "The battle of Alzheimer's Disease - the beginning of the future Unleashing the potential of academic discoveries." Front Pharmacol. 5:102.(doi): 10.3389/fphar.2014.00102. eCollection 02014.

110. Luscher, C., R. C. Malenka and R. A. Nicoll (1998). "Monitoring glutamate release during LTP with glial transporter currents." Neuron 21(2): 435-441.

111. Magnin, E., G. Sylvestre, F. Lenoir, E. Dariel, L. Bonnet, G. Chopard, G. Tio, J. Hidalgo, S. Ferreira, C. Mertz, M. Binetruy, L. Chamard, S. Haffen, I. Ryff, E. Laurent, T. Moulin, P. Vandel and L. Rumbach (2013). "Logopenic syndrome in posterior cortical atrophy." J Neurol. 260(2): 528-533. doi: 510.1007/s00415-00012-06671-00417. Epub 02012 Sep 00425.

112. Marosi, M., J. Fuzik, D. Nagy, G. Rakos, Z. Kis, L. Vecsei, J. Toldi, A. Ruban-Matuzani, V. I. Teichberg and T. Farkas (2009). "Oxaloacetate restores the long-term potentiation impaired in rat hippocampus CA1 region by 2-vessel occlusion." Eur J Pharmacol 604(1-3): 51-57.

113. Martins, I. C., I. Kuperstein, H. Wilkinson, E. Maes, M. Vanbrabant, W. Jonckheere, P. Van Gelder, D. Hartmann, R. D'Hooge, B. De Strooper, J. Schymkowitz and F. Rousseau (2008). "Lipids revert inert Abeta amyloid fibrils to neurotoxic protofibrils that affect learning in mice." Embo j 27(1): 224-233.

114. Masliah, E., M. Alford, M. Mallory, E. Rockenstein, D. Moechars and F. Van Leuven (2000). "Abnormal glutamate transport function in mutant amyloid precursor protein transgenic mice." Exp Neurol 163(2): 381-387.

115. Matos, M., E. Augusto, N. J. Machado, A. dos Santos-Rodrigues, R. A. Cunha and P. Agostinho (2012). "Astrocytic adenosine A2A receptors control the amyloid-beta peptide-induced decrease of glutamate uptake." J Alzheimers Dis 31(3): 555-567.

116. Matos, M., E. Augusto, C. R. Oliveira and P. Agostinho (2008). "Amyloid-beta peptide decreases glutamate uptake in cultured astrocytes: involvement of oxidative stress and mitogen-activated protein kinase cascades." Neuroscience 156(4): 898-910.

117. Mattson, M. P. (2003). "Neurobiology: Ballads of a protein quartet." Nature 422(6930): 385, 387.

118. McGeer, P. L., S. Itagaki, H. Tago and E. G. McGeer (1987). "Reactive microglia in patients with senile dementia of the Alzheimer type are positive for the histocompatibility glycoprotein HLADR." Neurosci Lett 79(1-2): 195-200.

119. Menting, K. W. and J. A. Claassen (2014). "beta-secretase inhibitor; a promising novel therapeutic drug in Alzheimer's disease." Front Aging Neurosci. 6:165.(doi): 10.3389/fnagi.2014.00165. eCollection 02014.

120. Min, M. Y., D. A. Rusakov and D. M. Kullmann (1998). "Activation of AMPA, kainate, and metabotropic receptors at hippocampal mossy fiber synapses: role of glutamate diffusion." Neuron 21(3): 561-570.

121. Minkeviciene, R., S. Rheims, M. B. Dobszay, M. Zilberter, J. Hartikainen, L. Fulop, B. Penke, Y. Zilberter, T. Harkany, A. Pitkanen and H. Tanila (2009). "Amyloid beta-induced neuronal hyperexcitability triggers progressive epilepsy." J Neurosci 29(11): 3453-3462.

122. Mintzer E. J., F. D. Mirski and S. K. Hoerning (2000). "Behavioral and psychological signs and symptoms of dementia: a practicing psychiatrist's viewpoint." Dialogues Clin Neurosci 2(2): 139155.

123. Mitani, H., Y. Shirayama, T. Yamada, K. Maeda, C. R. Ashby, Jr. and R. Kawahara (2006). "Correlation between plasma levels of glutamate, alanine and serine with severity of depression." Prog Neuropsychopharmacol Biol Psychiatry 30(6): 1155-1158.

124. Morgan, S. L. and T. J. Teyler (1999). "VDCCs and NMDARs underlie two forms of LTP in CA1 hippocampus in vivo." J Neurophysiol 82(2): 736-740.

125. Mura, E., S. Zappettini, S. Preda, F. Biundo, C. Lanni, M. Grilli, A. Cavallero, G. Olivero, A. Salamone, S. Govoni and M. Marchi (2012). "Dual effect of beta-amyloid on alpha7 and alpha4beta2 nicotinic receptors controlling the release of glutamate, aspartate and GABA in rat hippocampus." PLoS One 7(1): e29661. 
126. Nalivaeva, N. N. and A. J. Turner (2013). "The amyloid precursor protein: a biochemical enigma in brain development, function and disease." FEBS Lett 587(13): 2046-2054.

127. Ni, C. L., H. P. Shi, H. M. Yu, Y. C. Chang and Y. R. Chen (2011). "Folding stability of amyloidbeta 40 monomer is an important determinant of the nucleation kinetics in fibrillization." Faseb $\mathrm{j}$ 25(4): 1390-1401.

128. Nie, H. and H. R. Weng (2010). "Impaired glial glutamate uptake induces extrasynaptic glutamate spillover in the spinal sensory synapses of neuropathic rats." J Neurophysiol 103(5): 2570-2580.

129. Palmada, M. and J. J. Centelles (1998). "Excitatory amino acid neurotransmission. Pathways for metabolism, storage and reuptake of glutamate in brain." Front Biosci 3: d701-718.

130. Palop, J. J., J. Chin, E. D. Roberson, J. Wang, M. T. Thwin, N. Bien-Ly, J. Yoo, K. O. Ho, G. Q. Yu, A. Kreitzer, S. Finkbeiner, J. L. Noebels and L. Mucke (2007). "Aberrant excitatory neuronal activity and compensatory remodeling of inhibitory hippocampal circuits in mouse models of Alzheimer's disease." Neuron 55(5): 697-711.

131. Palop, J. J. and L. Mucke (2009). "Epilepsy and cognitive impairments in Alzheimer disease." Arch Neurol 66(4): 435-440.

132. Pappolla, M. A., R. A. Omar, K. Sambamurti, J. P. Anderson and N. K. Robakis (1992). "The genesis of the senile plaque. Further evidence in support of its neuronal origin." Am J Pathol 141(5): 1151-1159.

133. Patneau, D. K. and M. L. Mayer (1990). "Structure-activity relationships for amino acid transmitter candidates acting at N-methyl-D-aspartate and quisqualate receptors." J Neurosci 10(7): 2385-2399.

134. Perrin, R. J., A. M. Fagan and D. M. Holtzman (2009). "Multimodal techniques for diagnosis and prognosis of Alzheimer's disease." Nature 461(7266): 916-922.

135. Perry, R. H., E. K. Perry, C. J. Smith, J. H. Xuereb, D. Irving, C. A. Whitford, J. M. Candy and A. J. Cross (1987). "Cortical neuropathological and neurochemical substrates of Alzheimer's and Parkinson's diseases." J Neural Transm Suppl 24: 131-136.

136. Pomara, N., R. Singh, D. Deptula, J. C. Chou, M. B. Schwartz and P. A. LeWitt (1992). "Glutamate and other CSF amino acids in Alzheimer's disease." Am J Psychiatry 149(2): 251254.

137. Popoli, M., Z. Yan, B. S. McEwen and G. Sanacora (2012). "The stressed synapse: the impact of stress and glucocorticoids on glutamate transmission." Nat Rev Neurosci 13(1): 22-37.

138. Priestley, T., P. Laughton, J. Myers, B. Le Bourdelles, J. Kerby and P. J. Whiting (1995). "Pharmacological properties of recombinant human N-methyl-D-aspartate receptors comprising NR1a/NR2A and NR1a/NR2B subunit assemblies expressed in permanently transfected mouse fibroblast cells." Mol Pharmacol 48(5): 841-848.

139. Proper, E. A., G. Hoogland, S. M. Kappen, G. H. Jansen, M. G. Rensen, L. H. Schrama, C. W. van Veelen, P. C. van Rijen, O. van Nieuwenhuizen, W. H. Gispen and P. N. de Graan (2002). "Distribution of glutamate transporters in the hippocampus of patients with pharmaco-resistant temporal lobe epilepsy." Brain 125(Pt 1): 32-43.

140. Rao, S. C., G. Dove, G. D. Cascino and R. C. Petersen (2009). "Recurrent seizures in patients with dementia: frequency, seizure types, and treatment outcome." Epilepsy Behav 14(1): 118120.

141. Revett, T. J., G. B. Baker, J. Jhamandas and S. Kar (2013). "Glutamate system, amyloid ss peptides and tau protein: functional interrelationships and relevance to Alzheimer disease pathology." J Psychiatry Neurosci 38(1): 6-23.

142. Roberson, E. D., K. Scearce-Levie, J. J. Palop, F. Yan, I. H. Cheng, T. Wu, H. Gerstein, G. Q. Yu and L. Mucke (2007). "Reducing endogenous tau ameliorates amyloid beta-induced deficits in an Alzheimer's disease mouse model." Science 316(5825): 750-754.

143. Rossi, D. J., T. Oshima and D. Attwell (2000). "Glutamate release in severe brain ischaemia is mainly by reversed uptake." Nature 403(6767): 316-321. 
144. Rothstein, J. D., M. Dykes-Hoberg, C. A. Pardo, L. A. Bristol, L. Jin, R. W. Kuncl, Y. Kanai, M. A. Hediger, Y. Wang, J. P. Schielke and D. F. Welty (1996). "Knockout of glutamate transporters reveals a major role for astroglial transport in excitotoxicity and clearance of glutamate." Neuron 16(3): 675-686.

145. Rothstein, J. D., S. Patel, M. R. Regan, C. Haenggeli, Y. H. Huang, D. E. Bergles, L. Jin, M. Dykes Hoberg, S. Vidensky, D. S. Chung, S. V. Toan, L. I. Bruijn, Z. Z. Su, P. Gupta and P. B. Fisher (2005). "Beta-lactam antibiotics offer neuroprotection by increasing glutamate transporter expression." Nature 433(7021): 73-77.

146. Rothstein, J. D. and B. Tabakoff (1984). "Alteration of striatal glutamate release after glutamine synthetase inhibition." J Neurochem 43(5): 1438-1446.

147. Sah, P., S. Hestrin and R. A. Nicoll (1989). "Tonic activation of NMDA receptors by ambient glutamate enhances excitability of neurons." Science 246(4931): 815-818.

148. Sassi, C., R. Guerreiro, R. Gibbs, J. Ding, M. K. Lupton, C. Troakes, S. Al-Sarraj, M. Niblock, J. M. Gallo, J. Adnan, R. Killick, K. S. Brown, C. Medway, J. Lord, J. Turton, J. Bras, K. Morgan, J. F. Powell, A. Singleton and J. Hardy (2014). "Investigating the role of rare coding variability in Mendelian dementia genes (APP, PSEN1, PSEN2, GRN, MAPT, and PRNP) in late-onset Alzheimer's disease." Neurobiol Aging 35(12): 2881.e2881-2886.

149. Schneider, I., D. Reverse, I. Dewachter, L. Ris, N. Caluwaerts, C. Kuiperi, M. Gilis, H. Geerts, H. Kretzschmar, E. Godaux, D. Moechars, F. Van Leuven and J. Herms (2001). "Mutant presenilins disturb neuronal calcium homeostasis in the brain of transgenic mice, decreasing the threshold for excitotoxicity and facilitating long-term potentiation." J Biol Chem 276(15): 11539-11544.

150. Schneider, L. S., K. S. Dagerman, J. P. Higgins and R. McShane (2011). "Lack of evidence for the efficacy of memantine in mild Alzheimer disease." Arch Neurol 68(8): 991-998.

151. Scimemi, A., A. Fine, D. M. Kullmann and D. A. Rusakov (2004). "NR2B-containing receptors mediate cross talk among hippocampal synapses." J Neurosci 24(20): 4767-4777.

152. Scott, H. L., D. V. Pow, A. E. Tannenberg and P. R. Dodd (2002). "Aberrant expression of the glutamate transporter excitatory amino acid transporter 1 (EAAT1) in Alzheimer's disease." Neurosci 22(3): Rc206.

153. Selkoe, D. J. (2008). "Soluble oligomers of the amyloid beta-protein impair synaptic plasticity and behavior." Behav Brain Res 192(1): 106-113.

154. Selkoe, D. J. (2011). "Alzheimer's disease." Cold Spring Harb Perspect Biol 3(7).

155. Sepulveda-Falla, D., A. Barrera-Ocampo, C. Hagel, A. Korwitz, M. F. Vinueza-Veloz, K. Zhou, M. Schonewille, H. Zhou, L. Velazquez-Perez, R. Rodriguez-Labrada, A. Villegas, I. Ferrer, F. Lopera, T. Langer, C. I. De Zeeuw and M. Glatzel (2014). "Familial Alzheimer's diseaseassociated presenilin-1 alters cerebellar activity and calcium homeostasis." J Clin Invest 124(4): 1552-1567.

156. Shankar, G. M., B. L. Bloodgood, M. Townsend, D. M. Walsh, D. J. Selkoe and B. L. Sabatini (2007). "Natural oligomers of the Alzheimer amyloid-beta protein induce reversible synapse loss by modulating an NMDA-type glutamate receptor-dependent signaling pathway." J Neurosci 27(11): 2866-2875.

157. Shankar, G. M. and D. M. Walsh (2009). "Alzheimer's disease: synaptic dysfunction and Abeta." Mol Neurodegener 4: 48.

158. Shinohe, A., K. Hashimoto, K. Nakamura, M. Tsujii, Y. Iwata, K. J. Tsuchiya, Y. Sekine, S. Suda, K. Suzuki, G. Sugihara, H. Matsuzaki, Y. Minabe, T. Sugiyama, M. Kawai, M. Iyo, N. Takei and N. Mori (2006). "Increased serum levels of glutamate in adult patients with autism." Prog Neuropsychopharmacol Biol Psychiatry 30(8): 1472-1477.

159. Staubli, U., G. Rogers and G. Lynch (1994). "Facilitation of glutamate receptors enhances memory." Proc Natl Acad Sci U S A 91(2): 777-781.

160. Szegedi, V., G. Juhasz, C. G. Parsons and D. Budai (2010). "In vivo evidence for functional NMDA receptor blockade by memantine in rat hippocampal neurons." J Neural Transm 117(10): 1189-1194. 
161. Tackenberg, C., S. Grinschgl, A. Trutzel, A. C. Santuccione, M. C. Frey, U. Konietzko, J. Grimm, R. Brandt and R. M. Nitsch (2013). "NMDA receptor subunit composition determines beta-amyloid-induced neurodegeneration and synaptic loss." Cell Death Dis 4: e608.

162. Talantova, M., S. Sanz-Blasco, X. Zhang, P. Xia, M. W. Akhtar, S. Okamoto, G. Dziewczapolski, T. Nakamura, G. Cao, A. E. Pratt, Y. J. Kang, S. Tu, E. Molokanova, S. R. McKercher, S. A. Hires, H. Sason, D. G. Stouffer, M. W. Buczynski, J. P. Solomon, S. Michael, E. T. Powers, J. W. Kelly, A. Roberts, G. Tong, T. Fang-Newmeyer, J. Parker, E. A. Holland, D. Zhang, N. Nakanishi, H. S. Chen, H. Wolosker, Y. Wang, L. H. Parsons, R. Ambasudhan, E. Masliah, S. F. Heinemann, J. C. Pina-Crespo and S. A. Lipton (2013). "Abeta induces astrocytic glutamate release, extrasynaptic NMDA receptor activation, and synaptic loss." Proc Natl Acad Sci U S A 110(27): E2518-2527.

163. Tam, J. H., C. Seah and S. H. Pasternak (2014). "The Amyloid Precursor Protein is rapidly transported from the Golgi apparatus to the lysosome and where it is processed into betaamyloid." Mol Brain 7: 54.

164. Teichberg, V. I., K. Cohen-Kashi-Malina, I. Cooper and A. Zlotnik (2009). "Homeostasis of glutamate in brain fluids: an accelerated brain-to-blood efflux of excess glutamate is produced by blood glutamate scavenging and offers protection from neuropathologies." Neuroscience 158(1): 301-308.

165. Texido, L., M. Martin-Satue, E. Alberdi, C. Solsona and C. Matute (2011). "Amyloid beta peptide oligomers directly activate NMDA receptors." Cell Calcium 49(3): 184-190.

166. Teyler, T. J. and P. Discenna (1984). "Long-term potentiation as a candidate mnemonic device." Brain Res 319(1): 15-28.

167. Tominaga, T., Y. Tominaga and M. Ichikawa (2002). "Optical imaging of long-lasting depolarization on burst stimulation in area CA1 of rat hippocampal slices." J Neurophysiol 88(3): 1523-1532.

168. Townsend, M., G. M. Shankar, T. Mehta, D. M. Walsh and D. J. Selkoe (2006). "Effects of secreted oligomers of amyloid beta-protein on hippocampal synaptic plasticity: a potent role for trimers." J Physiol 572(Pt 2): 477-492.

169. Tyzio, R., A. Ivanov, C. Bernard, G. L. Holmes, Y. Ben-Ari and R. Khazipov (2003). "Membrane potential of CA3 hippocampal pyramidal cells during postnatal development." J Neurophysiol 90(5): 2964-2972.

170. Um, J. W., A. C. Kaufman, M. Kostylev, J. K. Heiss, M. Stagi, H. Takahashi, M. E. Kerrisk, A. Vortmeyer, T. Wisniewski, A. J. Koleske, E. C. Gunther, H. B. Nygaard and S. M. Strittmatter (2013). "Metabotropic glutamate receptor 5 is a coreceptor for Alzheimer abeta oligomer bound to cellular prion protein." Neuron 79(5): 887-902.

171. Um, J. W., H. B. Nygaard, J. K. Heiss, M. A. Kostylev, M. Stagi, A. Vortmeyer, T. Wisniewski, E. C. Gunther and S. M. Strittmatter (2012). "Alzheimer amyloid-beta oligomer bound to postsynaptic prion protein activates Fyn to impair neurons." Nat Neurosci 15(9): 1227-1235.

172. Varga, E., G. Juhasz, Z. Bozso, B. Penke, L. Fulop and V. Szegedi (2014). "Abeta(1-42) enhances neuronal excitability in the CA1 via NR2B subunit-containing NMDA receptors." Neural Plast 2014:584314.(doi): 10.1155/2014/584314. Epub 582014 Sep 584313.

173. Varga, E., G. Juhasz, Z. Bozso, B. Penke, L. Fulop and V. Szegedi (2014). "Amyloid-beta1-42 Disrupts Synaptic Plasticity by Altering Glutamate Recycling at the Synapse." J Alzheimers Dis.

174. Varghese, K., P. Molnar, M. Das, N. Bhargava, S. Lambert, M. S. Kindy and J. J. Hickman (2010). "A new target for amyloid beta toxicity validated by standard and high-throughput electrophysiology." PLoS One 5(1): e8643.

175. Villers, A., E. Godaux and L. Ris (2012). "Long-lasting LTP requires neither repeated trains for its induction nor protein synthesis for its development." PLoS One 7(7): e40823.

176. Vingtdeux, V., N. Sergeant and L. Buee (2012). "Potential contribution of exosomes to the prionlike propagation of lesions in Alzheimer's disease." Front Physiol 3: 229. 
177. Walsh, D. M., I. Klyubin, J. V. Fadeeva, M. J. Rowan and D. J. Selkoe (2002). "Amyloid-beta oligomers: their production, toxicity and therapeutic inhibition." Biochem Soc Trans 30(4): 552557.

178. Wang, P., G. Yang, D. R. Mosier, P. Chang, T. Zaidi, Y. D. Gong, N. M. Zhao, B. Dominguez, K. F. Lee, W. B. Gan and H. Zheng (2005). "Defective neuromuscular synapses in mice lacking amyloid precursor protein (APP) and APP-Like protein 2." J Neurosci 25(5): 1219-1225.

179. Wanngren, J., P. Lara, K. Ojemalm, S. Maioli, N. Moradi, L. Chen, L. O. Tjernberg, J. Lundkvist, I. Nilsson and H. Karlstrom (2014). "Changed membrane integration and catalytic site conformation are two mechanisms behind the increased Abeta42/Abeta40 ratio by presenilin 1 familial Alzheimer-linked mutations." FEBS Open Bio 4: 393-406.

180. Weiner, M. F., K. E. Neubecker, M. E. Bret and L. S. Hynan (2008). "Language in Alzheimer's disease." J Clin Psychiatry. 69(8): 1223-1227.

181. Willard, S. S. and S. Koochekpour (2013). "Glutamate, glutamate receptors, and downstream signaling pathways." Int J Biol Sci 9(9): 948-959.

182. Wood, S. J. and J. E. Tattersall (2001). "An improved brain slice model of nerve agent-induced seizure activity." J Appl Toxicol 21 Suppl 1: S83-86.

183. Wright, A. and B. Vissel (2012). "The essential role of AMPA receptor GluR2 subunit RNA editing in the normal and diseased brain." Front Mol Neurosci 5: 34.

184. Wyss-Coray, T., J. D. Loike, T. C. Brionne, E. Lu, R. Anankov, F. Yan, S. C. Silverstein and J. Husemann (2003). "Adult mouse astrocytes degrade amyloid-beta in vitro and in situ." Nat Med 9(4): 453-457.

185. Xia, P., H. S. Chen, D. Zhang and S. A. Lipton (2010). "Memantine preferentially blocks extrasynaptic over synaptic NMDA receptor currents in hippocampal autapses." J Neurosci 30(33): 11246-11250.

186. Xu, Y., D. H. Cao, G. M. Wu and X. Y. Hou (2014). "Involvement of P38MAPK activation by NMDA receptors and non-NMDA receptors in amyloid-beta peptide-induced neuronal loss in rat hippocampal CA1 and CA3 subfields." Neurosci Res 85: 51-57.

187. Yang, Y., O. Gozen, A. Watkins, I. Lorenzini, A. Lepore, Y. Gao, S. Vidensky, J. Brennan, D. Poulsen, J. Won Park, N. Li Jeon, M. B. Robinson and J. D. Rothstein (2009). "Presynaptic regulation of astroglial excitatory neurotransmitter transporter GLT1." Neuron 61(6): 880-894.

188. Yuste, R. and T. Bonhoeffer (2001). "Morphological changes in dendritic spines associated with long-term synaptic plasticity." Annu Rev Neurosci 24: 1071-1089.

189. Zhang, J., C. Wang, T. Deng, Z. Xue, X. Chen, L. Chang and Q. Wang (2013). "The preventive effect of NR2B and NR2D-containing NMDAR antagonists on Abeta-induced LTP disruption in the dentate gyrus of rats." Metab Brain Dis 28(4): 697-704.

190. Zhao, L. N., S. W. Chiu, J. Benoit, L. Y. Chew and Y. Mu (2012). "The effect of curcumin on the stability of Abeta dimers." J Phys Chem B 116(25): 7428-7435.

191. Zlotnik, A., B. Gurevich, S. Tkachov, I. Maoz, Y. Shapira and V. I. Teichberg (2007). "Brain neuroprotection by scavenging blood glutamate." Exp Neurol 203(1): 213-220. 


\section{SUPPLEMENTARY MATERIAL}

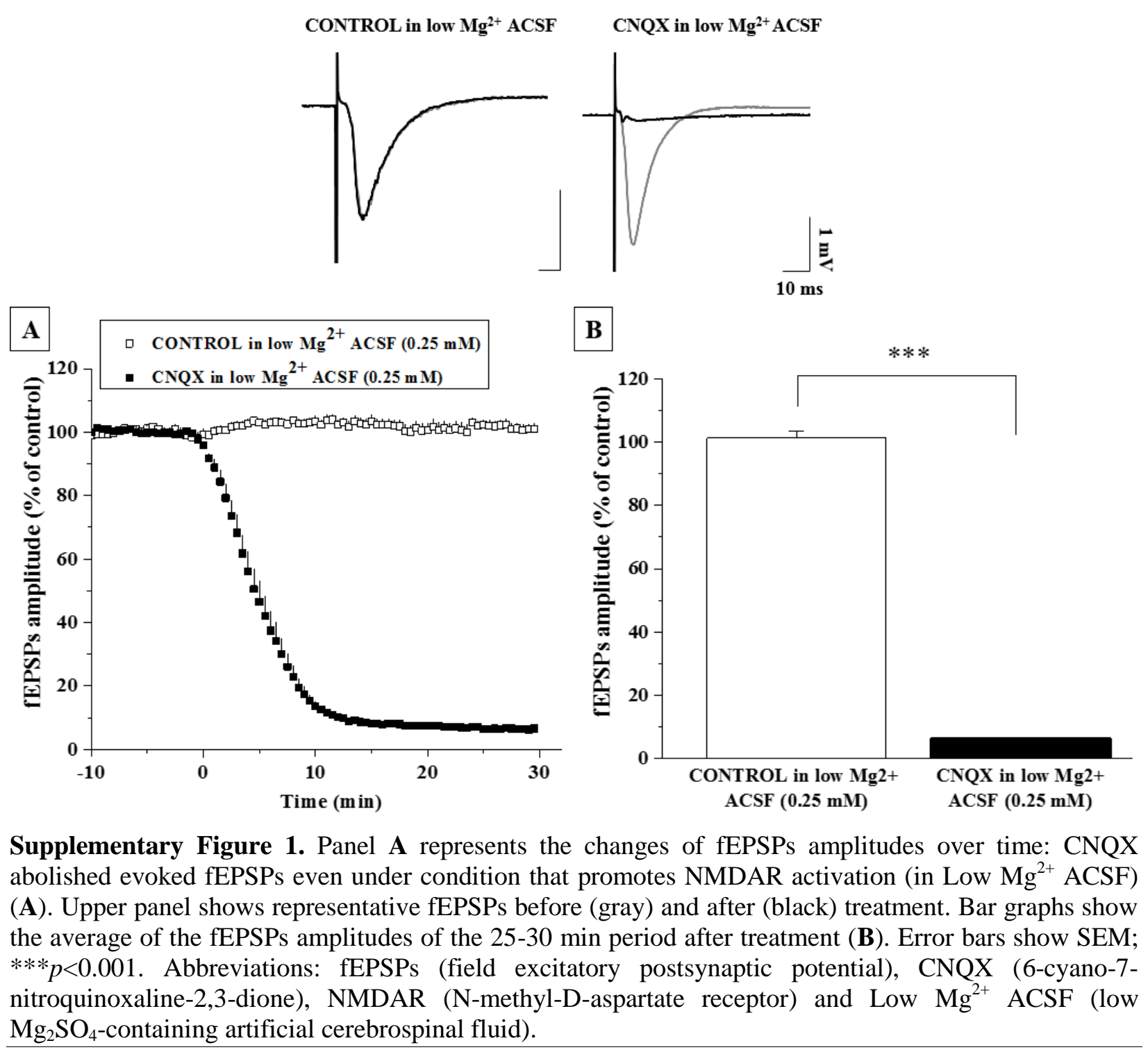



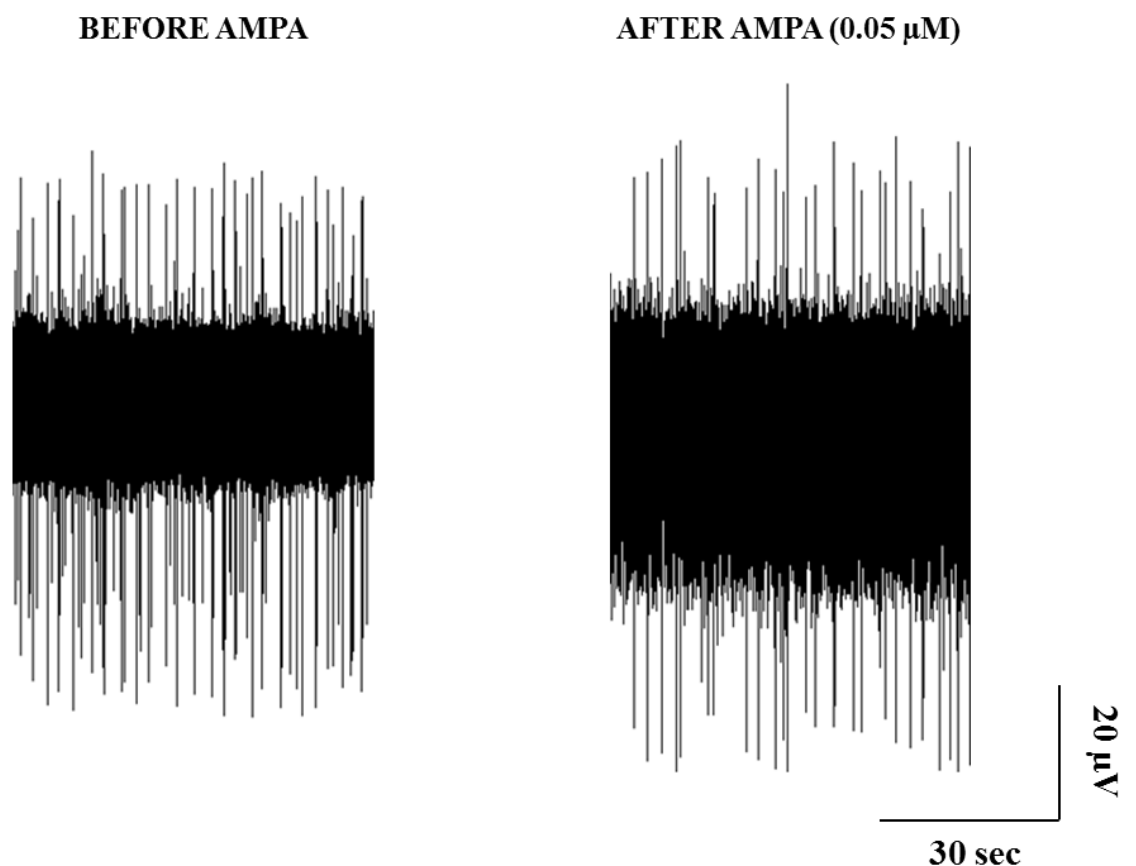

Supplementary Figure 2. Low concentration of AMPA $(0.05 \mu \mathrm{M})$ increased basal activity which hindered the effective detection of spikes. Figure shows representative traces before (left) and after (right) AMPA application. Abbreviation: AMPA ( $\alpha$-Amino-3-hydroxy-5-methyl-4-isoxazolepropionic acid). 


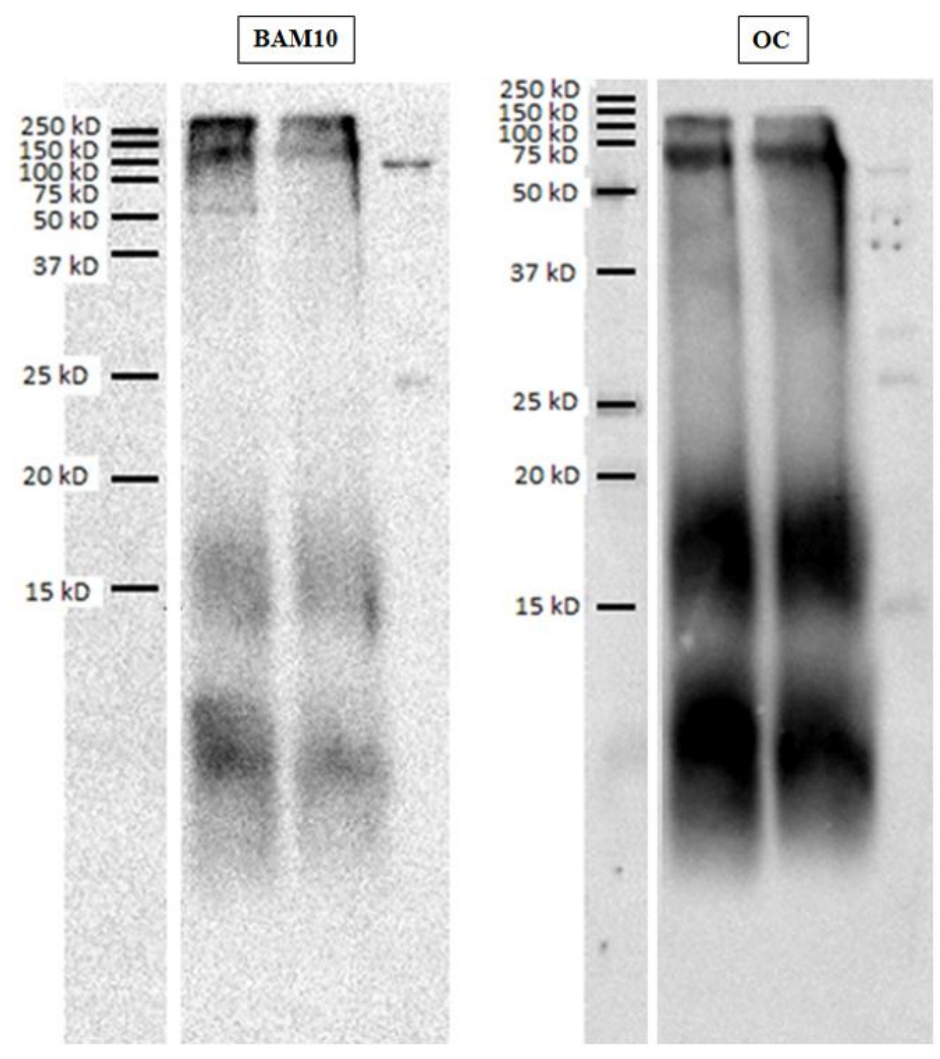

Supplementary Figure 3. Abeta(1-42) samples used for the recordings contained clearly detectable SDSstable trimers $(\approx 15 \mathrm{kDa})$ and higher molecular weight protofibrils. Staining with OC antibody, which is specific for species having beta-sheet conformation, shows that the small low-n oligomers are of prefibrillar nature. Abbreviation: Abeta(1-42) (amyloid-beta(1-42)). 


\section{XIII.APPENDIX}




\title{
Amyloid- $\beta_{1-42}$ Disrupts Synaptic Plasticity by Altering Glutamate Recycling at the Synapse
}

\author{
Edina Varga ${ }^{\mathrm{a}}$, Gábor Juhász ${ }^{\mathrm{a}}$, Zsolt Bozsóa ${ }^{\mathrm{a}}$, Botond Penke ${ }^{\mathrm{a}}$, Livia Fülöp ${ }^{\mathrm{a}}$ and Viktor Szegedi ${ }^{\mathrm{b}, *}$ \\ ${ }^{a}$ Department of Medical Chemistry, University of Szeged, Szeged, Hungary \\ ${ }^{\mathrm{b}}$ Biological Research Centre, Hungarian Academy of Sciences, Szeged, Hungary
}

Accepted 7 December 2014

\begin{abstract}
Alzheimer's disease (AD) is the most prevalent form of neurodegenerative disorders characterized by neuritic plaques containing amyloid- $\beta$ peptide $(A \beta)$ and neurofibrillary tangles. Evidence has been reported that $A \beta_{1-42}$ plays an essential pathogenic role in decreased spine density, impairment of synaptic plasticity, and neuronal loss with disruption of memoryrelated synapse function, all associated with $\mathrm{AD}$. Experimentally, $A \beta_{1-42}$ oligomers perturb hippocampal long-term potentiation (LTP), an electrophysiological correlate of learning and memory. A $\beta$ was also reported to perturb synaptic glutamate (Glu)recycling by inhibiting excitatory-amino-acid-transporters. Elevated level of extracellular Glu leads to activation of perisynaptic receptors, including NR2B subunit containing NMDARs. These receptors were shown to induce impaired LTP and enhanced long-term depression and proapoptotic pathways, all central features of $\mathrm{AD}$. In the present study, we investigated the role of Glu-recycling on $A \beta_{1-42}$-induced LTP deficit in the CA1. We found that $A \beta$-induced LTP damage, which was mimicked by the Glu-reuptake inhibitor TBOA, could be rescued by blocking the NR2B subunit of NMDA receptors. Furthermore, decreasing the level of extracellular Glu using a Glu scavenger also restores TBOA or A $\beta$ induces LTP damage. Overall, these results suggest that reducing ambient Glu in the brain can be protective against $A \beta$-induced synaptic disruption.
\end{abstract}

Keywords: Alzheimer's disease, glutamate scavenger, glutamate-reuptake, long-term potentiation, NR2B, TBOA

\section{INTRODUCTION}

Amyloid- $\beta$ (A $\beta)$, a misfolded peptide, is widely regarded as a central player in the pathogenesis of Alzheimer's disease (AD). The accumulation of soluble $A \beta$ [1] in the brain of patients and animal models of $\mathrm{AD}$ is associated with impairments of cognition and memory [2-4]. In addition, both the synthetic and brain-derived soluble $A \beta$ have been shown to damage certain forms of synaptic plasticity, correlates of learning and memory [5,6]. Despite intense research, the mechanisms involved in $A \beta$-mediated neuronal degeneration and dysfunction are not well understood.

${ }^{*}$ Correspondence to: Viktor Szegedi, PhD., Biological Research Center - Biochemistry, Temesvari krt. 32, Szeged H-6726, Hungary. Tel.: +36 70 2418260; E-mail: szegedi.viktor@brc.mta.hu.
The hippocampus is especially affected in $\mathrm{AD}$ including hippocampal-dependent cognitive abilities such as learning and memory. Long-term potentiation (LTP), a form of synaptic plasticity in the CA1 field of the hippocampus, is impaired in animal models of AD. Numerous studies reported that $A \beta_{1-42}$ oligomers block hippocampal LTP ex vivo [7-9] and in vivo $[10,11]$.

Although the increased neuronal excitability caused by $A \beta$ seems to contribute to and to be a key part of the pathomechanism of $\mathrm{AD}$, the exact mechanisms by which neuronal over-activity develops is unknown. Glutamate (Glu) excitotoxicity has been established to have a major role in $\mathrm{AD}$ pathogenesis; however, how $A \beta$ induces its effects is poorly understood. Numerous findings confirmed that excitotoxic effects of Glu contribute to progressive neuronal loss in AD [12-14]. Inhibited excitatory-amino-acid-transporters 
(EAATs) may be a central player in this mechanism, and indeed, recent findings suggest that $A \beta$ oligomers perturb synaptic plasticity by altering Glu-recycling at the synapse $[15,16]$, resulting in elevated ambient extracellular Glu-level in the brain $[17,18]$, which might be responsible for the overexcitation seen in AD. A $\beta$ blocks Glu-reuptake by inhibiting both neuronal and glial Glu transporters [16, 19], which might lead to extrasynaptic NMDAR (esyn NMDAR) activation. Esyn NMDAR activation causes inhibited LTP [5], enhanced long-term depression (LTD) [20], and apoptosis [21].

The aim of this study was to confirm that $A \beta$ causes synaptic Glu-spillover and esyn NMDAR activation, which leads to impaired synaptic plasticity in the CA1. We show that blocking Glu-reuptake with TBOA also impairs LTP, and both TBOA- and A $\beta$-induced synaptic damage could be rescued by blocking NR2B subunit. Moreover, reducing the level of extracellular Glu by applying a glutamate-scavenger enzyme GPT also provides protection against impaired synaptic plasticity by TBOA and $A \beta$.

\section{MATERIALS AND METHODS}

\section{Compounds}

For the preparation of artificial cerebrospinal fluid (ACSF), all salts, glucose, sodium pyruvate (Pyr), glutamic-pyruvic transaminase (GPT), DL-threo- $\beta$-benzyloxyaspartate (TBOA), and $\alpha$-(4Hydroxyphenyl)- $\beta$-methyl-4- benzyl-1-piperidineethanol (+)-tartrate salt (ifenprodil) were purchased from Sigma-Aldrich (St. Louis, MO). $A \beta_{1-42}$ was synthetized at the Department of Medical Chemistry University of Szeged, Hungary. Detailed description of the synthesis and characterization of $A \beta_{1-42}$ is reported in [7].

\section{Animals}

The study conformed to EU Directive 2010/63/EU and was approved by the regional Station for Animal Health and Food Control under Project License $\mathrm{XVI} / 8 / 2013$. BALB/c mice were housed in groups of 2-3 under standard conditions $\left(24^{\circ} \mathrm{C}, 12\right.$-h light-dark cycle) with food and water available ad libitum.

\section{Ex vivo electrophysiology}

Hippocampal slices of $400 \mu \mathrm{m}$ in thickness were prepared from the brains of 3-month old mice using a standard protocol [22]. Briefly, slices were incubated in ACSF gassed with $95 \% \mathrm{O}_{2}, 5 \% \mathrm{CO}_{2}$ at $35^{\circ} \mathrm{C}$ for $60 \mathrm{~min}$. ACSF was composed of (in $\mathrm{mM}$ ) 130 $\mathrm{NaCl}, 3.5 \mathrm{KCl}, 3 \mathrm{CaCl}_{2}, 1.5 \mathrm{MgSO}_{4}, 0.96 \mathrm{NaH}_{2} \mathrm{PO}_{4}$, $24 \mathrm{NaHCO}_{3}$, and $10 \mathrm{D}$-glucose, $\mathrm{pH}$ 7.4. Individual slices were transferred to a 3D-MEA chip with 60 tipshaped and $60 \mu \mathrm{m}$ high electrodes spaced by $200 \mu \mathrm{m}$ (Qwane Biosciences, Lausanne, Switzerland). The surrounding solution was quickly removed, and the slice was immobilized by placing a grid onto it. The slice was continuously perfused with oxygenated ACSF $\left(3 \mathrm{ml} / \mathrm{min}\right.$ at $\left.36^{\circ} \mathrm{C}\right)$ throughout the entire recording session. Unfiltered data were recorded using a standard, commercially available MEA 60 setup (Multi Channel Systems MCS GmbH, Reutlingen, Germany). Field excitatory postsynaptic potentials (fEPSPs) were recorded from the proximal stratum radiatum at $5 \mathrm{kHz}$.

\section{Stimulation protocol}

The Schaffer-collateral was stimulated by injecting a biphasic voltage waveform $(-100 /+100 \mu \mathrm{s})$ through one selected electrode at $0.033 \mathrm{~Hz}$. Care was taken to place the stimulating electrode in the same region at every slice. The peak-to-peak amplitudes of fEPSPs at the proximal stratum radiatum of CA1 were analyzed. After a 30-min incubation period, the threshold and maximum stimulation intensities for evoked responses were determined. To evoke responses, $30 \%$ of the maximal stimulation intensity was used. LTP was evoked by theta-burst stimulation (TBS). TBS comprised of 15 bursts given at $5 \mathrm{~Hz}$ and individual burst contained 4 pulses given at $100 \mathrm{~Hz}$ per burst. The level of LTP was compared to the average of the last 10 peak-to-peak amplitudes of evoked fEPSPs before TBS.

\section{Drug treatments}

After 10-min control level, slices were treated with $1 \mu \mathrm{M} \mathrm{A} \beta_{1-42}$ or $5 \mu \mathrm{M}$ TBOA for 60 -min before LTP was induced. Other cohort of slices was treated with $3 \mu \mathrm{M}$ ifenprodil or $0.82 \mathrm{mM}$ Pyr for $10-\mathrm{min}$ then 2.06 $\mathrm{U} / \mathrm{ml}$ GPT for 60 -min before LTP induction. Separate groups of slices were treated with these compounds together with $A \beta_{1-42}$ or TBOA.

\section{Statistics}

Statistical significance was determined by using ANOVA on ranks test with the post hoc Dunn's method (SigmaPlot 11 software package). The $p$ value $\leq 0.05$ was considered significant in all cases. 


\section{RESULTS}

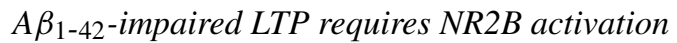

We recorded fEPSPs from the stratum radiatum of the CA1 using MEA electrodes. The peak-to-peak amplitudes of fEPSPs were analyzed from the proximal part of stratum radiatum.

First, we verified the effect of $A \beta_{1-42}$ preparation on LTP in the hippocampal slices. Untreated slices showed a persistent elevated level of fEPSPs after LTP induction $(168.33 \pm 5.58 \%, n=12)$, while $A \beta_{1-42}$ reduced the magnitude of LTP $(124.35 \pm 4.88 \%, n=9$, $p<0.05$, nonparametric ANOVA, Dunn post-hoc test; Fig. 1). Several recent studies suggested that different NR2 subunits of NMDARs may have divergent roles in NMDAR-dependent LTP activation and A $\beta$ pathology (see discussion). To test whether LTP acti- vation requires NR2B-containing NMDARs function, slices were treated with an NR2B antagonist, ifenprodil. We observed that ifenprodil did not alter the level of LTP compared to control $(176.81 \pm 4.93 \%$, $n=5$ ), suggesting that NR2B-activation is not required for LTP in the CA1. Furthermore, ifenprodil prevents the $\mathrm{A} \beta_{1-42}$ effect on LTP $(166.03 \pm 12.38 \%, n=5$, $p<0.05$, ANOVA on ranks, Dunn post-hoc test; Fig. 1), suggesting $A \beta_{1-42}$ induce LTP damage is via NR2Bcontaining NMDARs. None of the applied compounds altered the amplitude of fEPSPs during the wash-in period.

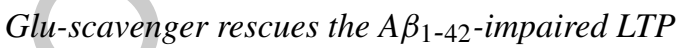

To determine whether $A \beta_{1-42}$ affects Glu-reuptake, we used an enzymatic Glu-scavenger system to reduce extracellular Glu-levels. Slices were treated

\section{UNTREATED}

\section{IFENPRODIL}
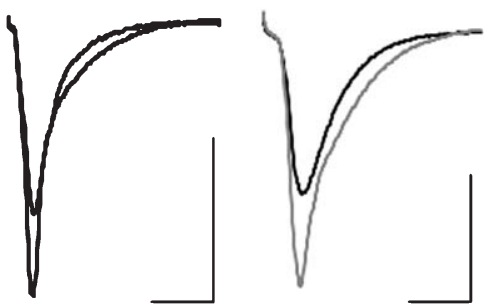

A

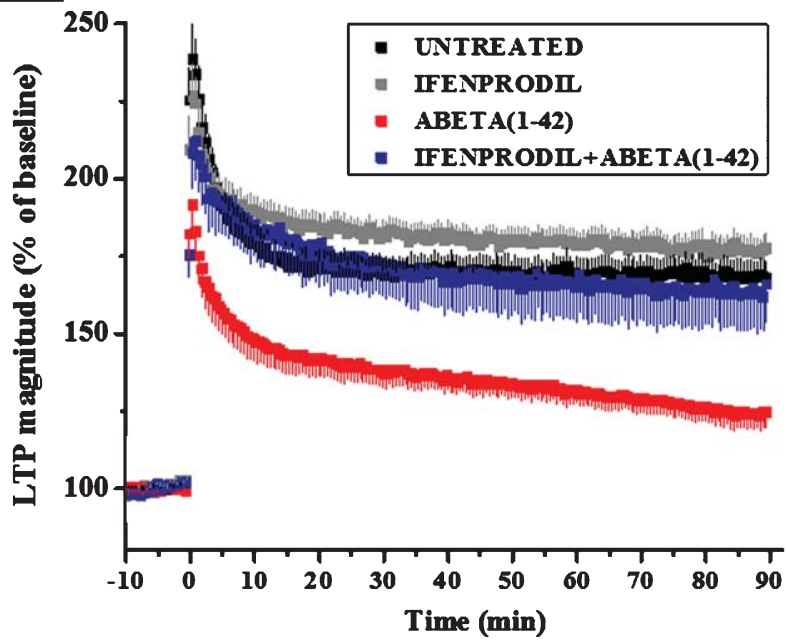

\section{IFENPRODIL}

+ABETA(1-42)

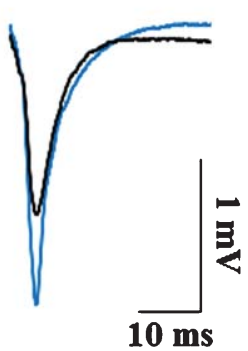

B

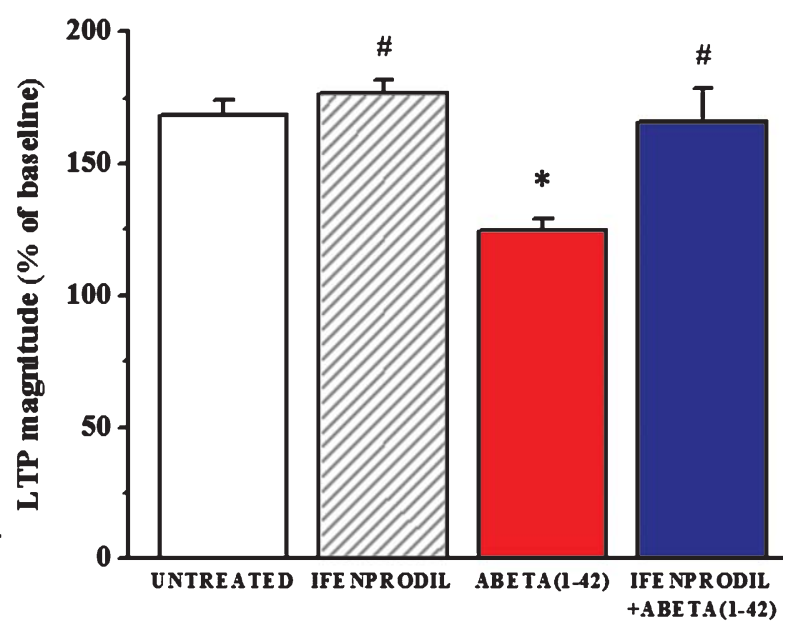

Fig. 1. Blocking NR2B subunit prevents $A \beta_{1-42}$-induced LTP damage. Insets show representative fEPSPs before (black) and after treatment. LTP was altered in $A \beta_{1-42}$ treated slices compared to untreated group (untreated versus $A \beta_{1-42}:{ }^{*} p<0.05$; ANOVA on ranks, Dunn post-hoc test). Ifenprodil did not change the level of LTP, however, it rescued the $\mathrm{A} \beta_{1-42}$-impaired LTP. Error bars represent SEM; ${ }^{\#} p<0.05$ versus $\mathrm{A} \beta_{1-42}$. 


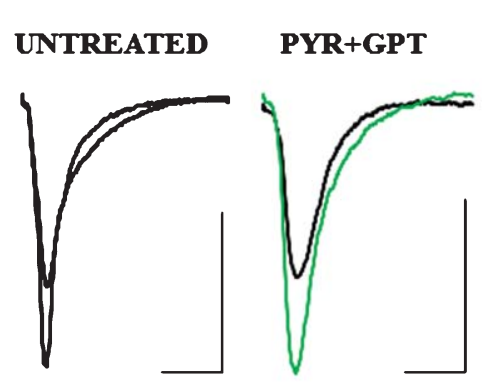

A

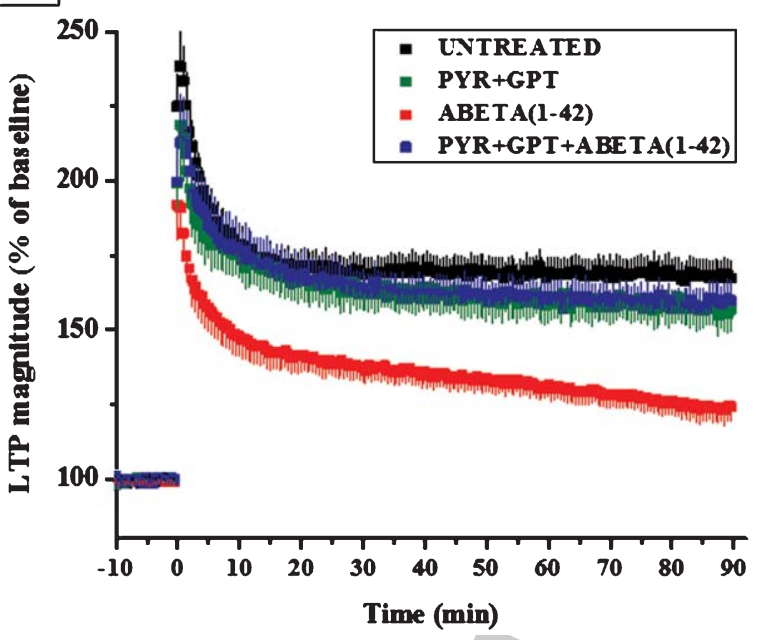

PYR+GPT

ABETA(1-42) +ABETA(1-42)
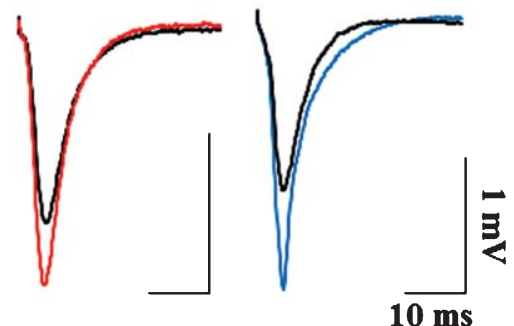

B

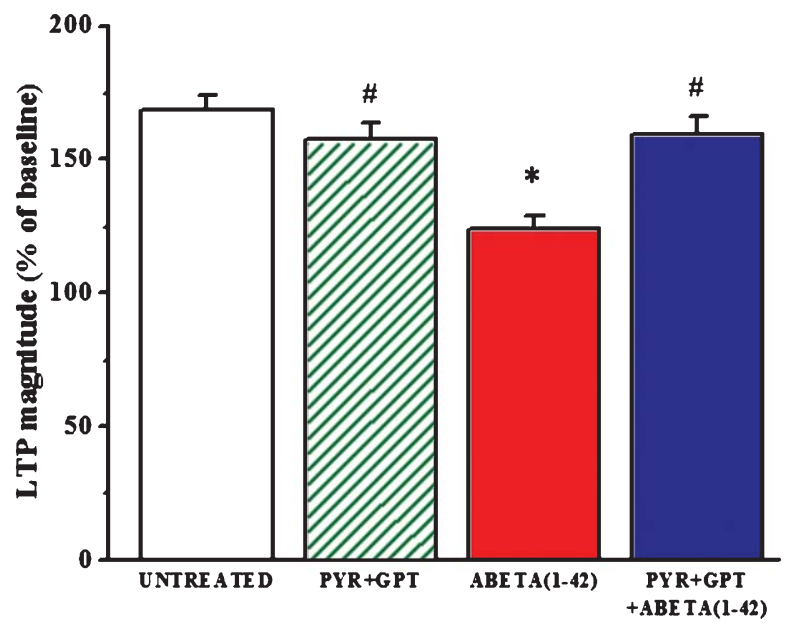

Fig. 2. Glu-scavenger restores $A \beta_{1-42}$-induced LTP damage. Insets show representative fEPSPs before (black) and after treatment. Pyr+GPT treatment did not affect the level of LTP compared to untreated slices, however A $\beta_{1-42}$ induced LTP impairment was prevented by Gluscavenger $\left(\mathrm{A} \beta_{1-42}\right.$ versus Pyr+GPT+A $\beta_{1-42}:{ }^{\#} p<0.05$; ANOVA on ranks, Dunn post-hoc test). Error bars represent SEM; ${ }^{*} p<0.05$ versus untreated; ${ }^{\#} p<0.05$ versus $\mathrm{A} \beta_{1-42}$.

with GPT and its substrate, Pyr for $10 \mathrm{~min}$ followed by $A \beta_{1-42}$ for $60 \mathrm{~min}$, then LTP was induced. We have found that Pyr+GPT treatment does not affect the level of LTP compared to control slices (157.32 $\pm 6.68 \%, n=5$; Fig. 2). However, $A \beta_{1-42-}$ induced LTP damage was prevented by Glu-scavenger $\left(\mathrm{Pyr}+\mathrm{GPT}+\mathrm{A} \beta_{1-42}: \quad 159.66 \pm 6.37 \%, \quad n=5 \quad\right.$ versus $\mathrm{A} \beta_{1-42}, p<0.05$, ANOVA on ranks, Dunn post-hoc test; Fig. 2).

The effect of $A \beta_{1-42}$ is mimicked by TBOA, a Glu-reuptake inhibitor

TBOA was applied for 60 min before LTP induction. LTP was impaired by TBOA compared to untreated slice $(123.22 \pm 3.48 \%, n=6, p<0.05$; ANOVA on ranks, Dunn post-hoc test, Fig. 3). Next, we tested whether NR2B subunit activation is required for the effect of TBOA. We have found that ifenprodil prevents TBOA-induced LTP damage suggesting NR2B subunit activation is essential for the effect of TBOA on LTP (ifenprodil+TBOA: $159.29 \pm 10.67 \%$, $n=4$ versus TBOA: $p<0.05$; ANOVA on ranks, Dunn post-hoc test, Fig. 3). We proceeded to apply Gluscavenger to test whether the inhibitory effect of TBOA was due to the elevated extracellular Glu-level. Indeed, TBOA-failed to impair LTP after Glu-scavenger treatment (Pyr+GPT+TBOA: $169.28 \pm 8.18, n=5$ versus TBOA, $p<0.05$; ANOVA on ranks, Dunn post-hoc test, Fig. 4). Collectively these results suggest that TBOA and $A \beta$ share common pathway in synaptotoxicity. The effect of $A \beta_{1-42}$ is mimicked by Glu-reuptake inhibition; however both could be prevented by a Gluscavenger and NR2B inhibition suggesting that $A \beta_{1-42}$ disrupts synaptic plasticity by altering Glu-recycling at the synapse in the CA1. Again, none of the applied compounds altered fEPSP amplitude during the washin period. 


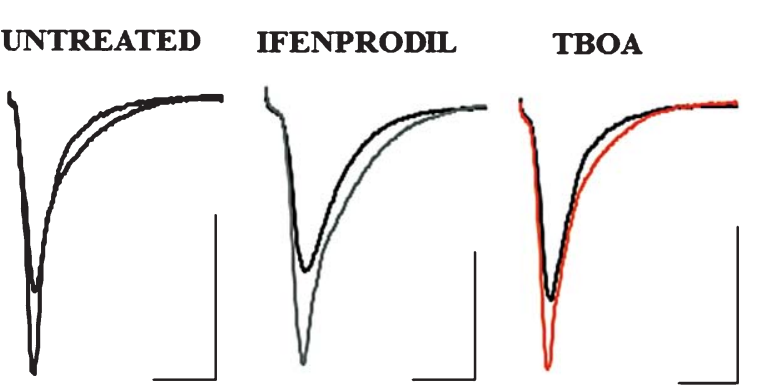

A

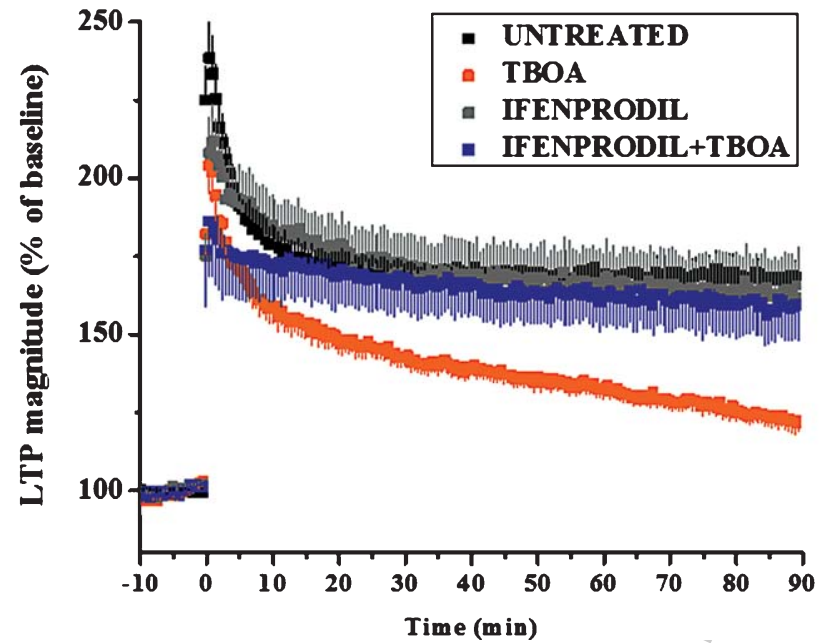

IFENPRODIL + TBOA

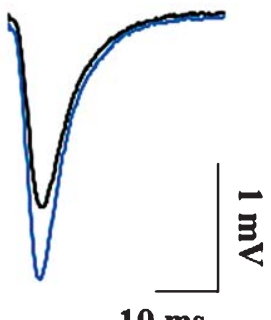

$10 \mathrm{~ms}$

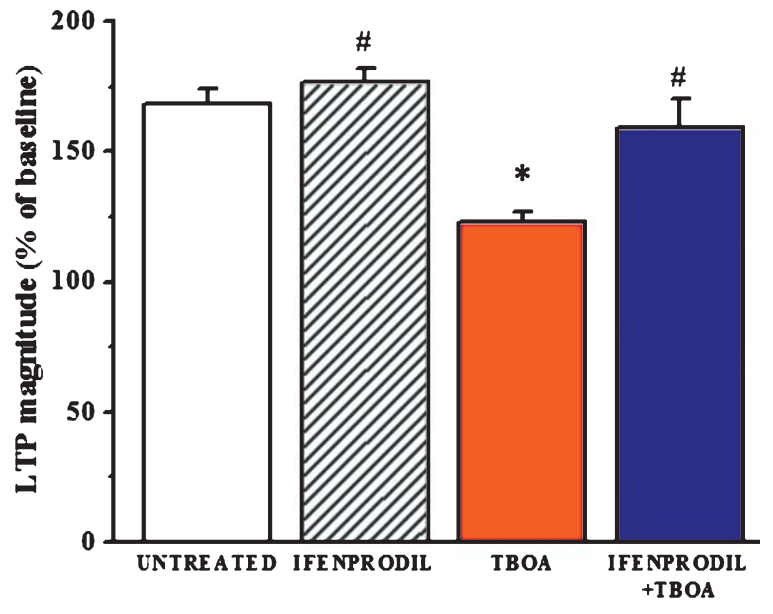

Fig. 3. Ifenprodil prevents TBOA-impaired LTP. Insets show representative fEPSPs before (black) and after treatment. LTP was impaired by TBOA compared to untreated group (untreated versus TBOA: ${ }^{*} p<0.05$; ANOVA on ranks, Dunn post-hoc test), however TBOA-induced LTP impairment was restored by ifenprodil (TBOA versus ifenprodil+TBOA: ${ }^{\#} p<0.05$; ANOVA on ranks, Dunn post-hoc test). Error bars represent SEM; ${ }^{*} p<0.05$ versus untreated; ${ }^{\#} p<0.05$ versus TBOA.

\section{DISCUSSION}

There is growing evidence that soluble $A \beta$ oligomers mediate synaptic impairment in $\mathrm{AD}$, but the exact mechanism of synaptotoxicity remains to be determined. Numerous studies have reported that $A \beta$ can affect the function of NMDARs [23-27], which may lead to excitotoxicity and neuronal hyperactivation seen in the early stage of AD. Recent findings suggest that $A \beta$ binds to prion protein, metabotropic Glu receptor 5, and integrin receptors, and this complex initiates a molecular cascade mediated by fyn kinase [28-30], which subsequently phosphorylates NMDARs.

An additional pathway of $A \beta$-mediated hyperexcitation could be, however, that the concentration of extracellular Glu is increased by $A \beta$. We have shown previously, that the excitatory effect of $A \beta$, as was determined by the rate of spontaneous spiking in hippocampal slices, is mediated by extrasynaptic NMDARs [22]. In the present study, we show that $A \beta$ causes Glu spillover and subsequent esyn NMDAR activation, which could be prevented by either NR2B blockade or by "mopping-up" Glu with a Glu-scavenger enzyme.

\section{TBOA mimics the effects of $A \beta$}

$\mathrm{A} \beta$ has been shown to elevate extracellular Glu concentration in the brain without altering gammaaminobutyric acid (GABA) level [18]. The mechanism behind this is probably the inhibition of the transporters mediating Glu-clearance. The level of brain extracellular Glu is regulated by EAATs expressed mainly on the astrocytes, which efficiently remove the excess of this neurotransmitter from the synaptic 


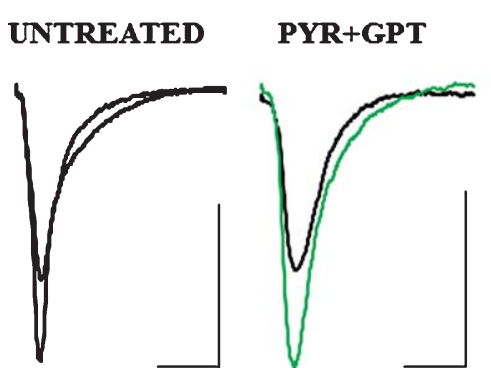

A

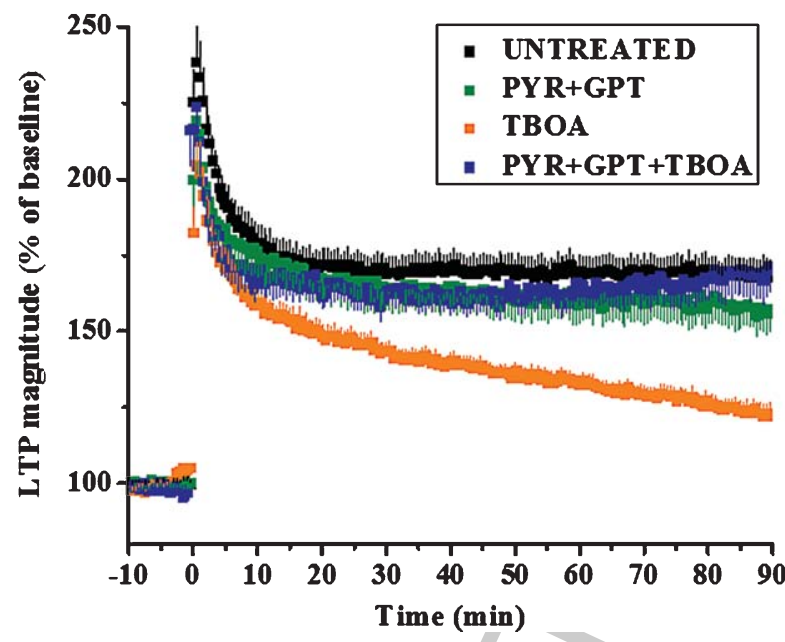

PYR+GPT

+ TBOA

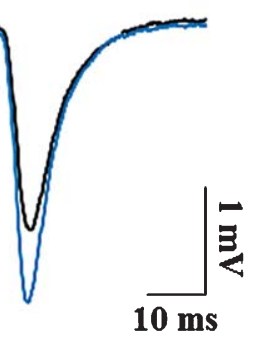

Fig. 4. Glu-scavenger prevents TBOA-induced LTP damage. Insets show representative fEPSPs before (black) and after treatment. TBOAinduced LTP impairment was restored by Glu-scavenger (TBOA versus Pyr+GPT+TBOA: ${ }^{\#} p<0.05$; ANOVA on ranks, Dunn post-hoc test). Error bars represent SEM; ${ }^{*} p<0.05$ versus untreated; ${ }^{\#} p<0.05$ versus TBOA.

cleft (reviewed by [31]). Indeed, $A \beta$ was shown to inhibit both glial and neuronal EAATs [16, 17, 32]. Moreover, Noda and coworkers have reported that A $\beta$ may even cause reverse functioning of EAAT, leading to Glu-release from glial cells [33]. Furthermore, down-regulation or abnormal expression and protein levels of EAAT1 and EAAT2 are altered in the hippocampus and frontal cortex of AD patients $[34,35]$ and in amyloid- $\beta$ protein precursor transgenic mice [32], further supporting that Glu-level regulation fails during AD pathomechanism. These effects may lead to Glu-spillover from the synapses and subsequent activation of esyn receptors. Of particular interest here, esyn NMDARs containing mainly NR2B subunit were shown to activate apoptotic pathways and promote synaptic depression [21]. In contrast, NR2A subunit-containing NMDARs localized mainly at the synaptic domain are antiapoptotic and participate in the induction of LTP in the CA1. We previ- ously reported that $A \beta_{1-42}$ induces hyperexcitability via NR2B-containing NMDARs [22]. Indeed, blocking selectively NR2B subunits protected against $A \beta$ effects (including LTP impairment), suggesting that NR2B could be a promising target against AD [5, 8 , 9, 36, 37]. Tackenberg et al. also suggest that esyn NR2B-containing NMDARs activation is essential for tau-dependent neurodegeneration [26]. It was also shown that the opposite form of synaptic plasticity, LTD requires both syn and esyn receptor activation [20], while LTP is not mediated by esyn NMDARs [8, 9]. It should be noted, however, that contradictory data is available on the role of NR2B NMDARs on LTP: esyn NDMARs are also recruited to the synapse during LTP [38] and may play an essential role in LTP maintenance $[39,40]$.

Our results extend this line of research by showing that reducing Glu that has been spilled-over from the synapse with a Glu-scavenger enzyme also prevents 
A $\beta$ induced LTP impairment. Moreover, we show that blocking EAATs by a selective inhibitor, TBOA, mimics the effects of $A \beta$ : both compounds impair LTP, and this could be prevented by ifenprodil or GPT (Gluscavenger).

Reducing ambient Glu in the brain is protective against $A \beta$ induced LTD enhancement [16]. A recent paper by Chen and Herrup makes the suggestion that although the level of glutamine-synthase is elevated in AD brains, its activity is severely compromised by oxidative damage, leading to impaired Glu-metabolism [41].

$A \beta$ and Glu-toxicity mediated dysfunction has been closely associated; however, decreasing the extracellular Glu-level can be protective in other conditions such as brain ischemia [42], stroke [43], traumatic brain injury [44] or certain psychiatric disorders [45, 46].

\section{CONCLUSIONS}

Collectively, our results provide evidence that $A \beta$ impair Glu-recycling at the synapse, which leads to Glu-spillover and NR2B activation. Blocking NR2B or decreasing extracellular Glu offers protection against the synaptic plasticity impairment caused by $A \beta$.

\section{ACKNOWLEDGMENTS}

This study was supported by the following grants: OTKA PD 83581 from the Hungarian National Scientific Fund, TÁMOP-4.2.2.A-11/1/KONV-2012-0052 from the National.

Development Agency (NFÜ) and FP7-PEOPLE2012-IAPP “STEMMAD”. V.S. is a Bolyai fellow. E.V. is supported by a predoctorial grant from Gedeon Richter Plc.

Authors' disclosures available online (http://jalz.com/manuscript-disclosures/14-2367r2).

\section{REFERENCES}

[1] Kuo YM, Emmerling MR, Vigo-Pelfrey C, Kasunic TC, Kirkpatrick JB, Murdoch GH, Ball MJ, Roher AE (1996) Water-soluble Abeta (N-40, N-42) oligomers in normal and Alzheimer disease brains. J Biol Chem 271, 4077-4081.

[2] Lue LF, Kuo YM, Roher AE, Brachova L, Shen Y, Sue L, Beach T, Kurth JH, Rydel RE, Rogers J (1999) Soluble amyloid beta peptide concentration as a predictor of synaptic change in Alzheimer's disease. Am J Pathol 155, 853-862.

[3] Rowan MJ, Klyubin I, Cullen WK, Anwyl R (2003) Synaptic plasticity in animal models of early Alzheimer's disease. Philos Trans R Soc Lond B Biol Sci 358, 821-828.

[4] Walsh DM, Klyubin I, Fadeeva JV, Cullen WK, Anwyl R, Wolfe MS, Rowan MJ, Selkoe DJ (2002) Naturally secreted oligomers of amyloid beta protein potently inhibit hippocampal long-term potentiation in vivo. Nature 416, 535-539.

[5] Li S, Jin M, Koeglsperger T, Shepardson NE, Shankar GM, Selkoe DJ (2011) Soluble Abeta oligomers inhibit long-term potentiation through a mechanism involving excessive activation of extrasynaptic NR2B-containing NMDA receptors. J Neurosci 31, 6627-6638.

[6] Fulop L, Mandity IM, Juhasz G, Szegedi V, Hetenyi A, Weber E, Bozso Z, Simon D, Benko M, Kiraly Z, Martinek TA (2012) A foldamer-dendrimer conjugate neutralizes synaptotoxic beta-amyloid oligomers. PLoS One 7, e39485.

[7] Bozso Z, Penke B, Simon D, Laczko I, Juhasz G, Szegedi V, Kasza A, Soos K, Hetenyi A, Weber E, Tohati H, Csete M, Zarandi M, Fulop L (2010) Controlled in situ preparation of A beta(1-42) oligomers from the isopeptide "iso-A beta(1-42)", physicochemical and biological characterization. Peptides 31, 248-256.

[8] Hu NW, Klyubin I, Anwyl R, Rowan MJ (2009) GluN2B subunit-containing NMDA receptor antagonists prevent Abeta-mediated synaptic plasticity disruption in vivo. Proc Natl Acad Sci U S A 106, 20504-20509.

[9] Zhang J, Wang C, Deng T, Xue Z, Chen X, Chang L, Wang Q (2013) The preventive effect of NR2B and NR2D-containing NMDAR antagonists on Abeta-induced LTP disruption in the dentate gyrus of rats. Metab Brain Dis 28, 697-704.

[10] Klyubin I, Betts V, Welzel AT, Blennow K, Zetterberg H, Wallin A, Lemere CA, Cullen WK, Peng Y, Wisniewski T, Selkoe DJ, Anwyl R, Walsh DM, Rowan MJ (2008) Amyloid beta protein dimer-containing human CSF disrupts synaptic plasticity: Prevention by systemic passive immunization. J Neurosci 28, 4231-4237.

[11] Olsen KM, Sheng M (2012) NMDA receptors and BAX are essential for Abeta impairment of LTP. Sci Rep 2, 225.

[12] Koh JY, Yang LL, Cotman CW (1990) Beta-amyloid protein increases the vulnerability of cultured cortical neurons to excitotoxic damage. Brain Res 533, 315-320.

[13] Pomara N, Singh R, Deptula D, Chou JC, Schwartz MB, LeWitt PA (1992) Glutamate and other CSF amino acids in Alzheimer's disease. Am J Psychiatry 149, 251-254.

[14] Harkany T, Abraham I, Timmerman W, Laskay G, Toth B, Sasvari M, Konya C, Sebens JB, Korf J, Nyakas C, Zarandi M, Soos K, Penke B, Luiten PG (2000) beta-amyloid neurotoxicity is mediated by a glutamate-triggered excitotoxic cascade in rat nucleus basalis. Eur J Neurosci 12, 2735-2745.

[15] Chen KH, Reese EA, Kim HW, Rapoport SI, Rao JS (2011) Disturbed neurotransmitter transporter expression in Alzheimer's disease brain. J Alzheimers Dis 26, 755-766.

[16] Li S, Hong S, Shepardson NE, Walsh DM, Shankar GM, Selkoe D (2009) Soluble oligomers of amyloid Beta protein facilitate hippocampal long-term depression by disrupting neuronal glutamate uptake. Neuron 62, 788-801.

[17] Matos M, Augusto E, Oliveira CR, Agostinho P (2008) Amyloid-beta peptide decreases glutamate uptake in cultured astrocytes: Involvement of oxidative stress and mitogen-activated protein kinase cascades. Neuroscience 156, 898-910.

[18] Mura E, Zappettini S, Preda S, Biundo F, Lanni C, Grilli M, Cavallero A, Olivero G, Salamone A, Govoni S, Marchi M (2012) Dual effect of beta-amyloid on alpha7 and alpha4beta2 nicotinic receptors controlling the release of glutamate, aspartate and GABA in rat hippocampus. PLoS One 7, e29661.

[19] Matos M, Augusto E, Machado NJ, dos Santos-Rodrigues A, Cunha RA, Agostinho P (2012) Astrocytic adenosine A2A receptors control the amyloid-beta peptide-induced decrease of glutamate uptake. J Alzheimers Dis 31, 555-567. 
[20] Liu DD, Yang Q, Li ST (2013) Activation of extrasynaptic NMDA receptors induces LTD in rat hippocampal CA1 neurons. Brain Res Bull 93, 10-16.

[21] Hardingham GE, Fukunaga Y, Bading H (2002) Extrasynaptic NMDARs oppose synaptic NMDARs by triggering CREB shut-off and cell death pathways. Nat Neurosci 5, 405-414.

[22] Varga E, Juhász G, Bozsó Z, Penke B, Fülöp L, Szegedi V (2014) Abeta(1-42) enhances neuronal excitability in the CA1 via NR2B subunit-containing NMDA receptors. Neural Plast 2014, 584314.

[23] Juhasz G, Marki A, Vass G, Fulop L, Budai D, Penke B, Falkay G, Szegedi V (2009) An intraperitoneally administered pentapeptide protects against Abeta (1-42) induced neuronal excitation in vivo. J Alzheimers Dis 16, 189-196.

[24] Xu Y, Cao DH, Wu GM, Hou XY (2014) Involvement of P38MAPK activation by NMDA receptors and non-NMDA receptors in amyloid-beta peptide-induced neuronal loss in rat hippocampal CA1 and CA3 subfields. Neurosci Res $\mathbf{8 5}$, 51-57.

[25] Dinamarca MC, Rios JA, Inestrosa NC (2012) Postsynaptic receptors for amyloid-beta oligomers as mediators of neuronal damage in Alzheimer's disease. Front Physiol 3, 464.

[26] Tackenberg C, Grinschgl S, Trutzel A, Santuccione AC, Frey MC, Konietzko U, Grimm J, Brandt R, Nitsch RM (2013) NMDA receptor subunit composition determines betaamyloid-induced neurodegeneration and synaptic loss. Cell Death Dis 4, e608.

[27] Shankar GM, Bloodgood BL, Townsend M, Walsh DM, Selkoe DJ, Sabatini BL (2007) Natural oligomers of the Alzheimer amyloid-beta protein induce reversible synapse loss by modulating an NMDA-type glutamate receptordependent signaling pathway. J Neurosci 27, 2866-2875.

[28] Larson M, Sherman MA, Amar F, Nuvolone M, Schneider JA, Bennett DA, Aguzzi A, Lesne SE (2012) The complex $\operatorname{PrP}(\mathrm{c})$-Fyn couples human oligomeric Abeta with pathological tau changes in Alzheimer's disease. J Neurosci 32, 16857-16871a.

[29] Um JW, Kaufman AC, Kostylev M, Heiss JK, Stagi M, Takahashi H, Kerrisk ME, Vortmeyer A, Wisniewski T, Koleske AJ, Gunther EC, Nygaard HB, Strittmatter SM (2013) Metabotropic glutamate receptor 5 is a coreceptor for Alzheimer abeta oligomer bound to cellular prion protein. Neuron 79, 887-902.

[30] Um JW, Nygaard HB, Heiss JK, Kostylev MA, Stagi M, Vortmeyer A, Wisniewski T, Gunther EC, Strittmatter SM (2012) Alzheimer amyloid-beta oligomer bound to postsynaptic prion protein activates Fyn to impair neurons. Nat Neurosci 15, 1227-1235.

[31] Anderson CM, Swanson RA (2000) Astrocyte glutamate transport: Review of properties, regulation, and physiological functions. Glia 32, 1-14.

[32] Masliah E, Alford M, Mallory M, Rockenstein E, Moechars D, Van Leuven F (2000) Abnormal glutamate transport function in mutant amyloid precursor protein transgenic mice. Exp Neurol 163, 381-387.

[33] Noda M, Nakanishi H, Akaike N (1999) Glutamate release from microglia via glutamate transporter is enhanced by amyloid-beta peptide. Neuroscience 92, 1465-1474.

[34] Jacob CP, Koutsilieri E, Bartl J, Neuen-Jacob E, Arzberger T, Zander N, Ravid R, Roggendorf W, Riederer P, Grunblatt E
(2007) Alterations in expression of glutamatergic transporters and receptors in sporadic Alzheimer's disease. J Alzheimers Dis 11, 97-116.

[35] Scott HL, Pow DV, Tannenberg AE, Dodd PR (2002) Aberrant expression of the glutamate transporter excitatory amino acid transporter 1 (EAAT1) in Alzheimer's disease. J Neurosci 22, RC206.

[36] Rammes G, Hasenjager A, Sroka-Saidi K, Deussing JM, Parsons CG (2011) Therapeutic significance of NR2B-containing NMDA receptors and mGluR5 metabotropic glutamate receptors in mediating the synaptotoxic effects of beta-amyloid oligomers on long-term potentiation (LTP) in murine hippocampal slices. Neuropharmacology 60, 982-990.

[37] Ronicke R, Mikhaylova M, Ronicke S, Meinhardt J, Schroder UH, Fandrich M, Reiser G, Kreutz MR, Reymann KG (2011) Early neuronal dysfunction by amyloid beta oligomers depends on activation of NR2B-containing NMDA receptors. Neurobiol Aging 32, 2219-2228.

[38] Harney SC, Jane DE, Anwyl R (2008) Extrasynaptic NR2Dcontaining NMDARs are recruited to the synapse during LTP of NMDAR-EPSCs. J Neurosci 28, 11685-11694.

[39] Foster KA, McLaughlin N, Edbauer D, Phillips M, Bolton A, Constantine-Paton M, Sheng M (2010) Distinct roles of NR2A and NR2B cytoplasmic tails in long-term potentiation. J Neurosci 30, 2676-2685.

[40] Hasegawa Y, Mukai H, Asashima M, Hojo Y, Ikeda M, Komatsuzaki Y, Ooishi Y, Kawato S (2014) Acute modulation of synaptic plasticity of pyramidal neurons by activin in adult hippocampus. Front Neural Circuit 8, 56.

[41] Chen J, Herrup K (2012) Glutamine acts as a neuroprotectant against DNA damage, beta-amyloid and $\mathrm{H} 2 \mathrm{O} 2$-induced stress. PLoS One 7, e33177.

[42] Marosi M, Fuzik J, Nagy D, Rakos G, Kis Z, Vecsei L, Toldi J, Ruban-Matuzani A, Teichberg VI, Farkas T (2009) Oxaloacetate restores the long-term potentiation impaired in rat hippocampus CA1 region by 2 -vessel occlusion. Eur $J$ Pharmacol 604, 51-57.

[43] Campos F, Sobrino T, Ramos-Cabrer P, Argibay B, Agulla J, Perez-Mato M, Rodriguez-Gonzalez R, Brea D, Castillo J (2011) Neuroprotection by glutamate oxaloacetate transaminase in ischemic stroke: An experimental study. JCereb Blood Flow Metab 31, 1378-1386.

[44] Boyko M, Melamed I, Gruenbaum BF, Gruenbaum SE, Ohayon S, Leibowitz A, Brotfain E, Shapira Y, Zlotnik A (2012) The effect of blood glutamate scavengers oxaloacetate and pyruvate on neurological outcome in a rat model of subarachnoid hemorrhage. Neurotherapeutics 9, 649-657.

[45] Mitani H, Shirayama Y, Yamada T, Maeda K, Ashby CR Jr, Kawahara R (2006) Correlation between plasma levels of glutamate, alanine and serine with severity of depression. Prog Neuropsychopharmacol Biol Psychiatry 30, 1155-1158.

[46] Shinohe A, Hashimoto K, Nakamura K, Tsujii M, Iwata Y, Tsuchiya KJ, Sekine Y, Suda S, Suzuki K, Sugihara G, Matsuzaki H, Minabe Y, Sugiyama T, Kawai M, Iyo M, Takei $\mathrm{N}$, Mori N (2006) Increased serum levels of glutamate in adult patients with autism. Prog Neuropsychopharmacol Biol Psychiatry 30, 1472-1477. 


\title{
Abeta(1-42) Enhances Neuronal Excitability in the CA1 via NR2B Subunit-Containing NMDA Receptors
}

\author{
Edina Varga, ${ }^{1}$ Gábor Juhász, ${ }^{1}$ Zsolt Bozsó, ${ }^{1}$ Botond Penke, \\ Lívia Fülöp, ${ }^{1}$ and Viktor Szegedi ${ }^{2}$ \\ ${ }^{1}$ Department of Medical Chemistry, University of Szeged, Szeged 6726, Hungary \\ ${ }^{2}$ Biological Research Center-Biochemistry, Hungarian Academy of Sciences, Temesvari Körút 32, Szeged 6726, Hungary
}

Correspondence should be addressed to Viktor Szegedi; szegedi.viktor@brc.mta.hu

Received 13 June 2014; Revised 5 August 2014; Accepted 17 August 2014; Published 3 September 2014

Academic Editor: Lucas Pozzo-Miller

Copyright (C) 2014 Edina Varga et al. This is an open access article distributed under the Creative Commons Attribution License, which permits unrestricted use, distribution, and reproduction in any medium, provided the original work is properly cited.

\begin{abstract}
Neuronal hyperexcitability is a phenomenon associated with early Alzheimer's disease. The underlying mechanism is considered to involve excessive activation of glutamate receptors; however, the exact molecular pathway remains to be determined. Extracellular recording from the CAl of hippocampal slices is a long-standing standard for a range of studies both in basic research and in neuropharmacology. Evoked field potentials (fEPSPs) are regarded as the input, while spiking rate is regarded as the output of the neuronal network; however, the relationship between these two phenomena is not fully clear. We investigated the relationship between spontaneous spiking and evoked fEPSPs using mouse hippocampal slices. Blocking AMPA receptors (AMPARs) with CNQX abolished fEPSPs, but left firing rate unchanged. NMDA receptor (NMDAR) blockade with MK801 decreased neuronal spiking dose dependently without altering fEPSPs. Activating NMDARs by small concentration of NMDA induced a trend of increased firing. These results suggest that fEPSPs are mediated by synaptic activation of AMPARs, while spontaneous firing is regulated by the activation of extrasynaptic NMDARs. Synaptotoxic Abeta(1-42) increased firing activity without modifying evoked fEPSPs. This hyperexcitation was prevented by ifenprodil, an antagonist of the NR2B NMDARs. Overall, these results suggest that Abeta(1-42) induced neuronal overactivity is not dependent on AMPARs but requires NR2B.
\end{abstract}

\section{Introduction}

Extracellular recording from hippocampal slices has long been a method of choice for determining the changes in excitability and synaptic plasticity of the CA1 microcircuitry [1]. Spontaneous spikes and, far more often, field excitatory postsynaptic potentials (fEPSPs) are recorded extracellularly from a local network of neurons; however, the relationship between these two phenomena is not fully clear. Intuitively, both electrophysiological events correlate with the excitability of the network under investigation, but these events are generated by different mechanisms. Field EPSPs are mainly composed of subthreshold events from a population of neurons, like dendritic depolarizations [2] and glial contributions to the net extracellular charge-flow, arising mainly from the function of transporters $[3,4]$. In contrast, spontaneous firing represents only neuronal suprathreshold events [5]. Another difference is that a fEPSP is evoked by a stimulus, and therefore it is the result of a coordinated and synchronized electrical activity of a cell population, mediated by synaptic connections. Spontaneous spikes, in contrast, are not evoked by an external stimulus, and they are more likely to be dependent on intrinsic network connections and properties [6].

N-Methyl-D-aspartate receptor (NMDAR) and $\alpha$-Amino-3-hydroxy-5-methyl-4-isoxazolepropionic acid receptor (AMPAR) play a key role in generating rapid excitatory events in the CA1, but these receptors serve different purposes. Their relative contribution to fEPSPs is well described [7]; however, their involvement in spontaneous spike-generation remains unknown and data on the correlation of extracellularly recorded field responses and action potentials are scarce. Activation of glutamate (Glu) receptors is known to play an important role in the mechanisms of neuronal plasticity 
that might be the cellular basis of learning and memory [8]. Several studies have shown that the synaptic plasticity is impaired in Alzheimer's disease (AD) [9], the most common form of neurodegenerative disease, characterized by the presence of insoluble amyloid deposits in the brain. Overwhelming evidence suggests that the main component of plaques, amyloid-beta (Abeta) peptide, is thought to be responsible for the synaptic and cellular pathology of $\mathrm{AD}$ (for review see [10]). Numerous studies have reported that the severity of $\mathrm{AD}$ strongly correlates with decreased synapse density in hippocampus and cortex and with disruption of memoryrelated synapse function. Literature data strongly support the synaptotoxicity of Abeta(1-42), and the accumulation of soluble Abeta(1-42) [11] in the brain of patients and animal models of $\mathrm{AD}$ is associated with impairments of cognition and memory [12-14]. Recently, Abeta(1-42) was shown to induce epileptiform activity, both in vitro [15] and in vivo, and transgenic mice overexpressing Abeta develop seizures over time [16]. Moreover, AD patients have an estimated 87 times higher probability of developing epileptic seizures compared to age-matched population [17]. Despite the recent advancement in the research of the pathomechanisms of $\mathrm{AD}$, the exact mechanism by which neuronal overactivity develops is unknown.

Recent findings suggest that Abeta blocks neuronal glutamate (Glu) uptake at synapses, leading to increased Glu level at the synaptic cleft [18]. Increased brain extracellular Glu, but not $\gamma$-aminobutyric acid (GABA), concentration was found upon Abeta administration by use of microdialysis technique $[19,20]$. A resultant rise in Glu levels would lead to a spillover and activation of extra- or perisynaptic NMDARs enriched in the $B$ isoform of the NMDAR 2 subunit (NR2B), which play a major role in the induction of long-term depression (LTD) [21] and have also been shown to help mediate the inhibition of long-term potentiation (LTP) by soluble Abeta oligomers [22].

In this study we investigated the mechanisms by which fEPSPs and spontaneous firing are regulated in the CA1 of hippocampal slices. We confirmed that fEPSP, but not spiking activity, is mainly mediated by AMPARs. In contrast, spontaneous activity is regulated by NMDARs. Bath application of synaptotoxic Abeta(1-42) greatly enhanced spontaneous firing rate, which could be prevented by blocking NR2B subunits.

\section{Experimental Procedures}

2.1. Compounds. For the preparation of artificial cere-brospinal fluid (ACSF), all salts, glucose, 6-cyano-7-nitroquinoxaline-2,3-dione (CNQX), (+)-MK-801 hydrogen maleate, and $\alpha$-(4-Hydroxyphenyl)- $\beta$-methyl-4-benzyl-1-piperidineethanol $(+)$-tartrate salt (ifenprodil) were purchased from Sigma-Aldrich (St. Louis, MO).

2.2. Animals. The study conformed to EU Directive 2010/63/EU and was approved by the regional Station for Animal Health and Food Control under Project License $\mathrm{XVI} / 8 / 2013$. BALB/c mice were housed in groups of $2-3$ under standard conditions $\left(24^{\circ} \mathrm{C}, 12 \mathrm{~h}\right.$ light-dark cycle $)$ with food and water available ad libitum.

2.3. Ex Vivo Electrophysiology. Hippocampal slices of $400 \mu \mathrm{m}$ in thickness were prepared from the brains of 3-monthold mice using a standard protocol [23]. Briefly, slices were incubated in artificial cerebrospinal fluid ACSF gassed with $95 \% \mathrm{O}_{2}$ and $5 \% \mathrm{CO}_{2}$ at $35^{\circ} \mathrm{C}$ for $60 \mathrm{~min}$. ACSF was composed of (in $\mathrm{mM}$ ) $130 \mathrm{NaCl}, 3.5 \mathrm{KCl}, 3 \mathrm{CaCl}_{2}, 1.5 \mathrm{MgSO}_{4}, 0.96$ $\mathrm{NaH}_{2} \mathrm{PO}_{4}, 24 \mathrm{NaHCO}_{3}$, and $10 \mathrm{D}$-glucose, $\mathrm{pH}$ 7.4. Individual slices were transferred to a 3D-MEA chip with 60 tip-shaped and $60 \mu \mathrm{m}$ high electrodes spaced by $200 \mu \mathrm{m}$ (Qwane Biosciences, Lausanne, Switzerland). The surrounding solution was quickly removed, and the slice was immobilized by placing a grid onto it. The slice was continuously perfused with oxygenated ACSF $\left(3 \mathrm{~mL} / \mathrm{min}\right.$ at $\left.36^{\circ} \mathrm{C}\right)$ throughout the entire recording session. Unfiltered data were recorded using a standard, commercially available MEA 60 setup (Multi Channel Systems MCS GmbH, Reutlingen, Germany). Field EPSPs were recorded from the proximal stratum radiatum at $5 \mathrm{kHz}$, while spontaneous spiking activity was recorded from the CA1 stratum pyramidale at a frequency of $25 \mathrm{kHz}$ for $5 \mathrm{~min}$ epochs. For analyzing and sorting the spiking activity, Spike2 software package (Cambridge Electronic Design, Cambridge, UK) was used. Recordings were filtered between 300 and $3000 \mathrm{~Hz}$ offline, and the threshold for spike detection was 2.5 fold higher than the noise level. The data of those electrodes were included in the analysis where the initial spiking activity was above $0.5 \mathrm{~Hz}$. Firing activity ranged from 150 to 1000 spikes $/ 5 \mathrm{~min}$. Data are considered as multiunit activity.

2.3.1. Stimulation Protocol. The Schaffer-collateral was stimulated by injecting a biphasic voltage waveform $(-100 /+100 \mu \mathrm{s})$ through one selected electrode at $0.033 \mathrm{~Hz}$. Care was taken to place the stimulating electrode in the same region at every slice. The peak-to-peak amplitudes of fEPSPs at the proximal stratum radiatum of CAl were analyzed. After a $30 \mathrm{~min}$ incubation period, the threshold and maximum stimulation intensities for evoked responses were determined. To evoke responses, $30 \%$ of the maximal stimulation intensity was used. The level of LTP (the last 10 peak-to-peak amplitudes) was compared to the average of the last 20 peak-to-peak amplitudes of evoked fEPSPs before applying theta-burst stimulation (TBS). TBS comprised of 15 bursts given at $5 \mathrm{~Hz}$ and individual burst contained 4 pulses given at $100 \mathrm{~Hz}$ per burst.

2.3.2. Drug Treatments. All slices were incubated for $30 \mathrm{~min}$ without stimulation in the recording chamber before any recording was done. Following the first spike-recording, slices were left to incubate a further $60 \mathrm{~min}$ with continuous fEPSP recording and then slices were treated with $10 \mu \mathrm{M}$ CNQX or $10 \mu \mathrm{M}$ MK801 or $25 \mu \mathrm{M}$ MK801 or ACSF containing low concentration of $\mathrm{Mg}_{2} \mathrm{SO}_{4}$ (low $\mathrm{Mg}^{2+}$ ACSF; $0.25 \mathrm{mM}$ ) or $0.5 \mu \mathrm{M}$ NMDA or $0.05 \mu \mathrm{M}$ AMPA for $30 \mathrm{~min}$ (see Figure 1(c)). Spontaneous activity was recorded before and $30 \mathrm{~min}$ after treatment for $5 \mathrm{~min}$ and the spiking data 


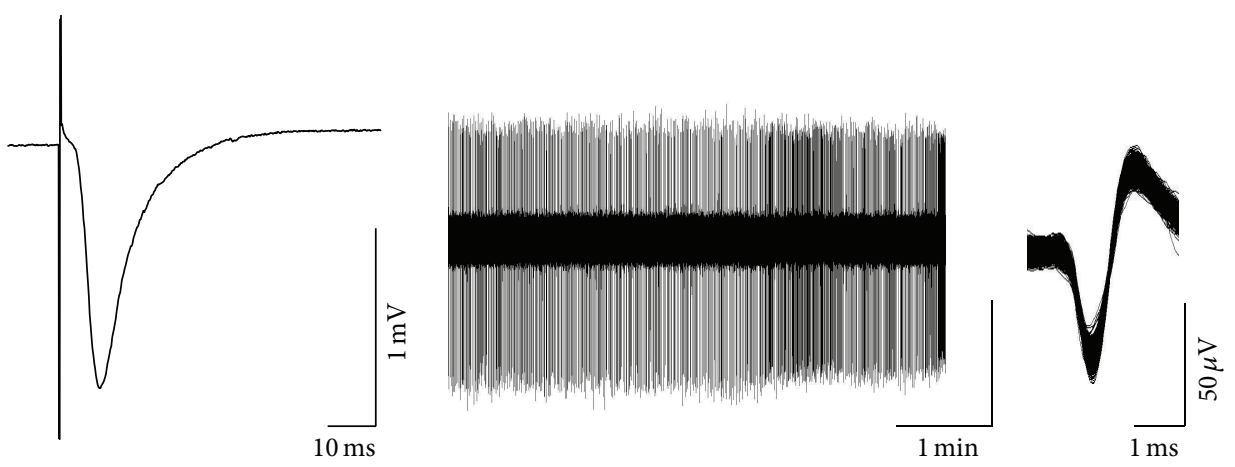

(a)

(b)

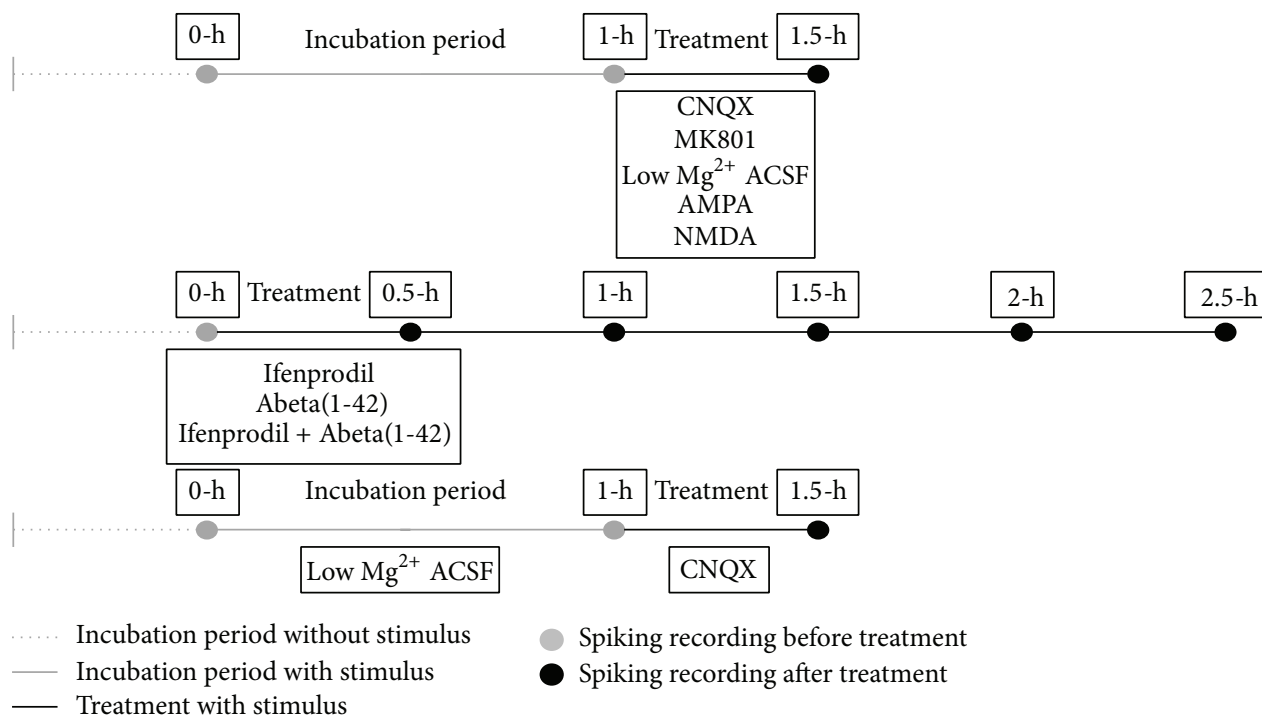

(c)

FIGURE 1: Exemplar recordings and the timeline of the experiments. Both evoked fEPSPs and spiking activity recording electrodes were located in the CA1 region of mouse hippocampal slice. The fEPSPs were recorded from the stratum radiatum (a) and the spontaneous spiking was recorded from the stratum pyramidale (b). Both fEPSPs and spiking activity were recorded from the same slice. Data were considered as multiunit activity. (c) shows the timeline of the recordings. The initial spiking activity (recorded at $0 \mathrm{~h}$ ) was considered as $100 \%$ in each slice.

was compared to the untreated group recorded at the same time point. Other cohorts of slices were treated with $1 \mu \mathrm{M}$ oligomer Abeta(1-42), ifenprodil $(3 \mu \mathrm{M})$, and ifenprodil + Abeta(1-42) for $2.5 \mathrm{~h}$. The spiking activity was recorded at every $30 \mathrm{~min}$ for $5 \mathrm{~min}$. The effect of CNQX was also tested in low $\mathrm{Mg}_{2} \mathrm{SO}_{4}$-containing $\mathrm{ACSF}(0.25 \mathrm{mM})$, where modified ACSF was perfused to the slices from the beginning of the experiment. Electric stimulation was stopped during spontaneous activity recordings. Spiking frequency of each slice (number of spikes) was normalized to the initial firing activity (following the first $30 \mathrm{~min}$ incubation; $0 \mathrm{~h}$ ), which was taken as $100 \%$ in all channels. Following this, slices were treated with $1 \mu \mathrm{M}$ oligomer Abeta(1-42) for $60 \mathrm{~min}$ and then LTP was induced by the TBS protocol. LTP was followed for $90 \mathrm{~min}$ after TBS. During treatment, evoked fEPSPs were recorded.

2.4. Synthesis and Characterization of Abeta(1-42). Detailed description of the synthesis and characterization of Abeta(1$42)$ is reported in $[23,24]$. Briefly, a depsipeptide derivative of Abeta(1-42) was synthesized and, after purification, it was used in lyophilized form. A $200 \mu \mathrm{M}$ stock solution of the peptide was prepared in $0.1 \mathrm{mM} \mathrm{NaOH}$, and the $\mathrm{pH}$ was set to 11.0. After incubation for $2 \mathrm{~h}$ at ambient temperature, the stock solution was diluted into ACSF to a concentration of $50 \mu \mathrm{M}$ and the $\mathrm{pH}$ was set to 7.3. The peptide solution was incubated for $12 \mathrm{~h}$ at $37^{\circ} \mathrm{C}$ and, prior to use, it was diluted with ACSF to a final concentration of $1 \mu \mathrm{M}$. Aggregation grade and the size distribution of the oligomers were checked by Western blots by following the methods described in [23]. Oligomers were detected either with sequence-specific BAM10 antibody (Sigma-Aldrich) or with conformation specific OC antibody (Millipore), which detects the oligomers of fibrillar nature, that is, with beta sheet structure.

\subsection{Statistics}

2.5.1. Statistical Analysis for fEPSPs. Testing for normality was done with the Kolmogorov-Smirnov normality 


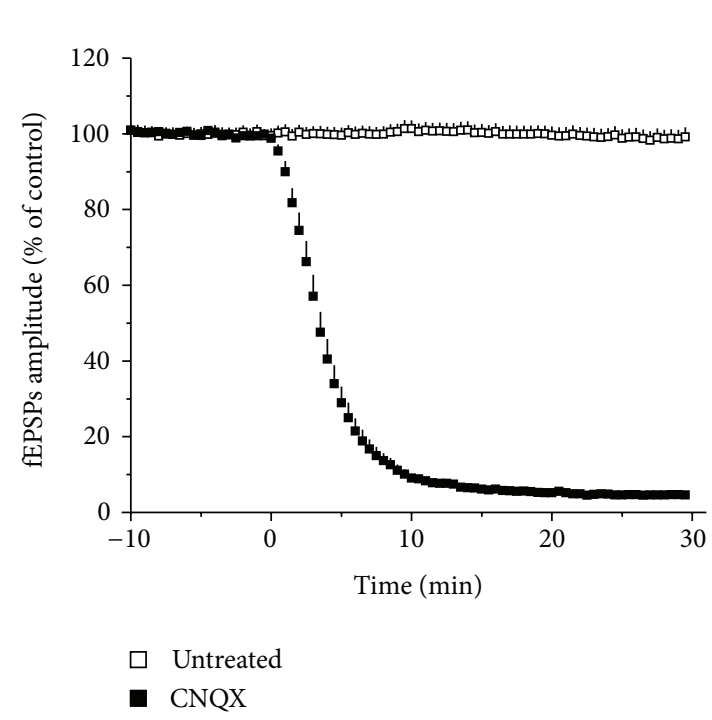

(a)

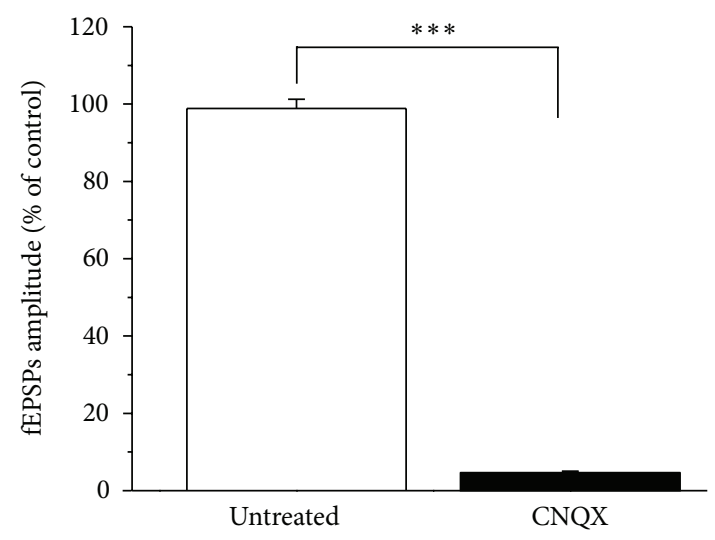

(b)
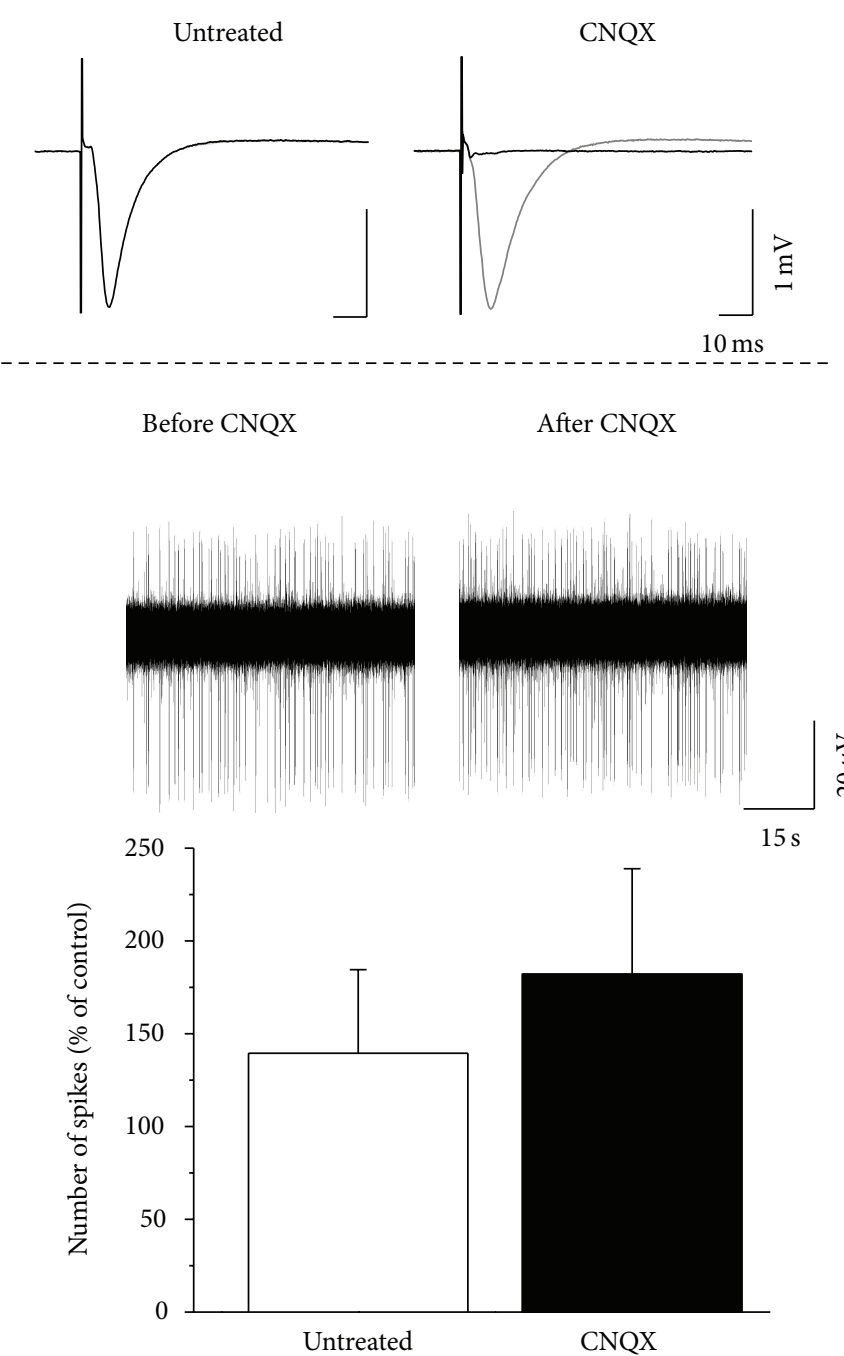

(c)

FIGURE 2: AMPA receptors mediate fEPSPs but not spontaneous activity. Blocking AMPARs abolished fEPSPs (a). Bar graphs show the average of the fEPSPs amplitudes of the 25-30 min period after treatment. CNQX induced a complete reduction of evoked fEPSPs $(n=5, P<0.001)$ (b); however the spiking activity was not affected (c). Inset at the right panel shows representative fEPSPs before (grey) and after (black) treatment and representative spike trains. Error bars show SEM; ${ }^{* * *} P \leq 0.001$.

test. Our data have shown normal distribution; hence, independent-samples $t$-test and one-way repeated measures analysis of variance (ANOVA) were used with the Bonferroni test for post hoc analysis. The $P$ value $\leq 0.05$ was considered significant in all cases. Data were analyzed using SPSS statistical software.

2.5.2. Statistical Analysis for Spiking Rate. KolmogorovSmirnov test was used also for testing normality of these data. Since our data have shown nonparametric distribution, we used nonparametric tests (Kruskal-Wallis test was followed by Mann-Whitney $U$ test) for determining differences between two and several groups. Data were analyzed using SPSS. $P$ value of $\leq 0.05$ was considered significant in all cases.

\section{Results}

3.1. Field EPSPs, but Not Spontaneous Spikes, Are Mediated by AMPARs. We recorded fEPSPs from the stratum radiatum (Figure 1(a)) and in parallel spontaneous spikes from the stratum pyramidale (Figure 1(b)) of the CA1. Both fEPSPs and spontaneous activity could be abolished by application of $1 \mu \mathrm{M}$ tetrodotoxin (data not shown).

First, we investigated the contribution of AMPARs to evoked fEPSPs and spontaneous activity, using CNQX, an AMPAR inhibitor. Blocking AMPARs resulted in a complete reduction of evoked fEPSPs (untreated: $n=5 ; 98.84 \pm 2.41 \%$ versus CNQX: $n=5 ; 4.62 \pm 0.45 \%, P=0.001$, independent samples $t$-test; Figures 2(a) and 2(b)). Conversely, spiking activity remained unchanged (untreated: $n=5$; $139.55 \pm 44.95 \%$ versus CNQX: $n=5 ; 182.18 \pm 56.76 \%$, 


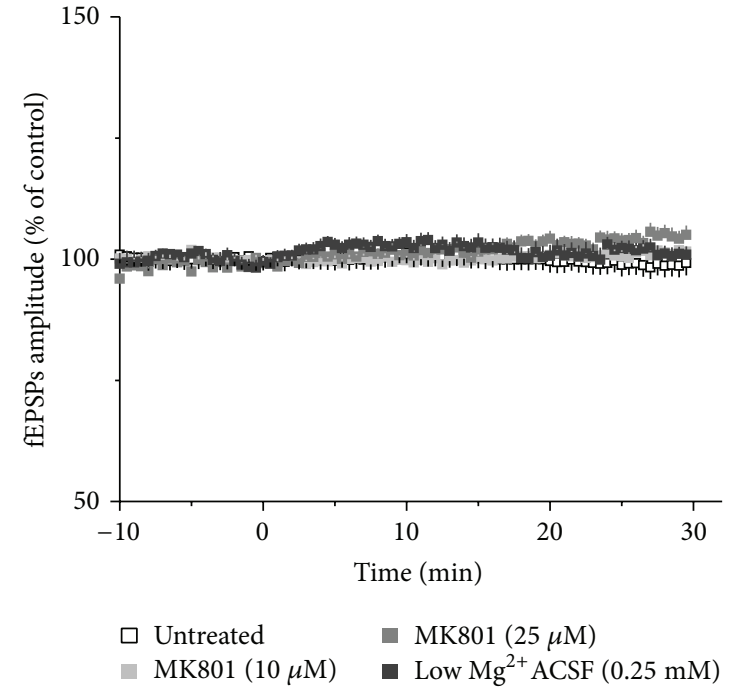

(a)

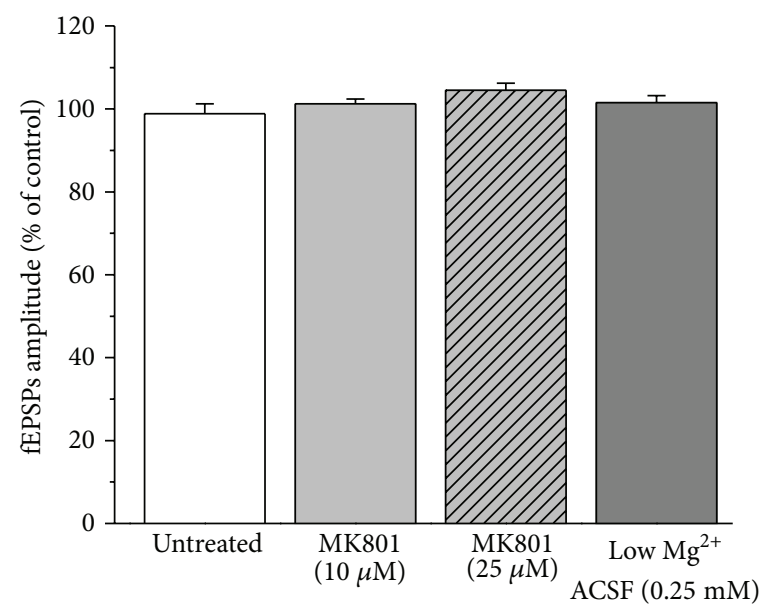

(b)
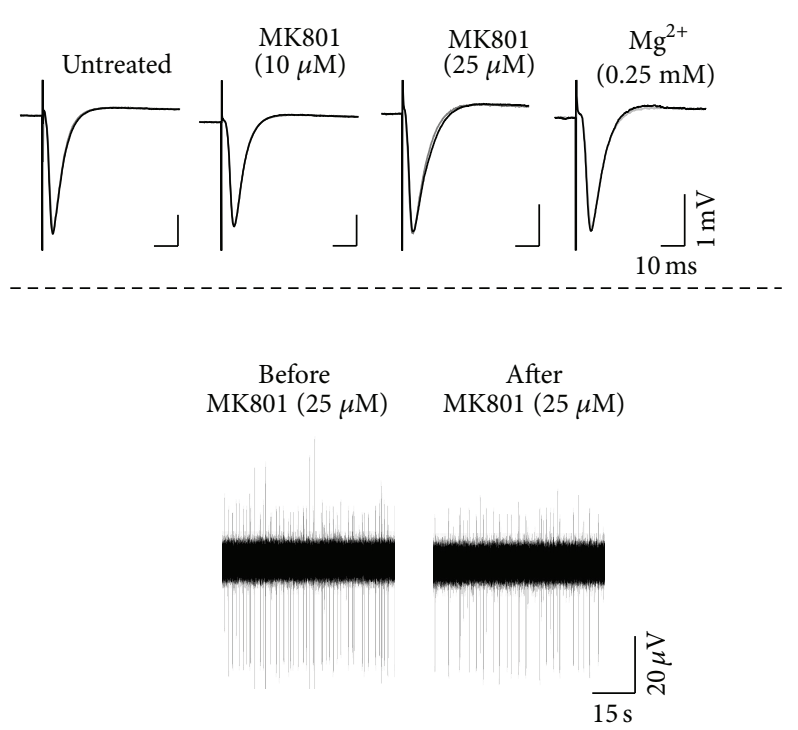

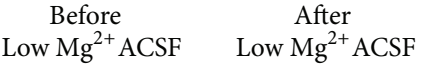

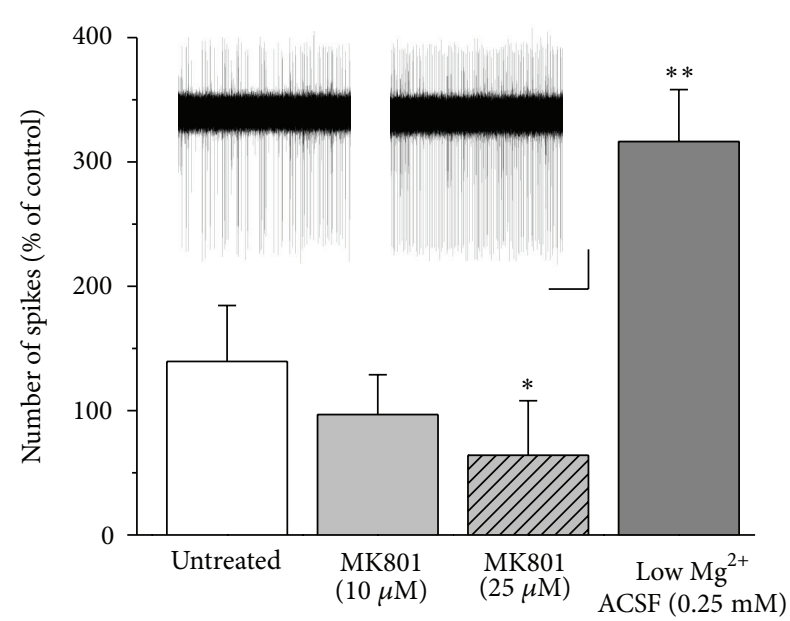

(c)

FIGURE 3: NMDA receptors mediate spontaneous activity but not fEPSPs. Blocking (MK801) or enhancing (low-Mg ${ }^{2+}$ ACSF) NMDAR function did not influence fEPSPs (a). Right panel shows representative fEPSPs before (grey) and after (black) treatment. Bar graphs show the average of the fEPSPs amplitudes of the 25-30 min period after treatment (b). In contrast, MK801 dose dependently reduced spiking frequency and low $\mathrm{Mg}^{2+}$ ACSF enhanced firing rate (untreated versus MK801 in $25 \mu \mathrm{M}: P=0.035$ and untreated versus low $\mathrm{Mg}^{2+} \mathrm{ACSF}$ $P=0.004$ ) (c). Inset shows representative spike trains. Error bars show SEM; ${ }^{*} P \leq 0.05,{ }^{* *} P \leq 0.01$.

Mann-Whitney $U$ test; Figure 2(c)), suggesting that AMPARs play a key role in generating fEPSPs but not spontaneous spiking. Under physiological conditions, NMDARs activation is dependent on depolarization, for example, on previous AMPARs activation. Thus we changed to low $\mathrm{Mg}^{2+}$ ACSF $(0.25 \mathrm{mM})$ to remove the depolarization-dependent $\mathrm{Mg}^{2+}$ plug from the NMDAR. Applying $10 \mu \mathrm{M}$ CNQX to low $\mathrm{Mg}^{2+}$ ACSF slices for $30 \mathrm{~min}$, fEPSPs were completely blocked (control: $n=6 ; 95.54 \pm 81 \%$ versus CNQX in low $\mathrm{Mg}^{2+}$ containing ACSF: $n=6 ; 6.44 \pm 0.36 \%, P<0.001$, independent samples $t$-test; see Supplementary Figure 1 available online at http://dx.doi.org/10.1155/2014/584314). We have also tried to activate AMPARs by applying a low concentration of AMPA $(0.05 \mu \mathrm{M})$, but we observed epileptiform field responses and a huge increase of basal activity which hindered the unambiguous detection of action potentials (Supplementary Figure 2).

3.2. Spontaneous Firing, but Not fEPSP, Is Governed by NMDAR Function. Next, we focused on NMDARs. Applying an NMDAR antagonist, MK801 resulted in a dose-dependent decrease of spiking rate (untreated: $n=5 ; 139.55 \pm 44.95 \%$ versus MK801 in $10 \mu \mathrm{M}: n=5 ; 96.73 \% \pm 32.22, P=0.48$; MK801 in $25 \mu \mathrm{M}: n=5 ; 29.23 \pm 22.93, P=0.031$, MannWhitney $U$ test; Figure 3(c)). MK801 did not have any effect on fEPSP in either $10 \mu \mathrm{M}$ or $25 \mu \mathrm{M}$ (untreated: $n=5$; $98.8 \pm 2.4 \%$ versus MK801 in $10 \mu \mathrm{M}: n=5 ; 101.23 \pm 1.17 \%$ versus MK801 in $25 \mu \mathrm{M}: n=5,104.49 \pm 1.72 \%$; one-way 


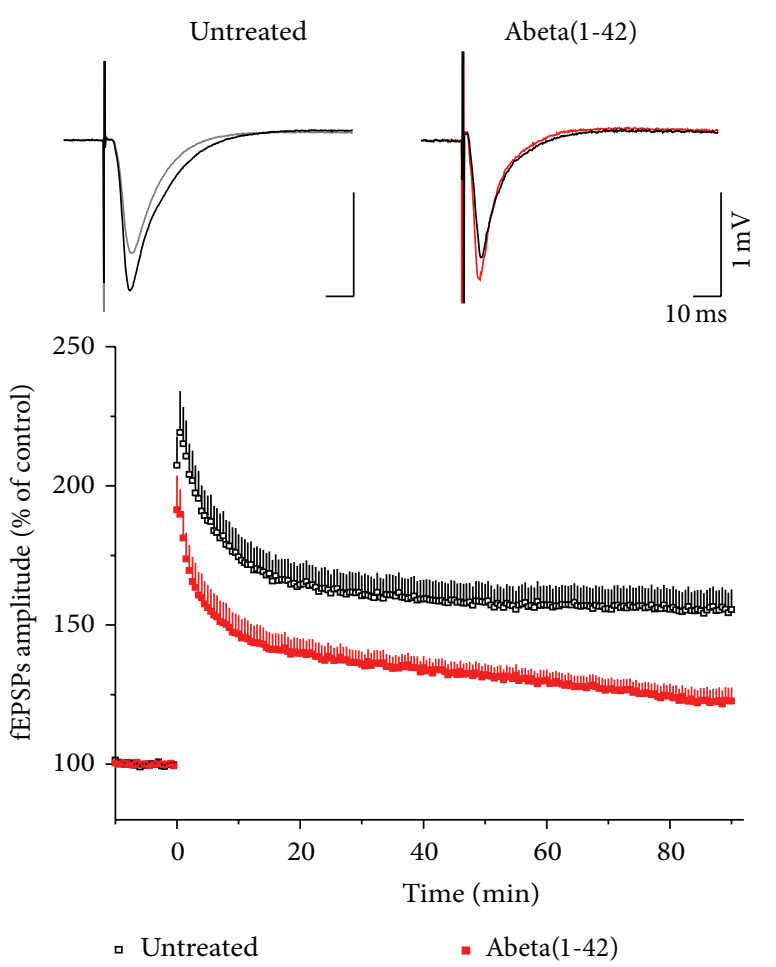

(a)

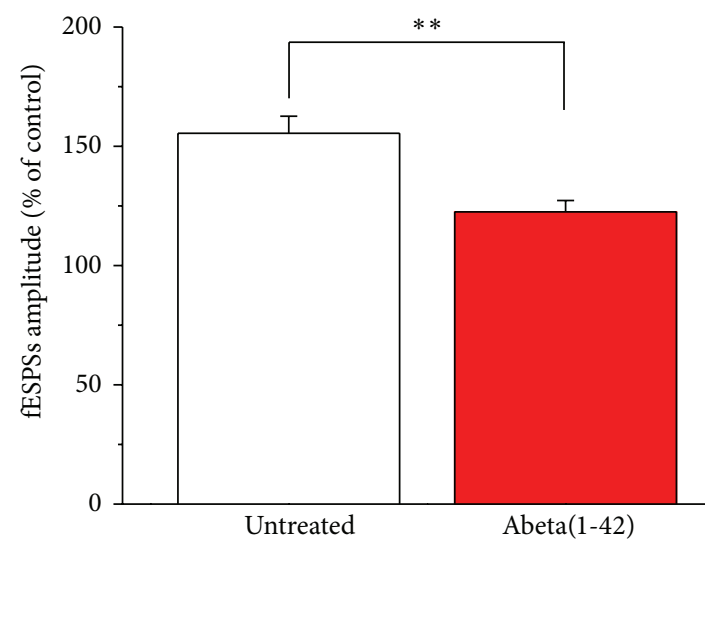

(b)

FIGURE 4: Abeta(1-42) impairs LTP. Representative fEPSPs from both control and Abeta(1-42) groups. Field EPSP was recorded before (grey) and 90 min after LTP induction (control is in black and Abeta(1-42) is in red) from the proximal stratum radiatum of CA1 (see above). Following $1 \mathrm{~h}$ of Abeta(1-42) treatment, LTP was induced by TBS protocol. LTP was reduced in Abeta(1-42) treated slices compared to controls 90 min after TBS (untreated versus Abeta: $P=0.002$ ) (a). The amplitudes of fEPSPs after TBS were normalized to pre-TBS control. Bar graphs show the average of the last 5 min of LTP. Error bars represent SEM; ${ }^{* *} P \leq 0.01$ (b).

ANOVA and Bonferroni post hoc test; Figures 3(a) and 3(b)). Another cohort of slices was treated with ACSF having reduced $\mathrm{Mg}^{2+}$ concentration for $30 \mathrm{~min}$. We have observed a massively elevated frequency of the spontaneous spiking activity compared to the untreated slices $(n=7,316.34 \pm$ $41.89 \%, P=0.004$, Mann-Whitney $U$ test; Figure 3(c)), but evoked fEPSP responses remained unaltered $(n=7,101.54 \pm$ $1.69 \%$, one-way ANOVA and Bonferroni post hoc test). Based on these results we hypothesized that spontaneous firing is mediated by the ambient Glu concentration acting on the extrasynaptic NMDARs. Therefore we tried to activate selectively this set of receptors by applying low concentration of NMDA $(0.5 \mu \mathrm{M})$ in normal ACSF [25]. This treatment resulted in unchanged fEPSPs (untreated: $n=5 ; 98.8 \pm 2.4 \%$ versus NMDA: $n=9 ; 94.03 \pm 1.04 \%$; independent-samples $t$-test) but induced a trend of elevated firing rate (untreated: $n=5 ; 139.55 \pm 44.95 \%$ versus NMDA: $n=9 ; 253.02 \pm 105.9 \%$, $P=0.51$, Mann-Whitney $U$ test; Supplementary Figure 3).

3.3. Abeta(1-42) Impairs LTP. A major drawback of Abeta studies is that the activity of various Abeta preparations may vary between protocols and even between batches. We verified the activity of Abeta batches we have used for this study by determining their effect on CA1 LTP. Abeta(1-42) was applied for $60 \mathrm{~min}$ before inducing LTP by using TBS.
Untreated slices showed a robust and permanent elevation of evoked fEPSPs after TBS $(n=7 ; 155.48 \pm 7.16 \% 90 \mathrm{~min}$ after TBS), while slices having received Abeta(1-42) failed to exhibit permanent LTP $(n=8 ; 122.54 \pm 4.75 \% 90$ min after TBS, $P=0.002$, independent-samples $t$-test; Figures 4 (a) and $4(\mathrm{~b}))$.

3.4. Abeta(1-42) Induces Hyperexcitation via NR2B. Firing rate was determined every $30 \mathrm{~min}$ in $5 \mathrm{~min}$ epochs within the time frame of the recordings. In the untreated slices the amplitude of fEPSPs increased slightly until $1.5 \mathrm{~h}$ reaching $103.36 \pm 2.67 \%$ of the initial amplitude and then decreased to initial value $(n=5 ; 0.5 \mathrm{~h}: 100.8 \pm 1.65 \% ; 1 \mathrm{~h}: 102.9 \pm 1.84 \%$; $2 \mathrm{~h}: 100.86 \pm 3.38 \%$; and $2.5 \mathrm{~h}: 98.18 \pm 4.04 \%$, one-way repeated measures ANOVA and Bonferroni post hoc test; Figures 5(a) and 5(b)). Similarly, spiking frequency did not change over time $(n=5 ; 0.5$ h: $124.34 \pm 29.72 \% ; 1$ h: $129.57 \pm 53.28 \%$; 1.5 h: $139.55 \pm 44.95 \% ; 2$ h: $102.48 \pm 28.42$; and 2.5 h: $76.16 \pm 28.08 \%$, Mann-Whitney $U$ test; Figure 6).

Abeta(1-42) applied in $1 \mu \mathrm{M}$ did not change fEPSPs amplitudes (Abeta(1-42): $n=7 ; 0.5 \mathrm{~h}: 107.08 \pm 2.43 \% ; 1 \mathrm{~h}$ : $106.41 \pm 2.93 \%$; 1.5 h: $103.54 \pm 3.07 \%$; 2 h: $100.92 \pm 3.06 \%$; and $2.5 \mathrm{~h}: 97.1 \pm 2.97 \%$ compared to untreated slices, see above; Figure 5), suggesting that Abeta(1-42) did not affect the AMPAR-mediated synaptic transmission. On the other 


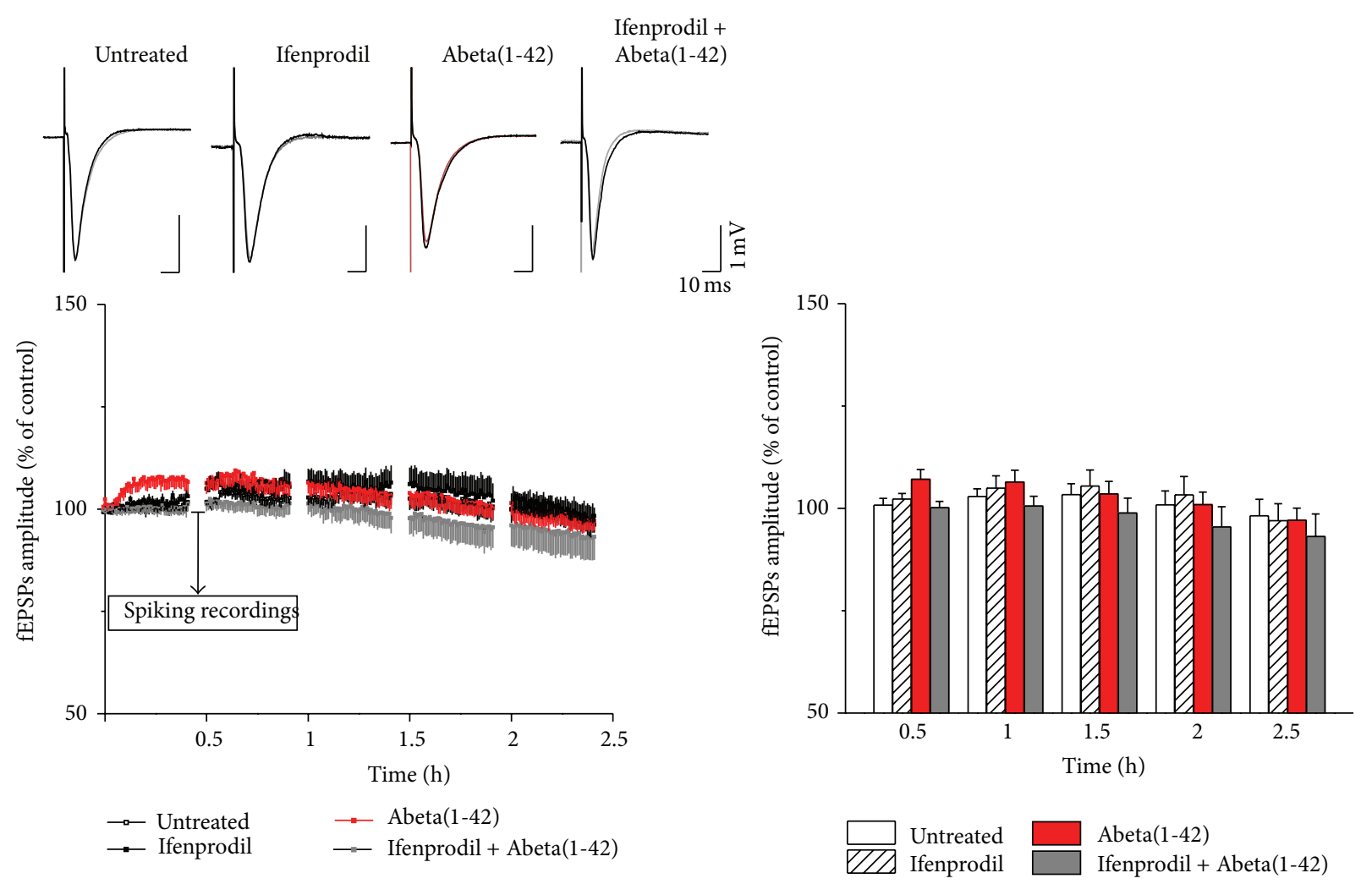

(a)

(b)

Figure 5: Neither Abeta(1-42) nor ifenprodil affects fEPSPs. Representative fEPSPs are shown before (grey) and after treatment in the upper panel. Neither Abeta(1-42) nor ifenprodil changed fEPSPs amplitudes (one-way repeated measures ANOVA with Bonferroni correction) (a). Bar graphs show the mean of the last 5 min of every recording epoch. Error bars represent SEM (b).

hand, Abeta(1-42) induced a massively elevated firing $(n=$ 7; 0.5 h: $182.6 \pm 30.91 \%$; 1 h: $242.29 \pm 83.31 \%, P=0.043$; 1.5 h: $233.29 \pm 83.31 \%$; 2 h: $240.32 \pm 85.0 \%, P=0.036$; and 2.5 h: $244.72 \pm 64.21 \%, P=0.001$, Mann-Whitney $U$ test; Figure 6) compared to untreated slices, suggesting that NMDARs are involved in the effect of Abeta(1-42). Several recent reports suggested that the deleterious effect of Abeta is mediated via the NR2B subunit-containing NMDARs (see Section 4). To test whether the observed hyperexcitation in our experimental setup is sensitive to NR2B antagonism, we have applied ifenprodil $(3 \mu \mathrm{M})$, an antagonist of the NR2B. Ifenprodil did not alter either fEPSPs (ifenprodil: $n=5 ; 0.5 \mathrm{~h}$ : $102.26 \pm 1.35 \% ; 1 \mathrm{~h}: 104.95 \pm 3.00 \%$; $1.5 \mathrm{~h}: 105.45 \pm 3.91 \% ; 2 \mathrm{~h}$ : $103.28 \pm 4.53 \%$; and $2.5 \mathrm{~h}: 96.99 \pm 4.15 \%$ compared to control, see above; Figure 5$)$ or spiking activity $(n=5$; ifenprodil: $0.5 \mathrm{~h}: 127.11 \pm 53.62 \%, 1 \mathrm{~h}: 163.58 \pm 101.77 \%$; $1.5 \mathrm{~h}: 81.37 \pm$ $37.37 \%, 2 \mathrm{~h}: 110.35 \pm 65.81 \%$; and $2.5 \mathrm{~h}: 120.26 \pm 64.58 \%$; Figure 6), suggesting that NR2B-activation is not required for basic synaptic transmission in the CA1. However, Abeta(1-42) induced elevated spiking activity was prevented by ifenprodil (ifenprodil + Abeta(1-42): $n=5$; $0.5 \mathrm{~h}: 157.44 \pm 84.19 \%$; $1 \mathrm{~h}$ : $196.87 \pm 79.61 \% ; 1.5$ h: $116.36 \pm 61.71 \% ; 2$ h: $101.72 \pm 76.26 \%$; and 2.5 h: $88.88 \pm 59.67 \%, P=0.048$, Mann-Whitney $U$ test compared to Abeta(1-42), see above; Figure 6) without changing of fEPSPs amplitudes (ifenprodil $+\operatorname{Abeta}(1-42): n=5$;
$0.5 \mathrm{~h}: 100.17 \pm 1.53 \% ; 1 \mathrm{~h}: 100.57 \pm 2.38 \% ; 1.5 \mathrm{~h}: 98.85 \pm$ 3.66\%; 2 h: $95.45 \pm 4.97 \%$; and 2.5 h: $93.15 \pm 5.47 \%$; Figure 5), suggesting that the hyperexcitability caused by Abeta(1-42) requires the activation of extrasynaptic NR2B receptors, but not AMPARs.

3.5. Characterization of Abeta(1-42). The size distribution of Abeta(1-42) oligomers formed in $50 \mu \mathrm{M}$ after incubation at $37^{\circ} \mathrm{C}$ was studied on Western blots by using two different antibodies; the monoclonal BAM10 antibody is sequence specific and binds to the $\mathrm{N}$-terminal end of the peptide, while OC stains the oligomers of fibrillar nature (protofibrils, oligomers with beta sheet structure) [26]. Supplementary Figure 4 shows the results of the WB experiments. BAM10 staining reveals the presence of both low- and high-molecularweight oligomers in the sample, while their positive staining with the OC antibody indicates that they have protofibrillar characteristics. The presence of SDS stable dimers and trimers in the sample closely resembles Abeta(1-42) derived from biological sources, namely, from transfected 7PA2 cells [27] and from human brain $[28,29]$. These species were shown to have strong synaptotoxic properties [30]. On the other hand, protofibrillar species, which are also abundant in our sample, were also reported to be synaptotoxic [16]. 


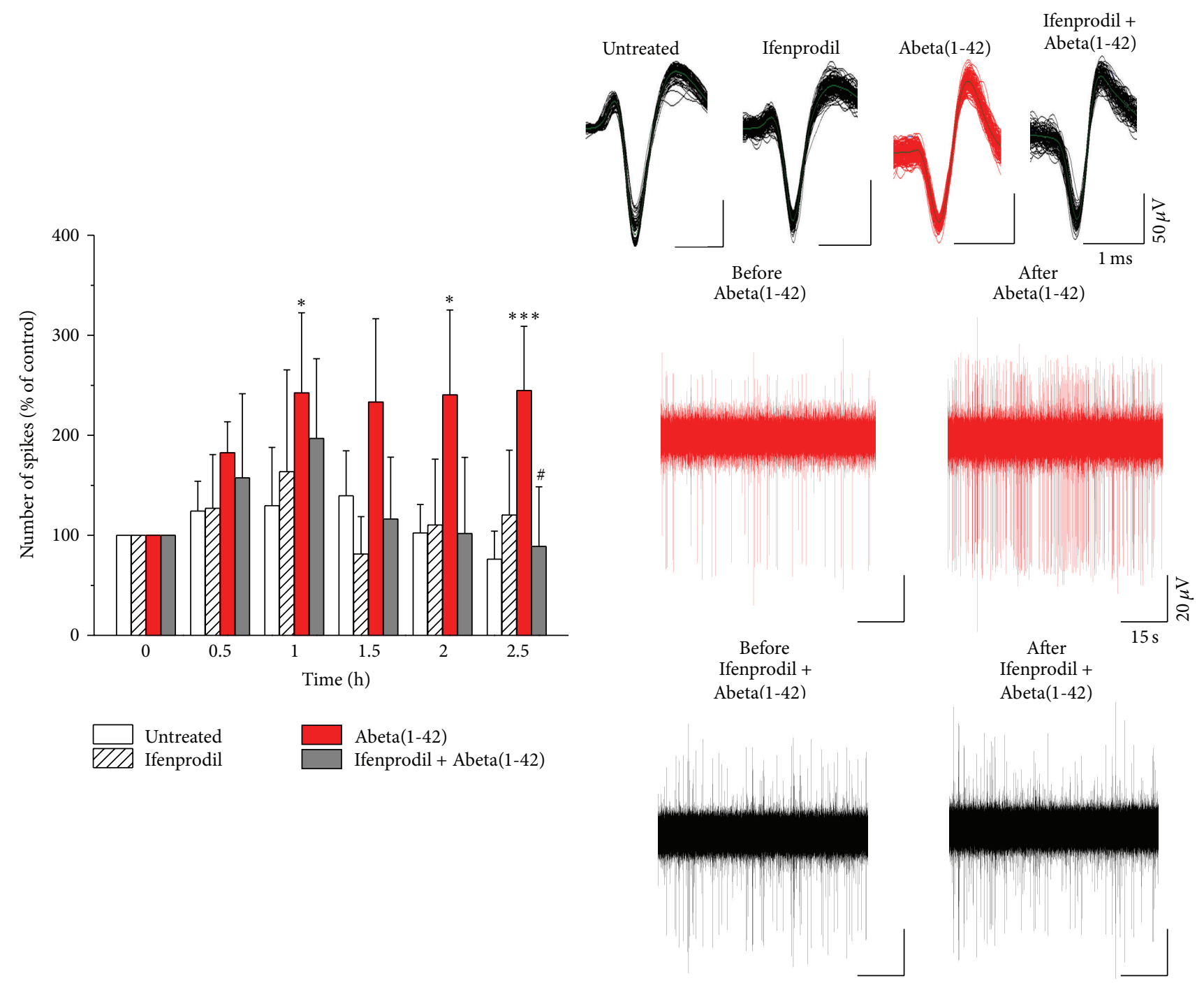

FIgURE 6: Abeta(1-42) induces hyperexcitation via NR2B. Abeta(1-42) induced increased spiking activity (untreated versus Abeta(1-42): 1 h: ${ }^{*} P=0.043 ; 2 \mathrm{~h}:{ }^{*} \mathrm{P}=0.036 ; 2.5 \mathrm{~h}:{ }^{* * *} \mathrm{P}=0.001$; Mann-Whitney $U$ test). Ifenprodil did not affect spontaneous activity but prevented the elevated spiking rate caused by Abeta(1-42) (Abeta(1-42) versus ifenprodil + Abeta(1-42) $2.5 \mathrm{~h},{ }^{*} P=0.038$; Mann-Whitney $U$ test). Upper panel shows exemplar units from the respective recordings, while bottom panel illustrates representative spike trains. Error bars represent $\mathrm{SEM} ;{ }^{*} \mathrm{P} \leq 0.05 ;{ }^{* * *} \mathrm{P} \leq 0.001 ;{ }^{*} \mathrm{P} \leq 0.05$.

\section{Discussion}

4.1. AMPA Receptors Regulate fEPSPs and NMDA Receptors Mediate Spontaneous Spiking. Extracellular fEPSP recordings are the gold standard for determining the excitation and synaptic plasticity in hippocampal slices. The changes of spontaneous spiking activity under conditions that modify network excitability are, however, less well studied in acute slices. In these sets of experiments we have studied the involvement of AMPARs and NMDARs in fEPSPs evoked by Schaffer-stimulation and in spontaneous firing in the CA1. We show that these two electrophysiological markers, previously thought to underlie measures of excitation, are not correlated. Importantly, the spikes we recorded here were almost exclusively localized to the pyramidal layer of CA1; hence, they were presumably from principal cells. Multiunit activity recordings do not allow separating the firing from individual neurons and may include bursts of spikes fired by the same neuron. Thus, in our study, spiking represents the global amount of activity within this network and most probably the activity of principal cells. The firing rates observed in this study were comparable to previously reported values in slices of CAl of the guinea pig (0.22 and 1.8 spikes/sec) [6]. Under our conditions, blocking AMPAR with CNQX inhibited fEPSPs, however, the spiking activity did not change. In contrast, modulating NMDAR function affected spontaneous firing without any change in evoked fEPSPs. Blocking NMDARs ablated, while enhancing NMDAR function increased spontaneous activity.

4.2. Possible Involvement of the CA1 Local Microcircuitry in the Regulation of Spontaneous Spiking. Direct comparison of data from CA3 spiking regulation and our CA1 data is 
difficult, because glutamatergic pyramidal cells of the CA3 form massive recurrent loops, a feature that is missing in the CA1. Therefore, the activity of CA1 pyramidal cells is regulated by the excitation arriving from $\mathrm{CA} 3$ through the Schaffer-collateral and by the inhibition of the local interneuron microcircuitry. Although the activity of CA1 inhibitory cells has been reported to be scarce, compared to CA3 in acute slices, powerful pyramidal somatic inhibition could be detected upon minimal electric stimulation [31], showing that the inhibition is very effective. What is the driving force of the interneuronal activity? One possible explanation is that the spontaneous activity of the incoming axons of the CA3 principal cells recruits a CA1 inhibitory microcircuitry via the Schaffer-collateral. This is unlikely, because there is no correlation between CA3 multiunit activity and the extracellularly recorded inhibitory postsynaptic potential in the CA1 [31]. Another possibility is that the spontaneous discharge of CA1 interneurons, although scarce, is keeping a strong blockade of the principal cells. Favoring this hypothesis, the resting membrane potential is more hyperpolarized in CA1 compared to CA3 pyramidal neurons $[32,33]$. These spontaneous discharges might be regulated by the ambient Glu concentration via NMDARs. Indeed, tonic activation of NMDARs by ambient glutamate has been described in virtually all pyramidal cells of the CA1 of the hippocampus in slice models [34-37]. Importantly, as Le Meur et al. have shown [38], neither AMPA/kainate receptors nor metabotropic glutamate receptors contribute to this tonic excitation of pyramidal neurons. This tonic current is not dependent on vesicular release of transmitters from neurons but is affected by inhibition of the enzyme converting Glu, in glutamine in glial cells, indicating that ambient Glu is mainly of glial origin. Consistent with these findings, we have also shown that spontaneous spiking is driven by NMDAR activity, but not by AMPARs, indicating that the tonic activation could reach the threshold of spike generation. The question arises as follows: why do not AMPARs mediate spontaneous activity? NMDARs have a much higher affinity for Glu than AMPARs do; in steady-state conditions, the EC50 for Glu at NMDARs is over two orders of magnitude lower than that at AMPARs [39]. Extrasynaptic NMDARs containing the NR2B subunit have even higher affinity than synaptic NR2A-containing receptors [40]. It should be noted that evoked firing, which is usually detected in the form of population spikes (pop-spikes for short) in CA1 extracellular recordings, is mediated by AMPAR signaling [41]. Under our conditions, action potentials were not inhibited by AMPAR blockade. The reason behind this discrepancy might be that evoked pop-spikes require a synchronous discharge of a population of cells. This coordinated function might be based on the fast AMPAR function.

4.3. Abeta(1-42) Impairs LTP and Hyperexcites without Altering fEPSPs in the CA1. Neuronal hyperexcitability in early $\mathrm{AD}$ and in $\mathrm{AD}$ modeling mice is an emerging finding that points to a network dysfunction as a critical component of the pathomechanism. Soluble Abeta species have been increasingly implicated as the key pathologic components of the disease, thus elucidating the mechanisms by which these species alter neuronal function is important. We confirmed that the Abeta(1-42) preparation we use is really synaptotoxic, impairing LTP. Next we tested its effect on spontaneous firing and found that it enhanced the rate of spontaneous discharges but did not alter evoked fEPSPs. These results suggest that NMDARs are involved in the hyperexcitability induced by Abeta(1-42). Similar results have been recently reported by Varghese et al. using cultured embryonic rat hippocampal cells. Abeta increased spontaneous firing activity dose dependently, reaching the maximum after 1 hour of treatment, which was followed by a complete cessation of spikes following a few hours [42]. The discrepancy between this and our result may be due to the fact that the authors have used a cell culture largely devoid of glial elements, while we have used a complex microcircuitry built up from all of the neuronal cell types (including glia) forming elaborate connections.

The forms of NMDAR are heterotetramer including two NR1 and two NR2 subunits [43]. One particular subunit, $\mathrm{NR} 2 \mathrm{~B}$, is mainly localized in extrasynaptic side. Abeta induced elevation of spiking activity could be prevented by blocking the NR2B subunits, suggesting that Abeta activates extrasynaptic NMDARs. The role of extrasynaptic or perisynaptic NMDARs in Abeta(1-42)-induced changes in functional synaptic plasticity and subsequent cell death has received much attention recently $[22,44,45]$. Extrasynaptic NMDARs contain predominantly NR2B subunits, which in contrast to NR2A-containing synaptic NMDARs trigger apoptotic signaling cascade [46]. Recently it was shown, using organotypic hippocampal cell cultures, that Abeta induces neuronal death and subsequent tau hyperphosporilation via extrasynaptic NR2B subunit [47]. Blocking NR2B subunits not only prevents hyperexcitation caused by Abeta but also rescues Abeta induced LTP impairment $[22,48]$, suggesting that blocking NR2B subunits might be a promising target in $\mathrm{AD}$. However, others have reported that Abeta oligomers directly activate NMDARs especially via NR2A subunit [49, 50].

\section{Conclusions}

Taken together, we show that two electrophysiological events, recorded from hippocampal slices, which evoked fEPSPs and spontaneous firing, are not mediated by the same mechanisms. Evoked fEPSPs, but not firing activity, were mainly regulated by AMPARs. In contrast, spontaneous spikes are governed by NMDAR function. Bath applications of synaptotoxic Abeta(1-42) enhanced firing activity in an NR2B-dependent manner without altering evoked fEPSPs. These effects may contribute to synaptic dysfunctions seen in early AD.

\section{Highlights}

(i) Spontaneous discharges and evoked fEPSPs were recorded from the CA1 of murine slices. 
(ii) AMPA receptor blockade ablates fEPSPs without any effect on spiking rate.

(iii) NMDA receptor modulation affects spontaneous spiking, but not evoked fEPSPs.

(iv) Synaptotoxic amyloid-beta leaves evoked fEPSPs unaltered but increases firing activity via NR2B.

(v) These results confirm that amyloid-beta induces hyperexcitation through NR2B activation.

\section{Abbreviations}

\begin{tabular}{|c|c|}
\hline Abeta(1-42): & Amyloid-beta(1-42) \\
\hline ACSF: & Artificial cerebrospinal fluid \\
\hline $\mathrm{AD}:$ & Alzheimer's disease \\
\hline AMPA: & $\begin{array}{l}\alpha \text {-Amino-3-hydroxy-5-methyl-4- } \\
\text { isoxazolepropionic } \\
\text { acid }\end{array}$ \\
\hline AMPAR: & $\begin{array}{l}\alpha \text {-Amino-3-hydroxy-5-methyl-4- } \\
\text { isoxazolepropionic acid } \\
\text { receptor }\end{array}$ \\
\hline ANOVA: & Analysis of variance \\
\hline CNQX: & $\begin{array}{l}\text { 6-Cyano-7-nitroquinoxaline-2,3- } \\
\text { dione }\end{array}$ \\
\hline fEPSP: & $\begin{array}{l}\text { Field excitatory postsynaptic } \\
\text { potential }\end{array}$ \\
\hline GABA: & Gamma-aminobutyric acid \\
\hline Glu: & Glutamate \\
\hline Low $\mathrm{Mg}^{2+}$ ACSF: & $\begin{array}{l}\text { Low magnesium } \\
\text { concentration-containing artificial } \\
\text { cerebrospinal fluid }\end{array}$ \\
\hline LTP: & Long-term potentiation \\
\hline MEA: & Multielectrode array \\
\hline NMDA: & N-Methyl-D-aspartate \\
\hline NMDAR: & N-Methyl-D-aspartate receptor \\
\hline TTX: & Tetrodotoxin \\
\hline WB: & Western blot. \\
\hline
\end{tabular}

\section{Conflict of Interests}

The authors declare that there is no conflict of interests regarding the publication of this paper.

\section{Authors' Contribution}

Zsolt Bozsó, Lívia Fülöp, and Botond Penke synthetized and characterized Abeta. Edina Varga performed the experiments, Edina Varga and Viktor Szegedi analyzed the data, and Edina Varga, Gábor Juhász, and Viktor Szegedi designed the experiments and wrote the paper.

\section{Acknowledgments}

This study was supported by the following Grants: OTKA PD 83581 from the Hungarian National Scientific Fund, TÁMOP-4.2.2.A-11/1/KONV-2012-0052 from the National Development Agency (NFÜ), and FP7-PEOPLE-2012-IAPP "STEMMAD." Viktor Szegedi is a Bolyai fellow. Edina Varga is supported by a predoctoral grant from Gedeon Richter Plc. The authors wish to thank Györgyi Utassy and Emöke Borbély for their help in the statistical analysis. The authors are also grateful to Alberto Sanchez-Aguilera for his comments on the paper.

\section{References}

[1] R. Dingledine, J. Dodd, and J. S. Kelly, "The in vitro brain slice as a useful neurophysiological preparation for intracellular recording," Journal of Neuroscience Methods, vol. 2, no. 4, pp. 323-362, 1980.

[2] T. Tominaga, Y. Tominaga, and M. Ichikawa, "Optical imaging of long-lasting depolarization on burst stimulation in area CA1 of rat hippocampal slices," Journal of Neurophysiology, vol. 88, no. 3, pp. 1523-1532, 2002.

[3] J. S. Diamond, D. E. Bergles, and C. E. Jahr, "Glutamate release monitored with astrocyte transporter currents during LTP," Neuron, vol. 21, no. 2, pp. 425-433, 1998.

[4] C. Lüscher, R. C. Malenka, and R. A. Nicoll, "Monitoring glutamate release during LTP with glial transporter currents," Neuron, vol. 21, no. 2, pp. 435-441, 1998.

[5] L. G. Brock, J. S. Coombs, and J. C. Eccles, "The recording of potentials from motoneurones with an intracellular electrode," The Journal of Physiology, vol. 117, no. 4, pp. 431-460, 1952.

[6] I. Cohen and R. Miles, "Contributions of intrinsic and synaptic activities to the generation of neuronal discharges in in vitro hippocampus," The Journal of Physiology, vol. 524, no. 2, pp. 485-502, 2000.

[7] W. C. Low, S. L. BeMent, and D. Whitehorn, "Field-potential evidence for extrasynaptic alterations in the hippocampal CA1 pyramidal cell population during paired-pulse potentiation," Experimental Neurology, vol. 80, no. 1, pp. 9-22, 1983.

[8] T. J. Teyler and P. Discenna, "Long-term potentiation as a candidate mnemonic device," Brain Research, vol. 319, no. 1, pp. 15-28, 1984.

[9] L. Mucke and D. J. Selkoe, "Neurotoxicity of amyloid $\beta$ protein: synaptic and network dysfunction," Cold Spring Harbor Perspectives in Medicine, vol. 2, no. 7, Article ID A006338, 2012.

[10] A. F. Teich and O. Arancio, "Is the amyloid hypothesis of Alzheimer's disease therapeutically relevant?" Biochemical Journal, vol. 446, no. 2, pp. 165-177, 2012.

[11] Y.-M. Kuo, M. R. Emmerling, C. Vigo-Pelfrey et al., "Watersoluble $\mathrm{A} \beta(\mathrm{N}-40, \mathrm{~N}-42)$ oligomers in normal and Alzheimer disease brains," The Journal of Biological Chemistry, vol. 271, no. 8, pp. 4077-4081, 1996.

[12] L.-F. Lue, Y.-M. Kuo, A. E. Roher et al., "Soluble amyloid $\beta$ peptide concentration as a predictor of synaptic change in Alzheimer's disease," The American Journal of Pathology, vol. 155, no. 3, pp. 853-862, 1999.

[13] M. J. Rowan, I. Klyubin, W. K. Cullen, and R. Anwyl, "Synaptic plasticity in animal models of early Alzheimer's disease," Philosophical Transactions of the Royal Society of London B: Biological Sciences, vol. 358, no. 1432, pp. 821-828, 2003.

[14] D. M. Walsh, I. Klyubin, J. V. Fadeeva et al., "Naturally secreted oligomers of amyloid $\beta$ protein potently inhibit hippocampal long-term potentiation in vivo," Nature, vol. 416, no. 6880, pp. 535-539, 2002.

[15] M. A. Busche, X. Chen, H. A. Henning et al., "Critical role of soluble amyloid- $\beta$ for early hippocampal hyperactivity in a mouse model of Alzheimer's disease," Proceedings of the 
National Academy of Sciences of the United States of America, vol. 109, no. 22, pp. 8740-8745, 2012.

[16] R. Minkeviciene, S. Rheims, M. B. Dobszay et al., "Amyloid $\beta$-induced neuronal hyperexcitability triggers progressive epilepsy," Journal of Neuroscience, vol. 29, no. 11, pp. 3453-3462, 2009.

[17] J. J. Palop and L. Mucke, "Epilepsy and cognitive impairments in alzheimer disease," Archives of Neurology, vol. 66, no. 4, pp. 435-440, 2009.

[18] S. Li, S. Hong, N. E. Shepardson, D. M. Walsh, G. M. Shankar, and D. Selkoe, "Soluble oligomers of amyloid $\beta$ protein facilitate hippocampal long-term depression by disrupting neuronal glutamate uptake," Neuron, vol. 62, no. 6, pp. 788-801, 2009.

[19] M. Matos, E. Augusto, C. R. Oliveira, and P. Agostinho, "Amyloid-beta peptide decreases glutamate uptake in cultured astrocytes: involvement of oxidative stress and mitogenactivated protein kinase cascades," Neuroscience, vol. 156, no. 4, pp. 898-910, 2008.

[20] E. Mura, S. Zappettini, S. Preda et al., "Dual effect of betaamyloid on $\alpha 7$ and $\alpha 4 \beta 2$ nicotinic receptors controlling the release of glutamate, aspartate and GABA in rat hippocampus," PLoS ONE, vol. 7, no. 1, Article ID e29661, 2012.

[21] L. Liu, T. P. Wong, M. F. Pozza et al., "Role of NMDA receptor subtypes in governing the direction of hippocampal synaptic plasticity," Science, vol. 304, no. 5673, pp. 1021-1024, 2004.

[22] S. Li, M. Jin, T. Koeglsperger, N. E. Shepardson, G. M. Shankar, and D. J. Selkoe, "Soluble a $\beta$ oligomers inhibit long-term potentiation through a mechanism involving excessive activation of extrasynaptic NR2B-containing NMDA receptors," The Journal of Neuroscience, vol. 31, no. 18, pp. 6627-6638, 2011.

[23] L. Fülöp, I. M. Mándity, G. Juhász et al., "A foldamer-dendrimer conjugate neutralizes synaptotoxic $\beta$-amyloid oligomers," PLoS ONE, vol. 7, no. 7, Article ID e39485, 2012.

[24] Z. Bozso, B. Penke, D. Simon et al., "Controlled in situ preparation of $A \beta(1-42)$ oligomers from the isopeptide "iso-A $\beta(1-42)$ ", physicochemical and biological characterization," Peptides, vol. 31, no. 2, pp. 248-256, 2010.

[25] S. C. Harney, D. E. Jane, and R. Anwyl, "Extrasynaptic NR2Dcontaining NMDARs are recruited to the synapse during LTP of NMDAR-EPSCs," The Journal of Neuroscience, vol. 28, no. 45, pp. 11685-11694, 2008.

[26] C. G. Glabe, "Structural classification of toxic amyloid oligomers," Journal of Biological Chemistry, vol. 283, no. 44, pp. 29639-29643, 2008.

[27] R. C. Davis, I. T. Marsden, M. T. Maloney et al., "Amyloid beta dimers/trimers potently induce cofilin-actin rods that are inhibited by maintaining cofilin-phosphorylation," Molecular Neurodegeneration, vol. 6, no. 1, article 10, 2011.

[28] G. M. Shankar, S. Li, T. H. Mehta et al., "Amyloid- $\beta$ protein dimers isolated directly from Alzheimer's brains impair synaptic plasticity and memory," Nature Medicine, vol. 14, no. 8, pp. 837-842, 2008.

[29] I. Klyubin, V. Betts, A. T. Welzel et al., "Amyloid $\beta$ protein dimer-containing human CSF disrupts synaptic plasticity: prevention by systemic passive immunization," Journal of Neuroscience, vol. 28, no. 16, pp. 4231-4237, 2008.

[30] M. Townsend, G. M. Shankar, T. Mehta, D. M. Walsh, and D. J. Selkoe, "Effects of secreted oligomers of amyloid $\beta$-protein on hippocampal synaptic plasticity: a potent role for trimers," The Journal of Physiology, vol. 572, part 2, pp. 477-492, 2006.
[31] A. Beyeler, A. Retailleau, C. Molter, A. Mehidi, J. Szabadics, and $\mathrm{X}$. Leinekugel, "Recruitment of perisomatic inhibition during spontaneous hippocampal activity in vitro," PLoS ONE, vol. 8, no. 6, Article ID e66509, 2013.

[32] D. Fricker, J. A. H. Verheugen, and R. Miles, "Cell-attached measurements of the firing threshold of rat hippocampal neurones," The Journal of Physiology, vol. 517, part 3, pp. 791804, 1999.

[33] R. Tyzio, A. Ivanov, C. Bernard, G. L. Holmes, Y. Ben-Ari, and R. Khazipov, "Membrane potential of CA3 hippocampal pyramidal cells during postnatal development," Journal of Neurophysiology, vol. 90, no. 5, pp. 2964-2972, 2003.

[34] P. Sah, S. Hestrin, and R. A. Nicoll, "Tonic activation of NMDA receptors by ambient glutamate enhances excitability of neurons," Science, vol. 246, no. 4931, pp. 815-818, 1989.

[35] N. O. Dalby and I. Mody, "Activation of NMDA receptors in rat dentate gyrus granule cells by spontaneous and evoked transmitter release," Journal of Neurophysiology, vol. 90, no. 2, pp. 786-797, 2003.

[36] M. C. Angulo, A. S. Kozlov, S. Charpak, and E. Audinat, "Glutamate released from glial cells synchronizes neuronal activity in the hippocampus," The Journal of Neuroscience, vol. 24, no. 31, pp. 6920-6927, 2004.

[37] P. Cavelier and D. Attwell, "Tonic release of glutamate by a DIDS-sensitive mechanism in rat hippocampal slices," The Journal of Physiology, vol. 564, part 2, pp. 397-410, 2005.

[38] K. Le Meur, M. Galante, M. C. Angulo, and E. Audinat, "Tonic activation of NMDA receptors by ambient glutamate of non-synaptic origin in the rat hippocampus," The Journal of Physiology, vol. 580, no. 2, pp. 373-383, 2007.

[39] D. K. Patneau and M. L. Mayer, "Structure-activity relationships for amino acid transmitter candidates acting at N-methyl-Daspartate and quisqualate receptors," The Journal of Neuroscience, vol. 10, no. 7, pp. 2385-2399, 1990.

[40] T. Priestley, P. Laughton, J. Myers, B. Le Bourdelles, J. Kerby, and P. J. Whiting, "Pharmacological properties of recombinant human $\mathrm{N}$-methyl-D-aspartate receptors comprising NR1a/NR2A and NR1a/NR2B subunit assemblies expressed in permanently transfected mouse fibroblast cells," Molecular Pharmacology, vol. 48, no. 5, pp. 841-848, 1995.

[41] S. J. Wood and J. E. Tattersall, "An improved brain slice model of nerve agent-induced seizure activity.", Journal of Applied Toxicology, vol. 21, supplement 1, pp. S83-S86, 2001.

[42] K. Varghese, P. Molnar, M. Das et al., "A new target for amyloid beta toxicity validated by standard and high-throughput electrophysiology," PLoS ONE, vol. 5, no. 1, Article ID e8643, 2010.

[43] H. Monyer, R. Sprengel, R. Schoepfer et al., "Heteromeric NMDA receptors: molecular and functional distinction of subtypes," Science, vol. 256, no. 5060, pp. 1217-1221, 1992.

[44] J. J. Palop and L. Mucke, "Amyloid-B-induced neuronal dysfunction in Alzheimer's disease: from synapses toward neural networks," Nature Neuroscience, vol. 13, no. 7, pp. 812-818, 2010.

[45] M. Talantova, S. Sanz-Blasco, X. Zhang et al., "Abeta induces astrocytic glutamate release, extrasynaptic NMDA receptor activation, and synaptic loss," Proceedings of the National Academy of Sciences of the United States of America, vol. 110, no. 27, pp. E2518-E2527, 2013.

[46] G. E. Hardingham, Y. Fukunaga, and H. Bading, "Extrasynaptic NMDARs oppose synaptic NMDARs by triggering CREB shutoff and cell death pathways," Nature Neuroscience, vol. 5, no. 5, pp. 405-414, 2002. 
[47] C. Tackenberg, S. Grinschgl, A. Trutzel et al., "NMDA receptor subunit composition determines beta-amyloid-induced neurodegeneration and synaptic loss," Cell Death \& Disease, vol. 4, article e608, 2013.

[48] J. Zhang, C. Wang, T. Deng et al., "The preventive effect of NR2B and NR2D-containing NMDAR antagonists on A $\beta$-induced LTP disruption in the dentate gyrus of rats," Metabolic Brain Disease, vol. 28, no. 4, pp. 697-704, 2013.

[49] L. Texidó, M. Martín-Satué, E. Alberdi, C. Solsona, and C. Matute, "Amyloid $\beta$ peptide oligomers directly activate NMDA receptors," Cell Calcium, vol. 49, no. 3, pp. 184-190, 2011.

[50] A. Domingues, S. Almeida, E. F. da Cruz e Silva, C. R. Oliveira, and A. C. Rego, "Toxicity of $\beta$-amyloid in HEK293 cells expressing NR1/NR2A or NR1/NR2B N-methyl-d-aspartate receptor subunits," Neurochemistry International, vol. 50, no. 6, pp. 872880, 2007. 


\title{
Overexpression of Hsp27 ameliorates symptoms of Alzheimer's disease in APP/PS1 mice
}

\author{
Melinda Erzsébet Tóth • Viktor Szegedi • Edina Varga • Gábor Juhász • \\ János Horváth • Emőke Borbély • Balázs Csibrány • Róbert Alföldi • \\ Nikolett Lénárt • Botond Penke • Miklós Sántha
}

Received: 11 December 2012 /Revised: 3 April 2013 / Accepted: 4 April 2013 /Published online: 21 April 2013

(C) Cell Stress Society International 2013

\begin{abstract}
Hsp27 belongs to the small heat shock protein family, which are ATP-independent chaperones. The most important function of Hsp27 is based on its ability to bind non-native proteins and inhibit the aggregation of incorrectly folded proteins maintaining them in a refolding-competent state. Additionally, it has anti-apoptotic and antioxidant activities. To study the effect of Hsp27 on memory and synaptic functions, amyloid- $\beta(A \beta)$ accumulation, and neurodegeneration, we generated transgenic mice overexpressing human Hsp27 protein and crossed with APPswe/PS1dE9 mouse strain, a mouse model of Alzheimer's disease (AD). Using different behavioral tests, we found that spatial learning was impaired in $\mathrm{AD}$ model mice and was rescued by Hsp27 overexpression. Electrophysiological recordings have revealed that excitability of neurons was significantly increased, and long-term potentiation (LTP) was impaired in AD model mice, whereas they were normalized in Hsp27 overexpressing AD model mice. Using anti-amyloid antibody, we counted significantly less amyloid plaques in the brain of APPswe/PS1dE9/Hsp27 animals compared to AD model mice. These results suggest that overexpression of Hsp27 protein might ameliorate certain symptoms of AD.
\end{abstract}

\footnotetext{
M. E. Tóth $(\varangle) \cdot$ V. Szegedi $\cdot$ B. Csibrány $\cdot$ R. Alföldi

N. Lénárt $\cdot M$. Sántha

Institute of Biochemistry, Biological Research Centre of the

Hungarian Academy of Sciences, Temesvari Ave. 62,

6726 Szeged, Hungary

e-mail: toth.e.melinda@gmail.com

E. Varga $\cdot$ G. Juhász $\cdot J$. Horváth $\cdot$ E. Borbély $\cdot$ B. Penke Deparment of Medical Chemistry, Faculty of Medicine, University of Szeged, Dóm Square 11,

Szeged, Hungary
}

Keywords Heat shock proteins · Transgenic mice - Mouse model $\cdot$ Alzheimer's disease $\cdot$ Amyloid plaques $\cdot$ Behavior tests · Electrophysiological recordings $\cdot$ Real-time Q-PCR

\section{Introduction}

$\mathrm{AD}$ is one of the most common neurodegenerative diseases, and its prevalence is strongly correlated with aging (Evans et al. 1989). AD is characterized by progressive loss of memory and cognitive functions (McKhann et al. 1984). The pathological hallmarks of AD are extracellular amyloid plaque deposition, formation of intracellular neurofibrillary tangles, and other alterations in the brain such as activation of microglial cells, oxidation of lipids, induction of reactive oxygen species, disruption of neuronal metabolic homeostasis, and neuronal cell death (Serrano-Pozo et al. 2011; Monji et al. 2001). Amyloid plaques and neurofibrillary tangles are present mainly in brain regions involved in learning, memory, and emotional behaviors, primarily in the hippocampus (Mattson 2004).

Heat shock proteins (Hsps) are ubiquitously expressed evolutionary conserved proteins which are upregulated by different stressors and also in various pathological conditions. Most of the stress-induced proteins are molecular chaperons, and they have an essential role in biosynthesis, transport, translocation, folding, and assembly of other proteins (Morimoto et al. 1992). Under stress, Hsps prevent protein misfolding and oligomerization, and they transfer misfolded proteins to the proteasome for degradation (Becker and Craig 1994). They also assist in the maintenance of normal cellular homeostasis and metabolism.

Hsp27 belongs to the small heat shock protein (sHsp) family, which are ATP-independent chaperones (Jakob et al. 1993). The most important function of sHsps is that they can 
inhibit the aggregation of incorrectly folded proteins by binding to non-native proteins, and maintain them in a refolding-competent state (Haslbeck and Buchner 2002). Moreover, they also have anti-apoptotic and antioxidant activities and can bind to the actin cytoskeleton and stabilize it (Arrigo et al. 2002, Preville et al. 1999, Wang and Spector 1996).

Hsps are upregulated in several neurodegenerative diseases and can protect brain cells against free radical injury, oxidative stress, and misfolded proteins (Kalmar and Greensmith 2009). Several studies indicate that chaperones are potent suppressors of neurodegeneration and are, therefore, promising therapeutic targets for protein conformational disorders (reviewed in Muchowski and Wacker 2005). For example, treating a polyglutamine disease model with an antiulcer drug, geranylgeranylacetone (GGA), which can induce the expression of different Hsps, could suppress the accumulation of pathogenic proteins and ameliorate the related phenotype (Katsuno et al. 2005). In a rat model of Parkinson's disease, Hsp104 was found to be similarly efficient (Lo Bianco et al. 2008). An increased level of expression of small Hsps and Hsp70 in the brain of AD patients has been reported in a number of studies (Perez et al. 1991; Muchowski and Wacker 2005). Several studies suggest that expression of Hsps could suppress the progression of $\mathrm{AD}$ (Magrané et al. 2004; Muchowski and Wacker 2005; Evans et al. 2006). Hoshino et al. (2011) investigated the effect of overexpression of Hsp70 on AD-related phenotypes, using double transgenic mice overexpressing Hsp70 and a mutant (Swedish) type of APP (APPswe). They demonstrated that overexpression of Hsp70 inhibited the development of the pathological phenotype of $\mathrm{AD}$ and the resultant cognitive deficit, possibly through its effects on antiaggregation, neuroprotection, and stimulation of $\mathrm{A} \beta$ clearance.

To study the effect of a small heat shock protein, Hsp27, on memory and synaptic functions, $A \beta$ accumulation, and neurodegeneration, we generated transgenic mice overexpressing the human Hsp27 protein and crossed them with the APPswe/PS1dE9 mouse strain, a widely used mouse model of $\mathrm{AD}$.

\section{Materials and methods}

Animals

The study conformed to EU Directive 2010/63/EU and was approved by the regional Station for Animal Health and Food Control (Csongrád, Hungary) under project license XVI/02752/2009. Mice were housed in groups of two to three under standard conditions $\left(24{ }^{\circ} \mathrm{C}, 12 \mathrm{~h}\right.$ light-dark cycle) with food and water available ad libitum.
Generation of APPswe/PS1dE9/Hsp27 transgenic mice

We have previously generated transgenic mice overexpressing the human Hsp27 protein on FVB genetic background (Tóth et al. 2010). Transgenic DNA construct contained the human Hsp27 cDNA driven from a cytomegalovirus (CMV) promoter. This transgenic line was crossed with C57BL/6 mice four times in order to establish a Hsp27 transgenic line on a homogenous C57BL/6 genetic background. B6C3$\mathrm{Tg}$ (APPswe/PS1dE9)85Dbo/Mmjax mice were purchased from The Jackson Laboratory (Bar Harbor, ME, USA) and maintained on C57BL/6 genetic background. Hsp27 transgenic mice then were crossed with APPswe/PS1dE9 mice to generate APPswe/PS1dE9/Hsp27 multiple transgenic strain. To identify the genotype of the offsprings, polymerase chain reaction (PCR) was performed from tail biopsies using the following primers: 5'-GTC CCT GGA TGT CAA CCA CT-3' and 5'-GAC TGG GAT GGT GAT CTC GT-3' for Hsp27; 5'GAC TGA CCA CTC GAC CAG GTT CTG-3' and 5'-CTT GTA AGT TGG ATT CTC ATA TCC G-3' for APP(Swe); and 5'-AAT AGA GAA CGG CAG GAG CA-3' and 5'-GCC ATG AGG GCA CTA ATC AT-3' for PS1dE9. The PCR amplification was done in a MJ Research PTC-200 Thermal Cycler using the following parameters: denaturation at $95{ }^{\circ} \mathrm{C}$ for $4 \mathrm{~min}$ followed by 29 cycles of denaturation at $95{ }^{\circ} \mathrm{C}$ for $1 \mathrm{~min}$, annealing at $56^{\circ} \mathrm{C}$ for $1 \mathrm{~min}$ and elongation at $72{ }^{\circ} \mathrm{C}$ $1 \mathrm{~min}$, and a final extension at $72{ }^{\circ} \mathrm{C}$ for $4 \mathrm{~min}$.

\section{Western blot analysis}

Expression of Hsp27 was determined from cortical and hippocampal tissues of 7 months old transgenic mice and wild type littermates. For ApoA1 protein level estimation, whole brain tissue was used. Total protein was isolated from frozen tissues homogenized in lysis buffer (containing $50 \mathrm{mM}$ Tris- $\mathrm{HCl}, 150 \mathrm{mM} \mathrm{NaCl}, 1 \%$ Triton X-100, $0.5 \% \mathrm{Na}$ deoxycholate, $0.1 \%$ SDS, and protease inhibitor), centrifuged at $10,000 \mathrm{rpm}$ for $10 \mathrm{~min}$ at $4{ }^{\circ} \mathrm{C}$, and the supernatant was used for western blot analysis. Protein concentration was measured at $280 \mathrm{~nm}$ using a NanoDrop spectrophotometer (NanoDrop Technologies). Protein samples $(50 \mu \mathrm{g})$ were separated by $10 \%$ SDSPAGE (Cambrex) and transferred electrophoretically onto Hybond-P PVDF membrane (Amersham). Membrane was blocked for $1 \mathrm{~h}$ in $5 \%$ milk powder. After a short wash in PBS-Tween buffer, membrane was incubated with anti-Hsp27 (1:500, Stressgen, Cat No: SPA-803), anti-ApoA1 (1:250, Rockland, Cat. No: 600-101-196), and anti- $\beta$-actin $(1: 1,400$, Sigma, Cat. No: A2103) antibodies overnight at $4{ }^{\circ} \mathrm{C}$. After a brief wash, membranes were incubated with anti-goat (1:10,000, Jackson ImmunoResearch, Cat. No: 305-035003) or anti-rabbit $(1: 35,000$, Jackson ImmunoResearch, Cat. No: 111-035-003) secondary antibodies for $45 \mathrm{~min}$ at 
room temperature. Signals were developed using Luminata Forte Western HRP Substrate (Millipore) according to the manufacturer's instructions. Signal intensities were quantified using ImageJ 1.45 software.

\section{Behavioral tests}

For behavioral testing, 7-month-old male mice were used. Before starting the tests, mice were handled daily for 2 weeks. Behavioral tests were performed between 9:00 a.m. and 4:00 p.m. Tests were recorded by video camera, and data were analyzed by EthoVision 2002 computer-controlled video tracking system (The Noldus Information Technology, The Netherlands).

\section{Open field}

Locomotor activity and anxiety-like behavior were studied using open field test. Each mouse was placed in the center of a plastic oval arena $(50 \times 70 \times 30 \mathrm{~cm})$ virtually divided into central and peripheral areas by the software. Total distance travelled (in centimeters), number of rearings, time spent with grooming, and time spent in the peripheral areas were measured. Data were collected for $5 \mathrm{~min}$. All animals were tested once.

\section{Barnes maze test}

In the Barnes maze test, using a bright light, animals were reinforced to escape from the open platform surface to a small dark chamber located under the platform called "target box." The experiment was performed according to a technique published on the internet (Sunyer et al. 2007). The maze consisted of a circular platform $(100 \mathrm{~cm}$ in diameter) with 20 holes (hole diameter, $5 \mathrm{~cm}$ ) along the perimeter. The circular open field was elevated $90 \mathrm{~cm}$ from the floor. A black escape (target) box $(19 \times 6 \times 7 \mathrm{~cm})$ was located under one of the holes. The location of the target box was consistent for any given mouse, but was randomized across mice. The platform was surrounded by curtains and visual cues on it to help the mice with orientation. Mice were placed in the middle of the maze and were free to explore it. The trial ended after $3 \mathrm{~min}$ or when the mouse entered the escape box. When a mouse entered the escape box, it was allowed to stay in it for $1 \mathrm{~min}$. If the mouse did not find the escape box, it was guided to it and left inside for $1 \mathrm{~min}$. One trial per day was performed for five consecutive days. Time of latency to enter the target box was measured. On day 8 , the probe trial was performed without the escape box to confirm that this spatial task was acquired based on navigation using distal-environment room cues. The trial ended after
2 min. Time of latency to reach the target hole was measured.

\section{Morris water maze test}

For the Morris water maze test, a circular pool $(130 \mathrm{~cm}$ in diameter and $60 \mathrm{~cm}$ in height) was filled to a height of $45 \mathrm{~cm}$ with water. Water temperature was maintained between $22{ }^{\circ} \mathrm{C}$ and $23{ }^{\circ} \mathrm{C}$, and it was made opaque by mixing milk in it. For the invisible platform test, a white colored platform $(5 \mathrm{~cm}$ in diameter) was placed at the center in one of four quadrants of the pool (training quadrant) and submerged $1 \mathrm{~cm}$ below the water surface so that it was invisible at water level. The pool was surrounded by curtains, and different spatial cues were attached to the curtains to help the mice with orientation. The location of the platform was fixed at the same quadrant while the start position of swimming was varied. Mice were given two trials per day for five consecutive days, during which they were allowed to find the platform within $90 \mathrm{~s}$. Once the mouse located the platform, it was permitted to stay on it for $10 \mathrm{~s}$. If the mouse did not find the platform within $90 \mathrm{~s}$, it was guided to the platform and placed on it for $10 \mathrm{~s}$. The escape latency, the time required for the mouse to find and climb onto the platform, was recorded. The means of the data from each day were used for statistics. Some of the mice have shown floating behavior in the Morris water maze test. This means that mice remained motionless most of the time during the trial period. These mice were also very passive in the Barnes maze test. We counted the trials when mice showed floating/passive behavior and found that three mice were motionless almost in the $70 \%$ of trials; therefore, these mice were excluded from the behavioral tests.

\section{Immunohistochemistry}

Subsequent to the behavioral tests, mice were sacrificed by cervical dislocation, and the brains were removed for further studies. Frozen sections $(10 \mu \mathrm{m})$ of the brains were processed for immunohistochemistry. Sections were fixed in acetone for $3 \mathrm{~min}$. After a brief wash with PBS, sections were incubated with $1.5 \% \mathrm{H}_{2} \mathrm{O}_{2}$ in methanol for $20 \mathrm{~min}$ then with $3 \% \mathrm{H}_{2} \mathrm{O}_{2}$ for $20 \mathrm{~min}$ to block endogenous peroxidases. PBS wash was followed by collagenase treatment using $0.1 \mathrm{mg} / \mathrm{ml}$ collagenase type II (Sigma) in a buffer containing $0.25 \mathrm{M} \mathrm{NaCl}, 50 \mathrm{mM}$ Tris- $\mathrm{HCl}, \mathrm{pH} 7.4$, and $1 \mathrm{mM}$ EDTA at $37{ }^{\circ} \mathrm{C}$ for $5 \mathrm{~min}$. After a brief wash in PBS, sections were incubated in $5 \%$ goat serum for $1 \mathrm{~h}$ at room temperature to prevent nonspecific binding of the antibody. Sections were then covered with anti-A $\beta$ [1-42] 
(1:60, Invitrogen, Cat No. 700254), anti-cleaved caspase-3 (1:50, Cell Signalling, Cat. No. Asp-175), or with antiHsp27 (1:50, Stressgen, Cat No: SPA-803) primary antibodies overnight at $4{ }^{\circ} \mathrm{C}$. Slides were washed with PBS, then goat anti-rabbit secondary antibody $(1: 150$, Jackson ImmunoResearch, Cat. No.111-035-003) was applied for $45 \mathrm{~min}$. After washing, slides were incubated with developing reagent (10\% dimethyl formamide, $10 \%$ imidazole, $0.02 \%$ aminoethyl carbazole, $0.04 \% \mathrm{H}_{2} \mathrm{O}_{2}$ ) at room temperature until the brown color appeared (approximately $10 \mathrm{~min}$ ). Sections were then counterstained with hematoxylin solution for $2 \mathrm{~min}$ at room temperature followed by washing with PBS, and they were covered with glycerol gelatin.

For $A \beta$ [1-42] and cleaved capase-3 antibody stainings, 7 -month-old transgenic $(n=6)$ and wild type $(n=6)$ animals were used. Stained sections were photographed using a light microscope equipped with CCD camera, and amyloid plaques or apoptotic cells were counted in 15 microscopic fields by two independent individuals.

\section{Fluoro-Jade C staining}

Brains were removed, and $10-\mu \mathrm{m}$ acetone-fixed frozen sections were prepared. Slides were immersed into $a b-$ solute ethanol for $5 \mathrm{~min}$, then rinsed in $70 \%$ ethanol for $2 \mathrm{~min}$, in $30 \%$ ethanol for an additional $2 \mathrm{~min}$, and finally in distilled water for $2 \mathrm{~min}$. Sections then were incubated in $0.06 \%$ potassium permanganate solution for $30 \mathrm{~min}$. Following a 2-min water rinse, sections were transferred into a $0.0004 \%$ solution of FluoroJade $\mathrm{C}$ (Chemicon) fluorescent dye dissolved in $0.1 \%$ acetic acid. Slides were washed three times in distilled water for $1 \mathrm{~min}$. After drying, sections were cleared in xylene for $2 \mathrm{~min}$ and coverslipped with DPX nonfluorescent mounting media. Degenerating neurons emitting green fluorescence were visualized under Nikon Eclipse E600 fluorescent microscope using a 520-nm fluorescein filter set. Six 7-month-old animals from each group were selected, and two slides of each animal's brain were stained using Fluoro-Jade C dye. On each slide, 15 digital photographs were taken, and degenerating neurons were counted by two independent individuals.

\section{Hippocampal slice electrophysiology}

Following standard procedures, $400-\mu \mathrm{m}$-thick transverse hippocampal slices were prepared from the brain of 7month-old mice using a McIlwain tissue chopper (Campden Instruments, Loughborough, UK). Slices were incubated in standard artificial cerebrospinal fluid (ACSF) at ambient temperature for $60 \mathrm{~min}$, which was constantly gassed with $95 \% \mathrm{O}_{2}-5 \% \mathrm{CO}_{2}$. ACSF contained (millimolar) $\mathrm{NaCl}$, 130; KCl, 3.5; $\mathrm{CaCl}_{2}, 2 ; \mathrm{MgCl}_{2}, 2 ; \mathrm{NaH}_{2} \mathrm{PO}_{4}, 0.96$; $\mathrm{NaHCO}_{3}, 24$; D-glucose, 10 ( $\mathrm{pH}$ 7.4). Individual slices were transferred to a 3D-MEA chip with 60 tip-shaped and $60-\mu \mathrm{m}$-high electrodes spaced by $200 \mu \mathrm{m}$ (Ayanda Biosystems, S.A., Lausanne, Switzerland). The slice was continuously perfused with oxygenated ACSF $(1.5 \mathrm{ml} / \mathrm{min}$ at $36{ }^{\circ} \mathrm{C}$ ) during the whole recording session. Data were recorded by a standard, commercially available MEA setup (Multi-Channel Systems MCS GmbH, Reutlingen, Germany). The Schaffer collateral was stimulated by injecting a biphasic voltage waveform $(-100 /+100 \mu \mathrm{s})$ through one selected electrode at $0.033 \mathrm{~Hz}$. Care was taken to choose the stimulating electrode in the same region from one slice to the other. The peak-to-peak amplitudes of fEPSPs at the stratum pyramidale and stratum radiatum of CA1 were analyzed. After a 30-min incubation period, the threshold and the maximum of stimulation intensity for evoked responses was determined. For evoking responses, $30 \%$ of the maximal stimulation intensity was used.

Following a stable 10-min control sequence, the stimulus intensity was continuously increased from 400 to $3,200 \mathrm{mV}$ with $400 \mathrm{mV}$ steps (input/output curve). Paired-pulse protocol consisted of two stimulation pulses injected with interstimulus intervals of $20,50,200$, and $500 \mathrm{~ms}$ with $0.033 \mathrm{~Hz}$. Three data points were obtained at every stimulation intensity/interstimulus intervals at the input/output curve and paired-pulse protocol. LTP was induced using a theta-burst stimulation (TBS) pattern applied at the maximum stimulation intensity. TBS comprised a train with ten bursts given at $5 \mathrm{~Hz}$ per train and four pulses given at $100 \mathrm{~Hz}$ per burst.

\section{RNA extraction and quantitative real-time PCR}

For quantitative real-time PCR (Q-PCR), 6-month-old Hsp27 transgenic $(n=3)$ and wild type mice $(n=3)$ were used. Total RNA was extracted from whole brain using Trizol reagent (Invitrogen), according to the manufacturer's protocol. RNA samples then were cleaned using NucleoSpin RNA Clean-up columns (Macherey-Nagel) and treated with DNaseI (Macherey-Nagel) for $30 \mathrm{~min}$. First-strand cDNA was synthesized by reverse transcription (5 $\mu \mathrm{g}$ RNA/30 $\mu \mathrm{l}$ reaction volume) using High-Capacity cDNA Archive kit (Applied Biosystems). The temperature profile of the reaction was as follows: $10 \mathrm{~min}$ at room temperature, $2 \mathrm{~h}$ at $37{ }^{\circ} \mathrm{C}, 5 \mathrm{~min}$ on ice, and finally, 10 min at $75{ }^{\circ} \mathrm{C}$.

Q-PCR was performed on a RotorGene 3000 instrument (Corbett Research, Sydney, Australia) using gene-specific primers listed in Table 1. The cDNA was diluted 1:20, and $9 \mu \mathrm{l}$ of this mix was used as a template in the reaction. 
Table 1 List of Q-PCR primers used in this study

\begin{tabular}{lll}
\hline Gene & Forward primer & Reverse primer \\
\hline Amyloid precursor protein (APP) & TACTGCATGGCGGTGTGT & CGTGGGAAGTTTATCAGGATCT \\
Apolipoprotein-AI (ApoAI) & TATGTGGATGCGGTCAAAGA & TGAACCCAGAGTGTCCCAGT \\
Apolipoprotein-D (ApoD) & GAAGGCTTTTACAGGCTCCA & GGCCAGGAACATCAGCAT \\
Apolipoprotein-E (ApoE) & CAATTGCGAAGATGAAGGCTC & TAATCCCAGAAGCGGTTCAG \\
Nitric oxide synthase-1 (Nos1) & CATCAGGCACCCCAAGTT & CAGCAGCATGTTGGACACA \\
Nitric oxide synthase-3 (Nos3) & CCAGTGCCCTGCTTCATC & GCAGGGCAAGTTAGGATCAG \\
LDL receptor-related protein-1 (Lrp1) & ACCACCATCGTGGAAAATG & GTCCCAGCCACGGTGATA \\
LDL receptor-related protein-2 (Lrp2) & GATGGATTAGCCGTGGACTG & TCCGTTGACTCTTAGCATCTGA \\
Low-density lipoprotein receptor (LDLr) & CAAGAGGCAGGGTCCAGA & CCAATCTGTCCAGTACATGAAGC \\
Heat shock protein 90 (Hsp90) & GTCTCGTGCGTGTTCATTCA & CATTAACTGGGCAATTTCTGC \\
\hline
\end{tabular}

Reactions were performed in a total volume of $20 \mu \mathrm{l}$ containing $10 \mu \mathrm{l}$ of FastStart SYBR Green Master mix (Roche) and $5 \mathrm{mM}$ of each primer. The amplification was carried out with the following cycling parameters: $15 \mathrm{~min}$ heat activation at $95^{\circ} \mathrm{C}$, followed by 45 cycles denaturation at $95{ }^{\circ} \mathrm{C}$ for $25 \mathrm{~s}$, annealing at $60{ }^{\circ} \mathrm{C}$ for $25 \mathrm{~s}$, and extension at $72{ }^{\circ} \mathrm{C}$ for $20 \mathrm{~s}$. Fluorescent signals were collected after each extension step at $72{ }^{\circ} \mathrm{C}$. Relative expression ratios were normalized to $\beta$-actin.

Statistical analysis

All data obtained in this experiment were expressed as mean \pm SEM. Statistical analysis was performed by one-way analysis of variance (ANOVA) followed by Fisher's post hoc test using OriginPro8 software. Electrophysiological data were analyzed by two-way ANOVA followed by Tukey's post hoc test. The level of statistical confidence was set at $p<0.05$.

\section{Results}

Generation of transgenic mice

Transgenic mice overexpressing the human Hsp27 protein were generated in our laboratory as described earlier (Tóth et al. 2010). By crossing the human Hsp27 overexpressing mice with the APPswe/PS1dE9 mouse strain, we generated a triple transgenic mouse strain. The APPswe/PS1dE9 strain (The Jackson Laboratory, Bar Harbor, ME, USA) is a widely used mouse model of AD (Jankowsky et al. 2004, Reiserer et al. 2007, Hamilton and Holscher 2012), and it shows several symptoms of the disease including impaired spatial learning, reduced long-term potentiation, widespread amyloid deposition, and mild neurodegeneration (The Jackson Laboratory (2013)) (http://jaxmice.jax.org/strain/004462.html). First, cerebral expression of the Hsp27 transgene was investigated. Using western blot analysis, robust expression of human Hsp27 was detected in the cortical and hippocampal tissues of Hsp27 and triple transgenic (AD/Hsp) brains, while no expression was found in wild type and APPswe/PS1dE9 (AD) littermates (Fig. 1a). Hsp27 expression was also confirmed in the brain of Hsp27 and APPswe/PS1dE9/Hsp27 animals using immunohistochemical staining (Fig. 1b). While Hsp27 antibody stained hippocampal tissues of Hsp27 transgenics homogeneously, it showed a spotted, plaque-like staining pattern in the hippocampal region of APPswe/ PS1dE9/Hsp27 brains (Fig. 1c).

\section{Behavioral tests}

Seven-month-old male mice were divided into three experimental groups: an AD mouse model group (APPswe/PS1dE9, $n=11)$, an APPswe/PS1dE9/Hsp27 triple transgenic group $(n=$ $12)$, and a wild type group $(n=9)$.

\section{Locomotor activity}

First, locomotor activity (total distance travelled), exploratory behavior (number of rearings), and anxiety (time spent on the periphery, time spent with grooming) were recorded using open field test. There was no significant difference between groups in these behavioral features (total distance travelled, $p=0.25$; rearings, $p=0.34$; time spent on periphery, $p=0.33$; grooming, $p=0.64$ ).

\section{Barnes maze test}

Spatial learning and memory were tested using Barnes maze and Morris water maze tests. Both tests are based on spatial navigation, and the performance of the animals depends on hippocampal function (Kennard and Woodruff-Pak 2011). In Barnes maze test, APPswe/PS1dE9 mice spent more than $130 \mathrm{~s}$ with searching the escape box on 
Fig. 1 a Detection of human Hsp27 expression in the hippocampus and cortex of wild type (Wt), APPswe/PS1dE9 (AD), APPswe/PS1dE9/Hsp27 (ADHsp), and Hsp27 transgenic mice (Hsp27) using western blot analysis. b Hsp27 immunostaining of brain sections of 7 months old wild type (Wt), Hsp27 transgenic (Hsp27), APPswe/PS1dE9, and APPswe/PS1dE9/Hsp27 mice.

Brown staining indicates human Hsp27

immunoreactivity (black arrows). Nuclei were counterstained with hematoxylin. Scale bar indicates $100 \mu \mathrm{m}$. c Higher magnification of the hippocampal region of Hsp27 transgenic and APPswe/ PS1dE9/Hsp27 mice stained by anti-Hsp27 antibody. Black arrows indicate a plaque-like staining of Hsp27. Scale bar represents $100 \mu \mathrm{m}$

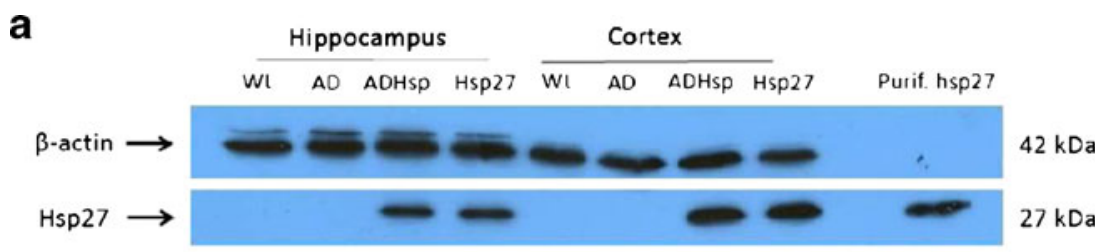

b
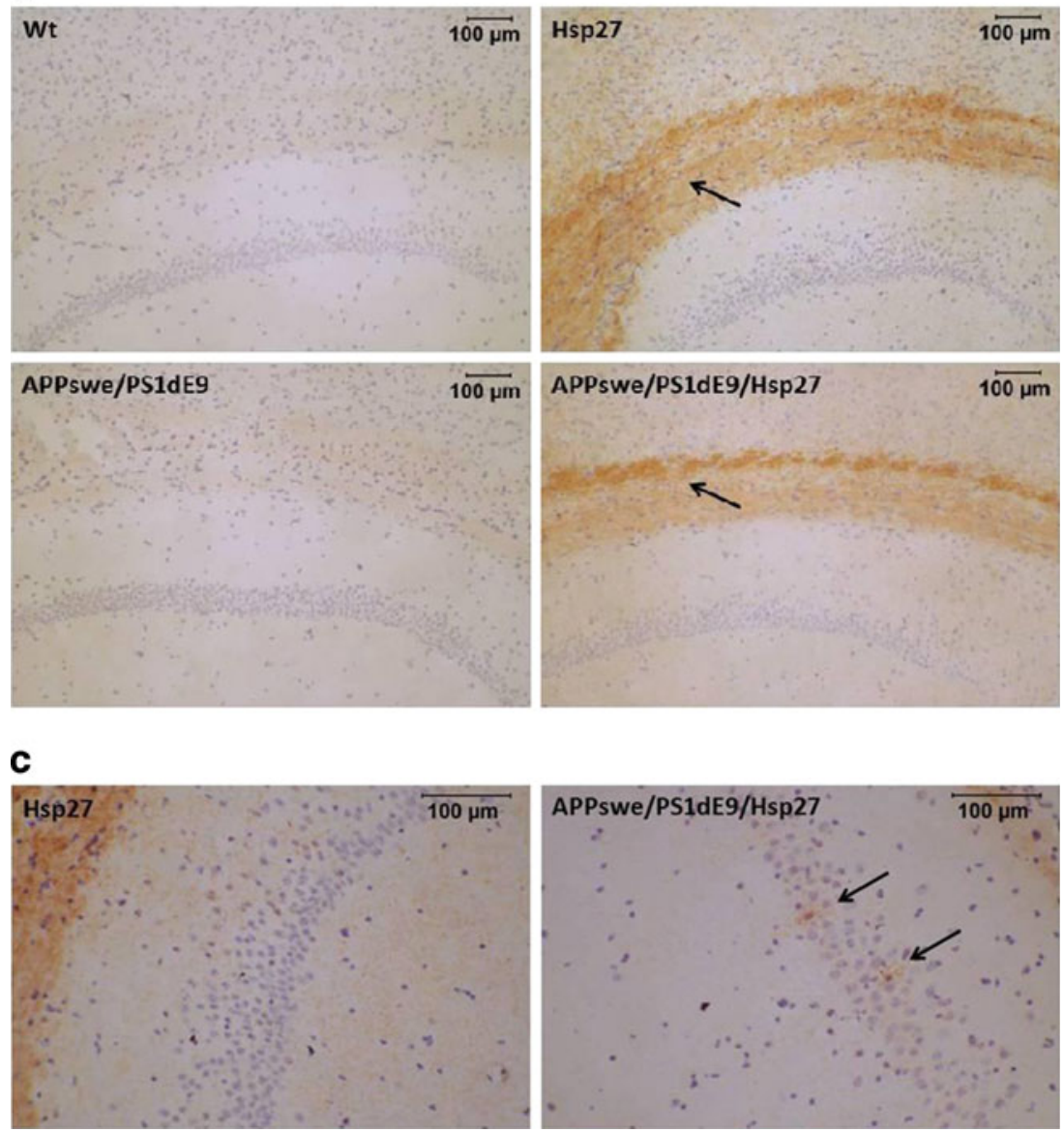

each day of the training period. In contrast, wild type and APPswe/PS1dE9/Hsp27 mice learned soon to find the escape hole as indicated by the reduction of escape latency. On the fourth day, mice from the wild type group spent $76 \mathrm{~s}$ with searching and performed significantly better than APPswe/PS1dE9 mice (140 s; $p<0.05$; Fig. 2a). However, there was no significant difference between the performance of wild type and APPswe/PS1dE9/Hsp27 mice. On the fifth day, the escape latency of the wild type and APPswe/PS1dE9/Hsp27 groups were 92 and $72 \mathrm{~s}$, respectively, performing significantly better then APPswe/PS1dE9 mice (169 s; $p<0.01$ and $p<0.001$ ), and again, there was no significant difference between APPswe/PS1dE9/Hsp27 and wild type groups (Fig. 2a). The probe trial was performed 3 days after the last training session. The result of the probe trial was similar to the previous trial; wild type and APPswe/PS1dE9/Hsp27 mice found the correct target hole within 50 and $41 \mathrm{~s}$, respectively, and these were significantly shorter compared to APPswe/PS1dE9 mice (93 s; $p<$ 0.05 and $p<0.01)$. No statistical difference was observed between wild type and APPswe/PS1dE9/Hsp27 groups (Fig. 2b).

\section{Morris water maze test}

Spatial learning was also tested using Morris water maze to confirm the result of Barnes maze test. On the third day, wild type mice find the escape platform in $41 \mathrm{~s}$ on average, and this was significantly shorter compared to APPswe/PS1dE9 group (76 s, $p<0.01$; Fig. $2 \mathrm{c}$ ). On the fourth day, the escape latency of the wild type and APPswe/PS1dE9/Hsp27 groups was 52 and $50 \mathrm{~s}$, respectively, performing significantly better than APPswe/PS1dE9 mice (74 s; $p<0.05)$. There was no difference 
Fig. 2 Assessment of learning and memory using behavioral assays. Cognitive behavior of 7 months old wild type (WT, $n=9)$, APPswe/PS1dE9 $(n=11)$, and APPswe/PS1dE9/Hsp27

$(n=12)$ transgenic mice were compared. Escape latency in seconds during training session (a) and probe test of the Barnes maze test (b). Escape latency in seconds in Morris water maze test (c). Mean \pm SEM is shown; ${ }^{*} p<0.05 ;{ }^{* *} p<0.01$;

$* * * p<0.001$ a

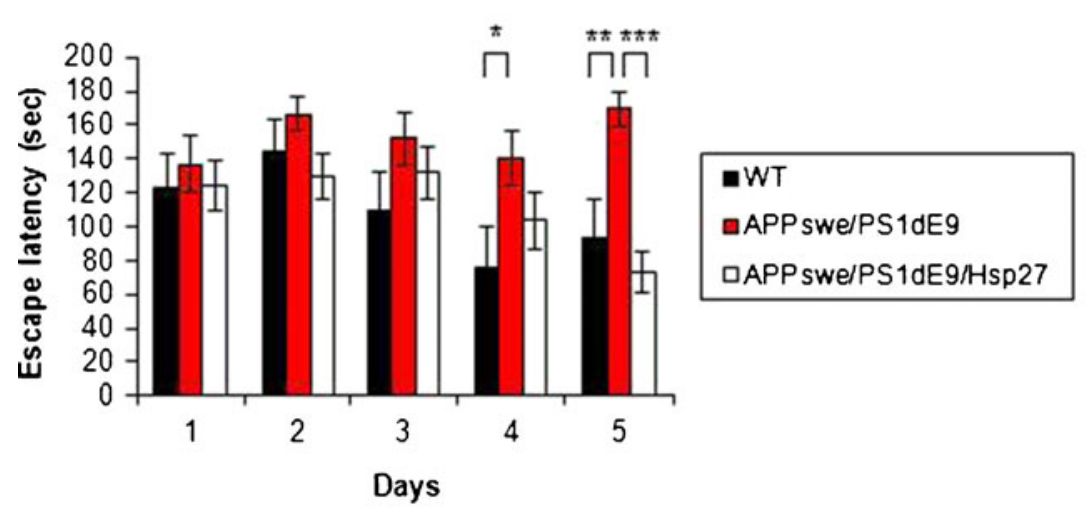

\section{b Escape latency in Barnes maze probe}

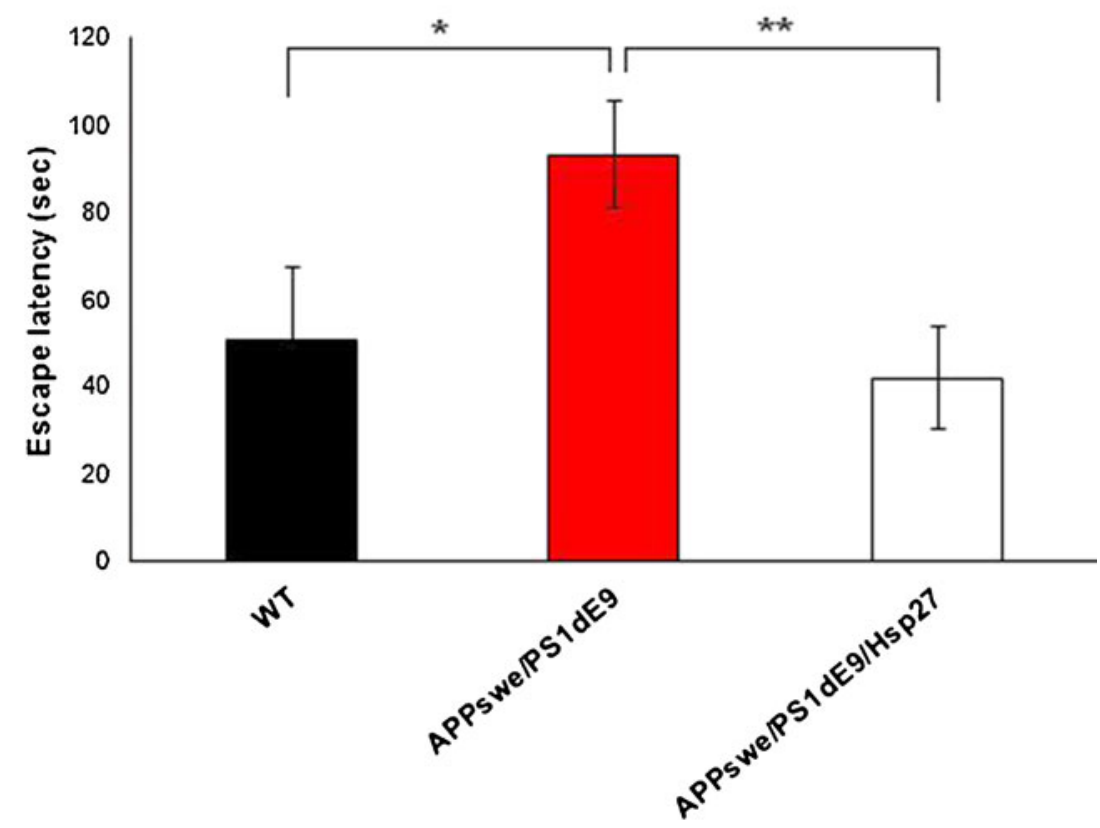

C Escape latency in Morris water maze test

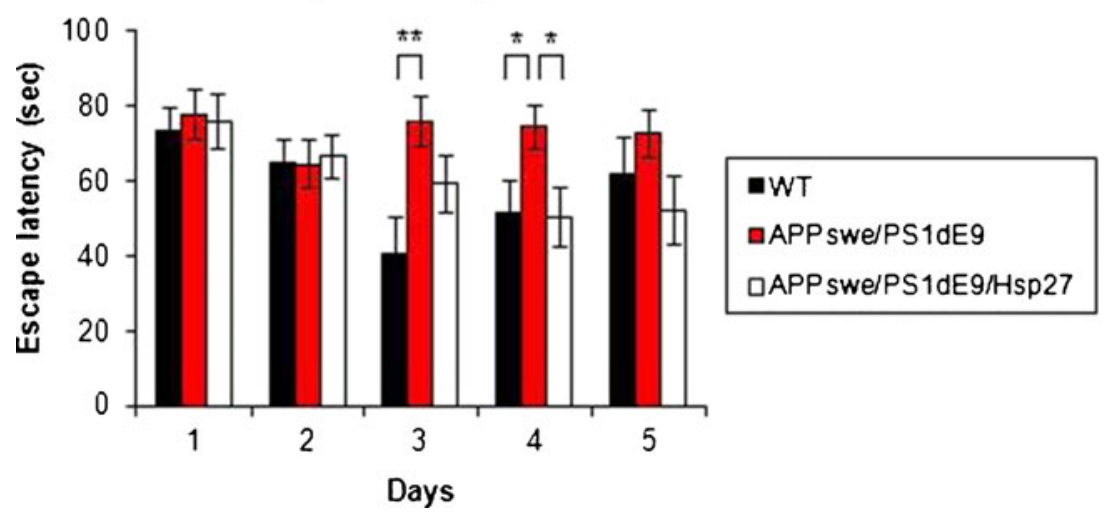

between the performance of APPswe/PS1dE9/Hsp27 and wild type groups (Fig. 2c). Interestingly, on the last day of training sessions, there was no statistical difference between groups, and the performance of most animals has declined.
Hippocampal slice electrophysiology

Hippocampal function was studied using paired-pulse facilitation (PPF) and long-term potentiation (LTP). Excitability 

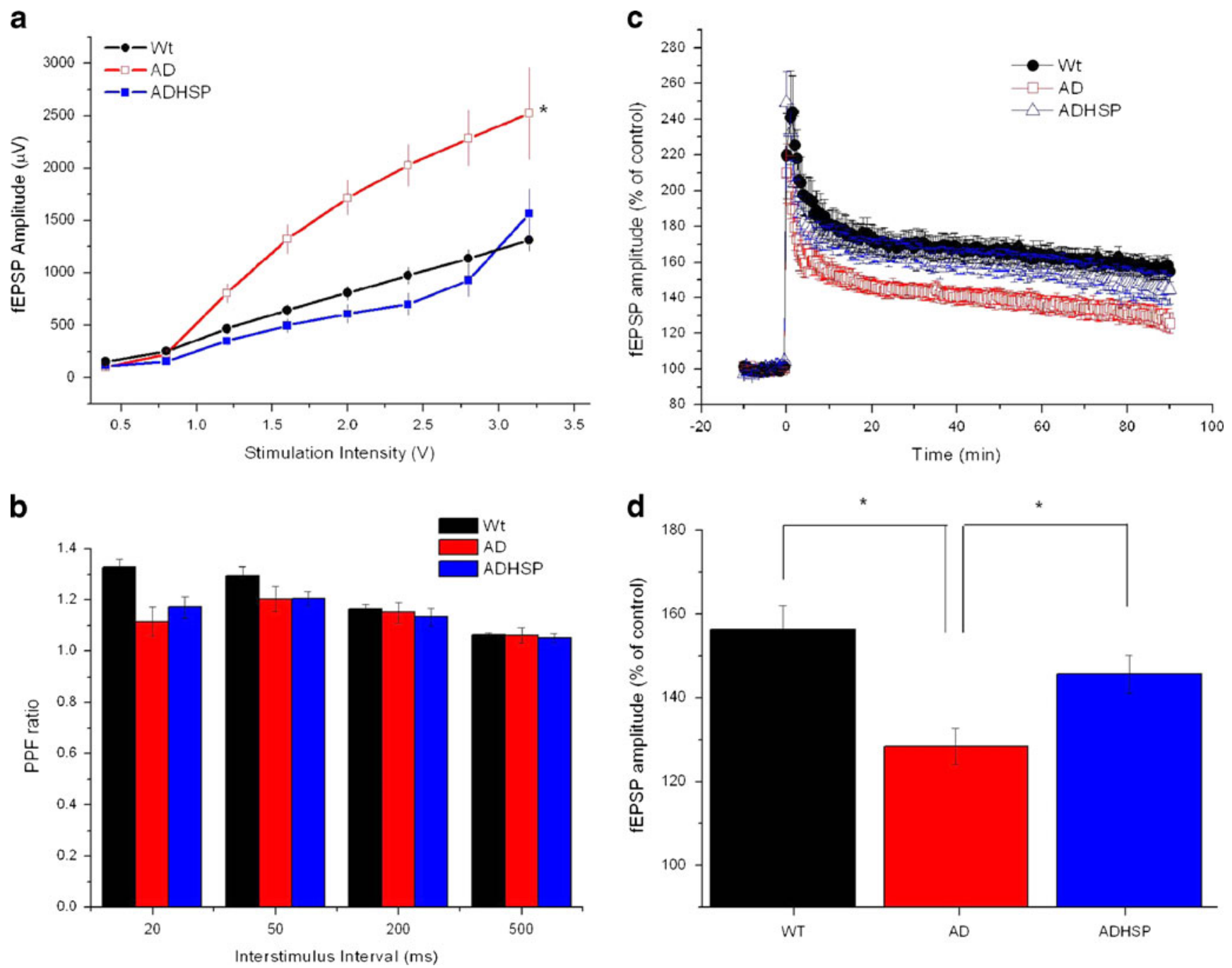

Fig. 3 Electrophysiological recordings on hippocampal slices from 7 months old mice. a Neuronal excitability of transgenic mice at different stimulation intensities. Data was analyzed by two-way ANOVA followed by Tukey's test. Asterisk denotes $p<0.05$. b Assessment of synaptic function in wild type (Wt, $n=8$ ), APPswe/PS1dE9 (AD, $n=6$ ), and APPswe/PS1dE9/Hsp27 (ADHSP, $n=7$ ) mice using

of neurons was studied at stimulation intensity of $0.4,0.8$, $1.2,1.6,2.0,2.4,2.8$, and 3.2 V. Slices prepared from brains of AD model (APPswe/PS1dE9) mice showed an elevated fEPSP increase at the same stimulus intensity compared to control, indicating an increased excitability of neurons ( $p \leq$ 0.05, two-way ANOVA; Fig. 3a). This increased synaptic excitability was normalized in APPswe/PS1dE9/Hsp27 mice (Fig. 3a). However, paired-pulse facilitation did not differ significantly among the groups, indicating that presynaptic function was unaffected by the genotype (Fig. 3b).

LTP is a cellular correlate of learning and memory. We found that LTP was impaired in the APPswe/PS1dE9 group ( $125 \pm 6 \%$ vs. $154 \pm 6 \%$ in the wild type, $p \leq 0.05$ ), but this was partially rescued in the APPswe/PS1dE9/Hsp27 geno-

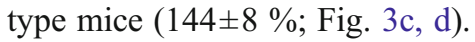

PPF. There was no significant difference in PPF values of different genotypes. c TBS induced LTP in transgenic (AD and ADHSP) and wild type mice. d Bar graph shows the fEPSP amplitude means of the last 5 min of LTP. Asterisk denotes $p \leq 0.05$ analyzed by ANOVA and post hoc Bonferroni test

\section{Amyloid staining}

Amyloid plaque formation was studied by immunostaining of frozen brain sections of 7-month-old transgenic and wild type mice using anti-A $\beta[1-42]$ antibody. Numerous amyloid deposits were observed in the hippocampus and cortex of APPswe/PS1dE9 transgenic animals (0.99/field of view and $1.08 /$ field of view, respectively), in contrast to wild type animals $(0.02 /$ field of view in the hippocampus and $0.06 /$ field of view in the cortex; Fig. 4a, b). Amyloid plaques were detected in APPswe/PS1dE9/Hsp27 brains as well (0.69/field of view in the hippocampus and 0.78 /field of view in the cortex; Fig. 4a, b); however, the number of plaques was significantly less in both regions than in APPswe/PS1dE9 group ( $p<0.05$; Fig. $4 \mathrm{c}$ ), indicating that Hsp 27 might prevent 
amyloid aggregation and plaque formation, or it can facilitate amyloid clearance and degradation in the brain.

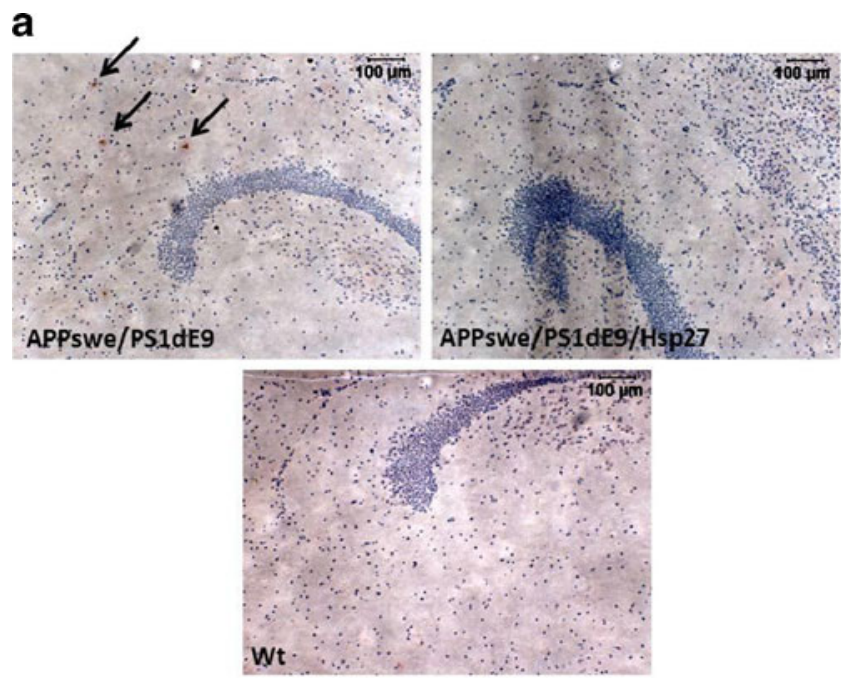

b
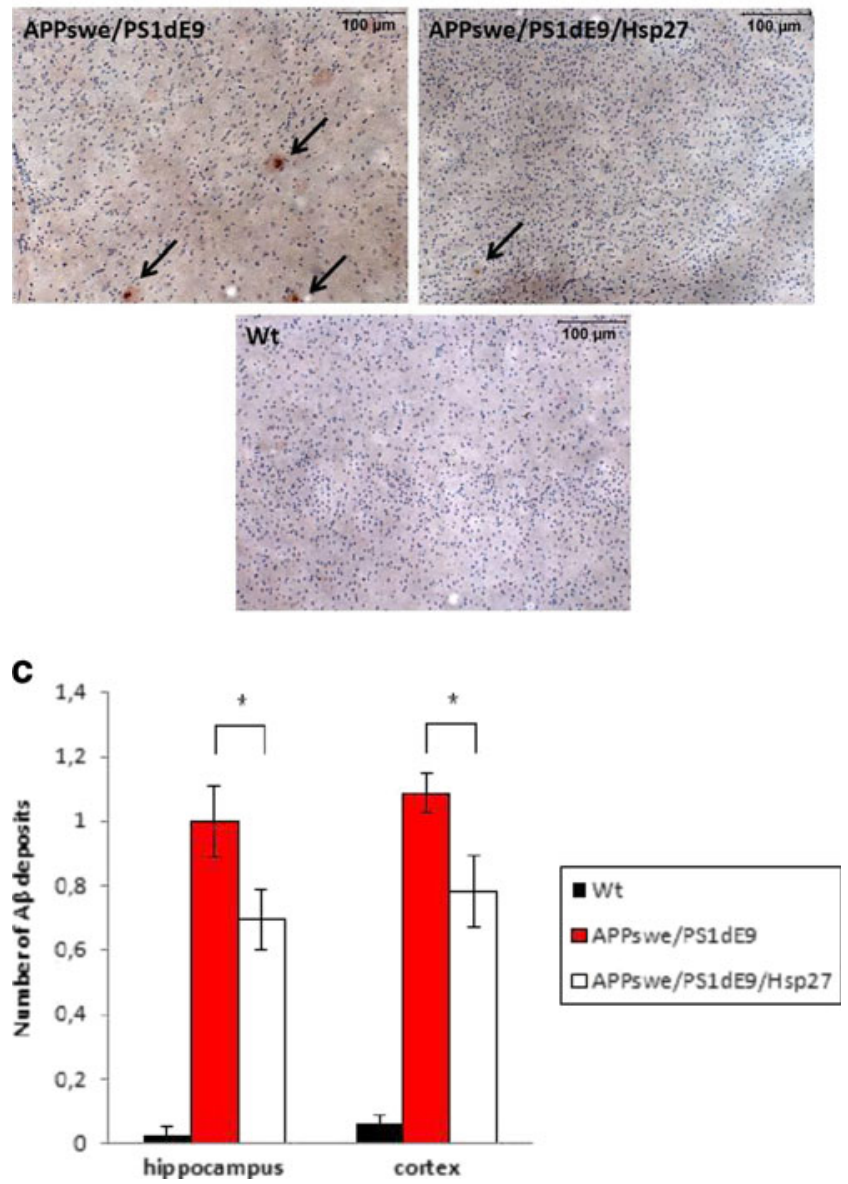

Fig. 4 Immunostaining of hippocampal (a) and cortical (b) amyloid plaques in 7 months old APPswe/PS1dE9, APPswe/PS1dE9/Hsp27 transgenic, and wild type (Wt) mice. Arrows indicate the presence of amyloid deposits. $\mathbf{c}$ Number of $\mathrm{A} \beta$ deposits/field of view in wild type (Wt, $n=6)$, APPswe/PS1dE9 $(n=6)$, and APPswe/PS1dE9/Hsp27 mice $\left(n=6\right.$; mean \pm SEM is shown; $\left.{ }^{*} p<0.05\right)$
Neuronal apoptosis

We used anti-active caspase-3 antibody and Fluoro-Jade C stainings to monitor apoptosis and neurodegeneration in the brain of 7-month-old transgenic mice. Activation of effector caspase-3 molecules triggers the activation of caspase cascade, which eventually leads to apoptosis of the cells (Boatright and Salvesen 2003). Fluoro-Jade C is an anionic fluorochrome, which sensitively and specifically binds to degenerating neurons (Schmued et al. 2005). We detected significantly increased number of apoptotic cells (Fig. 5a) and degenerated neurons (Fig. 5b) in the hippocampal as well as cortical regions of APPswe/PS1dE9 and APPswe/PS1dE9/Hsp27 transgenic brains compared to wild type animals $(p<0.001)$; however, there was no statistical difference between $\mathrm{AD}$ model mice and $\mathrm{AD}$ model mice expressing Hsp27.

Gene expression analysis of Hsp27 transgenic mice

Results obtained above indicated that Hsp27, as a molecular chaperone, might have a role in inhibition of amyloid
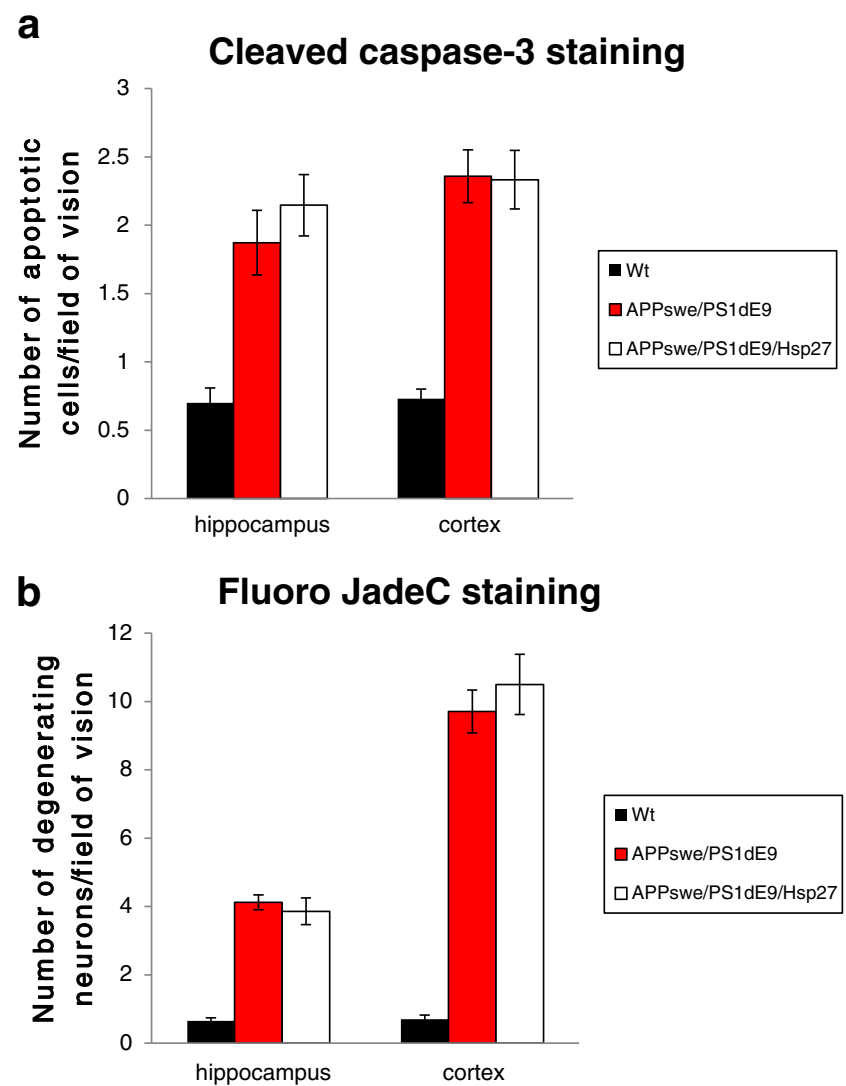

Fig. 5 Quantitative comparison of apoptotic cell (a) and degenerating neuron (b) numbers in the hippocampus and cortex of 7 months old wild type (Wt, $n=6)$, APPswe/PS1dE9 $(n=6)$, and APPswe/PS1dE9/ Hsp27 $(n=6)$ mice. Apoptotic cells were detected by anti-active caspase-3 antibody staining, while degenerating neurons were visualized using Fluoro-Jade C staining. Mean \pm SEM is shown 
accumulation/deposition or in enhanced amyloid clearing and degradation. In order to clarify its molecular role, we monitored the gene expression of several genes potentially involved in $\beta$-amyloid metabolism such as APP, ApoA1, ApoD, ApoE, LDLr, Lrp1, Lrp2, Hsp90, and neurodegeneration (NOS1 and NOS2) in the cortex of Hsp27 transgenic mice using Q-PCR. Primers used in this study are listed in Table 1. The expression level of ApoD and Lrp2 was slightly increased (128\% and $128 \%$, respectively), in the brain of Hsp27 transgenic mice compared to wild type controls (100\%), whereas there was no change in the mRNA level of APP, ApoE, LDLr, Lrp1, Hsp90, NOS1, and NOS3. Rather surprisingly, cortical expression of ApoA1 was reduced by half in Hsp27 transgenics versus wild type mice (Fig. 6a). Decreased ApoA1 expression in Hsp27 transgenic mice was further confirmed using western blotting. ApoA1 protein level was reduced in Hsp27 transgenic mice (61.1\%), but slightly elevated in AD model mice (126.7\%) compared to wild types (100\%). However, AD mice overexpressing human Hsp27 protein possessed similar ApoA1 protein level than wild type mice, indicating that Hsp27 influenced ApoA1 expression (Fig. 6b, c).

\section{Discussion}

In this study, we investigated the effects of small heat shock protein, Hsp27, on the development of AD-related phenotypes in transgenic mice. For this purpose, we used APPswe/PS1dE9 transgenic strain. These mice develop several AD-related phenotype including amyloid-beta deposits, abnormal spatial memory, axon degeneration, and synapse loss (The Jackson Laboratory (2013)) (http://jaxmice.jax.org/ strain/004462.html). We overexpressed the human Hsp27 protein in $\mathrm{AD}$ model mice and monitored learning and memory, synaptic function, amyloid deposition, and neuronal apoptosis in the triple transgenic mice.

Decline of the short-term memory is among the primary symptoms in $\mathrm{AD}$ patients. We found that spatial learning was impaired in APPswe/PS1dE9 mice as the time required to find the escape hole in Barnes maze test, or the platform in Morris water maze test was significantly longer compared to wild type mice. However, the performance of APPswe/PS1dE9/Hsp27 group was similar to the wild type group in both tests, which suggests that overexpression of Hsp27 protein ameliorates learning and memory deficits.

We have also found that synaptic excitability was increased in $\mathrm{AD}$ model mice, but this was normalized by Hsp27 overexpression. This is in accordance with earlier findings of others who demonstrated that seizure susceptibility is increased in AD model mice (Westmark et al. 2008; Vogt et al. 2009), and heat shock proteins can moderate chemically induced seizures (Akbar et al. 2003; Ekimova et al. 2010). LTP, a cellular correlate of learning and memory (Bliss and Colingridge 1993), was also investigated on hippocampal slices. Previously, it was demonstrated that soluble oligomers of $A \beta$ are able to inhibit LTP and cause learning and memory deficit (Haas and Selkoe 2007; Bozso et al. 2010). Our results have shown that LTP was impaired in APPswe/PS1dE9 mice indeed, but it was normalized upon Hsp27 overexpression. There is substantial evidence from transgenic mouse models that intracellular $A \beta$ initiates cellular dysfunction, synaptic, electrophysiological, and behavioral changes before it accumulates in extracellular plaques (Moechars et al. 1999; Kumar-Singh et al. 2000; Mucke et al. 2000). The toxic A $\beta$ molecules (either soluble oligomers or fibrillar forms) might initiate a cascade, which finally leads to neuronal dysfunction. Therefore, inhibition of $A \beta$ oligomerization and deposition or enhanced clearance of $A \beta$ might play a crucial role in the prevention and therapy of AD. We have found a significantly lower level of amyloid deposition in the brain of $\mathrm{AD} / \mathrm{Hsp} 27$ animals compared to the AD group, indicating that Hsp27 is somehow involved in these processes. In $\mathrm{AD}$, heat shock protein expression is associated with $A \beta$ deposition and neurofibrillary tangles, and recent findings suggest that Hsps prevent the accumulation of $\mathrm{A} \beta$ (Abdul et al. 2006; Evans et al. 2006). Wilhelmus et al. (2006) demonstrated that Hsp20, Hsp27, and $\alpha \mathrm{B}$-crystallin bind strongly to $\mathrm{A} \beta$ and inhibit its aggregation. Furthermore, Hsp20, Hsp27, and $\alpha \mathrm{B}$-crystallin inhibited cerebrovascular $A \beta$ toxicity, probably by reducing the accumulation of $A \beta$ at the cell surface.

Aggregated forms of $A \beta$ might lead to neurodegeneration through different pathways. Several studies have shown that chronic inflammatory response to deposited amyloid resulted in neurodegeneration (Akiyama et al. 2000; Wyss-Coray and Mucke 2002). Although heat shock proteins have protective effects in neurodegenerative disease models, the molecular basis of this protection is not fully understood. It is likely that heat shock proteins have effect at several levels, and their neuroprotective function might not be linked exclusively to their effect on protein aggregation (Muchowski and Wacker 2005). For example, Hsps are known to reduce oxidative stress and mediate apoptotic pathway. They can also facilitate proteasomal degradation, which might help in $A \beta$ clearance. However, the exact molecular mechanisms of $A \beta$-induced neurotoxicity are not fully known. These mechanisms are very diverse, and probably include the increased production of reactive oxygen species (ROS), altered calcium homeostasis, and enzyme activities. Several lines of evidence are available suggesting that $A \beta$ can interact with artificial and biological membranes altering their fluidity. Altered membrane fluidity can influence the function of other membrane components. Certain studies suggest that the insertion of $A \beta$ into the plasma membrane triggers different events catalyzed by perturbation of the conformation of membrane proteins, which finally leads to neurotoxicity (Kanfer et al. 1999). This 
Fig. 6 Gene expression profiles of different genes involved in amyloid metabolism in Hsp27 transgenic mice using Q-PCR analysis (a). Data was normalized to the endogenous $\beta$-actin, then expressed as a percent of wild type expression (100\%). b Representative western blot of ApoA1 expression in Hsp27 transgenic (Hsp27), wild type (Wt), AD model (APPswe/PS1dE9), and AD/Hsp27 (APPswe/PS1dE9/ Hsp27) brains. c Statistical analysis of western blot experiment. Hsp27 transgenic $(n=5)$, wild type (Wt, $n=6)$, $\mathrm{AD}$ model $(n=5)$, and $\mathrm{AD} / \mathrm{Hsp}$ triple transgenic mice $(n=6)$ were compared a

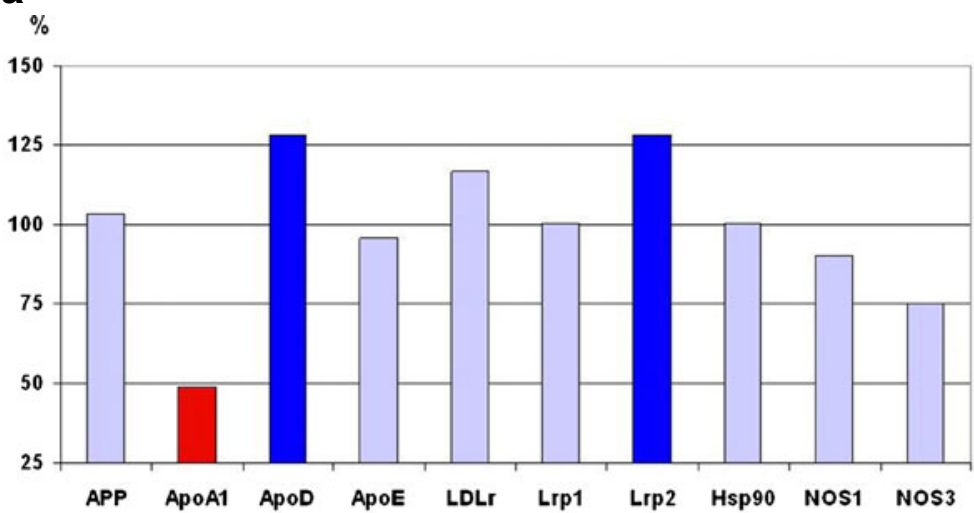

b

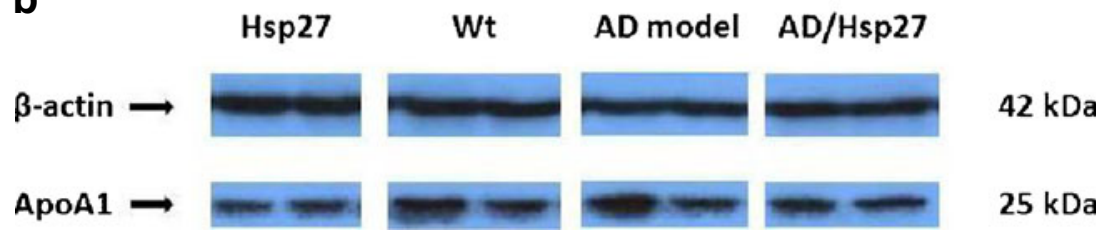

C

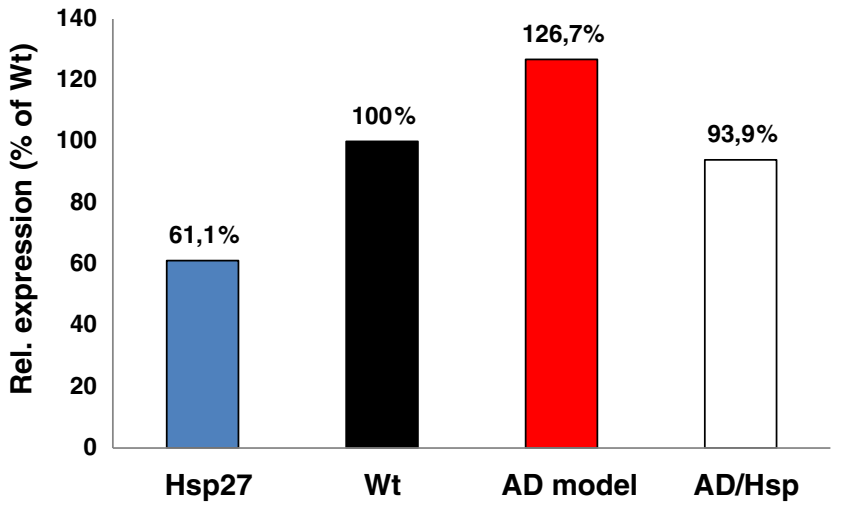

hypothesis suggests that the neurotoxic cascade of $A \beta$ is initiated in the cell membrane. It is also important, that $\alpha$-, $\beta$-, and $\gamma$-secretases are associated with cellular membranes; thereby, their function, such as APP processing, strongly depends on membrane fluidity. Peters et al. (2009) showed that oligomeric $A \beta$ can reduce membrane fluidity, which in turn stimulates the amyloidogenic processing of APP. Several studies suggest that a subpopulation of Hsps is present either on the surface or within the cellular membranes, and they have been shown to modulate major attributes of the membrane lipid phase such as fluidity and permeability. By stabilizing the membrane, Hsps can restore membrane functionality during stress conditions (Horváth et al. 2008). We can suppose that Hsp27 also can interact with and stabilize cellular membranes; thereby, it can diminish the level of $\mathrm{A} \beta$-induced neurotoxic cascade or, moreover, the production of $\mathrm{A} \beta$. The generation of ROS is also a crucial factor in the molecular mechanisms of $A \beta$-induced neurotoxicity. Lipid peroxidation, and protein and DNA oxidation are remarkable in the brain of $\mathrm{AD}$ patients, and $\mathrm{A} \beta$ might have a central role in the induction of these processes (reviewed in Butterfield et al. 2001). Hsp27 has a protective effect in oxidative stress; thereby, Hsp27 might eliminate the neurotoxicity of $\mathrm{A} \beta$ at least in part due to this property.

To know more about the role of Hsp27 in amyloid metabolism - whether it inhibits APP production or enhances amyloid clearance/degradation - we performed gene expression analysis. No decrease in APP production was detected; however, a subtle elevation of ApoD and LRP1 protein levels in Hsp27 transgenic brains was observed. Although ApoD and LRP1 proteins have important roles in neuroprotection and $\mathrm{A} \beta$ clearance, respectively (Terrise at al. 1998; Kalman et al. 2000; Thomas et al. 2001; Muffat et al. 2008; Kang et al. 2000), we do not consider that the mild changes obtained in their expression would be sufficiently enough to lead to efficient reduction of amyloid plaque 
numbers. Now it is widely accepted that ApoD is elevated in many neuropathological conditions, including Alzheimer's disease, Parkinson's disease, stroke, schizophrenia, and bipolar disorder. It was also demonstrated that in Drosophila, overexpressed ApoD had a protective effect against oxidative stress and heat shock (Muffat et al. 2008). In vitro LDL receptor-related protein 1 (LRP1) mediates the clearance of both $A \beta 40$ and $A \beta 42$ through a bona fide receptormediated uptake (Kang et al. 2000); therefore, LRP and its ligand ApoE have been proposed to be a clearance pathway for $A \beta$. At the same time, the role of ApoA1 in amyloid metabolism and $\mathrm{AD}$ pathology is controversial. Although it has been shown that $A p o A 1$ inhibits $A \beta$ aggregation in vitro (Koldamova et al. 2001), in vivo studies resulted different results. Crossing of ApoA1 null mice with $\mathrm{AD}$ model mice resulted no change in amyloid deposition in the brain (Fagan et al. 2004). Similarly, when ApoA1 overexpressing mice were crossed with $\mathrm{AD}$ model mice, no alteration in amyloid metabolism was observed (Lewis et al. 2010). Our result presented here shows that expression of ApoA1 was downregulated in Hsp27 transgenic mice, indicating that Hsp27 might have a role in the regulation (directly or indirectly) of ApoA1 expression.

Taken together, further investigations are necessary to reveal the exact molecular pathways involved in neuroprotective function of Hsp27.

Acknowledgments We thank S. Gonda and M. Mari for their technical assistance. This work was supported by the National Office for Research and Technology grants (TAMOP-4.2.2-08/1-2008-0002 and TAMOP-4.2.2.A-11/1/KONV-2012-0052 to B.P. and M.S., TAMOP 4.2.1B-1/9-KONV to B.P.), and OTKA PD 83581 to V.S. N.L. was a participant of the "PhD Support Program for Talented Students at University of Szeged" supported by NKTH (TAMOP-4.2.2/B-10/12010-0012).

Conflicts of interest The authors declare no competing financial interests.

\section{References}

Abdul HM, Calabrese V, Calvani M, Butterfield DA (2006) Acetyl-L-carnitine-induced up-regulation of heat shock proteins protects cortical neurons against amyloid-beta peptide 1-42-mediated oxidative stress and neurotoxicity: implications for Alzheimer's disease. J Neurosci Res 84:398-408

Akbar MT, Lundberg AM, Liu K, Vidyadaran S, Wells KE, Dolatshad H, Wynn S, Wells DJ, Latchman DS, de Belleroche J (2003) The neuroprotective effects of heat shock protein 27 overexpression in transgenic animals against kainate-induced seizures and hippocampal cell death. J Biol Chem 278:19956-19965

Akiyama H, Barger S, Barnum S, Bradt B, Bauer J, Cole GM, Cooper NR, Eikelenboom P et al (2000) Inflammation and Alzheimer's disease. Neurobiol Aging 21:383-421
Arrigo AP, Paul C, Ducasse C, Manero F, Kretz-Remy C, Virot S, Javouhey E, Mounier N, Diaz-Latoud C (2002) Small stress proteins: novel negative modulators of apoptosis induced independently of reactive oxygen species. Prog Mol Subcell Biol 28:185-204

Becker J, Craig EA (1994) Heat-shock proteins as molecular chaperones. Eur J Biochem 219:11-23

Bliss TVP, Collingridge GL (1993) A synaptic model of memory: long-term potentiation in the hippocampus. Nature 361:31-39

Boatright KM, Salvesen GS (2003) Mechanisms of caspase activation. Curr Opin Cell Biol 15:725-731

Bozso Z, Penke B, Simon D, Laczkó I, Juhász G, Szegedi V, Kasza A, Soós K, Hetényi A, Wéber E, Tóháti H, Csete M, Zarándi M, Fülöp L (2010) Controlled in situ preparation of A beta(1-42) oligomers from the isopeptide "iso-A beta(1-42)" physicochemical and biological characterization. Peptides 31:248-256

Butterfield DA, Drake J, Pocernich C, Castegna A (2001) Evidence of oxidative damage in Alzheimer's disease brain: central role for amyloid beta-peptide. Trends Mol Med 7:548-554

Ekimova IV, Nitsinskaya LE, Romanova IV, Pastukhov YF, Margulis BA, Guzhova IV (2010) Exogenous protein Hsp70/Hsc70 can penetrate into brain structures and attenuate the severity of chemically-induced seizures. J Neurochem 115:1035-1044

Evans CG, Wisen S, Gestwicki JE (2006) Heat shock proteins 70 and 90 inhibit early stages of amyloid beta-(1-42) aggregation in vitro. J Biol Chem 281:33182-33191

Evans DA, Funkenstein HH, Albert MS, Scherr PA, Cook NR, Chown MJ, Hebert LE, Hennekens CH, Taylor JO (1989) Prevalence of Alzheimer's disease in a community population of older persons. Higher than previously reported. JAMA 262:2551-2556

Fagan AM, Christopher E, Taylor JW, Parsadanian M, Spinner M, Watson M, Fryer JD, Wahrle S, Bales KR, Paul SM, Holtzman DM (2004) ApoAI deficiency results in marked reductions in plasma cholesterol but no alterations in amyloid-beta pathology in a mouse model of Alzheimer's disease-like cerebral amyloidosis. Am J Pathol 165:1413-1422

Haass C, Selkoe DJ (2007) Soluble protein oligomers in neurodegeneration: lessons from the Alzheimer's amyloid betapeptide. Nat Rev Mol Cell Biol 8:101-112

Hamilton A, Holscher C (2012) The effect of ageing on neurogenesis and oxidative stress in the APP(swe)/PS1(deltaE9) mouse model of Alzheimer's disease. Brain Res 1449:83-93

Haslbeck M, Buchner J (2002) Chaperone function of sHSPs. Prog Mol Subcell Biol 28:37-59

Horváth I, Multhoff G, Sonnleitner A, Vígh L (2008) Membraneassociated stress proteins: more than simply chaperones. Biochim Biophys Acta 1778:1653-1664

Hoshino T, Murao N, Namba T, Takehara M, Adachi H, Katsuno M, Sobue G, Matsushima T, Suzuki T, Mizushima T (2011) Suppression of Alzheimer's disease-related phenotypes by expression of heat shock protein 70 in mice. J Neurosci 31:5225-5234

Jakob U, Gaestel M, Engel K, Buchner J (1993) Small heat shock proteins are molecular chaperones. J Biol Chem 268:1517-1520

Jankowsky JL, Fadale DJ, Anderson J, Xu GM, Gonzales V, Jenkins NA, Copeland NG, Lee MK, Younkin LH, Wagner SL, Younkin SG, Borchelt DR (2004) Mutant presenlins specifically elevate the levels of the 42 residue beta-amyloid peptide in vivo: evidence for augmentation of 42-specific gamma secretase. Hum Mol Genet 13:159170

Kalman J, McConathy W, Araoz C, Kasa P, Lacko AG (2000) Apolipoprotein $\mathrm{D}$ in the aging brain and in Alzheimer's dementia. Neurol Res 22:330-336

Kalmar B, Greensmith L (2009) Induction of heat shock proteins for protection against oxidative stress. Adv Drug Deliv 61:310-318

Kanfer JN, Sorrentino G, Sitar DS (1999) Amyloid beta peptide membrane perturbation is the basis for its biological effects. Neurochem Res 24:1621-1630 
Kang DE, Pietrzik CU, Baum L, Chevallier N, Merriam DE, Kounnas MZ, Wagner SL, Troncoso JC, Kawas CH, Katzman R, Koo EH (2000) Modulation of amyloid beta-protein clearance and Alzheimer's disease susceptibility by the LDL receptor-related protein pathway. J Clin Invest 106:1159-1166

Katsuno M, Sang C, Adachi H, Minamiyama M, Waza M, Tanaka F, Doyu M, Sobue G (2005) Pharmacological induction of heatshock proteins alleviates polyglutamine-mediated motor neuron disease. Proc Natl Acad Sci U S A 102:16801-16806

Kennard JA, Woodruff-Pak DS (2011) Age sensitivity of behavioral tests and brain substrates of normal aging in mice. Front Aging Neurosci 3:9

Koldamova RP, Lefterov IM, Lefterova MI, Lazo JS (2001) Apolipoprotein A-I directly interacts with amyloid precursor protein and inhibits A beta aggregation and toxicity. Biochemistry 40:3553-3560

Kumar-Singh S, Dewachter I, Moechars D, Lübke U, De Jonghe C, Ceuterick C, Checler F, Naidu A, Cordell B, Cras P, Van Broeckhoven C, Van Leuven FS (2000) Behavioral disturbances without amyloid deposits in mice overexpressing human amyloid precursor protein with Flemish (A692G) or Dutch (E693Q) mutation. Neurobiol Dis 7:9-22

Lewis TL, Cao D, Lu H, Mans RA, Su YR, Jungbauer L, Linton MF, Fazio S, Ladu MJ, Li L (2010) Overexpression of human apolipoprotein A-I preserves cognitive function and attenuates neuroinflammation and cerebral amyloid angiopathy in a mouse model of Alzheimer's disease. J Biol Chem 285:36958-36968

Lo Bianco C, Shorter J, Régulier E, Lashuel H, Iwatsubo T, Lindquist S, Aebischer P (2008) Hsp104 antagonizes alpha-synuclein aggregation and reduces dopaminergic degeneration in a rat model of Parkinson disease. J Clin Invest 118:3087-3097

Magrané J, Smith RC, Walsh K, Querfurth HW (2004) Heat shock protein 70 participates in the neuroprotective response to intracellularly expressed $\beta$-amyloid in neurons. J Neurosci 24:1700-1706

Mattson MP (2004) Pathways towards and away from Alzheimer's disease. Nature 430:631-639

McKhann G, Drachman D, Folstein M, Katzman R, Price D, Stadlan EM (1984) Clinical diagnosis of Alzheimer's disease: report of the NINCDS-ADRDA Work Group under the auspices of Department of Health and Human Services Task Force on Alzheimer's Disease. Neurology 34:939-944

Moechars D, Dewachter I, Lorent K, Reversé D, Baekelandt V, Naidu A, Tesseur I, Spittaels K, Haute CV, Checler F, Godaux E, Cordell B, Van Leuven F (1999) Early phenotypic changes in transgenic mice that overexpress different mutants of amyloid precursor protein in brain. J Biol Chem 274:6483-6492

Monji A, Utsumi H, Ueda T, Imoto T, Yoshida I, Hashioka S, Tashiro K, Tashiro N (2001) The relationship between the aggregational state of the amyloid-beta peptides and free radical generation by the peptides. J Neurochem 77:1425-1432

Morimoto RI, Sarge KD, Abravaya K (1992) Transcriptional regulation of heat shock genes. A paradigm for inducible genomic responses. J Biol Chem 267:21987-21990

Muchowski PJ, Wacker JL (2005) Modulation of neurodegeneration by molecular chaperones. Nat Rev Neurosci 6:11-22

Mucke L, Masliah E, Yu GQ, Mallory M, Rockenstein EM, Tatsuno G, Hu K, Kholodenko D, Johnson-Wood K, McConlogue L (2000) High-level neuronal expression of $A \beta 1-42$ in wild-type human amyloid protein precursor transgenic mice: synaptotoxicity without plaque formation. J Neurosci 20:4050-4058
Muffat J, Walker DW, Benzer S (2008) Human ApoD, an apolipoprotein up-regulated in neurodegenerative diseases, extends lifespan and increases stress resistance in Drosophila. Proc Natl Acad Sci U S A 105:7088-7093

Perez N, Sugar J, Charya S, Johnson G, Merril C, Bierer L, Perl D, Haroutunian V, Wallace W (1991) Increased synthesis and accumulation of heat shock 70 proteins in Alzheimer's disease. Brain Res Mol Brain Res 11:249-254

Peters I, Igbavboa U, Schütt T, Haidari S, Hartig U, Böttner S, Copanaki E, Deller T, Kögel D, Wood WG, Müller WE, Eckert GP (2009) The interaction of beta-amyloid protein with cellular membranes stimulates its own production. Biochim Biophys Acta 1788:964-972

Preville X, Salvemini F, Giraud S, Chaufour S, Paul C, Stepien G, Ursini MV, Arrigo AP (1999) Mammalian small stress proteins protect against oxidative stress through their ability to increase glucose-6-phosphate dehydrogenase activity and by maintaining optimal cellular detoxifying machinery. Exp Cell Res 247:61-78

Reiserer RS, Harrison FE, Syverud DC, McDonald MP (2007) Impaired spatial learning in the APP + PSEN1DeltaE9 bigenic mouse model of Alzheimer's disease. Genes Brain Behav 6:54-65

Schmued LC, Stowers CC, Scallet AC, Xu L (2005) Fluoro-Jade C results in ultra high resolution and contrast labeling of degenerating neurons. Brain Res 1035:24-31

Serrano-Pozo A, Frosch MP, Masliah E, Hyman BT (2011) Neuropathological alterations in Alzheimer disease. Cold Spring Harb Perspect Med 1(1):a006189

Sunyer B, Patil S, Höger H, Lubec G (2007) Barnes maze, a useful task to assess spatial reference memory in the mice. Protocol Exchange. doi:10.1038/nprot.2007.390

Terrisse L, Poirier J, Bertrand P, Merched A, Visvikis S, Siest G, Milne R, Rassart E (1998) Increased levels of apolipoprotein D in cerebrospinal fluid and hippocampus of Alzheimer's patients. $\mathrm{J}$ Neurochem 71:1643-1650

The Jackson Laboratory (2013) http://jaxmice.jax.org/strain/ 004462.html

Thomas EA, Dean B, Pavey G, Sutcliffe JG (2001) Increased CNS levels of apolipoprotein D in schizophrenic and bipolar subjects: implications for the pathophysiology of psychiatric disorders. Proc Natl Acad Sci U S A 98:4066-4071

Toth ME, Gonda S, Vigh L, Santha M (2010) Neuroprotective effect of small heat shock protein, Hsp27, after acute and chronic alcohol administration. Cell Stress Chaperones 15:807-817

Vogt DL, Thomas D, Galvan V, Bredesen DE, Lamb BT, Pimplikar SW (2009) Abnormal neuronal networks and seizure susceptibility in mice overexpressing the APP intracellular domain. Neurobiol Aging 32:1725-1729

Wang K, Spector A (1996) $\alpha$-Crystallin stabilizes actin filaments and prevents cytochalasin-induced depolymerization in a phpsphorilation-dependent manner. Eur J Biochem 242:56-66

Westmark CJ, Westmark PR, Beard AM, Hildebrandt SM, Malter JS (2008) Seizure susceptibility and mortality in mice that over-express amyloid precursor protein. Int J Clin Exp Pathol 1:157-168

Wilhelmus MM, Boelens WC, Otte-Höller I, Kamps B, de Waal RM, Verbeek MM (2006) Small heat shock proteins inhibit amyloidbeta protein aggregation and cerebrovascular amyloid-beta protein toxicity. Brain Res 1089:67-78

Wyss-Coray T, Mucke L (2002) Inflammation in neurodegenerative disease - a double-edged sword. Neuron 35:419-432 